Hegemonialstellung aufrechtzuerhalten und dringliche Appelle an die europäische Solidarität gegen den Bolschewismus zu richten. Dennoch wurde die wesensmäßig antiföderale Struktur der nationalsozialistischen Europakonzeption zu keinem Zeitpunkt ernsthaft in Zweifel gezogen. Sie war logische Konsequenz der Verbindung von rassischem Hierarchiedenken und imperialistischer Raumpolitik.

Doch ist es nicht euphemistisch, von einer nationalsozialistischen Europaideologie zu sprechen. Spätestens seit dem deutschen Angriff auf die Sowjetunion formte sich aus der ideologischen Verknüpfung von antisemitischem Rassismus und Lebensraumimperialismus ein gezielt auf Kontinentaleuropa zugeschnittenes Herrschaftskonzept. Daß der implizite deutsche Hegemonialanspruch dem heutigen Europaverständnis als Zusammenschluß mehrerer gleichberechtigter Staaten zur Verfolgung gemeinsamer wirtschaftlicher und politischer Ziele diametral entgegenstand, ändert nichts daran, daß es sich bei den NS-Plänen um ein - wenngleich den Europagedanken pervertierendes - Europakonzept mit einer seit 1941 manifesten ideologischen Grundlage handelte.

\title{
2. Europa im Diskurs: \\ die Entwicklung europäischer Einigungspläne im Exil 1938-1945
}

Das mit der Annexion Österreichs und der Preisgabe des Sudetenlandes im Münchner Abkommen aufziehende Szenario eines Europas unter dem Hakenkreuz verunsicherte die politischen Flüchtlinge in allen Exilländern nachhaltig. Mit dem beginnenden Übergriff des Nationalsozialismus auf andere Länder näherte sich die seit spätestens 1922 zu beobachtende Ausweitung totalitärer Herrschaft in Europa ${ }^{163}$ ihrem Höhepunkt. Sie ließ das deutsche Exil erkennen, daß das Ziel der Überwindung des Hitler-Regimes in einen umfassenderen, europäischen Zusammenhang gerückt werden mußte, um als Gegenstand realpolitischer Agitation weiterhin aufrechterhalten werden zu können. Mithin stellt sich die Phase zwischen der mehrheitlich als Bedrohung empfundenen Annexion Österreichs und dem nahezu einhellig verurteilten Münchner Abkommen als Auftakt zu einer Qualifizierungsphase des Europadiskurses dar.

In ihrer Initialwirkung für die innereuropäische Rückbesinnung der deutschen Flüchtlinge sind die Ereignisse zwischen März 1938 und dem deutschen Einmarsch in die Tschechoslowakei im März 1939 kaum zu überschät-

163 Am 27. 10. 1922 schickte Benito Mussolini seine Anhänger von Neapel aus auf den legendären "Marsch auf Rom" - während er selbst von Mailand per Zug nach Rom reiste, um dort von König Victor Emanuel III. mit der Regierungsbildung beauftragt zu werden. 
zen, müssen aber in engem Zusammenhang mit der vergleichbaren Bedeutung des deutsch-sowjetischen Nichtangriffspakts für den antibolschewistischen Faktor des Europadiskurses gesehen werden ${ }^{164}$. Bevor der Zweite Weltkrieg am 1. September 1939 ausbrach, waren zwei der wesentlichen Komponenten des Europadiskurses, die innereuropäische Rückbesinnung und der Antibolschewismus, schon benannt. Doch durch die ständig wechselnde militärische Lage und die infolgedessen rasante politische Entwicklung während des Krieges rückte die Diskussion um die Kriegsziele in den Vordergrund der politischen Debatten des Exils. Unter dem Schlagwort der Kriegs- bzw. Friedensziele wurden nicht nur Sofortmaßnahmen nach der nahezu einhellig erwarteten Niederlage Deutschlands erörtert, sondern auch langfristig angelegte Überlegungen zur Nachkriegsordnung Deutschlands, Europas und der Welt.

Die Emigranten verstanden die kontroverse Konturierung des Europagedankens als einen spezifischen Beitrag zum Widerstand gegen den Nationalsozialismus. Der seit 1936 entwickelte Ansatz eines exilierten Widerstandes durch Planung wurde infolge der Schockreaktionen auf das Münchner Abkommen und den deutsch-sowjetischen Nichtangriffspakt weithin zum common sense des deutschen Exils und seines politischen Selbstbewußtseins, wenngleich viele Flüchtlinge sich nicht schon durch „München“ oder „Moskau", sondern erst durch die militärische Niederlage Frankreichs im Juni 1940, manche gar noch später, zu dieser Schlußfolgerung veranlaßt sahen.

Der zentrale Konnex zwischen Widerstand und Europaplanung sollte sich in den Jahren von 1938 bis 1945 als politischer und psychologischer Nukleus des Europadiskurses im Exil, als Grundmotivation europäischer Überlegungen und Sehnsüchte erweisen. Längst wurde die Überwindung des deutschen Faschismus nicht mehr als bloß nationales, sondern als ein zutiefst europäisches Anliegen betrachtet. So sah im Juni 1939 der Linkssozialist Alexander Schifrin in der Beseitigung des Hitler-Regimes und der Neuordnung Europas die beiden Hauptaufgaben der Emigration. In der Hoffnung auf eine antinationalistische Kehrtwende der deutschen Arbeiterschaft beschwor er die proeuropäische Sprengkraft einer antifaschistischen Widerstandsbewegung: "So werden die betrogenen und unterdrückten Massen für eine demokratische und europäische Gesinnung freigesetzt: sie sind nicht nur gegen Hitler, sondern auch für Europa [Hervorhebungen d. Verf., B. S.] ${ }^{\alpha 165}$. Diese Entwicklung mußte genutzt werden, um „der Hitlerschen Konzeption vom Mitteleuropäischen Reich eine schöpferische Konzeption entgegenzustellen“ 166 .

164 Eingehend zu den Diskurselementen der innereuropäischen Rückbesinnung und der antisowjetischen Wendung zwischen dem Münchner Abkommen und dem HitlerStalin-Pakt SCHILMAR, Pariser Positionen 2002.

165 SCHIfRIN, Zwei gemeinsame Aufgaben, in: Die Zukunft, II. Jg., Nr. 23 (9. 6. 1939), S. 4.

166 HeRB [d. i. Brehm], Bemerkungen zur Außenpolitik (II), in: SW, 13. Jg., H. 41 (14. 10. 1938), S. 977-980 (979). 
Die Überlegungen des Exils zur Zukunft des europäischen Kontinents wurden beeinflußt durch die jeweilige politische Ideologie der beteiligten Emigranten, ihre Wahrnehmung und Verarbeitung der jüngsten deutschen Geschichte sowie die gruppeninternen Erörterungen und gruppenübergreifenden Einigungsbemühungen. Auch dem biographischen Aspekt kommt in zweierlei Hinsicht eine nicht zu unterschätzende Bedeutung zu: Die eigene, ständigem Wandel unterliegende Exilsituation ließ die Emigranten die Schlüsselereignisse des Europadiskurses nicht nur als politisch denkende Menschen, sondern zugleich als persönlich Betroffene erleben. So stellte das Münchner Abkommen die in die Tschechoslowakei geflüchteten Exilanten vor die Notwendigkeit fortgesetzter Flucht, während sich die in Großbritannien und Frankreich weilenden Flüchtlinge von ihren Gastländern verraten und verlassen fühlten. Der Hitler-Stalin-Pakt und der Kriegsausbruch setzten nicht nur die emigrierten Kommunisten vielerorts der Verfolgung als feindliche, der Spionage verdächtige Ausländer aus. Der deutsche Einmarsch in Paris bedeutete die Reduzierung des europäischen Exils auf Großbritannien und die Schweiz. Schließlich erzwangen die Konferenzen von Teheran und Potsdam eine oft ungewollte Politisierung der rückkehrwilligen Emigranten mit der Folge, daß etlichen Emigranten die Rückkehr in ihre Heimat versperrt blieb.

Dieser biographische Aspekt läßt erkennen, welch bedeutende Funktion dem Europadiskurs neben der politischen Widerstandsleistung zukam. Er ermöglichte trotz aller Differenzen im einzelnen eine breite Solidarisierung hinter der Zukunftsvision eines geeinten Europas. Zugleich bot der Europadiskurs den politischen Flüchtlingen im Ausland ein wahrnehmbares Stück Heimat, das den einzelnen an das aktive politische Engagement der Weimarer Zeit anknüpfen ließ und ihm das Gefühl vermittelte, unverändert Adressat sozialer Akzeptanz und persönlichen Respekts zu sein. Mit diesen in der Persönlichkeit des Individuums gründenden Einflußfaktoren erklärt sich die Tatsache, daß sich mit der Zeit die (partei)politischen Bindungen lockerten und die Europakonzepte zunehmend als das Werk einzelner erschienen. Die einzige wesentliche Ausnahme in dieser Entwicklung war die Gründung der Union deutscher sozialistischer Organisationen in Großbritannien, die sich um eine breitangelegte Einigung des linken, nichtkommunistischen Spektrums bemühte.

Mit der 1938 einsetzenden Intensivierung des Europadiskurses und dem Ausbau seiner strategischen Funktion als intellektueller Widerstand rückt die Frage nach der Motivation, die den Europaplanungen der Emigranten zugrunde liegt, deutlicher in den Vordergrund. Im folgenden sollen die Motive der innereuropäischen Rückbesinnung im Exil zwischen 1938 und 1945 herausgearbeitet werden, wobei den Besonderheiten der deutschen Exilsituation Rechnung zu tragen ist. Neben den Grundmotivationen erfährt die Frage des Verhältnisses zu West und Ost, mithin der Positionierung Europas in der bipolaren Welt zwischen den USA und der UdSSR zunehmende Brisanz. Es 
gilt zu untersuchen, inwieweit die deutschen Emigranten diese Brisanz erkannten und welche Konsequenzen sie daraus zogen. Darüberhinaus soll auch den Überlegungen zu einer Institutionalisierung der erstrebten europäischen Einigung nachgegangen werden. Im Mittelpunkt der Quellenarbeit steht dabei das Föderalismusverständnis des deutschen Exils und die Frage nach frühen Ansätzen supranationaler Europamodelle.

\section{1. „Bilanz nach München" - europäische Selbstfindung im Exil (1938/39)}

Nach der Annexion Österreichs, dem Münchner Abkommen und dem deutschen Einmarsch in die Tschechoslowakei erfuhr die außenpolitische Diskussion des Exils eine dezidiert europäische Wendung. Mit der greifbaren $\mathrm{Ge}-$ fahr eines unter dem Hakenkreuz vereinigten Europas wuchs der Druck, ein antitotalitäres Gegenmodell für die Zukunft des europäischen Kontinents zu entwerfen. Dies um so mehr, als viele Emigranten in der deutschen Annexion Österreichs am 13. März 1938 erste Anzeichen eines Kriegsszenarios erblickt hatten.

Als nun die westlichen Demokratien das Sudetenland dem europäischen Frieden opferten, war sich das deutsche Exil in der Beurteilung nahezu ausnahmslos einig: München sei ein Scheinfrieden, der nur kurzfristig einen europäischen Krieg verhindert habe, tatsächlich aber eine Kapitulation Großbritanniens und Frankreichs vor Hitler bedeute und gerade deshalb die Kriegsgefahr noch erhöht habe ${ }^{167}$. Jederzeit könne der neue Weltkrieg ausbrechen, den die SAP zutreffend als nationalsozialistischen „Vorstoß um die Neuaufteilung der Welt" voraussah ${ }^{168}$. So wurde die bisher auf die sozialistische Revolution in Deutschland abzielende Frage „Was kommt nach Hitler?" 1938/39 um die außenpolitische Dimension bereichert.

Aus marxistischer Sicht erschien das Münchner Abkommen als Abwehr der kapitalistischen Welt gegen linksrevolutionäre Tendenzen und damit als eine „schwere Niederlage des internationalen Proletariats “169. Der wortgewandte Eugen Brehm, der schon nach der Annexion Österreichs "neue Raubzüge gegen die ČSR “ prophezeit hatte, sah nach Hitlers Einmarsch in die Tschechoslowakei Anfang 1939 den „Friedensengel von München“ umhergehen: „Staaten sterben, die seine Knochenhand berührt; der gute Geist der Völker verdorrt unter seinem Atem; zerfetzte Abmachungen rascheln

167 MARCK, Ein gemeinsames Weltbild, in: Die Zukunft, I. Jg. (4. 11. 1938), S. 6.

168 Erklärung der SAP, in: Die Neue Front, 6. Jg., Nr. 10 (Oktober 1938), Beilage „Zur Kriegsfrage“, S. 1. Schon im Februar 1938 hatte die SAP gemeinsam mit dem ISK und der Landesgruppe deutscher Sozialdemokraten in Frankreich eine Erklärung abgegeben, in der „vor der Utopie, man könne den faschistischen Imperialismus Deutschlands durch politische oder wirtschaftliche Zugeständnisse endgültig befriedigen“, gewarnt wurde; Gemeinsame Erklärung von ISK, SAP und der SPD-Landesgruppe Frankreich, in: SW, 13. Jg., H. 8 (25. 2. 1938), S. 172f. (173).

169 Hitler-„Frieden“ über Europa, in: Die Neue Front, 6. Jg., Nr. 10 (Oktober 1938), S. 1, $4(4)$. 
wie die fahlen Blätter eines Trauerkranzes. Schneller als der Chronist es aufzuzeigen vermag, verändern sich die Lebensformen Europas. "170 Für die linke Sozialdemokratie geißelte Alexander Schifrin das Abkommen als "größte Erpressung der Weltgeschichte“, die durch ein selbstbewußteres Auftreten der beiden demokratischen Signatarstaaten hätte verhindert werden können. Man habe um den Frieden gefleht, statt ihn zu sichern ${ }^{171}$. Zustimmend sprach Neu Beginnen von einem "machtpolitischen Erdrutsch" ${ }^{172}$.

Liberale Stimmen, wie diejenige des Publizisten Leopold Schwarzschild, zogen eine nachdenklich-pessimistische „Bilanz nach München“, die die europäische Bevölkerung in einen nur „vorübergehenden Rausch der Friedensrettung" gestürzt habe. Dessen Vergänglichkeit aber habe insbesondere der britische Premier Chamberlain bis zuletzt verkannt ${ }^{173}$. Auch die Pazifisten stimmten in die allgemeine Kritik am Abkommen von München ein, das ihre im Zuge der Annexion Österreichs aufgekommenen Ahnungen noch übertraf ${ }^{174}$. Von Friedrich Stampfer mußten sie sich entgegenhalten lassen, daß „München“ den Pazifismus in eine schwere Krise gestürzt und zu einem „Pazifaschismus" pervertiert habe 175 .

Nur wenige politische Flüchtlinge verweigerten sich einer Verurteilung des Münchner Abkommens und betrachteten es stattdessen als eine große Chance für die deutsche Nation, die durch den Versailler Vertrag erlittene Schmach zu überwinden: „Nach dem Münchner Abkommen mit den Westmächten eröffneten sich der deutschen Außenpolitik Perspektiven und Möglichkeiten, wie sie nach dem verlorenen Krieg auf lange Zeit niemand von uns zu hoffen gewagt hatte." 176 Dieser gerade aus dem Exil heraus betont nationale Standpunkt entsprach dem Selbstverständnis der Deutschen Freiheits-

170 HeRB [d. i. Brehm], Abschied von der Tschechoslowakei, in: SW, 14. Jg., H. 14 (7. 4. 1939), S. 340-345 (340).

171 SCHIFRIN, Krieg oder Weltkoalition?, in: Die Zukunft, I. Jg., Nr. 1 (12. 10. 1938), S. 15 f. (15). Angesichts dieser deutlichen Wortwahl Schifrins muß die Einschätzung von KELlER, Die Zukunft 1999, S. 72, die Zukunft habe nur verhaltene Kritik an dem von Daladier mitgetragenen Münchner Abkommen geübt, relativiert werden.

172 Der Erdrutsch - und unsere Zukunft, in: SIB, Nr. 42 (30. 10. 1938), S. 1-9 (1).

173 SCHWARZSCHILD, Bilanz nach München, in: NTB, 6. Jg., H. 41 (8. 10. 1938), S. 969971 (971). Schwarzschilds Kritik an Chamberlains politischen Fähigkeiten fiel vernichtend aus, ibid.: „Die Friedens-Erklärung, die er in München dem tragischen Vierer-Abkommen [gemeint ist das vorangegangene Godesberger Abkommen, B. S.] folgen ließ, ist ganz gewiß keine konkrete Abmachung und keine Bindung: sie ist nur ein Ausdruck seines vollendeten Unverständnisses für das Wesen und die Rolle seines Gegenübers und für sein betäubendes Nicht-Wissen um die Art der Kräfte, die heute in der Welt wirken und ihr Schicksal bestimmen."

174 Holl, Europa des pazifistischen Exils 1999, S. 276 urteilt, der Vorgang von „München 1938 " sei für die Pazifisten „vollends zum Menetekel" geraten.

175 F. ST.[Ampfer], München und die Parteien. Die Krise des Pazifismus, in: NV, Nr. 282 (13. 11. 1938), Beilage, S. 1.

176 [o. T.], Deutscher Freiheitsbrief, Nr. 57 (o. D.) [Anfang 1939], S. 1. 
partei (DFP) als Auslandsvertretung einer innerdeutschen liberal-konservativen Opposition. In den Parteiblättern Deutsche Freibeitsbriefe und Das Wabre Deutschland begrüßte man das Ergebnis von München sowohl bezüglich der Friedenssicherung als auch hinsichtlich des territorialen Zugewinns. Nur Hitler gönnte man diesen Erfolg nicht, sondern hätte ihn stattdessen lieber selbst errungen, denn: „Welcher Deutsche würde sich nicht der Mehrung des Reichtums, der Macht und Größe seines Vaterlandes freuen, wenn dadurch die Wohlfahrt des Volkes gefördert und die Eintracht und der Frieden der Völker nicht gefährdet wird.“"177

Solcherlei nationale Empfindungen trafen sich mit dem politischen Grundsentiment des emigrierten Nationalsozialisten Otto Strasser, der schon durch die Annexion Österreichs in eine vergleichbare Identitätskrise geraten war: In drei Denkschriften vom März 1938 hatte er den „Anschluß“ als historischen Erfolg der deutschen Nation gefeiert ${ }^{178}$ und ungeachtet seiner persönlichen Abneigung gegen Hitler und dessen Machtsystem offen eingestehen müssen: „Die zweifellos bestehenden Unterschiede unserer auBenpolitisch-nationalen Zielsetzung von der des Hitlersystems fallen bei einer Gegenüberstellung von Hitlers Verwirklichung und unserer Propagierung nicht mehr entscheidend ins Gewicht." ${ }^{179}$

Mit Blick auf das Friedenssicherungspotential des Münchner Abkommens vermochte Strasser, der sich unter Berufung auf ein Wort von Goebbels gerne zum "gefährlichsten Gegner" des nationalsozialistischen Regimes stilisierte $^{180}$, der in der DFP vertretenen Einschätzung nicht zu folgen. Während sich die liberal-konservative Sammelbewegung überzeugt gab, daß das Abkommen von München die Chance einer langfristigen Sicherung des europäischen Friedens bot, traf Strasser zumindest im Nachhinein ein vernichtendes Urteil über die „Munichois“: Angesichts des Hitler-Stalin-Paktes könne man eine gewisse Genugtuung über diesen ,sichtbare[n] Beweis, daß eine feige Politik auch eine dumme Politik ist", nicht unterdrücken ${ }^{181}$. Hermann Rau-

177 Europas schwarzer Tag, in: Das Wahre Deutschland (Oktober 1938), S. 1-3 (2).

178 Strasser, Denkschrift über den Kampf der Schwarzen Front nach dem Anschluß Österreichs, o. D. [Mitte März 1938], IfZ, NL Strasser, ED 118/20; ders., Großdeutschland und Europa, o. D. [Anfang 1938], ibid.; ders., Lagebericht der "Schwarzen Front ${ }^{*}$, Mitte März 1938, ibid.

179 Strasser, Denkschrift über den Kampf der Schwarzen Front nach dem Anschluß Österreichs, o. D. [Mitte März 1938], S. 2, IfZ, NL Strasser, ED 118/20.

180 Z. B. die Erwähnung in der von Kurt Singer, dem Generalsekretär der "FreiDeutschland“-Bewegung, verfaßten Einführung zu Strassers Buch: Hitlers Sturz durch die „Frei-Deutschland“-Bewegung, New York o. J. [1941].

181 Strasser, Der Pakt Stalin-Hitler, Typoskript, 22. 8. 1939, IfZ, NL Brehm, ED 228/ 11. Die Autorenschaft Strassers geht nicht nur aus der im Kopf des Manuskripts handschriftlich eingefügten Namensangabe hervor, sondern wird auch durch die Erwähnung eines Lageberichts der Schwarzen Front vom Juli 1939 (S. 1) bestätigt. Die Lageberichte der Schwarzen Front wurden ausnahmslos von Strasser selbst verfaßt. Entscheidendes Indiz ist jedoch der letzte Satz des Memorandums: „Wenn darüber das alte System von Gestern zusammenbricht, so freut uns zukunftswillige Menschen dies 
schning dagegen hob selbst nach dem Einmarsch Hitlers in die Tschechoslowakei Anfang 1939 noch das Frieden stiftende Potential des Münchner Abkommens hervor ${ }^{182}$. Der frühere nationalsozialistische Senatspräsident von Danzig, der im Exil mit dem Nationalsozialismus brach, zeigte sich überzeugt, daß „der Politik Hitlers [...] bereits im Münchner Abkommen die Spitze abgebrochen worden [ist]“183.

\subsubsection{Europäische Motivationen}

Der hohe Vertrauensverlust in die Widerstandsfähigkeit und den Oppositionswillen der westlichen Demokratien führte zu einer verstärkten Suche nach eigenen Lösungsansätzen des deutschen Exils. Dabei konnte nur schwer auf nationale Strategien zurückgegriffen werden, denn den politischen Flüchtlingen war die Nation als Grundlage außenpolitischen Handelns vorerst entzogen. Schon aus diesem Grund bemühte man sich um eine europäische Perspektive. Dies setzte voraus, daß zunächst das die Europäer Einende, das ihnen Gemeinsame, typisch Europäische definiert werden mußte. Auf diese Weise wurde 1938/39 die Diskussion um die europäische Identität angestoßen, die von Beginn an in den größeren Zusammenhang einer europäischen Neuordnung gestellt wurde. So mündete die „Bilanz nach München"184 in einen Prozeß der europäischen Selbstfindung im Exil.

Neben den Kommunisten, die weiterhin den Blick fest auf die UdSSR und nicht auf ein vereinigtes Europa gerichtet hatten, fanden sich auch unter den nichtkommunistischen Emigranten einige Stimmen, die einer Diskussion um die Zukunft Europas jeden Sinn absprachen. Sie verwiesen auf die zahlreichen Ungewißheiten zukünftiger Machtverhältnisse, die dazu führten, dass konkrete Planungen zu diesem frühen Zeitpunkt der Realität entbehrten. Eugen Brehm kritisierte, daß die Sozialdemokraten ebenso wie die Kommunisten „die Schaffung einer eigenen, den nationalen und übernationalen Bedürfnissen angepaßten außenpolitischen Konzeption praktisch bis auf den Tag nach der Machtübernahme verschieben, in der stillen Hoffnung, man werde schon schwimmen lernen, wenn man erst im Wasser liegt ${ }^{* 185}$. Tatsäch-

ebenso, wie daß Faschismus und Bolschewismus gemeinsam unter die Trümmer des dritten Reiches zu liegen kommen. "Hier sind die wesentlichen Axiome des Strasserschen Politikkonzeptes enthalten: die Dritte Front zwischen Faschismus und Bolschewismus, die beide als Träger des alten Mächtesystems überwunden werden müssen, sowie der Glaube an eine zukunftsorientierte europäische Jugend als Elitetruppe dieser Dritten Front.

182 RauSCHNING, Revolution des Nihilismus 21939, S. 464.

183 Ibid. S. 477.

184 SCHWARZSCHILD, Bilanz nach München, in: NTB, 6. Jg., H. 41 (8. 10. 1938), S. 969971.

185 Herb [d. i. Brehm], Bemerkungen zur Außenpolitik (II), in: SW, 13. Jg., H. 41 (14. 10. 1938), S. 978. Dieser als dreiteiliger Fortsetzungsartikel erschienene frühe Beitrag Brehms zur internationalen Politik, namentlich auch der europäischen Zukunft, widerlegt das pauschale Urteil von VoIGT (Hg.), Friedenssicherung 1988, S. 40, bis 
lich sprach sich Hilferding auf der Vorstandssitzung der Sopade vom 26. April 1939 gegen jede Neuordnungsdebatte aus, da man nur über das diskutieren könne, was bekannt sei186. Der Begründer des religiösen Sozialismus, Paul Tillich, pflichtete bei und sah sich zu einer Warnung veranlaßt, die in auffallendem Gegensatz zu seinem späteren Engagement im Council for a Democratic Germany stand: „Der Eindruck des Utopismus, den gewisse Versuche dieser Art machen, schädigt das Ansehen der Emigration und ihre wirkliche Aufgabe aufs Schwerste. “187

Auch Geyer und selbst der Paneuropäer Stampfer hielten am Postulat der Sinnlosigkeit einer solchen Auseinandersetzung fest, obgleich beide eine Erörterung allgemeiner außenpolitischer Leitlinien begrüßten und aktiv mittrugen ${ }^{188}$. Dies hinderte Geyer nicht, im Wege der parteipolitisch gebotenen, verdeckten Selbstkorrektur im Mai 1939 öffentlich zu behaupten: „Unsere Haltung zu den großen europäischen Fragen ist immer wohl definiert gewesen, in aller Offenheit und Freimütigkeit, noch zuletzt in der Septemberkrise in den Tagen von München." 189

Gerade die bedeutendste der europäischen Fragen, nämlich die Frage nach einer dauerhaften europäischen Einigung nach Überwindung des Hitler-Regimes, wurde von der Sopade 1938/39 mit vergleichsweise schwachem Interesse verfolgt. Dabei ging Siegfried Marck als Vertreter der Pariser SPD-Ortsgruppe noch weiter als Hilferding, indem er einer europäischen Einigung auf absehbare Zeit keinerlei Realisierungschancen einräumte. Marck rechnete infolge des "Münchner Scheinfriedens" mit einer Epoche des „heiligen Egoismus der miteinander ringenden imperialistischen Mächte“, die jede Europakonzeption höchst angreifbar mache ${ }^{190}$. Trotz der offiziellen Zurückhaltung

Kriegsbeginn habe es seitens der SAP keine Stellungnahme zur Zukunft des internationalen Staatensystems gegeben. Als Gründungsmitglied der SAPD und aktives Mitglied der SAP-Exilgruppe muß Brehm der SAP zugerechnet werden, auch wenn er zugleich zur "Gruppe" der emigrierten Pazifisten zählt.

186 Hilferding in der PV-Sitzung vom 26. 4. 1939, Protokoll der Sopade-PV-Sitzung vom 26. 4. 1939, abgedruckt in: BuChHOlz, Rother (Hg.), Parteivorstand, Dok. Nr. 146, S. 368-372 (372).

187 Tillich, Die politische und geistige Aufgabe der deutschen Emigration, Typoskript, 6. 7. 1938, IISG, NL Hertz, S11, M.S, Nr. 1, Bl. 9.

188 Stampfer, Deutschland wie es sein soll. Ein Katalog der Probleme, 9. 11. 1938, S. 26, AsD, NL Stampfer, Box 9, M. 46 sowie GEYER, Partei der Freiheit 1939, S. 69. Einige Passagen des Buches übernahm Geyer wörtlich für seinen vorab erschienenen Artikel: Im Sturm der Geschichte. Zwischen zwei Krisen - Die Lage der Demokratie in Europa, in: NV, Nr. 289 (1.1.1939), S. 1 f.

189 C. G[EYER], Der Kurs der deutschen Opposition. Das kommende Deutschland und das Bündnis mit Sowjetrußland, in: NV, Nr. 309 (21. 5. 1939), S. 1.

190 MarCK, Ein gemeinsames Weltbild, in: Die Zukunft, I. Jg. (4. 11. 1938), S. 6. Marck wandte sich damit insbesondere gegen entsprechende Uberlegungen Werner Thormanns, der zwei Wochen zuvor in derselben Zeitschrift behauptet hatte, das europäische Interesse verlange "gebieterisch“, das drohende Nachkriegschaos möglichst kurz zu halten und zügig mit dem gemeinsamen Wiederaufbau Europas zu beginnen; THORMANN, Umgrenzung der Aufgabe, in: Die Zukunft, I. Jg. (21. 10. 1938), S. 6 f. 
der Sopade als Partei beschäftigte sich der Vorstand auf drei weiteren Sitzungen im Juli 1939 recht intensiv mit der europäischen Frage. Das Protokoll verzeichnet einige Stimmen, die sich dafür aussprachen, die Aktualität und das Widerstandspotential der Europaidee unverzüglich zu nutzen. Hierzu zählte neben Hermann Budzislawski191, Karl Höltermann und Erich Rinner ${ }^{192}$ auch der Gewerkschafter Fritz Tarnow, der die Legitimation des Europadiskurses auf den Punkt brachte: „Der Kriegsausbruch wirft selbstverständlich auch sofort die Frage des Kriegsendes auf und damit beginnt ja eigentlich erst unsere große Aufgabe." 193 Dem stimmte die Gruppe Neu Beginnen ebenso zu wie der Individualist Eugen Brehm, der die außenpolitische Programmgestaltung zur unbedingten Notwendigkeit erklärte, wolle man nicht den innerdeutschen Machtanspruch endgültig aufgeben ${ }^{194}$.

Mag vor dem Hintergrund der internationalistischen Tradition der Sozialdemokratie der anfangs stiefmütterliche Umgang der Sopade mit dem Europagedanken verwundern, so gilt dies im umgekehrten Sinn erst recht für die Reaktion des liberal-konservativen Lagers, das sich durch das Ereignisfeld München veranlaßt sah, sich für die Entwicklung europäischer Zukunftsszenarien zu interessieren. In einer Stellungnahme der DFP vom April 1938 wurde erstmals der europäische Zusammenhang der deutschen Zukunft hervorgehoben und auf Deutschlands Mission als „Europas Herzstück“ hingewiesen ${ }^{195}$.

191 BuDZISLAWSKI, In voller Fahrt, in: Die neue Weltbühne, XXXV. Jg., Nr. 13 (30. 3. 1939), S. 381-388 (381 f.) offenbarte eine auffallend leistungsorientierte, an eine Art Staatsdarwinismus erinnernde Grundposition: „Während die Kräfte sich messen, wird ein Ringkampf der Ideen, der Prinzipien stattfinden [...], und am Ende wird nur das Lebensrecht desjenigen anerkannt werden, der in die neue europäische Gemeinschaft paßt. [...] Um bei der künftigen Neuordnung mitzusprechen, muß man vorher wesentliches zu ihr beitragen. Das Anrecht, gehört zu werden, will verdient sein."

192 Rinner in der PV-Sitzung am 26. 4. 1939: „Die wichtigste Frage ist, was wird nach dem Kriege?"; Protokoll der Sopade-PV-Sitzung vom 26.4. 1939, abgedruckt in: Buchholz, Rother (Hg.), Parteivorstand, Dok. Nr. 146, S. 370. Auf der PV-Sitzung vom 5. 7. 1939 bemerkte Höltermann: „Vor uns allen steht die große Frage: Was wird nach Hitler aus Deutschland werden?"; Protokoll der Sopade-PV-Sitzung vom 5.7. 1939, abgedruckt in: BuCHHOLz, ROTHER (Hg.), Parteivorstand, Dok. Nr. 154, S. $390-$ $393(390)$.

193 Fritz Tarnow in der PV-Sitzung vom 26. 4. 1939, Protokoll der Sopade-PV-Sitzung vom 26. 4. 1939, abgedruckt in: BuCHHOLz, Rother (Hg.), Parteivorstand, Dok. Nr. 146, S. 369. Ähnlich äußerten sich Rinner in derselben Sitzung, ibid. S. 370, und Karl Höltermann in der PV-Sitzung vom 5. 7. 1939, Protokoll der Sopade-PV-Sitzung vom 5. 7. 1939, abgedruckt in: BuchHOLZ, ROTHER (Hg.), Parteivorstand, Dok. Nr. 154, S. 390. Budzislawski hatte bereits im März bekannt: „Wir haben die Direktiven auszuarbeiten, falls es zu schrecklichen Ereignissen kommen sollte“; BUDZISLAWSKI, Nahe dem Krieg?, in: Die neue Weltbühne, XXXV. Jg., Nr. 12 (23. 3. 1939), S. 349-355 (353f.).

194 HerB [d. i. Brehm], Bemerkungen zur Außenpolitik (II), in: SW, 13. Jg., H. 41 (14. 10. 1938), S. 979; vgl. zu Neu Beginnen die Broschüre: Neu Beginnen. Was es will, was es ist und wie es wurde o. J. [1939], S. 43.

195 [o. T.], in: Deutscher Freiheitsbrief, Nr. 37 [April 1938], S. 1-4 (4). Zur Datierung: 
Mit dieser programmatischen Reaktion auf die Annexion Österreichs setzte eine Hinwendung des konservativen Spektrums zu europäischen Lösungsansätzen ein, die sich in der Folgezeit verstärkt mit Deutschlands europäischen Aufgaben auseinandersetzte ${ }^{196}$. Doch ist zu beachten, daß einige Kreise des bürgerlichen Exils die Hinwendung zu Europa schon längst vollzogen hatten. Für den politischen Katholizismus trifft dies auf Hubertus Prinz zu Löwenstein ebenso zu wie auf den altgedienten Europäer Werner Thormann, der nach dem Münchner Abkommen zu dem Schluß kam, daß die Programmdiskussion für die Opposition nunmehr zu einer Lebensnotwendigkeit geworden sei ${ }^{197}$.

\section{Nationalverständnis und Souveränitätskritik Die Appeasementpolitik} Englands und Frankreichs stieß den Europadiskurs des Exils auf einer qualitativ neuen Stufe an, die eine wesentliche Vertiefung der bisherigen Debatten und eine fortschreitende Konzeptionalisierung europäischer Denkmodelle hervorbrachte. Auftakt dieser neuen Diskursphase war bezeichnenderweise eine Debatte um das Verhältnis zur deutschen Nation. Die völkerrechtswidrige Preisgabe des Sudetenlandes sowie die Annexion Österreichs warfen Fragen nach der Legitimation des Selbstbestimmungsrechts der Völker auf. Dies um so mehr, als sich sowohl die Nationalsozialisten als auch die Tschechoslowaken auf dieses völkerrechtliche Prinzip beriefen.

Die Frage nach dem Verhältnis zur deutschen Nation stellte sich jedem politischen Flüchtling und bedurfte zunächst einer individuellen Prüfung, ob und inwieweit man sich mit Deutschland weiterhin identifizieren konnte und wollte ${ }^{198}$. In diskursiver Hinsicht wirkte sich diese Ausgangsfrage auf zweierlei Weise aus: Der deutlich überwiegende Teil der Neuordnungskonzeptionen fußte auf Begriff und Wesen der Nation als der maßgeblichen politischen Einheit, deren zukünftige Stellung im europäischen Gesamtgefüge zu definieren war. Dabei ging die Mehrheit des deutschen Exils zu diesem Zeitpunkt noch nahezu selbstverständlich von einer Schlüsselposition Deutschlands in Europa aus - wenngleich für diese Zukunftserwartung ideologisch unterschiedliche Begründungen angeboten wurden.

Im axiomatischen Spannungsverhältnis zur erwarteten deutschen Schlüsselposition in Europa übte das deutsche Exil eine unterschiedlich weit ge-

Dieser Artikel wurde offensichtlich unter unmittelbarem Eindruck der Annexion Österreichs im März 1938 geschrieben und ist wörtlich identisch mit dem Beitrag „Der Reichszerstörer", der als Leitartikel in Das Wabre Deutschland (April 1938), S. 1 f. erschien. Dies spricht für eine zeitgleiche Publizierung.

196 So z. B. in einem ungezeichneten Beitrag in: Deutscher Freiheitsbrief, Nr. 60 [Juli? 1939], S. 4.

197 ThormanN, Umgrenzung der Aufgabe, in: Die Zukunft, I. Jg. (21. 10. 1938), S. 6. 198 Darauf verwies Stampfer in einem Artikel für den Neuen Vorwärts: „Für den einzelnen kann die Trennung Rettung bedeuten, für die Partei ist sie auf alle Fälle Selbstmord.“; F. ST[AMPFER], Nochmals Versailles. Ohne ein freies Deutschland kein friedliches Europa, in: NV, Nr. 309 (21. 5. 1939), S. 3. 
faßte Kritik am bisherigen, häufig als übertrieben empfundenen Nationalverständnis. Soweit das Selbstbestimmungsrecht der Völker als Konstante, zumindest als politisches Schlagwort Eingang in die Diskussionen fand, wurde es von den erklärten Antinationalisten als historisch überholt, angesichts der jüngsten Ereignisse gar als kontraproduktiv angesehen. Dagegen bekannten sich die national denkenden Emigranten zu einer strengen Beachtung des Selbstbestimmungsrechts, um auf dieser Grundlage eine Revision des Versailler Vertrages zu erreichen.

Gewandelt durch die Frage nach dem Verhältnis zur Nation, nahm der Europadiskurs des deutschen Exils ab 1938 eine entscheidende Wende, die eine Vertiefung des Europabewußtseins und eine stetig an Präzision gewinnende Konzeptionalisierung zur Folge hatte. Im Zuge der Ereignisse der Jahre 1938/39 stand die Kritik am Nationalismus im Vordergrund der Europadebatten, so daß eine schleichende Distanzierung von der Idee der Nation die Folge war. Durch die Begründung einer allgemein erwarteten künftigen Schlüsselposition Deutschlands in Europa wurde dieser Aspekt des Europadiskurses ergänzt. Diese in der Nationalismusdebatte (weiter)entwickelten Einstellungen sollten in ihren vielfältigen ideologischen Bezügen die spätere Konzeptionalisierung der Europavorstellungen nachhaltig prägen.

Daß Deutschland nach Hitler eine zentrale Rolle spielen werde, stand 1938/39 für die meisten Emigranten außer Frage. Verbunden war damit die Vision des neuen, des "Anderen Deutschlands“199. Den Emigranten bot die Vorstellung eines von Hitler befreiten und dennoch starken Deutschlands eine nicht zu unterschätzende psychologische Stütze: Die Hoffnung auf einen Ausweg aus den dunklen Zeiten der Heimatlosigkeit bedeutete ständige Selbstvergewisserung der eigenen Bedeutsamkeit für zukünftige Tage. Ins Zentrum der Auseinandersetzungen rückte die ideologische Begründung und die konzeptionelle Verwertung dieser Grundannahme.

Die sozialistischen Europavorstellungen zeichneten sich mehrheitlich durch eine Kumulation der Negativabgrenzungen Antikapitalismus, Antiimperialismus und Antinationalismus aus: Kapitalismus und Imperialismus wurden als die innen- und außenpolitische Seite derselben Medaille betrachtet. Beide erführen mit dem Faschismus momentan ihren historischen Höhepunkt. Nur durch die sozialistische Revolution könnten sie endgültig überwunden und zum Positiven gewendet werden. Dabei vertraute man auf die schöpferische Kraft des Proletariats, das als einzige gesellschaftliche Autorität in der Lage sei, die drei Grundübel gleichzeitig zu besiegen: „Das Weltproletariat, das nur durch seine soziale Befreiung zugleich mit dem Kapitalismus auch Faschismus und Imperialismus beseitigen kann, ist in dieser Lage die einzige zuverlässige antifaschistische Kraft. ${ }^{200}$ Eine der wenigen Aus-

199 Der Begriff wurde z. B. für die lateinamerikanische Exilzeitschrift La Otra Alemania. Das Andere Deutschland verwendet.

200 Erklärung der SAP, in: Die Neue Front, 6. Jg., Nr. 10 (Oktober 1938), Beilage „Zur Kriegsfrage", S. 1. 
nahmen war der evangelische Theologe und Sozialist Paul Tillich, der schon Anfang Juli 1938 davon ausging, daß die Realisierungschancen des sozialistischen Ideals als ebenso gering einzuschätzen seien wie diejenigen des religiösen Sozialismus ${ }^{201}$.

Die Linkssozialisten der SAP und der Gruppe Neu Beginnen gingen davon aus, daß der besondere historische Ort Deutschlands und die aktuelle Herausforderung des nationalsozialistischen Regimes den Auftakt der sozialistischen Revolution in Deutschland zur Folge haben müsse. Anschließend müsse die Revolutionsbewegung zumindest europaweit ausgedehnt werden 202. Mithin sei die Umgestaltung Europas nur unter der Prämisse einer vorherigen Neuorganisation Deutschlands denkbar ${ }^{203}$.

Gerade in dieser Verknüpfung sahen viele Sozialisten die sicherste Gewähr für einen europäischen Frieden, den dauerhaft nur ein europäischer Sozialismus ermöglichen werde. In einem internen Thesenpapier für den Vorstand der Sopade erklärte Friedrich Stampfer zustimmend, daß „ein freies, einiges Deutschland in einem freien und einigen Europa [...] ein Garant des dauernden Friedens sein" werde ${ }^{204}$. In einem etwa zeitgleich publizierten Artikel für den Neuen Vorwärts faßte er diese Erkenntnis in einer knappen Formel zusammen: „Ohne ein freies Deutschland kein friedliches Europa“205.

Nur zwei Wochen vor der Unterzeichnung des Münchner Abkommens versuchte die Sopade in einem Flugblatt, die deutsche Bevölkerung aufzurütteln: „Der Krieg ist in nächster Nähe. [...] Die Zerstörung des Weltfriedens ist von Anfang an das Ziel der nationalsozialistischen Politik gewesen.“206

201 Tillich, Die politische und geistige Aufgabe der deutschen Emigration, Typoskript, 6. 7. 1938, IISG, NL Hertz, S11, M. S, Nr. 1, Bl. 5. Tillich, ibid. Bl. 6, sah auch die innerdeutsche Situation, insbesondere die der Arbeiterbewegung realistischer als viele seiner Gesinnungsgenossen: „Das Proletariat steht unter Terror und Militarismus, ist teils befriedigt durch Beseitigung der Arbeitslosigkeit, teils wartet es auf seine Stunde, die aber vor einer außenpolitischen Katastrophe überaus unwahrscheinlich ist. Die kritische Intelligenz ist vertrieben oder zum Schweigen gebracht."

202 Erklärung der SAP, in: Die Neue Front, 6. Jg., Nr. 10 (Oktober 1938), Beilage „Zur Kriegsfrage“, S. 1. Für Neu Beginnen: Rußlands Schwenkung - und die sozialistische Bewegung, in: SIB, Nr. 49 (Anfang Dezember 1939), S. 20-31 (31).

203 Vgl. z.B. C. G[EYER], Im Sturm der Geschichte, in: NV, Nr. 289 (1. 1. 1939), S. 2.

204 Stampfer, Vorschlag Stampfer: Die Politik der Sozialdemokratischen Partei Deutschlands im Kriege, Typoskript, o. D. [Sommer 1939], AsD, Bestand PV-Emigration Sopade, M. 178. Volgt (Hg.), Friedenssicherung 1988, S. 35 f. datiert dieses Dokument auf „1939/40“, was angesichts der Formulierung „der nächste Krieg“ [Hervorhebung d. Verf., B. S.] kaum haltbar ist. Überzeugender ist BEHRING, Demokratische Außenpolitik 1999, S. 385, Anm. 109, der „Sommer 1939“ annimmt. Jedenfalls muß das Dokument vor Ausbruch des Krieges entstanden sein. Der in Teilen nahezu identische Wortlaut des am 21. 5. 1939 publizierten Artikels „Nochmals Versailles. Ohne ein freies Deutschland kein friedliches Europa“ (s. folgende Anmerkung) spricht dafür, daß Stampfer seinen Vorschlag zwischen Mai und August 1939 formulierte.

205 F. ST[AMPFER], Nochmals Versailles, in: NV, Nr. 309 (21. 5. 1939), S. 3.

206 Der Vorstand der Sozialdemokratischen Partei Deutschlands, An das deutsche 
Mit dem wenig später abgeschlossenen Münchner Abkommen wurde diese Befürchtung greifbare Realität und veranlaßte den sozialdemokratischen Parteivorstand, das Feld der Außenpolitik nicht mehr allein den Einzelkämpfern Geyer und Stampfer zu überlassen. Stattdessen bemühte man sich verstärkt, ein aktualisiertes außenpolitisches Profil zu zeigen und die bisherige Grundposition „mit dem Gesicht nach Deutschland“ zu revidieren. Für die Europadebatten jedoch galt dies nur in eingeschränktem Maße, da der spezifisch europäischen Dimension erst mit Hilferdings Vorstandsreferat vom Januar 1940 eingehende Erörterungen gewidmet wurden.

Auch der ISK sah das künftige Deutschland in einer verantwortlichen Position, betonte jedoch stärker die zentrale Bedeutung der Zusammenarbeit mit Frankreich: „Die möglichst weitgehende Verständigung zwischen diesen beiden Ländern und nur diese Verständigung kann den Frieden in Europa sichern. "207 Einen bedeutenden Mitstreiter für die deutsch-französische Aussöhnung hatte der ISK in dem einflußreichen Verleger Willi Münzenberg, der am 28. April 1939 in seinem Organ Die Zukunft die Gründung der Union franco-allemande verkündete und sich in diesem Rahmen für einen durch das deutsch-französische Tandem angetriebenen europäischen Einigungsprozeß engagierte ${ }^{208}$. Wie für viele Sozialisten war auch für Münzenberg die deutsche Arbeiterklasse der entscheidende Gestaltungsfaktor künftiger Politik. Außenpolitisch hätten sich die deutsche und die französische Arbeiterklasse „in außerordentlicher Weise gegenseitig befruchtet", so daß nur mit Hilfe eines deutsch-französischen Zusammenspiels ein neues Europa errichtet werden könne 209 .

In Deutschland sahen die bürgerlichen Emigranten das natürliche Herzstück Europas, das den europäischen Frieden und die Sicherheit gewährleiste - was auf Grund ihres ohnehin stärker ausgeprägten Nationalstolzes nicht verwundert ${ }^{210}$. Die DFP räumte dem von Hitler befreiten Deutschland eine europäische Schlüsselposition ein: „Das neue, das wahre Deutschland aber

Volk! Der Krieg ist in nächster Nähe, Typoskript, 14. 9. 1938, AsD, Bestand PV-Emigration Sopade, Mappe 181.

207 DIERKSEN [d. i. Auerbach] an Eichler, 3. 4. 1938, S. 3, AsD, Bestand IJB/ISK, Box 35. Zustimmend HART [d. i. Eichler], Furor teutonicus, in: SW, 13. Jg., H. 11 (18. 3. 1938), S. 241-246 (245f.).

208 Vgl. Die Zukunft, II. Jg., Nr. 17 (28.4. 1939), S. 1. Der Gründung der Union franco-allemande waren zwei Besprechungen in Paris vorausgegangen (13. und 20.4. 1939). Münzenberg verwies auf so namhafte Unterzeichner der Gründungserklärung wie den ehemaligen französischen Außenminister Yvon Delbos, den ehemaligen Ministerpräsidenten Jean Paul-Boncourt und Pierre Viénot, die emigrierten Schriftsteller Alfred Döblin und Franz Werfel und die politischen Flüchtlinge Otto Klepper, Hermann Rauschning, Werner Thormann, Alexander Schifrin und Anna Siemsen. Zu Münzenbergs außenpolitischer Sichtweise vgl. auch seinen Beitrag: Die Arbeiterklasse - ein Garant der Verständigung zwischen den Völkern, in: Die Zukunft, II. Jg., Nr. 17 (28. 4. 1939) S. 7.

209 MünZENBERG, in: Die Zukunft, II. Jg., Nr. 17 (28. 4. 1939), S. 12.

210 [o. T.], in: Deutscher Freiheitsbrief, Nr. 37 [April 1938], S. 4. 
soll Herold des wiedererwachten europäischen Gewissens werden. Das neue Deutschland will in ein erneuertes Europa, will Glied und Eckstein eines festen Verbandes der Vereinigten Staaten Europas werden. ${ }^{211}$ Diese These war auch in der Sopade mehrheitsfähig. Dennoch sollte nicht übersehen werden, daß die Motivation einerseits dem klassisch machtpolitischen Kalkül, andererseits dem Internationalismus entsprang - ein dogmatisches Oxymoron, das für die Einschätzung des Reformpotentials beider Grundkonzeptionen von essentieller Bedeutung ist.

In der nationalkonservativen Konzeption stand das "wirklich abendländische Großdeutschland von Morgen "212 im Vordergrund, das nach der Vereinigung der historischen Rivalen Preußen und Österreich nicht nur „Träger und Unterpfand" eines vereinigten Europas sein werde, sondern auch dessen wesentliche Voraussetzung ${ }^{213}$. Hier griff Otto Strasser seine frühen Gedanken einer wohlwollenden deutschen Hegemonie im Zeichen der Dritten Front zwischen Faschismus und Bolschewismus auf und konstruierte das "Großdeutschland von Morgen" als primus inter pares in einer europäischen Föderation. Methodisch setzte er auf eine übergreifende Revolution des „Deutschen Sozialismus“. An dieser Stelle offenbaren sich zwei zentrale Unterschiede in den Zukunftsvisionen Strassers und Rauschnings: Setzte Strasser allein auf Deutschland als europäische Schutzmacht, hielt Rauschning einen deutsch-französischen Ausgleich für ratsam ${ }^{214}$. Hierin wußte er sich in Übereinstimmung mit dem ISK sowie dem linken Pazifisten Max Barth, der wie Rauschning Münzenbergs Union franco-allemande angehörte und trotz einer betont nationalen Ausgangsposition das deutsch-französische Tandem als unerläßlich für jede europäische Bemühung ansah ${ }^{215}$.

Der zweite wesentliche Unterschied zwischen den beiden emigrierten $\mathrm{Na}$ tionalsozialisten bestand in ihrem konträren Revolutionsverständnis. Strasser wählte gerade die sozialistische Revolution, um die Außenpolitik des künftigen Deutschlands zu europäisieren, während der ehemalige Danziger Senatspräsident aus einer zutiefst antirevolutionären Grundhaltung heraus die Beendigung der (nationalsozialistischen) Revolution als unabdingbare Voraussetzung für eine europäische Perspektive der deutschen Politik bezeichnete 216 .

Ungeachtet der gruppenübergreifend vorausgesetzten Schlüsselposition

211 [Leitartikel], in: Deutscher Freiheitsbrief, Nr. 48 (o. D.), S. 4.

212 Strasser, Großdeutschland und Europa, o. D. [Anfang 1938], S. 5, IfZ, NL Strasser,

ED 118/20.

213 STRASSER, Masaryk 1938, S. 194.

214 Rauschning an Thormann (Red. "Die Zukunft“) vom 18. 5. 1939, ANF, F7 15124, M. R.

215 In dem unveröffentlichten Artikel vom 29. 8. 1939, Diskussion des nationalen Problems, S. 3, ANF, F7 15123, M. B, erklärte Barth: „Die geistige und kulturelle Erhaltung des Okzidents auf europäischem Boden [...] hängt von der deutsch-französischen Einigung ab.“

216 RausCHNing, Revolution des Nihilismus 21939, S. 489. 
Deutschlands in Europa setzte mit der Annexion Österreichs und dem Münchner Abkommen eine allgemeine Kritik an der absoluten Souveränität des Nationalstaates ein. Sie weitete sich in vielen Fällen zu einer grundsätzlichen Auseinandersetzung mit dem deutschen Nationalismus und der Idee der Nation als Ordnungsprinzip multilateraler Beziehungen aus. Mit seiner facettenreichen Souveränitätskritik knüpfte das politische Exil an die Rechtswissenschaft der zwanziger Jahre an, die eine Abkehr von der rechtspositivistischen Betrachtung der Souveränität in die Wege geleitet hatte ${ }^{217}$. Allerdings geschah dies nicht in jedem Fall durch eine bloße Rückkehr zum christlichen Naturrecht oder seiner säkularisierten Spielart, dem von Grotius, $\mathrm{Pu}$ fendorf, Leibniz und Wolff entwickelten Vernunftrecht, sondern vermehrt auch durch die Suche nach neuen Wegen ${ }^{218}$.

Das Bemühen um neue Ansätze des Rechtsverständnisses resultierte aus der Kritik des Positivismus an der naturrechtlichen Doktrin, die Grundentscheidung für ein bestimmtes Ordnungsprinzip entziehe sich der kritischen Überprüfung. Diese Kritik fällt auf den Positivismus selbst zurück, denn der Positivismus geht von unabänderlichen Gesetzen (der Ökonomie, Gesellschaft, Geschichte) aus. Damit wird statt der naturrechtlichen Grundentscheidung für das Rechtssystem die positivistische Gesetzmäßigkeit dieses Rechtssystems absolut gesetzt. Folglich erklären sowohl Naturrechtslehre als auch Positivismus ihre jeweiligen Axiome - Existenz eines (gottgewollten) Naturrechts beziehungsweise unabänderliche Gesetzmäßigkeiten - für sakrosankt und der Kritik nicht zugänglich. Dies konnte die deutschen Emigranten in der konkreten Situation heimatlicher Entwurzelung nicht befriedigen, so daß auf der Grundlage eines kritischeren Rechtsverständnisses die multifunktionale Dimension des Föderalismus als völkerrechtliches Ordnungsprinzip an Bedeutung gewann.

Die Kritik am „entarteten Nationalstaat" 219 gestaltete sich mit fortschreitender Zeit eo ipso zu einem Motiv europäischer Integration. Doch entsprang diese diskursive Entwicklung keineswegs durchgängig einer „weltanschauliche[n] Besinnung gegen die Staatsvergottung", auch wenn zumindest der einzelne dabei häufig ein europäisches Zusammengehörigkeitsgefühl empfand 220 .

Die Quellen fordern eine differenzierte Sichtweise und lassen drei Intensitätsgrade der Kritik erkennen:

- eine fundamental verstandene Kritik im Sinne eines Antinationalismus, der

217 Vgl. z. B. KeLSEN, Das Problem der Souveränität und die Theorie des Völkerrechts, Tübingen 1920; WEBER, Die Krise des modernen Staatsgedankens in Europa, Stuttgart 1925.

218 So etwa der von Rudolf Smend in der Weimarer Zeit vertretene Irrationalismus. Die Rückkehr zum christlich definierten Naturrecht wurde z. B. verfochten von J. P. Steffes und H. Rommen.

219 LIPGENS, Anfänge 1977, S. 52-55.

220 So aber ibid. 
sich insbesondere im linken Spektrum zuweilen auf die Idee der Nation übertrug,

- eine demgegenüber abgeschwächte Form der Kritik, die sich nicht gegen die Idee der Nation als solche richtet, sondern lediglich gegen das großdeutsche Nationalverständnis der Nationalsozialisten und daher als Antinationalsozialismus bezeichnet werden kann,

- und schließlich der vom nationalkonservativen Milieu favorisierte Antihitlerismus, der sich weder gegen die Idee der Nation als völkerrechtliches Ordnungsprinzip noch gegen den großdeutschen Ansatz des Nationalsozialismus wendete, sondern allein gegen die für Hitler typische Methode politischer Erpressung zur Durchsetzung des großdeutschen Ideals.

Mit dem sozialistischen Internationalismus stand dem linken Spektrum des Exils ein Ansatzpunkt für eine ideologisch verankerte Kritik am übersteigerten Nationalbewußtsein des deutschen Faschismus zur Verfügung. Allmählich setzte eine Rückbesinnung auf die internationalistische Tradition ein und sollte sich erst im Verlauf der dramatischen Kriegsereignisse zu einer dezidiert antinationalistischen Grundposition entwickeln. 1938/39 begnügte man sich zumeist noch mit pauschalen Appellen an die Solidarität der europäischen Sozialisten, die zu diesem Zeitpunkt auch in der privaten Korrespondenz nur selten konkretisiert wurden. So schrieb der Gewerkschafter Walter Auerbach nach der Annexion Österreichs an Willi Eichler: „Heute gibt es eine klare Front: Alles Linke gegen Hitler!"221 Nur anderthalb Jahre später wurde Auerbachs Einfront-These durch den Abschluß des deutschrussischen Nichtangriffspaktes widerlegt.

In ihrer Grundsatzerklärung vom Oktober 1938 interpretierte die SAP die Vernichtung des europäischen Faschismus unter Führung des deutschen $\mathrm{Na}$ tionalsozialismus als "das entscheidende nächste Kettenglied der proletarischen Weltrevolution" 222 und bekannte sich damit zu einer globalen, notwendig antinationalen Betrachtungsweise. Diese Konsequenz ergab sich für die orthodox marxistische Partei aus dem sozialistischen Grundverständnis, das auf eine weltweite Ausbreitung der sozialistischen Revolution ausgerichtet und hinsichtlich seiner langfristigen Realisierungschancen auf eine weltumfassende Einheitsideologie angewiesen war.

Eine frühe Verfechterin des proeuropäischen Antinationalismus war Anna Siemsen. Die engagierte Sozialistin und ehemalige Reichstagsabgeordnete beantwortete unmittelbar nach dem Münchner Abkommen die Frage „Großdeutschland oder Föderation?" mit einer klaren Absage an den deutschen Nationalismus jedweder Ausprägung ${ }^{223}$. Obgleich sie in Einzelfällen dem Ruf nach nationaler Einigung eine gewisse Berechtigung zubilligte, verur-

221 Dierksen [d. i. Auerbach] an Eichler, 3. 4. 1938, S. 2, AsD, Bestand IJB/ISK, Box 35.

222 Erklärung der SAP, in: Die Neue Front, 6. Jg., Nr. 10 (Oktober 1938), Beilage „Zur Kriegsfrage", S. 1.

223 SIEMSEN, Großdeutschland oder Föderation?, in: Die Zukunft, I. Jg., Nr. 2 (21. 10. 1938), S. 7. 
teilte sie die bisherigen Versuche der deutschen Nationsbildung - kleindeutsch, großdeutsch oder alldeutsch - als verhängnisvoll und „unvereinbar mit europäischer Befriedung und europäischer Ordnung “224. Mit ihrem Urteil stellte sich Anna Siemsen in Widerspruch zum Exilvorstand ihrer ehemaligen politischen Heimat, der Sozialdemokratie, die seit München zwar die internationale Solidarität aller "demokratischen Kräfte in Europa" einforderte $^{225}$, im Kern aber während des gesamten Exils dem deutschen Nationaldenken enger verbunden blieb als manch bürgerlicher Emigrant.

Dies gilt auch für Stampfer, der sicherlich zu den exponierten Kämpfern einer europäischen Einigung zählte und dies Ende 1938 in einem unveröffentlichten Katalog der Probleme erneut unter Beweis stellte ${ }^{226}$, zugleich aber die europäische Einigung allein auf der Grundlage eines starken Deutschland betrachtete ${ }^{227}$. Erst unter dem Druck einer drohenden Spaltung Deutschlands und Europas, insbesondere nach der Konferenz von Teheran, setzte er sich vehement für eine Übertragung der europäischen Führungsrolle auf Frankreich ein, um doch noch den Erhalt Gesamtdeutschlands zu sichern $^{228}$.

In diesem Zusammenhang ist erwähnenswert, daß es auch der Sozialistischen Arbeiter-Internationale (SAI) bis zu ihrer Auflösung nicht gelungen ist, die unermüdlich geforderte ,einheitliche internationale Politik des Sozialismus im Kampfe um die Demokratie"229 umzusetzen. Der von Georg Reinbold mitverfaßte idealistische Vorschlag, "alle Parteien der SAI zu einer einheitlichen internationalen politischen Kraft zusammenzuschweißen"230, blieb hoffnungsvolles Wunschdenken.

Auch vor dem Hintergrund des Versagens der SAI riefen linkssozialistische Stimmen zunehmend lauter nach einer umfassenden Koordination der

224 Ibid.

225 Der Vorstand der Sozialdemokratischen Partei Deutschlands, An das deutsche Volk! Der Krieg ist in nächster Nähe, Typoskript, 14. 9. 1938, AsD, Bestand PV-Emigration Sopade, M. 181.

226 Stampfer, Deutschland wie es sein soll, 9. 11. 1938, AsD, NL Stampfer, Box 9, M. 46, S. 27: „Es gilt, die Schlagbäume nicht nach der einen oder nach der anderen Seite zu verschieben, sondern sie niederzureißen und den Weg mutig zu beschreiten, der zu den Vereinigten Staaten von Europa führt."

227 Vgl. etwa ibid. S. 26; ders., Vorschlag Stampfer, o. D. [Sommer 1939], AsD, Bestand PV-Emigration Sopade, M. 178.

228 Dies bekannte Stampfer in einem Brief an Hans Vogel vom 12. 1. 1944: „Wir [...] propagieren eine kontinentale Föderation unter Führung Frankreichs (um die hysterische Angst vor ,verkapptem Pangermanismus' zu beruhigen)."; AsD, Bestand PV-Emigration Sopade, M. 132. Vgl. desweiteren STAMPFER, Für die Vereinigten Staaten von Europa: Vive la France!, in: NVZ, 13. Jg., Nr. 2 (8.1. 1944), S. 1; DERS., Gruß nach Frankreich. Die europäische Mission der französischen Sozialisten, in: NVZ, 13. Jg., Nr. 34 (19.8. 1944), S. 1.

229 Dan, Jugow, Schwarz, Der Kampf um die Demokratie, August 1938, abgedruckt in: LangKau-Alex (Hg.), „Der Kampf für die Demokratie und den Frieden“ 21992, Dok. Nr. 1, S. 20.

230 Ibid. S. 21. 
Widerstandsarbeit der internationalen Arbeiterbewegung. Im Sturz des NSRegimes erkannte Neu Beginnen - in Anknüpfung an Löwenthals früher geäußerte Gedanken - die entscheidende Voraussetzung für eine Befreiung der Welt vom deutschen Faschismus durch den Sozialismus ${ }^{231}$. Ihre Berliner Untergrundgruppe forderte in Übereinstimmung mit dem exilierten Teil der Bewegung Neu Beginnen "ganze Maßnahmen, denn mit diesen kryptonationalistischen Lösungen [werden wir] nicht weiterkommen"232. Gerade für die ethnisch höchst vielfältige Bevölkerung Mitteleuropas sei eine nationalstaatliche Lösung weder gerecht noch zukunftsweisend ${ }^{233}$. Doch redeten die Vertreter von Neu Beginnen keineswegs einem strikten Internationalismus das Wort. Vielmehr strebte man schrittweise zuerst die Überwindung des Nationalismus in Deutschland an, der anschließend in einer europäischen Föderation seine endgültige Aufhebung finden und letztlich den Wiederaufstieg der sozialistischen Weltkräfte ermöglichen sollte ${ }^{234}$.

Auch das liberale und bürgerlich-konservative Exil verschloß sich nicht einer kritischen Hinterfragung des Nationalverständnisses, beschränkte die Kritik jedoch zumeist auf die nationalsozialistische Interpretation des Begriffs. Scharf wandte sich die DFP gegen die „Vaterlandslosigkeit“ des Internationalismus und geißelte den historischen Materialismus als eine „Sünde wider den Geist“235. Damit war der wesentliche dogmatische Unterschied zum sozialistischen Internationalismus benannt: Statt auf eine den nationalen Rahmen notwendig sprengende, übergreifende Bewegung zu vertrauen, knüpfte das konservative, in weiten Teilen auch das bürgerlich-liberale Lager des deutschen Exils an die Nation eines "Anderen Deutschland“ als dem wahren „Vaterland“ 236 an.

Um so bedeutender war für diesen Teil der politischen Emigration die klare Abgrenzung zwischen Hitler einerseits und Deutschland als historischem Ort andererseits. Man hoffte auf die Stunde, „in der man nicht mehr mit Hitler, sondern mit Deutschland über die Rettung Europas verhan-

231 Rußlands Schwenkung - und die sozialistische Bewegung, in: SIB, Nr. 49 (Anfang Dezember 1939), S. 20-31 (26).

232 BRILL et al., Erläuterung der „Zehn Punkte“, Februar 1938, abgedruckt in: LIPGENS (Hg.), Föderationspläne, Dok. Nr. 25, S. 103f. (104).

233 Vgl. Entscheidungskampf um die Tschechoslowakei, in: SIB, Nr. 36/37 (10. 5. 1938), S. $1 \mathrm{f}$.

234 Vgl. ibid. S. 2 sowie: Rußlands Schwenkung - und die sozialistische Bewegung, in: SIB, Nr. 49 (Anfang Dezember 1939), S. 31.

235 Der Kampf um das künftige Deutschland, in: Das Wahre Deutschland (August 1939), S. 14-16 (16). Die von der katholischen Heilslehre geprägte Wortwahl läßt auf die maßgebliche Figur des Wabren Deutschland, den früheren Zentrumspolitiker Carl Spiecker als Verfasser schließen.

236 Der Begriff des Vaterlandes taucht in den bürgerlichen Quellen häufig auf und bezeichnet die enge Verbundenheit mit der Heimat, auch in politischer Hinsicht, vgl. zum Beispiel den ungezeichneten Beitrag: Was soll aus Deutschland werden?, in: Das Wahre Deutschland (Juli 1939), S. 1-4. 
delt“237. Dementsprechend entwickelte sich jedenfalls für die christlich-konservativen Stimmen der Kampf gegen den Nationalsozialismus zu einem rücksichtslosen Kreuzzug: „Es ist nicht mehr der Halbmond, dessen blutige Sichel Europa bedroht, sondern das Hakenkreuz, das Zeichen der Knechtschaft, der Entwürdigung, der Barbarei, das unseren Erdteil mit Untergang bedroht." ${ }^{238}$ Dieser Kreuzzug sei in erster Linie eine deutsche Aufgabe, da er allein Deutschlands geschichtliche Schuld, den Nationalsozialismus zur Herrschaft gebracht zu haben, sühnen könne.

Der Antinationalsozialismus der liberal-konservativen Emigration wurde von den nationalkonservativen Vertretern Rauschning und Strasser noch weiter auf einen bloßen Antihitlerismus reduziert, der die Ziele und Pläne des Nationalsozialismus befürwortete, dessen durch Hitler repräsentierte Erscheinungsform und die ihr eigene Gewalt jedoch ablehnte. Rauschning störte sich lediglich an Hitlers bellizistischer Maßlosigkeit und bekannte: „Wenn Hitler zur Mäßigung finden würde [...], dann freilich wäre unser Urteil über den Nationalsozialismus falsch, und wir würden freimütig bekennen, geirrt und menschliche Größe nicht erkannt zu haben. "239

Die eigentliche Mißbilligung der nationalsozialistischen Gewaltpolitik findet ihren tieferen Grund in der Befürchtung, gerade dadurch das von Rauschning und Strasser enthusiastisch bejahte Ziel eines Großdeutschlands zu gefährden. Der von Strasser vertretenen Ansicht, „daß eine Einigung Europas mit Gewalt nicht nur unsittlich, sondern auch unmöglich ist" 240 , stimmte Rauschning uneingeschränkt zu: „Die ganze Idee einer auf Herrschaft und Gewalt beruhenden Ordnung, eines Weltimperiums [...] ist absurd und praktisch undurchführbar" und ende in Selbstzerstörung ${ }^{241}$. Für Rauschning spiegelte sich das typisch Europäische in den grundlegenden Ordnungsprinzipien des christlichen Abendlandes wider, zu denen er zunächst die „Freiheit und Vielfalt seiner Nationen" zählte ${ }^{242}$. Ein übernationales Europa war für Rauschning undenkbar, da es - ähnlich dem als „ungeheuerlichste Simplifikation des Lebens" ${ }^{243}$ gebrandmarkten Hitlerschen Nihilismus - die Nation als wesentlichen Bestandteil des europäischen Wertekanons ignorierte. Vor diesem politphilosophischen Hintergrund trat das ehemalige NSDAPMitglied dafür ein, die nationale Souveränität nur dann anzutasten, wenn sie einem gemeinsamen geistigen Prinzip untergeordnet werden könne, wie es im Heiligen Römischen Reich Deutscher Nation der Fall gewesen sei244. Ohne dieses geistige Prinzip, die auctoritas, ausdrücklich zu benennen,

237 Was soll aus Deutschland werden?, in: Das Wahre Deutschland (Juli 1939), S. 3.

238 [o. T.], in: Deutscher Freiheitsbrief, Nr. 48, o. D. [März 1939], S. 4.

239 RaUSCHNING, Revolution des Nihilismus 21939, S. 490.

240 Strasser, Masaryk 1938, S. 193.

241 RAUSCHNING, Revolution des Nihilismus 21939, S. 480.

242 Ibid. S. 492.

243 Ibid. S. 481.

244 Ibid. S. 480. 
dachte Rauschning hierbei mit Sicherheit an die katholische Kirche, der er sich als gläubiger Katholik sehr verbunden fühlte.

Otto Strasser war infolge der Annexion Österreichs durch das Deutsche Reich in eine politische und zugleich persönliche Zwangslage geraten, deren schrittweise Lösung die Lektüre von drei unveröffentlichten Typoskripten vom März 1938 offenbart. In demselben Augenblick, in dem er den sogenannten „Anschluß" als nationalen Sieg feierte und sogar zum methodischen Vorbild der gesamteuropäischen Neuordnung erkor, mußte er sich eingestehen, daß damit seinem Haupteinwand gegen Hitler, der Wahl des Krieges als außenpolitisches Mittel, die Grundlage entzogen worden war: Die Annexion war gerade nicht das Ergebnis einer kriegerischen Auseinandersetzung gewesen $^{245}$. Damit stellte sich die Frage nach der weiteren Existenzberechtigung der Schwarzen Front als Widerstandsgruppe im Exil.

In ersten, von Verunsicherung und offensichtlichen Selbstzweifeln geprägten Überlegungen hatte Strasser an eine Zusammenarbeit der Schwarzen Front mit Hitler gedacht, bei der die Arbeit seiner Auslandszentrale "fast ausschließlich geistiger, erzieherischer, lehrhafter Art" wäre, wobei er dann seine eigene Führungsrolle angesichts des persönlichen Hasses gegen das Hitlersystem in Frage stellte ${ }^{246}$. Strassers ideologische Verunsicherung führte kurzzeitig sogar zu einer wesentlichen Relativierung des bisherigen Kampfrufes der Schwarzen Front - „nationale Freiheit, soziale Gerechtigkeit, europäische Föderation " - mit der den Widerstandswillen nahezu leugnenden $\mathrm{Pa}$ role „Über Hitler hinaus - zum Deutschen Sozialismus“247. Kurz darauf aber besann er sich auf die Unterschiede zwischen seinem Konzept eines „Großdeutschland von Morgen" und dem "Großdeutschland Hitlers"248 und ordnete das wiederentdeckte Widerstandspotential schließlich in den ideologischen Zusammenhang seines am Jugendideal orientierten „deutschen Sozialismus" ein"249.

Wie Rauschning sah auch Strasser in der „Mannigfaltigkeit“ Europas einen „integrierende[n] Bestandteil seines Wesens, seiner Existenz, seiner Größe" 250 . Doch wünschte sich der ehemalige NSDAP-Politiker gerade nicht den großdeutschen Staat als Ordnungsprinzip der deutschen Nation, sondern das großdeutsche Volk. Anders als Rauschning, der den Rassebegriff

${ }^{245}$ Strasser, Denkschrift über den Kampf der Schwarzen Front nach dem Anschluß Österreichs, o. D. [Mitte März 1938], S. 1, IfZ, NL Strasser, ED 118/20.

246 Ibid. S. 2.

247 Ibid. S. 3.

248 Vgl. Strasser, Großdeutschland und Europa, o. D. [Anfang 1938], IfZ, NL Strasser, ED $118 / 20$.

249 Vgl. Strasser, Lagebericht der „Schwarzen Front“, Mitte März 1938, S. 2, IfZ, NL Strasser, ED 118/20. Diese geistige Entwicklung läßt zugleich den Rückschluß auf eine entsprechend chronologische Datierung dieser drei Quellen zu, die im Abstand weniger Tage verfaßt worden sein müssen.

250 STRASSER, Masaryk 1938, S. 193; auch S. 169. 
jedenfalls als Grundlage einer Rechtsordnung ablehnte ${ }^{251}$, setzte sich Strasser unter Verweis auf die „Dritte Front" zwischen Faschismus und Bolschewismus für einen völkischen Pangermanismus ein. Als positive Kehrseite des auf bloße Eroberung ausgerichteten Pangermanismus bemühe sich die völkische Variante um eine einvernehmliche Sammlung aller Deutschen und orientiere sich insoweit am Panslawismus ${ }^{252}$. Dabei wollte Strasser das Ordnungsprinzip der Nation nicht durch dasjenige der völkischen Rasse ersetzt sehen, sondern den imperialistischen Mißbrauch der Außenpolitik seiner wahrhaft nationalen Bestimmung eines "Großdeutschland von Morgen“ zuführen ${ }^{253}$. Mithin hielt Strasser an der Idee der Nation fest, beanspruchte jedoch eine andere - gleichwohl ebenso nationalistische - Interpretation als die Nationalsozialisten und gab für die Schwarze Front die Parole aus: „Gegen Hitler für Deutschland und Europa!"254 Darunter verstand er den Vollzug des nationalen Sozialismus in mehreren Etappen: Die momentanen Machthaber Europas - Hitler, Stalin und Mussolini - seien Männer von gestern, die die alte, längst morsche Ordnung repräsentierten. Diese alte Ordnung werde augenblicklich von ihren eigenen Extremen, dem Faschismus und dem Bolschewismus, zerstört. In der völkischen Entwicklung sei momentan die zerstörende Phase erreicht, der demnächst die aufbauende Phase der Dritten Front folgen werde, die unter Führung ihrer Elitetruppe, der Schwarzen Front, den deutschen Sozialismus auf revolutionärem Wege begründen werde. Schließlich werde der deutsche Sozialismus auf die europäische Ebene übergreifen und die Dritte Front als europaweite Bewegung eines wahrhaft nationalen Sozialismus etablieren ${ }^{255}$. In Anlehnung an den zum „Führer eines neuen Europa" stilisierten Tomasz Masaryk plädierte Strasser für den Dreiklang aus Sozialismus, Demokratie und Nationalismus, der in einer künftigen Europäischen Föderation seine höchste Erfüllung finden werde. Trotz stellenweise abweichender Lippenbekenntnisse bekannte sich der charismatische Nationalsozialist also ausdrücklich zum Nationalismus als Grundlage deutscher Außenpolitik ${ }^{256}$, so daß sich sein Antihitlerismus auf eine bloße Methodenfrage reduzieren läßt.

251 RaUSCHNING, Revolution des Nihilismus ${ }^{2} 1939$, S. 486.

252 STRASSER, Masaryk 1938, S. 173.

253 STRASSER, Denkschrift über den Kampf der Schwarzen Front nach dem Anschluß Österreichs, o. D. [Mitte März 1938], S. 2, IfZ, NL Strasser, ED 118/20. Das Konzept des „Großdeutschland von Morgen“, das er als Gegenentwurf zum „Großdeutschland Hitlers" verstand, erläuterte Strasser insbesondere in dem unveröffentlichten Manuskript Großdeutschland und Europa, o. D. [Anfang 1938], IfZ, NL Strasser, ED 118/ 20.

254 Strasser, Lage und Entwicklung, 1. 10. 1939, S. 2, IfZ, NL Strasser, 118/20.

255 Vgl. Strasser, Lagebericht der "Schwarzen Front“, Mitte März 1938, S. 2, IfZ, NL Strasser, ED 118/20.

256 STRASSER, Masaryk 1938, S. 277. 
Freibeit und Demokratie Der Initialcharakter der Nationalstaatsdebatte wurde schon früh ergänzt durch das ideologische Doppelmotiv „Freiheit und Demokratie". In Fortsetzung des in der Frühphase des deutschen Exils erörterten Demokratieverständnisses bemühten sich die Exilgruppen nach dem Münchner Abkommen noch stärker um eine unmißverständliche $\mathrm{Ab}$ grenzung vom nationalsozialistischen Deutschland. Sie stellten auf das traditionsreiche politische Schlagwort der Freiheit ab und setzten diesem die nationalsozialistische Sklaverei entgegen. Ähnlich dem teils revolutionär, teils sozial oder schlicht bürgerlich verstandenen Demokratiebegriff erfuhr auch der Ruf nach Freiheit eine übereinstimmende Terminologie, die jedoch unterschiedliche Auffassungen kolportierte257.

In der sozialistischen Interpretation las sich der Freiheitsbegriff als Freiheit der Arbeiterklasse von kapitalistischer Unterdrückung258. Curt Geyer fügte seinem antinationalsozialistischen Konzept von der europäischen Demokratie die Komponente der „europäischen Freiheit“ hinzu259. Dabei knüpfte er an die Französische Revolution an, legte den Schwerpunkt des Freiheitsverständnisses aber auf die antikapitalistische Stoßrichtung. Für ihn war der Freiheitskampf immer ein Kampf der Schwächeren, als deren Anwalt sich die Sozialdemokratie verstand ${ }^{260} .1939$ bezeichnete er in einem oft kritisierten Buch die Sopade als die „Partei der Freiheit" und deklarierte "die geistige Übereinstimmung der Völker im Willen zur Freiheit" als wichtigstes Axiom des Sozialismus ${ }^{261}$.

Innerhalb des linkssozialistischen Exils ist Brehms Freiheitsbegriff bemerkenswert, der gerade nicht auf die Freiheit der Arbeiterklasse abstellt, son-

257 LiPGENS, Anfänge 1977, S. 22 bezeichnet die Achtung vor dem Menschen, die Freiheit und Würde des einzelnen als eines der wichtigsten Anliegen des Exils. Dabei wird außer acht gelassen, daß der Antibolschewismus nicht allen Widerstandsgruppen zu eigen war. Mithin ist der Schluß, das Eintreten für die Freiheit des einzelnen habe zur Ablehnung der Sowjetunion führen müssen, nicht in jedem Fall zwingend, zumal die UdSSR insbesondere für die Linkssozialisten noch immer der Bannerträger der sozialen und individuellen Freiheit war, unabhängig von den temporären Verirrungen des Stalinismus.

258 Vgl. stellvertretend für viele Linkssozialisten das Programm der Gruppe Neu Beginnen zur Interdependenz von Planung und Freiheit sowie den demokratischen Rechten und freiheitlichen Traditionen der Arbeiterbewegung: Neu Beginnen. Was es will, was es ist und wie es wurde, hg. v. Auslandsbüro Neu Beginnen, London o. J. [1939], S. 6 .

${ }^{259}$ Vgl. z.B. C. G[EYER], Was Deutschland gebührt. Mr. Chamberlain und der Kampf der deutschen Opposition, in: NV, Nr. 282 (13.11. 1938), S. 1 f.; DERS., Im Sturm der Geschichte, in: NV, Nr. 289 (1. 1. 1939), S. 1 f.; DerS., Partei der Freiheit 1939; Ders., Die Zukunft der Tschechoslowakei. Eine Aufgabe der europäischen Demokratie, in: NV, Nr. 317 (16. 7. 1939), S. 1.

260 C. G.[EYER], Was Deutschland gebührt, in: NV, Nr. 282 (13. 11. 1938), S. 1 f. (1).

261 GEYER, Partei der Freiheit 1939, S. 69. Dagegen beschränkte sich der Pragmatiker Stampfer auf ein enges Verständnis der Freiheit des deutschen Volkes von der nationalsozialistischen Unterdrückung; vgl. F. ST[AMPFER], Nochmals Versailles, in: NV, Nr. 309 (21. 5. 1939), S. 3. 
dern primär die Freiheit des Staates, seine Souveränität und Integrität im Blick hat. Brehm zufolge war die Freiheit des Individuums, die 1789 von den französischen Revolutionären proklamiert worden war, nach den Ereignissen von $1938 \mathrm{zu}$ eng geworden. Sie bedürfe der Ergänzung durch die Freiheit des Staates von imperialistischen Einflüssen. Erst dieses Zusammenspiel von individueller und staatlicher Freiheit ermögliche schließlich ein Recht der Völker, das Brehm als vorrangige internationale Aufgabe des Sozialismus verstand ${ }^{262}$. Damit legte Brehm eine Subordination der Individualfreiheit durch die neu zu gewinnende Kollektivfreiheit der Völker nahe ${ }^{263}$ und trug auf diese Weise der strikten Auffassung der SAP vom sozialistischen Solidaritätsgedanken Rechnung 264 . Doch trat er im Gegensatz zu seiner Partei für eine verstärkte Wahrnehmung der europäischen Handlungsebene ein, der gegenüber dem Weltszenario eine höhere Priorität zukommen müsse.

Im Gegensatz hierzu steht eine konservative Auffassung von Freiheit, die vorrangig die Freiheit des einzelnen meint und die nationale Freiheit als Freiheit von internationalem $Z$ wang, also das Selbstbestimmungsrecht versteht. Rauschning und Strasser betrachteten die Freiheit des einzelnen als Fundament der abendländisch-christlichen Lebensordnung ${ }^{265}$, und Strasser konstruierte aus der Individualfreiheit, der Abendlandkultur und der „völkischen Eigenart" gar die weltpolitische Bedeutung des neuen Europas ${ }^{266}$.

Frieden und Sicherbeit Wie jeder Europadiskurs zeichnete sich auch der des deutschen Exils durch die Sehnsucht nach Frieden und Sicherheit aus. Dieses Grundmotiv war allen Überlegungen zur Zukunft Europas immanent. Gerade weil dieses Motiv aber als selbstverständlich vorausgesetzt wurde, ergab sich insoweit kaum Diskussionsbedarf, zumal die Frage der Notwendigkeit des Krieges und seiner Legitimation bereits in den Exiljahren bis 1937 ausgiebig erörtert worden war. Dies änderte sich erst im Verlauf des Krieges, als erste Skizzen einer europäischen Sicherheitsarchitektur für die Nachkriegszeit entworfen wurden und sich die Frage ihrer institutionellen Verankerung stellte.

Im Rahmen des Europadiskurses beschränkten sich die Beteiligten 1938/ 39 auf eine Überprüfung ihrer eigenen Positionen in der Kriegsfrage, die

262 Vgl. Herb [d. i. Brehm], Bemerkungen zur Außenpolitik (II), in: SW, 13. Jg., H. 41 (14. 10. 1938), S. 980 sowie DerS., Der Krieg, in: SW, 14. Jg., H. 39 (13.10. 1939), S. 928-931 (931).

263 Dies übersieht Lipgens, Anfänge 1977, S. 22, der Freiheit und Würde des einzelnen pauschal als eines der wichtigsten Anliegen „des Exils“ bezeichnet.

264 In der Erklärung der SAP, in: Die Neue Front, 6. Jg., Nr. 10 (Oktober 1938), Beilage „Zur Kriegsfrage“, S. 1 wird die Eigenständigkeit des Weltproletariats als Prämisse dafür bezeichnet, daß die Überwindung des deutschen und italienischen Faschismus „in der Errichtung der Vereinigten sozialistischen Republiken der Welt ausmündet, in denen die Freiheit aller die Voraussetzung sein wird für die Freiheit eines jeden".

265 Vgl. RauschnING, Revolution des Nihilismus 21939, S. 491.

266 Strasser, Großdeutschland und Europa, o. D. [Anfang 1938], S. 4, IfZ, NL Strasser, ED 118/20. 
nach „München“ unmittelbar in das politische Denken sowie das Lebensumfeld der Emigranten hineinragte. Ein „Hitlerfrieden“ nach dem Vorbild des Münchner Abkommens stieß auf einhellige Ablehnung 267 . In vielen bisher stärker pazifistisch orientierten Exilgruppen setzte daher ein Umdenken ein, das den Krieg als ultima ratio zur Niederwerfung des Hitler-Regimes nicht mehr grundsätzlich ausschloß. Zwar hoffte man noch immer auf eine friedliche Eindämmung des Faschismus, doch wurde ein Krieg zur Überwindung des nationalsozialistischen Regimes überwiegend als unausweichlich beurteilt ${ }^{268}$. Falls es tatsächlich zum Krieg komme, würde dieser nach allgemeiner Auffassung mit der Niederlage Hitlers enden und müsse unbedingt zur Errichtung einer zweiten deutschen Demokratie führen. Nur so könne der europäische Frieden gesichert werden ${ }^{269}$. Allein Otto Strasser meinte nach der Annexion Österreichs Ansätze einer friedlichen Politik Hitlers erkennen zu können und erklärte sich aufgrund seiner Zielidentität vorab solidarisch mit einer solchen Politik ${ }^{270}$.

In der Kriegsfrage zurückhaltender zeigte sich Hilferding, der noch im Juli 1939 unverdrossen die alte sozialdemokratische Forderung nach international kontrollierter Abrüstung unterstrich ${ }^{271}$. Und der überzeugte Pazifist Eugen Brehm war unsicher geworden: Hatte er nach der Annexion Öster-

267 Vgl. stellvertretend für viele GEYER, Kein Hitlerfrieden. Der Krieg für Frieden und Freiheit in Europa, in: NV, Nr. 330 (15. 10. 1939), S. 1 f. sowie: Was soll aus Deutschland werden?, in: Das Wahre Deutschland (Juli 1939), S. 3 f.

$268 \mathrm{Vgl.} \mathrm{z.} \mathrm{B.} \mathrm{den} \mathrm{Beitrag} \mathrm{von} \mathrm{Neu} \mathrm{Beginnen:} \mathrm{Kriegsaufgaben} \mathrm{der} \mathrm{deutschen} \mathrm{Sozialisten,}$ in: SIB, Nr. 40 (15. 8. 1938), S. 8-13 (11). Eine Gemeinsame Erklärung von ISK, SAP und der SPD-Landesgruppe Frankreich, in: SW, 13. Jg., H. 8 (25. 2. 1938), S. $172 \mathrm{f}$,, warnte sogar vor Hoffnungen auf eine friedliche Lösung und bezeichnete sie als gefährliche "Utopie" (S. 173).

269 So etwa Löwenstein, Nach Hitlers Fall, in: Die Neue Weltbühne, XXXV.Jg., Nr. 31 (3. 8. 1939), S. 958-962 (959).

270 Strasser, Denkschrift über den Kampf der Schwarzen Front nach dem Anschluß Österreichs, o. D. [Mitte März 1938], S. I f., NL Strasser, IfZ, ED 118/20.

${ }^{271}$ Hilferding, Vorschlag Hilferding, o. D. [Juli 1939], S. 1, AsD, Bestand PV-Emigration Sopade, M. 79. Gerade durch die strenge Ausrichtung an früheren Programmentwürfen der Partei stellt Hilferdings Vorschlag des Jahres 1939 einen der wenigen Beiträge zur Europadiskussion dar, der neben der Friedenssicherung - die auch für Hilferding das Hauptmotiv der europäischen Einigung war - auch den wirtschaftlichen Aspekt erwähnt und rudimentäre Überlegungen zur Institutionalisierung von Frieden und Wirtschaftskooperation enthält. Zur Datierung: Hilferdings Vorschlag geht zurück auf eine Anregung Stampfers in der PV-Sitzung vom 12. 7. 1939. Der Entwurf war gedacht als Antwort auf das Rundschreiben eines englischen Kreises um Seton Watson und Wickham Steed zur Europapolitik, die dem PV von Wilhelm Sander übermittelt worden war. Da die Vorlage des Hilferding-Entwurfs für den 19. 7. 1939 vorgesehen war und das Protokoll vom 19.7. 1939 die einstimmige Verabschiedung des Entwurfs vermerkt, kann die Entstehung dieses Dokumentes mit an Sicherheit grenzender Wahrscheinlichkeit auf die Woche $z$ wischen dem 12. und dem 19.7.1939 datiert werden; vgl. Protokoll der Sopade-PV-Sitzung vom 12. 7. 1939, abgedruckt in: BUCHHOLZ, ROTHER (Hg.), Parteivorstand, Dok. Nr. 155, S. 394-396 (394f.) sowie der Sitzung vom 19.7. 1939, abgedruckt in: ibid. Dok. Nr. 156, S. 396f. (396). 
reichs noch die Verteidigung Europas „selbst um den Preis des Friedens“ gefordert ${ }^{272}$, geißelte er nach „München“ die kriegerische Lösung als „ebenso gefährlich wie kurzsichtig“273.

Wirtschaftliche Kooperation Ebenso wie die Aspekte Sicherheit und Frieden zählte seit Beginn des Diskurses auch die Notwendigkeit einer wirtschaftlichen Föderation Europas zu den konvergierenden Elementen aller Europakonzeptionen. Als Selbstverständlichkeit wurde sie deshalb - jedenfalls in dieser Diskursphase - nur als zusätzliches Argument angeführt. Gerade in den Jahren 1938/39 war die wirtschaftliche Einigung Europas ein wenig aus dem Blick geraten, da die Emigranten das über die bloße wirtschaftliche Zweckmäßigkeit hinausgehende identitätsstiftende Potential eines gemeinsamen Wirtschaftsraumes selten zu erkennen vermochten. Auch wurde die beginnende Ausweitung des Faschismus in Europa zunächst kaum in ihrer wirtschaftlichen Dimension erkannt. Vor allem beanspruchten andere Fragen, insbesondere die Friedensfrage und die Bemühungen um eine allgemeinverbindliche Definition der europäischen Identität, die Aufmerksamkeit der politischen Emigration. Daher ist es nicht verwunderlich, daß sich das bürgerliche Exil zur wirtschaftlichen Einigung vorerst kaum äußerte und auch im sozialistischen Lager dieser Teilaspekt zunächst nur zurückhaltend erörtert wurde.

Soweit die europäische Frage in wirtschaftlicher Hinsicht betrachtet wurde, resultierten die Unterschiede zum einen aus der ideologischen Frontstellung zwischen Planwirtschaft und Marktwirtschaft, zum anderen aus der divergierenden Einschätzung der notwendigen Integrationsgeschwindigkeit. Stampfer und Hilferding propagierten den Übergang von der Autarkiewirtschaft zur kooperativen Friedenswirtschaft, wobei Hilferding einen vorsichtigen, etappenweise vorzunehmenden Abbau der Hochschutzzölle für sinnvoll erachtete ${ }^{274}$. Stampfer dagegen sprach von den „schöpferisch-konstruktive[n] Aufgaben" eines vereinigten Europas, die eine möglichst zügige Auflösung der nationalstaatlichen „Autarkie der manipulierten Währungen, der Rohstoffversorgung, des Menschen-, Waren- und Geldverkehrs" erfordere ${ }^{275}$. Für die Linkssozialisten Schifrin und Brehm kam einer möglichst engen Wirtschaftskooperation hauptsächlich eine strategische, das heißt friedenssichernde Funktion $\mathrm{zu}^{276}$.

272 Herb [d. i. Brehm], Österreichs Ende?, in: SW, 13. Jg., H. 9 (4. 3. 1938), S. 211-215 (215).

273 Ders., Bemerkungen zur Außenpolitik (I), in: SW, 13. Jg., H. 40 (7. 10. 1938), S. 953-956 (953).

274 Hilferding, Vorschlag Hilferding, o. D. [Juli 1939], S. 1, AsD, Bestand PV-Emigration Sopade, M. 79.

275 Stampfer, Vorschlag Stampfer, o. D. [Sommer 1939], S. 5, AsD, Bestand PV-Emigration Sopade, M. 178.

276 SCHIFRIN, Zur Außenpolitik der deutschen Linken, in: Die Zukunft, Jg. I, Nr. 6 (18. 11. 1938), S. 6f. (6); HERB [d. i. Brehm], Bemerkungen zur Außenpolitik (III), in: 


\subsubsection{Europäische Identität}

Mit dem wieder erwachenden Europabewußtsein vieler politischer Flüchtlinge stellte sich zugleich die Frage nach der künftigen außenpolitischen Orientierung Europas. Dabei ist zunächst festzuhalten, daß 1938/39 eine Spaltung des Kontinents in ein politisches Ost- und Westeuropa noch nicht vorhersehbar war, so daß die Diskussion des Exils auf die Positionierung Gesamteuropas im bipolaren Gefüge der Weltpolitik abzielte. Schon die Formulierung der Axiome gestaltete sich äußerst schwierig, galt es doch, die Grenzen Europas zu definieren, bevor man Europas Position in Abgrenzung zu anderen Machtblöcken umschreiben konnte. Im Mittelpunkt der Debatten stand aber nicht die abstrakte Fragestellung nach den Grenzen eines gemeinsamen Europas, sondern die viel aktuellere Frage nach dem Verhältnis zu den USA und der UdSSR - den beiden außereuropäischen Staaten, die sich seit 1918 kontinuierlich zu neuen Weltmächten aufgebaut hatten ${ }^{277}$. Die diesbezüglich entwickelten Positionen können - mit Ausnahme der Sopade im wesentlichen auf die beiden schon erörterten Grundmodelle europäischer Identifikation zurückgeführt werden: europäischer Sozialismus und (christlich) abendländischer Kulturkreis.

Der europäische Sozialismus war zukunftsorientiert und zielte auf die künftige soziale Identität Europas. Der Abendlandgedanke dagegen war vergangenheitsbezogen und stellte auf die schon bestehende kulturelle Identität Europas ab. Für beide Identifikationsmodelle war das Verhältnis zur kommunistischen UdSSR ein konstitutives Element, während sich die Einstellung zu den USA denknotwendig aus der antikapitalistischen Grundeinstellung des Sozialismus oder der antikommunistischen Grundeinstellung des Liberalismus ergab. Vor diesem Hintergrund gilt das Wort Jacob Walchers, daß es wenige Fragen gebe, die für die gesamte Arbeiterbewegung von solchem Interesse und von solch einschneidender Bedeutung seien, wie die Stellung zur Sowjetunion ${ }^{278}$, in negativer Konnotation auch für den Liberalismus und den Konservatismus. Während der antikommunistisch verstandene Abendlandgedanke per definitionem mit einer ostwärts gewandten Blickrichtung unvereinbar war, stellte das sozialistische Exil keineswegs einen monolithischen Block einseitiger Ostorientierung dar. Vielmehr ist zwischen den Befürwortern einer klaren Ostorientierung, den Fürsprechern einer oft

SW, 13. Jg., H. 42 (21. 10. 1938), S. 1006-1008 (1007f.). Auf die innerhalb der SAP abweichende Position Brehms wurde bereits mehrfach hingewiesen.

277 Neu Beginnen hatte in dem ungezeichneten Artikel Entscheidungskampf um die Tschechoslowakei, in: SIB, Nr. 36/37 (10.5. 1938) S. 14, die weltpolitische Bedeutung der beiden aufsteigenden Weltmächte klar erkannt: „Auf einen der mächtigen Faktoren [...] haben wir schon hingewiesen: die Sowjetunion. Der zweite sind die Vereinigten Staaten“; vgl. auch Die Vollstreckung von München - der Anfang vom Ende?, in: SIB, Nr. 45 (Anfang April 1939), S. 5-15 (14).

278 Vgl. WalCHER, Um die Stellung zur SU, in: Neue Front, 7. Jg., H. 5 (Mai 1939), S. 106-109 (106). 
ebenso klaren Westorientierung sowie denjenigen, die Europa als eigenständigen dritten Machtblock zwischen Ost und West zu etablieren suchten, zu differenzieren.

Hinsichtlich des Begriffs der West- oder Ostorientierung, der für die weitere Quelleninterpretation von erheblicher Bedeutung sein wird, sei vorab eine klarstellende Bemerkung erlaubt. In seiner grundlegenden Untersuchung über die sozialdemokratische Emigration hat Erich Matthias das häufig kritisierte Unterscheidungsmerkmal der Ost- bzw. Westorientierung der Sozialdemokraten geprägt. Die Kritik scheint tatsächlich insoweit berechtigt, als Matthias' Erklärungsmuster im Einzelfall oft nur knapp einem Pauschalurteil entgeht und darüber hinaus eine sprachliche Schieflage schafft, die seine eigentliche Aussage verdeckt: Mit „Osten" war das Orientierungsmonopol der Sowjetunion gemeint, während der "Westen“ ein Konglomerat verschiedener Staaten mit divergierenden Anknüpfungspunkten für eine „Orientierung" darstellte. Ausschlaggebend ist der Grundgedanke, den Matthias zum Ausdruck bringt: Bei Ost und West handelte es sich um die Symbolträger zweier völlig unterschiedlicher Wertegemeinschaften, die gezielt als Gegenkonzepte entworfen und auch als Gegenkonzepte verstanden wurden. Interessanterweise wurden beide Gesellschaftsentwürfe mit den Grundwerten Freiheit, Demokratie und Gerechtigkeit assoziiert, die dem jeweiligen Gegner wechselseitig abgesprochen wurden.

Europäischer Sozialismus und abendländischer Kulturkreis Das Verhältnis der emigrierten Linkssozialisten zur UdSSR war seit den ersten Moskauer Schauprozessen 1936/37 mehrmals Zerreißproben ausgesetzt gewesen ${ }^{279}$. Nach dem XVIII. Parteitag der KPdSU im März 1939, auf dem Stalin in einer programmatischen Grundsatzrede das „Einholen und Überholen“ der kapitalistischen Staaten und die Aufrechterhaltung des Terrorapparates dekretiert hatte, regten sich verschiedentlich Zweifel an der ideologischen Zuverlässigkeit der Moskauer Führung. Die emigrierten linkssozialistischen Gruppierungen überdachten die Rolle der Sowjetunion in einem künftigen Europa, ohne jedoch von ihrer grundsätzlichen Ostorientierung abzurücken. $\mathrm{Daß}$ die deutsche Revolution die Hilfe der UdSSR in Anspruch nehmen werde, stand außer Zweifel. Der erforderliche Intensitätsgrad dieser Hilfestellung wurde jedoch unterschiedlich bewertet.

In der SAP begann eine harte Auseinandersetzung um den künftigen Kurs der Partei. Jacob Walcher befürchtete, daß viele Sozialisten anläßlich der Schauprozesse „das Kind mit dem Bade ausschütten und sich überhaupt von der Sowjetunion abwenden “ 280 würden. Er befürwortete unter Bewahrung

279 FRIESIUS [d. i. Eichler], Unteilbarer Friede, in: SW, 14. Jg., H. 14 (7. 4. 1939), S. 325328 (327), sprach stellvertretend für viele Linkssozialisten, als er rückblickend feststellte: "Die Sowjetunion selber tat vieles, was die Abneigung gegen sie verstärken mußte. Dahin gehört ihre "Prozeß'-Politik vor allem."

280 WALCHER, Um die Stellung zur SU, in: Neue Front, 7. Jg., H. 5 (Mai 1939), S. 108. 
der Unabhängigkeit der deutschen Arbeiterbewegung eine „durchaus positive Stellung zur SU“281. Daraus resultierte zwangsläufig die demonstrative Abkehr von den westlichen Demokratien, deren Unzuverlässigkeit man in den Ergebnissen der Münchner Konferenz, an der die Sowjetunion gerade nicht beteiligt gewesen war, abzulesen meinte ${ }^{282}$.

Gemäßigtere Stimmen wie diejenige des Publizisten Fritz Sternberg sahen in einer allzu unkritischen Hinnahme der Ereignisse in der UdSSR die Gefahr einer tödlichen Umarmung ${ }^{283}$. Sternberg traf insoweit auf die Zustimmung der Gruppe Neu Beginnen, die sich als betont „unabhängige Freunde und unabhängige Verbündete, kritisch zur Mythologie des Stalinismus" bezeichnete 284 und aus diesem Selbstverständnis heraus vor einer deutschen „Filiale der Stalindiktatur" warnte285. Willi Eichler nahm die Kontroverse zwischen Walcher und Sternberg zum Anlaß, trotz vieler Vorbehalte gegenüber dem Willkürregime Stalins die Solidarität des ISK mit der Sowjetunion zu betonen, wenngleich man für die Oktoberrevolution Lenins „freudige[re]n Herzens" eingetreten sei ${ }^{286}$.

Für einen europäisch definierten Sozialismus warben vor allem die linkssozialistischen Organisationen Neu Beginnen und ISK. Dabei konnte auf eine gewisse Ausrichtung am sozialistischen Vorbild der Sowjetunion nicht gänzlich verzichtet werden. Dies lag anfangs auch nicht in der Absicht der linkssozialistischen Repräsentanten. Dennoch sah sich Eichler 1938 außer Stande, die künftige internationale Rolle der UdSSR einzuschätzen und setzte zunächst auf Frankreich, die USA und vor allem Großbritannien ${ }^{287}$. Darin ist noch keine endgültige Abwendung vom Osten zu sehen, sondern lediglich ein vorübergehendes Ausblenden der temporär unberechenbaren UdSSR aus den Europaplanungen des ISK. Die Schuld am Scheitern des alten Systems kollektiver Sicherheit sowie des Völkerbundes wies der führende Kopf des ISK Großbritannien zu, das bewußt abseits gestanden habe, statt die europäische Führung zu übernehmen. Nachdem aber Frankreich mit

281 DERS., Zwanzig Jahre Komintern, in: Neue Front, 7. Jg., H. 4 (April 1939), S. 82-88 (88).

282 Vgl. etwa Die Neue Front, 6. Jg., Nr. 10 (Oktober 1938), S. 1-4, insb. S. 4.

283 STERnBERG, Eine Replik, in: Neue Front, 7. Jg., Heft 5 (Mai 1939), S. 109-112 (112).

284 FrANK, Wandlungen der Sowjet-Union. Zur Neubeurteilung der russischen Frage nach dem achtzehnten Parteitag, hg. v. Auslandsbüro Neu Beginnen, London o.J. [1939], S. 52.

285 Neu Beginnen. Was es will, was es ist und wie es wurde, hg. v. Auslandsbüro Neu Beginnen, London o. J. [1939], S. 3.; vgl. auch den Richtlinien-Entwurf: Die deutsche sozialistische Arbeiterbewegung und der kommende Krieg, o. D. [Frühjahr 1939], IISG, Coll. Neu Beginnen, M. 30, Bl. 19: „Selbstständigkeit gegenüber der Sowjetunion“. Zutreffend datiert Rainer BEHRING, Demokratische Außenpolitik 1999 die Quelle auf Frühjahr 1939.

286 Holz [d. i. Eichler], Um die Stellung zur Sowjet-Union, in: SW, 14. Jg., H. 24 (16. 6. 1939), S. 571-574, hier S. 573.

287 Vgl. HART [d. i. Eichler], Furor teutonicus, in: SW, 13. Jg., H. 11 (18. 3. 1938), S. $245 \mathrm{f}$. 
dem Münchner Abkommen seine letzten außenpolitischen Kraftreserven preisgegeben hatte und die bisher favorisierte deutsch-französische Verständigung als europäischer Motor vorerst ausgeschieden war, wünschte sich Eichler ein rückhaltloses Bekenntnis des britischen Inselreichs zur Idee der kollektiven Sicherheit und ein aktives Engagement für den Europagedanken in leitender Verantwortung 288. Widerspruch erfuhr diese anglophile Wendung insbesondere durch den Gewerkschafter Walter Auerbach, der in einem Brief an Eichler eine Sanktionierung des bisherigen britischen Verhaltens forderte und für eine Beschränkung Großbritanniens auf eine konsultative Funktion in Europa plädierte: „Die Finger des britischen Außenamts [dürfen] niemals mehr in kontinentalen Fragen dominierend zu regieren haben. England darf mitreden, aber es darf nichts mehr entscheiden." 289

Im Gegensatz zu den Linkssozialisten herrschte bei der Sopade eine nicht nur antistalinistische, sondern eine dezidiert antikommunistische Grundhaltung vor. Geyer verstand seine europäischen Schlagworte der Freiheit und Demokratie als Antithese zur Sowjetunion ${ }^{290}$, und Rinner kolportierte im Vorgriff auf die US-amerikanische Nachkriegspolitik sogar die Idee eines demokratischen Deutschlands als „beste[n] Wall gegen eine Bolschewisierung Mitteleuropas“291. In der Befürchtung einer kommunistischen Europarevolution nach Hitlers Sturz ${ }^{292}$ hielten führende Sozialdemokraten eine Ostorientierung der deutschen Außenpolitik für fatal und plädierten für eine Annäherung an die westlichen Demokratien. Ähnlich wie der Intensitätsgrad der Ostorientierung die Linkssozialisten zunehmend spaltete, konnten sich die Sozialdemokraten nicht auf eine einheitliche Westannäherung verständigen. Geyer und Stampfer propagierten offen eine Anlehnung an den „westeuropäisch-amerikanische[n] Kulturkreis“293, wobei Stampfer allein aus taktischen Gründen die behutsame Einbeziehung der Sowjetunion in ein europäisches System der kollektiven Sicherheit empfahl294. In einem ähnlichen

288 DERS., Totaler Chock. Rafft sich Europa auf?, in: SW, 13. Jg., H. 12 (25. 3. 1938), S. 267: „Ein Bekenntnis Englands zur kollektiven Sicherheit, und zwar ein von Taten begleitetes, würde geradezu Wunder wirken."

289 Dierksen [d. i. Auerbach] an Eichler, 3. 4. 1938, S. 3, AsD, Bestand IJB/ISK, Box 35. 290 Vgl. C. G[EYER], Der Kurs der deutschen Opposition, in: NV, Nr. 309 (21. 5. 1939), S. 1 f. (1).

291 Rinner an Wilhelm Sollmann, 20.7. 1939, AsD, Bestand PV-Emigration Sopade, Rinner-Korrespondenz, M. 34. In Verkennung der tatsächlichen weltpolitischen Machtverhältnisse betrachtete Rinner jedoch Großbritannien noch immer als den einzigen Adressaten solcher Vorschläge.

292 Vgl. z. B. Fritz Tarnow in der PV-Sitzung vom 26. 4. 1939, Protokoll der SopadePV-Sitzung vom 26. 4. 1939, abgedruckt in: BUCHHOLZ, ROTHER (Hg.), Parteivorstand, Dok. Nr. 146, S. 369: „Meine große Sorge ist das Verhalten der Kommunisten bei Kriegsende. Ich fürchte, daß Rußland zwar nicht die Weltrevolution, wohl aber die Kontinental-Europa-Revolution im Augenblick des Zusammenbruchs Hitlers erzwingen will."

293 F. ST[AMPFER], Nochmals Versailles, in: NV, Nr. 309 (21. 5. 1939), S. 3.

294 Stampfer in der PV-Sitzung vom 26. 4. 1939, Protokoll der Sopade-PV-Sitzung vom 
Sinn forderte Hilferding eine rückhaltlose Unterstützung Englands und Frankreichs als „Vorkämpfer [...] der Kulturentwicklung“295.

Der Chefredakteur der Neuen Weltbühne, Hermann Budzislawski, nahm eine abwartende Haltung ein. Soweit es sich im Augenblick übersehen lasse, würden sich in einem künftigen System kollektiver Sicherheit die beiden Westmächte mit dem Materiallieferanten USA in der zweiten Linie einerseits sowie Polen und Rumänien mit dem russischen Kriegspotential im Rücken andererseits gegenüberstehen: „[Bleibt die Frage], wie intensiv sich die ,Großmächte der zweiten Linie', Amerika und die Sowjetunion, an den militärischen Maßnahmen beteiligen werden." 296 Mit wenigen Worten hatte Budzislawski die letztlich ausschlaggebende Ost-West-Konfrontation skizziert und zwischen den Zeilen die Gefahr einer Spaltung Europas erkennen lassen.

Die Ignoranz der SAP-Führung und anderer Sozialisten gegenüber einem spezifisch europäischen Sozialismus stieß auf die scharfe Kritik von Heinz Kühn, der das Eintreten für einen unmittelbar globalen Sozialismus als „farblosen Weltrepublikanismus" ablehnte ${ }^{297}$ und sich für eine klare europäische Ausrichtung des internationalen Sozialismus aussprach. Kühn forderte eine „europäische Neuordnung aus sozialistischem Geist“298, um die verpaßten Chancen nun nachzuholen. In einem ähnlichen Sinn forderte Schifrin die europäische sozialistische Bewegung auf, europäisch und machtpolitisch denken und handeln zu lernen ${ }^{299}$. Sowohl Kühn als auch Schifrin ergänzten mit ihren Stellungnahmen jedenfalls faktisch Geyers Entwurf einer europäischen Demokratie in europäischer Freiheit.

Für das bürgerliche Lager nahm der Gedanke der christlich-abendländischen Wertegemeinschaft die Funktion der europäischen Integrationsidee wahr. Die Legitimation einer gezielt gegen den Osten gerichteten Abgrenzung des christlich-abendländischen Raumes basierte nicht nur auf einem traditionellen Kulturbewußtsein, sondern auch auf einem strikten Antikommunismus. Mit persönlicher Abscheu sprach Leopold Schwarzschild von der „Bolschewisterei“" als „Ur-Syphilis“, die die „Folge-Syphilis“ des Faschismus

26. 4. 1939, abgedruckt in: BUCHHOLZ, ROTHER (Hg.), Parteivorstand, Dok. Nr. 146, S. 371 stellte Stampfer daher klar: „In meiner Stellung zu den Kommunisten unterscheide ich mich in taktischer Beziehung von meinen Kollegen, ohne daß ich deshalb weniger entschiedener Antibolschewist bin als die anderen."

295 KERN [d. i. Hilferding], Die Krönung des Verrats. Stalin als militärischer Bundesgenosse Hitlers, in: NV Nr. 327 (24.09. 1939), S. 4.

296 BuDZISLAWSKI, Weltkrieg oder Kapitulation, in: Die neue Weltbühne, XXXV. Jg., Nr. 14 (6. 4. 1939), S. 413-420 (418).

297 FrANS [d. i. Kühn], Zur Krise des Internationalismus, in: SW, 13. Jg., H. 51 (23. 12. 1938), S. 1215-1219 (1216).

298 Ibid. S. 1218. Zur Person Heinz Kühns vgl. neuerdings Düding, Heinz Kühn 2002.

299 Vgl. SCHIFrIN, Krieg oder Weltkoalition?, in: Die Zukunft, Jg. I, Nr. 1 (12. 10. 1938), S. 15. 
und Nazismus nach sich gezogen habe ${ }^{300}$. Dies um so mehr, als man der Ansicht war, die reale Bedeutung Rußlands als Militär- und Wirtschaftsmacht sei in letzter Zeit ungeheuerlich übertrieben worden ${ }^{301}$. Dem Antikommunismus lag eine grundsätzliche Antipathie gegenüber dem asiatischen Raum zugrunde, die ein anonymer Verfasser im Deutschen Freibeitsbrief der DFP historisch zu erklären suchte: „Es war des deutschen Reiches Verhängnis von Anbeginn, daß es nicht vom kulturellen Westen her fundamentiert und aufgebaut worden ist, sondern daß es aus dem wesensfremden Osten Geist und Gepräge erhielt. " ${ }^{302}$ So erschien der Kommunismus als Ausprägung einer wesensimmanenten Gegensätzlichkeit zwischen Ost und West. Angesichts der Doppelgefahr durch Kommunismus und Faschismus in Europa, die man nach dem Münchner Abkommen um so drohender wahrnahm, stellte Das Wabre Deutschland die bange Frage: „Wann wird Europa wieder die Heimat christlicher Kultur und Gesittung werden? Wann werden die Völker das heute geschändete - Recht wieder auf seinen Thron erheben?"303

Das Motiv der zweiseitigen Zwangslage zwischen Bolschewismus und Faschismus erinnert an Strassers Theorie der Dritten Front. In konsequenter Anwendung der völkischen Idee glaubte der exilierte Nationalsozialist Strasser an einen organischen Aufbau internationaler Institutionen und verfocht die These, daß ein Staatenbund ebenso auf dem äquivalenten Kulturkreis basieren müsse wie der Staat auf der Nation ${ }^{304}$. Grundelement dieser Anschauung war die Familie als kleinste völkische Einheit, über die sich der Staat, der Staatenbund und schließlich der Völkerbund als Wahrer der Menschheitskultur wölbe. Dahinter stand auch bei Strasser eine durch Negativabgrenzungen umrissene Vorstellung vom christlichen Abendland als Bollwerk gegen innereuropäische und äußere Destruktionsbestrebungen.

Nach "München" sah der Publizist Leopold Schwarzschild die Westmächte als nachhaltig geschwächt an ${ }^{305}$. Insbesondere Frankreich war seiner Ansicht nach nicht mehr in der Lage, die ihm ursprünglich zugedachte europäische Führungsrolle zu übernehmen. In Betracht komme nur noch Großbritannien, das eine europäische Anti-Hitler-Koalition herbeiführen könne. Insofern stimmte Schwarzschild mit der gewandelten Position des ISK überein.

Obwohl die Idee des abendländischen Kulturkreises als europäisches Identifikationsmerkmal doch vorrangig eine Domäne der liberalen und konservativen Emigration war, fand sie auch in sozialdemokratischen Kreisen

300 SCHWARZSCHILD, Das zweite Brest-Litowsk, in: NTB, 7. Jg., H. 35 (26. 8. 1939), S. 825-827 (826).

301 Ibid.

302 [o. T.], in: Deutscher Freiheitsbrief, Nr. 37, o. D. [April 1938], S. 1-4 (3).

303 Europas schwarzer Tag, in: Das Wahre Deutschland (Oktober 1938), S. 3.

304 STRASSER, Masaryk 1938, S. 165.

305 Vgl. SCHWARZSCHILD, Bilanz nach München, in: NTB, 6. Jg., H. 41 (8. 10. 1938), S. 971 . 
Anhänger. So betonte Anna Siemsen die kulturelle Identität Europas stärker als die Gemeinsamkeiten der europäischen Arbeiterbewegung. Und der $\mathrm{Pa}$ zifist Max Barth, der hauptsächlich mit sozialdemokratischen Exilorganisationen in Verbindung stand ${ }^{306}$, betrachtete den Nationalsozialismus als Derivat östlich-asiatischen Einflusses und hoffte, „daß [...] in Deutschland die Herrschaft des abendländischen Geistes und der abendländischen Prinzipien, zu denen unter anderem Humanitarismus, Individualismus, Demokratismus gehören, gesichert wird anstelle der jetzt herrschenden östlichen Ideologie

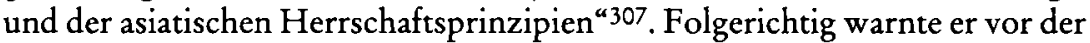
Vernichtung Deutschlands durch die Alliierten, weil ein solches Vorgehen eine Fortsetzung der Politik Hitlers wäre, „nämlich die Auslieferung Europas an den Osten" 308 .

Europas Eigenständigkeit Nur wenige Emigranten formulierten schon 1938/39 das Ziel der politischen Eigenständigkeit Europas zwischen dem westlichen und dem östlichen Einflußgebiet. In dieser Diskursphase entsprangen solche Überlegungen in der Regel eher dem Kreis des europäischen Sozialismus. Zu nennen ist hier zunächst Alexander Schifrin. Schifrin, der sich mit unverändertem Engagement für die europäische Idee einsetzte, hatte früh die Gefahr einer Spaltung des europäischen Kontinents vorhergesehen und lehnte entschieden eine engere Zusammenarbeit mit dem Westen ab. Wie bereits erläutert hatte sich Schifrin bereits 1934, also lange vor den ersten Moskauer Prozessen, ebenso entschieden gegen eine europäische Ausrichtung gen Osten ausgesprochen. Seine Grundidee eines harmonischen Ausgleichs zwischen Ost und West, eines Brückenschlages zwischen London, Paris und Moskau unter späterer Einbeziehung Deutschlands hatte durch das Münchner Abkommen jedoch einen schweren Rückschlag erlitten ${ }^{309}$. Doch schon Ende 1938 hatte er seine Zuversicht wiedergewonnen und artikulierte

306 Erst vor der Bundestagswahl 1969 trat Barth schließlich in die SPD ein, da „es jetzt auf jede Stimme ankommt"; zit. n.: BARTH, Flucht in die Welt 1986, S. 283.

307 Barth, Diskussion des nationalen Problems, o. D. [August 1939], ANF, F7 15123, M. B. Es sei darauf hingewiesen, daß sich die von Barth empfundene Bedrohung des eigenen Wertesystems durch den östlichen, insbesondere den asiatischen Einfluß in dem bekannten Zehn-Punkte-Katalog der Berliner Untergrundgruppe von Neu Beginnen wiederfindet - Brill et al., Erläuterung der „Zehn Punkte“, Februar 1938, abgedruckt in: LIPGENS (Hg.), Föderationspläne 1968, Dok. Nr. 25, S. 103: „[Die Europäer seien vor die Frage gestellt:] Wollt Ihr durch Selbstzerfleischung dazu beitragen, daß Europa in dreißig, fünfzig oder hundert Jahren von den Völkern Asiens aus der Geschichte verdrängt ist? Wem die europäische Kultur etwas wert ist - und wem könnte sie gleichgültig sein? - kann darauf nur mit Nein antworten. Also darf man nicht nur von Europa reden, man muß es organisieren."

308 Barth, Diskussion des nationalen Problems, o. D. [August 1939], ANF, F7 15123, M. B.

309 Vgl. SCHIfrin, Krieg oder Weltkoalition?, in: Die Zukunft, Jg. I, Nr. 1 (12. 10. 1938), S. $15 \mathrm{f}$. 
die politische Hoffnung, „daß England und Frankreich durch die Sowjetunion und die Vereinigten Staaten flankiert werden können" $" 310$.

In einem Richtlinienentwurf bemühte sich auch die Gruppe Neu Beginnen um eine Legitimation der politischen Eigenständigkeit Europas. Es wurden Zweifel erhoben, ob allein die revolutionäre Kraft eines europäischen Sozialismus ausreiche, um das unveränderte Fernziel der Weltrevolution herbeizuführen $^{311}$. In diesem Kreis betrachtete man die europäische Einigung als ein notwendiges Zwischenstadium, dessen Legitimität als selbstständiges Ziel keineswegs aufgegeben wurde ${ }^{312}$. Da eine europäische Neuordnung nur sozialistisch denkbar seij ${ }^{313}$, komme eine Zusammenarbeit mit den imperialistischen Mächten des Westens nur für die Dauer des Kampfes gegen den Faschismus in Betracht. Langfristig setzte sich Neu Beginnen für die eigene Unabhängigkeit zwischen West und Ost ein, gerade weil die Linkssozialisten frühzeitig die entscheidende Rolle der Weltmächte USA und UdSSR erkannt hatten ${ }^{314}$. Aus ideologischen Gründen hielt man dennoch an der inneren Verbundenheit mit der UdSSR fest. Nicht zuletzt daher erklärt sich die strikte Ablehnung einer führenden Rolle Großbritanniens in Europa. Man befürchtete einen Ausverkauf der Freiheit und Unabhängigkeit der kleineren europäischen Staaten zum Vorteil des „englischen Imperialismus" 315 und verwies auch nach dem Münchner Abkommen - im Gegensatz zu Eichler - unverändert auf einen deutsch-französischen Ausgleich als Kern jeder kontinentalen Neuordnung.

310 Ders., Friedenspolitik ist Weltpolitik. Die Lehre des Jahres 1938, in: Die Zukunft, Jg. I, Nr. 11 (23. 12. 1938), S. 2. Vgl. auch Ders., Zwei gemeinsame Aufgaben, in: Die Zukunft, Jg. II, Nr. 23 (9.6. 1939), S. 4: „Der anglo-französisch-sowjetrussische Block bildet eine mächtige Grundlage für die Verteidigung Europas. Die Zukunft Europas wird gesichert werden, wenn es gelingt, die Kräfte der europäischen Demokratie und der deutschen Opposition zusammenzuführen und ihre Zusammenarbeit auf lange Sicht zu organisieren."

311 Richtlinien-Entwurf: Die deutsche sozialistische Arbeiterbewegung und der kommende Krieg, Ausarbeitung o. V., o. D. [Frühjahr 1939], IISG, Coll. Neu Beginnen, M. 30, Bl. $17 \mathrm{f}$.

312 Kriegsaufgaben der deutschen Sozialisten, in: SIB, Nr. 40 (15. 8. 1938), S. 8-13 (10).

313 Entscheidungskampf um die Tschechoslowakei, in: SIB, Nr. $36 / 37$ (10.5. 1938), S. 2.

314 Vgl. Großdeutschland - Und was weiter?, in: SIB, Nr. 35 (15. 3. 1938), S. 10, sowie: Kriegsaufgaben der deutschen Sozialisten, in: SIB, Nr. 40 (15. 8. 1938), S. 8-13 (13). LIPGENS, Anfänge 1977, S. 55, ist der Auffassung, das Ziel der politischen Eigenständigkeit Europas sei erst gegen Ende des Krieges formuliert worden, zumal es ein „machtpolitisch zu mißverstehende[s] Argument" für die europäische Einigung sei. Demgegenüber belegen die Stellungnahmen von Neu Beginnen und Schifrin, daß eine selbständige Position Europas im globalen Machtgefüge durchaus früher erörtert wurde.

315 Die Vollstreckung von München - der Anfang vom Ende?, in: SIB, Nr. 45 (Anfang April 1939), S. 6; vgl. ferner: Zur Internationalen Lage nach der Annexion Österreichs, Entwurf o. V., diktiert Ende März 1938, IISG, NL Hertz, S11, M. T, Nr. 1, Bl. 3. 


\subsubsection{Europäische Institutionen}

Fragen der Institutionalisierung der angestrebten Vereinigung Europas wurden in diesem recht frühen Stadium des Europadiskurses kaum behandelt sieht man von einigen zumeist pauschalen Rückgriffen auf ältere Vorschläge einer Neuauflage des Völkerbundes oder nebulösen Verweisen auf die "Vereinigten sozialistischen Republiken der Welt" ab. In dieser Diskursphase konnte die Frage nach gemeinsamen europäischen Institutionen und einer langfristigen Verankerung der europäischen Zielsetzungen auch noch gar nicht im Vordergrund stehen, da zuvor das staatsphilosophische Problem des Stellenwertes der Nation geklärt und die damit verbundenen Zweifel am Wert der Souveränität diskutiert werden mußten.

Doch mit der Intensivierung des Europadiskurses stand auch die Frage nach dem strukturellen Ordnungsprinzip eines vereinigten Europas im Raum. Erheblichen Diskussionsbedarf wiesen die Frage nach einer Verbesserung des Völkerrechts, insbesondere die mögliche Einschränkung des Selbstbestimmungsrechts der Völker, sowie die Frage des Föderalismus als angestrebtes Strukturprinzip auf. Diese beiden Grundfragen wurden kontrovers diskutiert, wobei nach dem jeweiligen Integrationsgrad drei grundlegende Ansichten unterschieden werden können: die radikale Auffassung eines modifizierten, auf die europäischen Bedürfnisse anwendbaren Völkerrechts im Sinne einer integrationsstarken Föderation mit konsequenter Beschneidung des nationalen Selbstbestimmungsrechts, die gemäßigte Variante einer bloßen Konföderation ohne starke Zentralgewalt und die im Kern antiföderalistische Ansicht einer strikten Beibehaltung des Selbstbestimmungsrechts und einer Rückkehr zur nationalstaatlichen „balance-of-power“-Politik.

Einige politische Flüchtlinge widmeten sich schon früh der grundsätzlichen Bedeutung des Völkerrechts als Mittel zur Lösung anstehender europäischer Probleme. Insoweit konnte zunächst auf die konkreten Erfahrungen des Völkerbundes zurückgegriffen werden, dessen Schwächen eine grundlegende Verbesserung der völkerrechtlichen Standards nahelegten.

Stein des Anstoßes war vor allem das bisher tragende völkerrechtliche Prinzip des Selbstbestimmungsrechts der Völker bzw. dessen negatives Pendant, das Nichteinmischungsprinzip - Grundsätze, die auf dem Gedanken der absoluten Staatssouveränität beruhen. Grundvoraussetzung jeder über eine traditionell machtpolitische Kooperation hinausgehenden Staatenstruktur ist folglich die Einschränkung der Staatssouveränität, um der übergeordneten Gesamtkonstruktion überhaupt einen gewissen Handlungsspielraum einzuräumen. Hieran wird deutlich, daß es sich bei den Fragen eines modifizierten Völkerrechts und einer föderalistischen Staatenordnung um die völkerrechtlichen Bezüge der eingangs analysierten Diskussion um den künftigen Stellenwert der nationalen Souveränität handelt.

Der Gedanke der Föderation bildete die Nahtstelle zwischen staatsrechtlicher und völkerrechtlicher Souveränitätsbeschränkung einerseits und politischer Einigungsbestrebung andererseits. Je weiter der Europadiskurs fort- 
schritt, desto deutlicher war zu erkennen, daß der Föderalismus als völkerrechtliches Ordnungsprinzip nicht nur ein mögliches Instrumentarium zur Umsetzung der europäischen Neugestaltung war, sondern zugleich als Gegenkonzept zum Nationalismus entwickelt wurde. Je deutlicher die Kritik am omnipotenten Nationalstaat ausfiel, desto nachdrücklicher wurde eine europäische Föderation mit starken Exekutivbefugnissen gefordert. Von denjenigen, die an einer im wesentlichen uneingeschränkten Souveränität festhielten, wurde der föderale Gedanke auf europäischer Ebene jedoch abgelehnt, da er die Mitgliedstaaten einem äußeren, der nationalen Regelungskompetenz entzogenen Machtfaktor unterwarf ${ }^{316}$.

Föderalismus: ein Völkerrecht für Europa Diejenigen Emigranten, die in der bloßen Wiederherstellung des alten intergouvernementalen Systems kollektiver Sicherheit keine Zukunft sahen und eine Institutionalisierung des Friedens und der Sicherheit in Europa für unerläßlich erachteten, redeten einem neuen Völkerrecht das Wort. Auf der Grundlage nationaler Souveränitätsbeschränkung sollten allgemeinverbindliche Normierungen staatlichen Handelns völkerrechtlich festgeschrieben werden. Dies hätte eine wesentliche Beschneidung des Selbstbestimmungsrechts der Völker und eine völkerrechtliche Relativierung des Nichteinmischungsprinzips bedeutet. Für die europäischen Einigungsbestrebungen machte dies die Errichtung einer europäischen Föderation mit einer starken Zentralgewalt notwendig. Die Anhänger dieser progressiven Tendenz fanden sich in allen politischen Lagern. Sie einte nicht nur die gemeinsame Auffassung, daß der Völkerbund versagt

316 Eine institutionalisierte Form staatlicher Zusammenarbeit, die den Mitgliedstaaten die Übertragung staatlicher Regelungs- und Handlungskompetenzen auf die Staatengemeinschaft abverlangt, ist notwendig eine Föderation. Doch ist nicht zu leugnen, daß sich der Begriff der Föderation in den Jahren zwischen 1933 und 1945 gerade für die europäischen Widerstandsgruppen zu einem überstrapazierten, häufig falsch verstandenen Modebegriff entwickelte, dessen eigentlichem Inhalt die jeweiligen Konzeptionen oft nur bedingt gerecht wurden. Aus zeitgenössischer Sicht artikulierte Mary Saran diese Kritik an der begrifflichen Ungenauigkeit: „The terms Federation and Confederation are at present being used confusedly to mean the same thing. Federation in the strict sense implies that national sovereignty has gone and been replaced by a common federal government with certain defined powers. The regional groups of states envisaged by the Benes Plan and the Eastern and South-Eastern Blocs imply no abolition of national sovereignty and should really be called Confederations."

Der Völkerrechtler BÜLCK, Föderalismus 1964, passim, unterscheidet drei je ein Jahrhundert kennzeichnende Spielarten des Föderalismus als internationales Ordnungsprinzip: die dynastische Föderation des 18. Jahrhunderts, die nationale Föderation des 19. Jahrhunderts und die funktionale Föderation des 20. Jahrhunderts. Erst nach dem Ende des Zweiten Weltkrieges sollte sich die funktionale Föderation durchsetzen, deren Errichtung 1919 an einem noch zu starken nationalen Widerstand gescheitert war. Das diesem neuartigen Föderalismuskonzept zugrunde liegende völkerrechtliche Strukturelement der Supranationalität findet sich, wie zu zeigen sein wird, schon in zahlreichen Überlegungen des deutschen Exils und des europäischen Widerstandes. 
hatte, sondern auch der gemeinsame Wille, nach Überwindung des nationalsozialistischen Regimes ein neues Deutschland in eine föderative europäische Ordnung zu integrieren.

Seit dem Münchner Abkommen wurde intensiver als bisher die Frage diskutiert, warum die Ansätze einer kollektiven Friedensorganisation in der Zwischenkriegszeit versagt hatten. Meist wurden zwei Hauptgründe genannt $^{317}$ : Zunächst sei der Völkerbund zur Kriegsprävention gar nicht in der Lage gewesen, da er als völkerrechtliche Verbindung souveräner Staaten gegründet worden sei. Des weiteren habe sein Zwittercharakter den Völkerbund seiner Effizienz beraubt, denn er sei weder dem Universalitätsanspruch gerecht geworden, noch habe er sich konstruktiv an der Lösung der europäischen Probleme beteiligt. Zwar wäre es zu weitreichend, aus diesen Kritikansätzen eine allgemein erkannte "Notwendigkeit supranationaler Autorität" herauszulesen ${ }^{318}$, doch umfaßte die kritische Auseinandersetzung mit dem Wirken des Völkerbundes auch die Frage einer starken europäischen Föderativgewalt mit einschneidenden Befugnissen gegenüber den Mitgliedstaaten. Infolgedessen war der Europadiskurs eng mit der Völkerbundsdiskussion verknüpft, die ihn sinnvoll ergänzte ${ }^{319}$.

In der Tradition Leonard Nelsons stehend wurde dessen ehemaliger Privatsekretär, Willi Eichler, nicht müde, für die Idee eines pragmatischen Völkerrechts zu kämpfen und geißelte das Prinzip staatlicher Souveränität als „sittlichen Skandal"320. Auch der Gewerkschafter Walter Auerbach war der Auffassung, daß die Europäer bei uneingeschränkter Anwendung des Selbstbestimmungsrechts der Völker nicht in der Lage sein werden, die Krisenregion Balkan dauerhaft zu befrieden. Statt einer Auflösung in zahlreiche Nationalstaaten sprach er sich für eine wirtschaftliche Einigung des Balkans aus, die sich unter dem Schutz des Völkerbundes zu einer der Schweiz vergleichbaren Föderation vertiefen sollte ${ }^{321}$.

Selbst die stärker dem Nationalstaatsgedanken verpflichtete Sopade betrachtete das Selbstbestimmungsrecht der Völker als ein nationalistisches Instrument, das keine sozialdemokratische Forderung sein könne ${ }^{322}$. Mit Blick

317 Vgl. die gelungene Zusammenfassung bei LIPGENS, Anfänge 1977, S. 48.

318 So aber LIPGENS, Anfänge 1977, S. 48.

319 Dagegen vertritt HoLL, Europa des pazifistischen Exils 1992, S. 277 die Ansicht, die Völkerbunddiskussion sei seit Beginn des Krieges völlig von der Diskussion um die Zukunft Europas verdrängt worden. Dem steht jedenfalls die Tatsache entgegen, daß die überwiegende Mehrheit der europäisch denkenden Emigranten eine europäische Föderation im Rahmen eines modifizierten Völkerbundes befürwortete. Zustimmend VOIGT (Hg.), Friedenssicherung 1988, S. 16-19, insb. S. 18.

320 HART [d. i. Eichler], Furor teutonicus, in: SW, 13. Jg., H. 11 (18. 3. 1938), S. 242.

321 Dierksen [d. i. Auerbach] an Eichler, 3. 4. 1938, S. 2, AsD, Bestand IJB/ISK, Box 35.

322 Hilferding fragte sich auf einer Vorstandssitzung im Juli 1939, "welchen Grund wir als Sozialisten haben, dafür einzutreten, daß alles, was deutsch spricht, in einem Staat vereinigt sei“; Protokoll der Sopade-PV-Sitzung vom 21. 7. 1939, abgedruckt in: BuCHHOLZ, ROTHER (Hg.), Parteivorstand, Dok. Nr. 157, S. 400. Auf dieser Sitzung, die auf den ausdrücklichen Wunsch und in Anwesenheit des sudetendeutschen Sozialdemo- 
auf den Austritt Deutschlands aus dem Völkerbund sekundierte Rinner, daß das Selbstbestimmungsrecht einem Volk zwar das Ausscheiden aus einem Staatenverband ermögliche, über einen Wiedereintritt aber nicht allein entschieden werden könne ${ }^{323}$. Folglich sei das Selbstbestimmungsrecht politisches Blendwerk. Notwendig sei ein von den Sozialdemokraten schon zuvor gefordertes internationales Recht, das nicht nur die Gebote der Vertragstreue und der Menschlichkeit zu berücksichtigen habe ${ }^{324}$, sondern auch einen effektiven Minderheitenschutz ${ }^{325}$.

Das SAP-Mitglied Eugen Brehm rückte der sozialdemokratischen Position recht nahe, indem er ebenfalls einen neuen Völkerbund verlangte und davor warnte, daß das den Völkerbund tragende völkerrechtliche Prinzip durch die Schwächen der Organisation zu Unrecht diskreditiert werden könnte ${ }^{326}$. Brehms detaillierter Trilogie „Bemerkungen zur Außenpolitik“ lag die Auffassung zugxunde, daß sich der zu erwartende Krieg primär als ideologischer Konflikt zwischen dem imperialistischen Gewaltprinzip und dem sozialistisch definierten Völkerrechtsprinzip darstellen werde ${ }^{327}$. Dieser „Kampf der Geister“ werde dem deutschen Sozialismus die Gelegenheit bieten, zum Bannerträger der Völkerrechtsidee aufzusteigen. Langfristig wünschte sich Brehm die Substitution des Gewaltprinzips durch das Rechtsprinzip, indem die nationalen Außenpolitiken dem Völkerrecht untergeordnet würden ${ }^{328}$.

Aus der Forderung nach einer Einschränkung des Nationalstaatsgedankens und dessen völkerrechtlicher Legitimation, dem Selbstbestimmungsrecht der Völker, resultierte nahezu zwangsläufig das Postulat einer Föderation, also eines multilateralen Zusammenschlusses mit beschränkter Kompe-

kraten Wenzel Jaksch stattfand, beschäftigte sich die Sopade ausführlich mit der politischen Zukunft Europas.

323 Erich Rinner in der PV-Sitzung vom 21. 7. 1939, Protokoll der Sopade-PV-Sitzung vom 21.7. 1939, abgedruckt in: BuchHOLZ, RoTHER (Hg.), Parteivorstand, Dok. Nr. 157, S. 399.

324 Vgl. Stampfer, Deutschland wie es sein soll, 9. 11. 1938, S. 26, AsD, NL Stampfer, Box 9, M. 46.

325 Vgl. Hilferding, Vorschlag Hilferding, o. D. [Juli 1939], S. 1, AsD, Bestand PV-Emigration Sopade, M. 79.

326 Herb [d. i. Brehm], Bemerkungen zur Außenpolitik (I), in: SW, 13. Jg., H. 40 (7. 10. 1938), S. 954. Brehm hielt der SPD vor, seit dem Heidelberger Programm weder das politische Schlagwort der "Vereinigten Staaten Europas" definiert noch sich mit den brennendsten Fragen einer solchen Konstruktion - nationale Binnengrenzen, Einheits- oder Föderalstaat, kulturelle Identität, Realisierungschancen - auseinandergesetzt zu haben; vgl. Ders., Bemerkungen zur Außenpolitik (II), in: SW, 13. Jg., H. 41 (14. 10. 1938), S. 977.

327 Ibid. S. 979.

328 Vgl. HerB [d. i. Brehm], Bemerkungen zur Außenpolitik (I), in: SW, 13. Jg., H. 40 (7. 10. 1938), S. 956. In einem Thesenentwurf zur künftigen deutschen Außenpolitik formulierte Brehm: „Deutschland [...] bekennt sich zum Prinzip des Völkerrechts, das für alle Staaten der Erde gleichermaßen verbindlich sein soll."; HERB [d. i. Brehm], Bemerkungen zur Außenpolitik (III), in: SW, 13. Jg., H. 42 (21. 10. 1938), S. 1006 f. 
tenzübertragung auf eine gemeinsame Bundesgewalt. Seine Protagonisten erachteten daher eine europäische Föderation als Endpunkt völkerrechtlicher Modifizierungen. Andere Stimmen sahen das Projekt eines geeinten sozialistischen Europas lediglich als Transitorium zu den „Vereinigten sozialistischen Republiken der Welt " an ${ }^{329}$.

Unter den Stellungnahmen für eine Föderation der europäischen Staaten überwog die Konstellation eines europäischen Staatenbundes als Regionalorganisation des Völkerbundes. Der bemerkenswerteste Beitrag zum Europadiskurs der Jahre 1938/39 stammt von Eugen Brehm, der als einer der ersten Exilanten bereits im Jahre 1938 ein detailliertes und pragmatisch angelegtes Programm für eine gezielt eurozentrische Außenpolitik des neuen Deutschlands entwickelte 330 . Das eigenwillige Mitglied der SAP verstand sein Europakonzept als konkreten Gegenentwurf zu Hitlers hegemonialer Mitteleuropakonzeption ${ }^{331}$ und als Substitution des überholten Ansatzes kollektiver Sicherheit, der mit dem Einmarsch in die Tschechoslowakei im März 1939 endgültig versagt habe ${ }^{332}$. Während der erneuerte Völkerbund als Garant des Völkerrechts alle rechtstreuen Staaten der Welt umfassen sollte, konzipierte Brehm zur Lösung regionaler Fragen einen "Europäischen Staatenbund“, der „als europäische Kollektivorganisation ein Bestandteil des planetaren Bundes werden soll“333. Notfalls müsse dieser Europäische Staatenbund schrittweise durch die Errichtung regionaler Teilföderationen herbeigeführt werden. Die Mitgliedschaft sollte allen europäischen Staaten offenstehen, soweit sie sich dem internationalen Rechtsgedanken verpflichtet fühlten - aber auch den im Nordwesten, Osten und Südosten Europas angrenzenden Staaten, denn Europa habe keine eindeutig bestimmbare geographische Form ${ }^{334}$.

In ausführlichen Detailstudien legte Brehm einen Kompetenzkatalog der europäischen Zentralgewalt vor, der von der schrittweisen Einführung einer europäischen Planwirtschaftsunion mit gemeinsamer Währung über die verbindliche Schlichtung innereuropäischer Konflikte durch ein Schiedsgericht bis zu einer gemeinsamen Außenpolitik mit einem europäischen Bundesheer reichte, wobei das ius belli ac pacis beim Bund liegen müsse $\mathrm{e}^{335}$. In organisatorischer Hinsicht sah der Entwurf zunächst drei Organe vor: einen „Europäischen Bundesrat" als Vertretung der Völker und ethnischen Minderheiten,

329 Erklärung der SAP, in: Die Neue Front, 6. Jg., Nr. 10 (Oktober 1938), Beilage „Zur Kriegsfrage ${ }^{\alpha}$, S. 1.

330 HerB [d. i. Brehm], Bemerkungen zur Außenpolitik (III), in: SW, 13. Jg., H. 42 (21. 10. 1938), S. 1006-1008.

331 Vgl. DerS., Bemerkungen zur Außenpolitik (II), in: SW, 13. Jg., H. 41 (14. 10. 1938), S. 979.

332 Vgl. Ders., Abschied von der Tschechoslowakei, in: SW, 14. Jg., H. 14 (7. 4. 1939), S. 342 .

333 DERS., Bemerkungen zur Außenpolitik (III), in: SW, 13. Jg., H. 42 (21. 10. 1938), S. 1007.

334 Ibid.

335 Ibid. S. $1007 \mathrm{f}$. 
ein „Europäisches Zentralamt" als Exekutive und außenpolitische Koordinationsstelle sowie ein „Europäisches Kolonialamt“ für die Verwaltung des gemeinsamen Kolonialbesitzes.

In vielen Punkten stimmte Brehms detailreiche Konzeption mit den Vorstellungen Friedrich Stampfers überein, ohne daß Stampfer zu diesem Zeitpunkt ein vergleichbar ausgearbeitetes Gesamtkonzept bieten konnte. Stampfer, der sich in den 20er Jahren der Paneuropa-Bewegung Coudenhove-Kalergis angeschlossen hatte, forderte wie Brehm eine europäische Sektion des erneuerten Völkerbundes ${ }^{336}$, die er in einem internen Papier nur als „erste Entwicklungsform der Vereinigten Staaten von Europa" bezeichnete ${ }^{337}$. Deren Beitrittsbedingungen sollten die „einfachsten Grundsätze des modernen bürgerlichen Rechtsstaates, [nämlich] Freiheit der Persönlichkeit, der Meinungsäußerung, des Wahlrechts" sein ${ }^{338}$.

Im Vorstand der Sopade traf Brehms Vereinnahmung des Völkerbundgedankens für die sozialistische Bewegung insbesondere auf Geyers Zustimmung. In bezeichnender Diktion stellte Geyer im Neuen Vorwärts die an die sowjetfreundlichen Linkssozialisten gerichtete rhetorische Frage: „Und nun sollen wir für die Zeit nach dem Sturze Hitlers uns auf das Bündnis mit Sowjetrußland orientieren und nicht auf die Grundideen des Völkerbundpaktes?" 339 Erwartungsgemäß betrachtete Geyer das „Prinzip der europäischen Freiheit“ als Grundlage des vereinigten Europas ${ }^{340}$ und forderte „kaum mehr sichtbare Grenzen" in Europa ${ }^{341}$.

Im Gegensatz zu Stampfer und Geyer beschränkte sich der übrige SopadeVorstand in dieser Phase des Diskurses darauf, die von Geyer aufgeworfenen Schlagworte der „europäischen Demokratie“ und der „europäischen Freiheit $z u$ penetrieren ${ }^{342}$ und sich im übrigen auf den europapolitischen Lorbeeren

336 Vgl. Stampfer, Deutschland wie es sein soll, 9.11. 1938, S. 28, AsD, NL Stampfer, Box 9, M. 46; erneut: ders., Vorschlag Stampfer, o. D. [Sommer 1939], S. 5, AsD, Bestand PV-Emigration Sopade, M. 178.

337 Stampfer, Vorschlag Stampfer, o. D. [Sommer 1939], S. 4, AsD, Bestand PV-Emigration Sopade, M. 178.

338 Ibid. Im Manuskript Deutschland wie es sein soll, 9. 11. 1938, AsD, NL Stampfer, Box 9, M. 46, S. 26 nennt Stampfer des weiteren die Gebote des internationalen Rechts, der „Menschlichkeit" und den römischrechtlichen Grundsatz der Vertragstreue.

339 C. G[EYER], Der Kurs der deutschen Opposition, in: NV, Nr. 309 (21. 5. 1939), S. 1 f. (2).

340 Ibid. S. 1.

341 Curt Geyer in der PV-Sitzung vom 21. 7. 1939, Protokoll der Sopade-PV-Sitzung vom 21. 7. 1939, abgedruckt in: BuchHolz, Rother (Hg.), Parteivorstand, Dok. Nr. 157, S. 400.

342 Den Begriff der „europäischen Demokratie“ hatte Geyer schon 1935 in einem Aufsatz entwickelt, vgl. KLINGER [d. i. Geyer], Völkerbund gegen Faschismus. Die Internationale und die europäische Demokratie, in: NV, Nr. 123 (20.10.1935), S. 1 f. Die terminologische Erweiterung zum „Prinzip der europäischen Freiheit" folgte unter der seit „München“ gesteigerten Befürchtung eines Europas unter dem Hakenkreuz, vgl. C. G[EYER], Der Kurs der deutschen Opposition, in: NV, Nr. 309 (21. 5. 1939), S. 1. 
des Heidelberger Programms von 1925 auszuruhen. Erst im Juli 1939 begann im Ansatz eine Erörterung der sozialdemokratischen Europakonzeption. Im Nachgang zu den ersten beiden Sitzungen warnte Erich Rinner in einem privaten Brief an Sollmann davor, Deutschland ohne ein adäquates Gegengewicht in einen mitteleuropäischen Staatenbund zu integrieren, denn das wirtschaftliche und politische Übergewicht Deutschlands würde den föderalen Charakter eines solchen Konstruktes faktisch aufheben ${ }^{343}$.

Auf Anregung Stampfers arbeitete das nicht stimmberechtigte Vorstandsmitglied Hilferding noch im Juli 1939 ein Dispositionspapier zu den außenpolitischen Positionen der Sopade aus. Er formulierte die Einsicht, daß internationale Kooperation nicht ohne permanente internationale Institutionen auskomme und betonte erneut die Notwendigkeit eines modifizierten Völkerbundes mit einer europäischen Sektion ${ }^{344}$. Es erstaunt nicht, daß Hilferdings Entwurf kein Wort über die künftige Rolle Deutschlands verliert, da das Papier als Antwortschreiben an britische Sozialisten gedacht war und außenpolitische Umsicht zur Vermeidung von Mißverständnissen - auch im Hinblick auf den Vansittartismus - erforderlich erschien.

Seit dem Münchner Abkommen vertrat der Vorstand der Sopade mehrheitlich die These vom Krieg gegen Hitler und setzte sich in Abkehr von früheren Überzeugungen für eine internationale Aufrüstung der antifaschistischen Front ein, um dem nationalsozialistischen Terror ein Ende zu bereiten. Vor diesem Hintergrund wirken Hilferdings Worte wie aus einer längst vergessenen Welt, wenn er seine Partei an alte Überzeugungen erinnerte: „Voraussetzung für die Funktionsfähigkeit des Völkerbundes ist die international kontrollierte Abrüstung. "345 Dennoch ist der Entwurf des sozialdemokratischen Granden von Bedeutung für den Europadiskurs, stellt er doch gerade durch die strenge Ausrichtung an früheren Programmentwürfen der Partei einen der wenigen Beiträge zur Europadiskussion dar, der neben der Friedenssicherung - die auch für Hilferding das Hauptmotiv ist - auch den wirtschaftlichen Aspekt erwähnt und rudimentäre Überlegungen zur Institutionalisierung von Frieden und Wirtschaftskooperation enthält. Hierin wußte er sich einig mit dem Revolutionären Sozialisten Alexander Schifrin, der die fehlende Kopplung von Politik und Wirtschaft im Völkerbund als einen der entscheidenden Strukturmängel kritisierte ${ }^{346}$.

Unter dem unmittelbaren Eindruck des Münchner Abkommens skizzierte Anna Siemsen in der Zukunft das Ideal einer doppelten Föderalabsiche-

343 Vgl. Rinner an Sollmann, 20. 7. 1939, AsD, Bestand PV-Emigration Sopade, RinnerKorrespondenz, M. 34.

344 Hilferding, Vorschlag Hilferding, o. D. [Juli 1939], S. 1, AsD, Bestand PV-Emigration Sopade, M. 79.

345 Ibid.

346 Vgl. SCHIFRIN, Zur Außenpolitik der deutschen Linken, in: Die Zukunft, Jg. I, Nr. 6 (18. 11. 1938), S. 6. 
rung ${ }^{347}$. Betrachte man den föderalen Gedanken primär als strukturelles Instrument der langfristigen Friedenssicherung in Europa, sei die Wiedereinführung einer föderalistischen Struktur auf deutscher Ebene notwendige Vorbedingung einer europäischen Föderation. Dahinter stand Siemsens Grundannahme einer gegenseitigen Befruchtung von deutscher und europäischer Kultur, die nur durch eine vorherige Zerschlagung des deutschen Machtstaates, namentlich Preußens wiedererweckt werden könne. Siemsens Credo lautete deshalb: „Kein Viertes Reich! Sondern ein föderalistisches Deutschland innerhalb der Vereinigten Staaten Europas! “348

Einen schwierigen Spagat zwischen Nationalstaatsgedanke und Sozialismus versuchte Neu Beginnen. Einige Vertreter der Gruppe skizzierten nach der Annexion Österreichs ein "sozialistisches Großdeutschland" und verlangten vor diesem konkreten Hintergrund die Anerkennung des vollen Selbstbestimmungsrechts der Völker ${ }^{349}$. Zugleich aber wurde ein Entwurf für eine demokratische Föderation der südosteuropäischen Nationen ausgearbeitet. Im Ergebnis zeigte sich Neu Beginnen durchaus überzeugt, daß der Föderalismus ein geeignetes Mittel zur Überwindung des Nationalismus sei und besann sich auf Löwenthals bereits vor 1938 konzipierte „Freie Föderation der europäischen Nationen " 350 innerhalb eines neu zu gestaltenden Völkerbundes.

Mit Blick auf die geplante Zusammenarbeit mit der orthodoxen SAP351 ließ sich Neu Beginnen in einem Richtlinien-Entwurf vom Frühjahr 1939 dazu verleiten, sich vollends vom Völkerbund zu distanzieren und schlug statt dessen einen "Block sozialistischer Staaten“ als Völkerbundsurrogat vor $^{352}$. Die Berliner Gruppe Neu Beginnen formulierte deutlicher als die Exilorganisation den Wunsch nach einer wirklichen Föderation und bekannte sich „zu einem Völkerbund, der keine ausschließliche Souveränität

${ }^{447}$ Vgl. SIEMSEN, Großdeutschland oder Föderation?, in: Die Zukunft, I. Jg., Nr. 2 (21. 10. 1938), S. 7.

348 Ibid.

${ }^{349} \mathrm{Vgl}$. Richtlinien-Entwurf: Die deutsche sozialistische Arbeiterbewegung und der kommende Krieg, Ausarbeitung o. V., o. D. [Frühjahr 1939], IISG, Coll. Neu Beginnen, M. 30, Bl. 18a. Dagegen findet sich im Nachlaß Paul Hertz' ein Manuskript, das die Annexion Österreichs als „aggressive imperialistische Expansion“ verurteilte: Zur Internationalen Lage nach der Annexion Österreichs, Entwurf, diktiert Ende März 1938, IISG, NL Paul Hertz, S11, M. T, NR. 1, Bl. 3.

350 Entscheidungskampf um die Tschechoslowakei, in: SIB, Nr. 36/37 (10.5. 1938), S. 2.

${ }^{351}$ Mitte Juli 1939 gaben SAP, NB und die Revolutionären Sozialisten Österreichs (RSÖ) eine gemeinsame Broschüre heraus, die im linkssozialistischen Exil lange nachwirkte: HAGEN [d. i. Frank] et al., Der kommende Weltkrieg 1939.

352 So die Gruppe Neu Beginnen in dem anonymen Richtlinien-Entwurf: Die deutsche sozialistische Arbeiterbewegung und der kommende Krieg, Ausarbeitung o. V., o. D. [Frühjahr 1939], IISG, Coll. Neu Beginnen, M. 30, Bl. 20. 
seiner Mitglieder anerkennt und ein echter Staatenbund ist“353. Damit war trotz der irreführenden Bezeichnung „Staatenbund“ eine Föderation gemeint.

Konföderalismus Für die Vertreter einer konföderalistischen Neuordnung Europas im Sinne eines Staatenbundes hatte Coudenhove-Kalergis Europaentwurf Vorbildfunktion. Coudenhove strebte ein konföderiertes Paneuropa unter Ausschluß Großbritanniens und der Sowjetunion an. Unter Rückgriff auf die schon 1923/24 formulierte paneuropäische Leitlinie gab er 1938 die Schrift „Kommen die Vereinigten Staaten von Europa?" heraus, in der er drei europapolitische Szenarien entwarf: eine enge Bindung an die Sowjetunion, eine nationalsozialistische Hegemonie oder einen Staatenbund auf der Grundlage nationaler Gleichberechtigung nach paneuropäischem Muster ${ }^{354}$. Eine Wiederbelebung des für endgültig gescheitert erklärten Völkerbundes lehnte Coudenhove ab, und die zugrunde liegende Idee eines weltumspannenden Systems kollektiver Sicherheit erklärte er für momentan nicht durchsetzbar. Nur Europa lebe noch im Größenwahn, „die Welt zu beherrschen und darum mit ihr mehr oder weniger identisch zu sein “355. Statt dessen sollten die fünf Kontinentalkonföderationen in friedlicher Koexistenz verharren, bis eines Tages die Frage einer Weltunion akut werde ${ }^{356}$. Strukturell sollte Paneuropa einem „European Commonwealth" vergleichbar sein ${ }^{357}$, also einem reinen Staatenbund ohne wesentliche Kompetenzübertragungen auf den Bund ${ }^{358}$. In diesem Sinne ist auch Coudenhoves vage Andeutung auf eine "common policy controlling foreign relations, armaments, and economic affairs" ${ }^{359}$ zu verstehen: Gemeint war lediglich eine Kooperation in diesen Politikfeldern. Die einzige Neuerung gegenüber der Erstveröffentlichung von 1924 betraf die paneuropäische Rolle Großbritanniens. Hatte Coudenhove Großbritannien unter Verweis auf die zahlreichen außereuropäischen Interessen bisher stets von der Paneuropa-Union ausgeschlossen, konstatierte der zunächst in London ansässige Emigrant nun, daß von Großbritannien "niemand eine [...] Hegemonie befürchten kann“. Vielmehr sei Großbritannien prädestiniert, eine Rolle ähnlich der amerikanischen in der Panamerikanischen Union zu übernehmen ${ }^{360}$. Doch ist darin eine bloß vorübergehende

353 Brill et al., Erläuterung der „Zehn Punkte“, Februar 1938, abgedruckt in: LiPGENS (Hg.), Föderationspläne 1968, Dok. Nr. 25, S. 104.

$354 \mathrm{Vgl}$. Coudenhove-KalergI, Kommen die Vereinigten Staaten von Europa? 1938, S. $96 \mathrm{f}$.

355 Ibid. S. 102.

356 Ibid. S. 103.

357 COUdenhove-Kalergi, Europe must unite 1939, S. 8.

358 So die ausdrückliche Klarstellung CoudENHOVE-KALERGIS, Kommen die Vereinigten Staaten von Europa? 1938, S. 106.

359 DERS., Europe must unite 1939, S. 8.

360 Vgl. DerS., Kommen die Vereinigten Staaten von Europa? 1938, S. 107. 
Rücksichtnahme auf die in aller Deutlichkeit erkannten Machtverhältnisse in Europa zu sehen.

Coudenhoves Paneuropa-Idee prägte nicht nur die Mitglieder seiner Bewegung wie Friedrich Stampfer und viele andere prominente Politiker der Weimarer Republik, sondern berührte auch die politische Vorstellungswelt von Nicht-Mitgliedern wie Leopold Schwarzschild, der 1939 an „etwas Paneuropa-Ähnliches“ dachte, um der politischen und wirtschaftlichen Notwendigkeit größerer Raumeinheiten gerecht zu werden ${ }^{361}$.

Antiföderalismus Andere dagegen sahen schon in einer bloßen Rückkehr zum „Europäischen Konzert" eine hinreichende Gewähr für Sicherheit und Frieden, zumal damit das Prinzip der nationalen Souveränität ohne Einschränkungen aufrechterhalten werden könnte. Folgerichtig pochten die Vertreter dieser Auffassung auf die unbedingte Beachtung des Selbstbestimmungsrechts der Völker und weigerten sich, Interventionen anderer Staaten oder gar eines übergeordneten Staatenbundes in die Angelegenheiten eines Mitgliedstaates zuzulassen.

Ein ungenannter Verfasser fragte bezeichnenderweise im DFP-Organ Das Wabre Deutschland, welchen Platz Deutschland im Konzert der Völker einnehmen könne und solle ${ }^{362}$. Zwar wurde wiederholt das Schlagwort der „Vereinigten Staaten Europas“ aufgegriffen, tatsächlich aber war diese Bezeichnung weder im föderalistischen noch im konföderalistischen Sinn gemeint. Vielmehr dachte man an eine bloße Zusammenarbeit der Länder beim Wiederaufbau Europas, möglichst im Rahmen des Völkerbundes, der bei dieser Gelegenheit wieder aufleben würde ${ }^{363}$. Das Ziel war die „Rückkehr unseres Vaterlandes, als große und gleichberechtigte Macht, in den Kreis der freien Nationen"364. Die wesentlichen Regelungs- und Handlungskompetenzen sollten bei den Nationalstaaten verbleiben, namentlich Militär, Polizei und Währung ${ }^{365}$. Mit dem Ruf nach einem „wirklich miteinander verbundene[n] Europa" 366 war also eine Verbundenheit gemeint, die sich aus den gemeinsamen machtpolitischen Interessen und dem nebulös gebliebenen $\mathrm{My}-$ thos des christlichen Abendlandes nährte. Eine ähnliche Vorstellung findet sich bei Rauschning, der nicht von einer europäischen, sondern explizit von einer nationalen Rückbesinnung ausging und die Vielfalt der Nationen sowie der politischen Ordnungselemente zu den konstituierenden Prinzipien des Abendlandes erklärte ${ }^{367}$.

361 SCHWARZSCHILD, Der Tag danach, in: NTB, 7. Jg., H. 29 (15. 7. 1939), S. 682-686 (686).

362 Deutschland von morgen, in: Das Wahre Deutschland (Mai 1939), S. 1-4 (1 f.).

363 Ibid.

364 Was soll aus Deutschland werden?, in: Das Wahre Deutschland (Juli 1939), S. 4.

365 Vgl. Deutschland von morgen, in: Das Wahre Deutschland (Mai 1939), S. 3.

366 Ibid.

367 Vgl. RauschnING, Revolution des Nihilismus 21939, S. 492. 
Auch der sozialdemokratisch orientierte Journalist und Schriftsteller Max Barth setzte sich für Deutschlands "nationale Konsolidierung" ein und wollte die europäische Frage 1939 als eine "nationale Frage“, nicht aber eine Frage der sozialistischen Problematik definiert wissen ${ }^{368}$. Unabdingbare Ausgangsbasis für jedes Konzept kontinentaler Zusammenarbeit war nach Barths Auffassung eine strikte Einhaltung des Selbstbestimmungsrechts der Nationen: „Die europäische Gesellschaft [muß] eine Gesellschaft von Gleichen und Gleichberechtigten werden, und das kann nur erreicht werden durch die endliche Inkraftsetzung jenes 1918 verkündeten, in Versailles verratenen europäischen Grundgesetzes: des Selbstbestimmungsrechts der Völker. " 369

Auch Strasser ist hier einzuordnen, da er zwar eine europäische Föderation forderte, sie aber auf das Fundament des völkischen Nationalismus zu stützen gedachte ${ }^{370}$. Mit dem Nationalismus aber, erst recht mit der weiter ausgreifenden völkischen Variante, war eine das Selbstbestimmungsrecht der Nationen notwendig relativierende Föderation unter keinen Umständen vereinbar. Strasser selbst bekannte sich klar zur Unverletzlichkeit des Selbstbestimmungsrechts ${ }^{371}$, wollte aber zugleich den Föderalismus als grundsätzlichen Gegenentwurf zu Hitlers Gewaltprinzip verstanden wissen ${ }^{372}$. Andererseits begrüßte er die Annexion Österreichs, die dem auf Freiwilligkeit beruhenden föderalen Gedanken zutiefst widersprach und redete einer "mehr oder minder freiwillige[n] Eingliederung der kleinen Völker" Europas das Wort ${ }^{373}$. Folglich war Strasser ein engagierter Verbalföderalist, der in seiner tiefsten politischen Überzeugung an die herausragende Bestimmung Deutschlands für Europa glaubte und sich in den entscheidenden Fragen konsequent an den Parametern seines völkischen Nationalismus orientierte. Das öffentlichkeitswirksame Schlagwort der „europäischen Föderation“ wußte er ebenso geschickt in seine Ideologie des wahren National-Sozialismus zu integrieren wie die eigenwillig interpretierten Begriffe „Demokratie“, „christliches Abendland" und "Sozialismus" - eine ideologische Mixtur, die möglichst alle Fronten zu bedienen versuchte und doch nur auf den völkisch-nationalistischen Grundzug als unverwechselbares Charakteristikum verwies.

368 Barth, Diskussion des nationalen Problems [August 1939], S. 2f., ANF, F7 15123, M. B.

369 Ibid. S. 3.

370 Vgl. STRASSER, Masaryk 1938, S. 281 in Verbindung mit 170. Zum völkischen Nationalismus vgl. Strassers Manuskript: Großdeutschland und Europa, o. D. [Anfang 1938], IfZ, NL Strasser, ED 118/20.

371 Vgl. STRASSER, Masaryk 1938, S. 170: „nationale Freiheit, staatliche Selbstständigkeit und völkische Entwicklungsmöglichkeit aller Völker und Nationen Europas - ob klein, ob groß“.

372 Strasser, Denkschrift über den Kampf der Schwarzen Front nach dem Anschluß Österreichs, o. D. [Mitte März 1938], S. 2, IfZ, NL Strasser, ED 118/20.

373 Ibid. Zur ideologischen Verunsicherung Strassers nach der Annexion Österreichs siehe die Erörterungen zu Beginn dieses Kapitels. 


\section{2. „Russischer Dolchstoß" - die antikommunistische Diskurswende nach dem Hitler-Stalin-Pakt (1939/40)}

In seiner Bedeutung für den Europadiskurs des deutschen Exils wurde der Ausbruch des Zweiten Weltkrieges bei weitem von dem Nichtangriffspakt zwischen dem Deutschen Reich und der Sowjetunion übertroffen. ${ }^{374}$ War der Kriegsausbruch allseits erwartet worden, barg der Abschluß des deutschsowjetischen Paktes einen Überraschungseffekt unerhörten Ausmaßes. Darüber hinaus wirkte sich der Hitler-Stalin-Pakt aufgrund des ideologischen und grundsatzpolitischen Elementes unmittelbar auf den Europadiskurs aus, während der Ausbruch des Krieges zwar die politischen Rahmenbedingungen veränderte, auf die Europakonzeptionen des Exils aber keinen nennenswerten Einfluß hatte. Davon zu unterscheiden ist die Tatsache des Krieges an sich, der sich selbstverständlich in der diskursiven Entwicklung widerspiegelt. Nur hatte das politische Exil die Kriegsgefahr spätestens seit 1934 in ihren europapolitischen Überlegungen berücksichtigt und damit den Kriegsausbruch gedanklich vorweggenommen.

Dabei soll jedoch nicht unberücksichtigt bleiben, daß der Kriegsausbruch in den kriegführenden Exilländern harte Einschränkungen des Emigrantenlebens nach sich zog. Stigmatisierung als feindlicher Ausländer, behördliche Schwierigkeiten und Internierung erschwerten die Lebensbedingungen der Emigranten nachhaltig. Auch die Exilpublizistik unterlag nun in der Regel einer deutlich schärferen Zensur. Seit September 1939 wies die Redaktionskorrespondenz der Zukunft - neben Schwarzschilds Neuem Tage-Buch die einzige deutsche Exilschrift, die während der drôle de guerre erscheinen durfte ${ }^{375}$ - zahlreiche Ablehnungen eingereichter Artikel auf, die als politisch zu „freizügig" oder inopportun erschienen ${ }^{376}$.

Einen Tag vor Ausbruch des Zweiten Weltkrieges hatte der russische Außenminister Molotow verkündet: „Der Nichtangriffspakt zwischen der UdSSR und Deutschland bildet einen Wendepunkt in der Geschichte Europas, und nicht nur Europas. " 377 Wenngleich Molotow diese Einschätzung in einem ganz anderen Sinn verstanden wissen wollte, stimmt sie hinsichtlich der historischen Bedeutung des „russischen Dolchstoßes “378 mit der Beurtei-

374 Vgl. dazu Schilmar, Pariser Positionen 2002, S. 176-179.

375 Dies war wohl hauptsächlich auf den dezidiert antikommunistischen Kurs dieser beiden Exilorgane zurückzuführen, die damit im Einklang mit Daladiers Politik standen. Für Die Zukunft zeichnete zudem der französische Christdemokrat Guy Menant offiziell als Herausgeber; vgl. Th. KELLER, Die Zukunft 1999, S. 72.

$376 \mathrm{Vgl}$. das Redaktionsarchiv in den Archives nationales de France, Paris, Fonds $\mathrm{F}^{7}$ 15123-15130. Die alphabetisch sortierte Redaktionskorrespondenz findet sich unter den Signaturen $F^{7} 15123$ und $F^{7} 15124$.

377 Zit. n.: SCHWARZ [d. i. Reinbold], Kommunisten und der deutsch-russische Pakt, in: SW, 14. Jg., 37. H. (29. 9. 1939), S. 882-885 (882).

378 So der Titel einer Stellungnahme von MüNZENBERG, in: Die Zukunft, II. Jg., Nr. 38 (22. 9. 1939), S. 1. 
lung des deutschen Exils überein. So prophezeite Budzislawski: „Die Arbeiterbewegung aller Länder wird diesen Vertrag noch diskutieren, wenn er nur noch ein Stück Papier in den Archiven ist." 379

Kaum ein Thema hat ganze Gesellschaften so tief und unversöhnlich gespalten wie die Einstellung zum Kommunismus. Dabei muß sprachlich genau differenziert werden zwischen dem Antistalinismus als Gegnerschaft (nur) zur stalinistischen Prägung der Sowjetunion, dem Antibolschewismus als Kritik an dem von Lenin begründeten Sowjetsystem als solchem und dem Antikommunismus als ideologischer Grundsatzopposition. Gerade für die Analyse des linkssozialistischen Exils ist diese Unterscheidung hilfreich, obgleich die Grenzen in der Praxis und im Sprachgebrauch der Quellen selbst fließend sind und es oft an der notwendigen Klarheit fehlt.

Im Exil stellte sich die Frage des Verhältnisses zum Kommunismus nahezu unverändert, gleichwohl auf brisante Weise auf die Einstellung zur Sowjetunion verdichtet ${ }^{380}$. Gerade diese Präzisierung komplizierte die Beantwortung der Frage in der Zeit des Stalinismus. Ein bloßes Bekenntnis zur Sowjetunion als dem Vorkämpfer des Weltproletariats und der Weltrevolution war so einfach nun nicht mehr möglich, denn es blieb völlig offen, ob das Bekenntnis gerade der momentanen stalinistischen Richtung galt oder nur der Sowjetunion per se.

Auch im Rahmen des Europadiskurses spielte das Verhältnis zur Sowjetunion eine entscheidende Rolle. Entweder zählte das Bekenntnis zur UdSSR zum ideologischen Selbstverständnis oder man bekannte sich ebenso dogmatisch zur Gegenrichtung des offenen Antikommunismus. Schließlich blieben diejenigen, die - frei von ideologischen Scheuklappen - jedenfalls die machtpolitische Brisanz dieser Frage klar erkannten. Mit dem deutsch-sowjetischen Nichtangriffspakt sollte sich dieses über zwei Jahrzehnte gefestigte ideologische Gefüge nachhaltig verschieben.

\subsubsection{Die Haltung der KPD}

Daß die mit dem deutsch-russischen Nichtangriffspakt einsetzende antisowjetische Wendung für den Europadiskurs ein zentrales Moment darstellt, mag für die liberalen und konservativen Kreise ebensowenig Erstaunen hervorrufen wie für die vereinzelten Vertreter nationalkonservativen Gedankengutes, auch wenn der Antikommunismus dieser Emigrantengruppen ein beherrschendes Motiv ihrer Zukunftsplanungen war und blieb. Hinsichtlich der zahlreichen sozialistischen und sozialdemokratischen Gruppierungen kam die nach dem Hitler-Stalin-Pakt vielfach vollzogene Abkehr von der stalinistischen Sowjetunion einer dogmatischen Revolution gleich. Dabei wurde

379 Budzislawski, Die europäische Tragödie, in: Die neue Weltbühne, XXXV.Jg., Nr. 35 (31. 8. 1939), S. 1081-1086 (1081).

${ }^{380}$ Zur Bedeutung des Nichtangriffspakts in der Geschichte der KPD in Frankreich vgl. PFEIL, Pariser Auslandssekretariat der KPD 2002. 
der Prozeß der antisowjetischen Wende durch das Verhalten der KPD-Auslandsleitung unter Ulbricht und Pieck nach dem 23. August 1939 beschleunigt, so daß an dieser Stelle zunächst die Haltung der deutschen Kommunisten zu Stalins außenpolitischer Wende und ihre gezielt zurückhaltende Rolle im Europadiskurs beleuchtet werden soll.

Für die Kommunisten verbot sich von Anfang an jeder Gedanke an die Bildung eines vereinigten europäischen Machtblocks. Diese Einstellung resultierte aus der unbedingten Subordination unter die außenpolitischen Maximen und die über die Komintern verbreiteten Direktiven Moskaus. Die ablehnende Haltung Stalins gegenüber einem starken Europa vor der sowjetischen Haustür war hinlänglich bekannt und forderte die politische Identifizierung aller kommunistischen Parteien mit den außenpolitischen Zielen der Sowjetunion. Nach kommunistischem Verständnis bedeutete internationale Friedenspolitik vor allem das Bündnis aller linientreuen Kommunisten mit der Sowjetunion und eine Völkerverständigung „auf der Grundlage der Gleichberechtigung“"381, mit anderen Worten auf der Grundlage des Selbstbestimmungsrechts. Vor dem Hintergrund der stalinistischen Doktrin des "Sozialismus in einem Land" stellte ein strikt beachtetes Selbstbestimmungsrecht der Völker die einzige logische Schlußfolgerung für eine kommunistische Außenpolitik dar. Folgerichtig versuchte die Komintern, den ideologischen Gehalt der Nation für die kommunistische Idee in Anspruch zu nehmen und definierte im Jahre 1938: „Nation - das ist nicht eine Bande von Faschisten, reaktionären Finanzleuten und Industriemagnaten, die das Volk ausplündern und verraten. Nation - das ist die Millionenmasse der Arbeiter, Bauern und Werktätigen, das ist das Volk, das seinem Lande treu ist, das seine Freiheit liebt und seine Unabhängigkeit verteidigt. “" 382 Für den europäischen Kontinent wurde der Gedanke der Völkerverständigung prosowjetisch interpretiert, ein System kollektiver Sicherheit unter russischem Schutzschirm angestrebt. Dies entsprach dem Konzept einer nationalstaatlichen Ordnung Europas unter sowjetischer Führung, wie es seit der Oktoberrevolution nahezu ununterbrochen propagiert worden war.

Mit der im Frühsommer 1939 auf Geheiß der Komintern einsetzenden Reideologisierung der KPD, die Ulbricht in vorauseilendem Gehorsam und mit einem erstaunlichen Instinkt für den richtigen Augenblick noch im Juni 1939 dekretierte ${ }^{383}$, entfernten sich die Kommunisten einen weiteren Schritt

381 Dahlem, Die dringendste Aufgabe. Sammlung und Einigung aller Antifaschisten in der Deutschen Volksfront, o. D. [Juni/Juli 1938], S. 7, BAB, NY 4072/58. Es handelt sich um das Manuskript für einen Aufsatz, der am 10.7.1938 auf S. 4 der DVZ veröffentlicht wurde. Ein ausdrücklicher Hinweis auf den hohen Stellenwert des Selbstbestimmungsrechts findet sich in einer Flugschrift des ZK der KPD vom März 1939: Nieder mit Hitlers Verbrechen an der Tschechoslowakei!, Paris o. D. [Ende März 1939], Faksimile in: PIKARSKI, UeBel (Hg.), Widerstandskampf der KPD 1978, Dok. Nr. 119. 382 Komintern, Aufruf zum 21. Jahrestag der Großen Sozialistischen Revolution, Flugblatt, o. D. [Okt./Nov. 1938].

383 Vgl. SYWOTTEK, Volksdemokratie 1971, S. 93 f. Die innenpolitische Dimension der 
von den Föderalismusdebatten und pochten nunmehr auf eine außenpolitische Nibelungentreue zur Sowjetunion. Mithin verzichtete man auf eigene Stellungnahmen zu Fragen der internationalen Beziehungen, so daß sich das außenpolitische Konzept in der einseitigen Fokussierung auf die unbedingte Unterstützung der UdSSR erschöpfte. Im Rahmen solch eindeutig sowjetorientierter, jede Föderation strikt ablehnender Zukunftsszenarien spielte der Europagedanke zwangsläufig keine Rolle ${ }^{384}$.

Eindrucksvolles Exempel dieser Position ist das 1940 von Max Seydewitz publizierte Buch mit dem vielversprechenden Titel „Hakenkreuz über Europa“. Seydewitz, der sich nach einer politischen Odyssee vom Sozialdemokraten zum Gründungsmitglied der SAP, Revolutionärem Sozialisten und schließlich zum Stalinisten wandelte, ließ im außenpolitisch brisanten Jahr 1940 in seinem Werk mehr als 100 Seiten verstreichen, ohne mit einem einzigen Wort eine europäische Neuordnung anzudenken. Unbeirrbar stellte er ein halbes Jahr nach dem Abschluß des Hitler-Stalin-Paktes fest: „Das entscheidende Hindernis für den Sieg des Hakenkreuzes über Europa war, ist und bleibt die UdSSR. “385 Zudem war der Begriff der Einigung in der kommunistischen Terminologie bis 1939 dogmatisch besetzt mit der Einigung des deutschen Exils im Rahmen einer Volksfront ${ }^{386}$. Internationale Politikansätze erschöpften sich, soweit sie nicht lediglich das Bündnis mit der Sowjetunion betonten, in leeren Parolen wie „Für den Weltfrieden!“, „Für die Freiheit!“ oder „Für den menschlichen Fortschritt!“387

„Es lebe die Weltfront der Völker gegen die faschistischen Angreifer!“ - so lautete die Parole der Komintern, die das Exekutivkomitee noch Ende 1938 verkündet hatte. Die Sowjetunion wurde als „unüberwindlicher Schutzwall

Reideologisierung äußerte sich in dem Abschied vom Einheitsparteigedanken und den damit eng verknüpften Volksfrontbemühungen.

384 Dem stehen die gelegentlichen pauschalen Bekenntnisse zu einem „neuen Europa“ nicht entgegen, da wohlweislich keinerlei Konkretisierungsversuche unternommen wurden, was unter einem "neuen Europa“ zu verstehen sei; vgl. etwa: Das Münchner Abkommen, in: DVE, Jg. I, Nr. 23 (9. 10. 1938), S. 6. Bemerkenswert ist in diesem Zusammenhang ein Typoskript Bleichmanns über den wirtschaftlichen Wiederaufbau nach Hitler, in dem der Verfasser eine „Koordinierung der Kräfte im europäischen und weltwirtschaftlichen Rahmen" forderte und eine weltwirtschaftliche Arbeitsteilung als unabdingbare Voraussetzung des Weltfriedens bezeichnete (Bleichmann, Nach Hitler der wirtschaftliche Wiederaufbau, o. D. [Juni 1939], S. 9, ANF, F7 15130, M. 7).

385 SEYDEwITZ, Hakenkreuz über Europa? 1940, S. 28.

386 Die durchsichtigen Versuche der Auslandsleitung der KPD, über eine Volksfrontkoalition die kommunistische Partei zu erneuern und auf diese Weise eine moskautreue Einheitspartei zu schaffen, sind vielfach dargelegt worden. Als interessanter Quellenfund sei in diesem Zusammenhang auf einen Brief Franz Dahlems an den Chefredakteur der Zukunft, Werner Thormann, vom 20. 9. 1938, ANF, F7 15123, M. D verwiesen, in dem sich Dahlem einer Mitarbeit an der neu gegründeten Zeitschrift verschließt, da er deren Hintermänner nicht kenne und es tief bedaure, "daß nunmehr auch auf diesem Gebiet eine weitere Zersplitterung und Spaltung erfolgt".

${ }^{387}$ An das deutsche Volk! An das französische Volk!, Flugblatt, 6. 9. 1938, in: PIKARSKI, UEBEL (Hg.), Widerstandskampf der KPD 1978, Dok. Nr. 105. 
aller Völker der Erde gegen die faschistische Versklavung " gepriesen, und die „Proletarier aller Länder" wurden zur „Einheit der Völker gegen die faschistische Aggression" aufgerufen ${ }^{388}$. Einen Schritt weiter ging die KPD und postulierte auf ihrer sogenannten Berner Konferenz den Sturz des Kriegstreibers Hitler als „höchste nationale Aufgabe aller Deutschen “389. Zehn Monate später stand die KPD vor einem unauflösbaren Widerspruch: Das „Bollwerk gegen den Faschismus" hatte am 23. August 1939 mit dem gerade noch als Kriegstreiber geschmähten Faschisten Hitler einen Nichtangriffspakt geschlossen. Die KPD zeigte sich von den außenpolitischen Manövern Stalins dermaßen überrascht, daß sie für nahezu zwei Jahre paralysiert wurde und eine schwere Krise ideologischer Verunsicherung durchstehen mußte. In blindem Gehorsam nahmen Führungskader der KPD die neuen Moskauer Losungen entgegen und beschworen die verwirrte Parteibasis: „Die Politik der Sowjetunion ist die Politik des Friedens! Der Nichtangriffspakt ist kein Bündnis und kein Beistandspakt! “390 In entlarvender Hilflosigkeit zog man sich auf formaljuristische Unterschiede zwischen einem Nichtangriffspakt und einem bilateralen Bündnisvertrag zurück und bäumte sich verzweifelt gegen aufkommende Gerüchte über territoriale - in der kommunistischen Diktion also imperialistische - Gelüste Stalins auf: „Sie wollen Euch einreden, jetzt hätte das Dritte Reich freie Hand gegen Polen. Sie lügen sogar, Stalin wolle mit Hitler Polen teilen. [...] Sie lügen, sie lügen!"391 Nur drei Wochen später besetzten zwei sowjetische Heeresgruppen ostpolnische Gebiete.

Besondere Beachtung verdient eine Äußerung Franz Dahlems vom 11. September 1939. Dahlem war im Zuge der Reideologisierung im Mai/Juni 1939 zum Nachfolger Ulbrichts als Leiter des Pariser ZK-Sekretariats ernannt worden. Bei seiner polizeilichen Vorführung in Paris begrüßte er den Nichtangriffspakt als neuen, die Fehler von „München“ revidierenden Weg zum Erhalt des Friedens ${ }^{392}$. In der später im Internierungslager Le Vernet verbreiteten Erklärung Dahlems hieß es dann: „Das von meinen Freunden

388 Komintern, Aufruf zum 21. Jahrestag der Großen Sozialistischen Revolution, Flugblatt, o. D. [Okt./Nov. 1938].

389 Resolution der Berner Konferenz der KPD (30. Januar bis 1. Februar 1939), originalgetreue Reproduktion in: PIKARSKI, UEBEL (Hg.), Widerstandskampf der KPD 1978, Beilage II.

390 So der Titel eines Flugblattes der KPD-Abschnittsleitung Süd[deutschland], Zürich, 25. 8. 1939, Faksimile in: PIKARSKI, UEBEL (Hg.), Widerstandskampf der KPD 1978, Dok. Nr. 133.

391 Ibid.

392 DaHLEM, Eine Antwort. Die demokratische Volksrepublik nach dem Sturz Hitlers, September 1939, abgedruckt in: DERS., Weg und Ziel des antifaschistischen Kampfes 1952, S. 73 f. Ähnlich hatte sich zuvor das Pariser ZK-Sekretariat zu Wort gemeldet und in dem deutsch-russischen Nichtangriffspakt erwartungsgemäß einen schweren Schlag gegen den "Weltfaschismus und die Weltreaktion" gesehen, vgl. Erklärung des Zentralkomitees der Kommunistischen Partei Deutschlands zum Abschluß des Nichtangriffspaktes zwischen der Sowjetunion und Deutschland [Rundschreiben], 26. 8. 1939, ANF, F? 15131. 
und mir selbst verfolgte außenpolitische Ziel ist eine aufrichtige Freundschaft und ein Bündnis zwischen einem neuen, freien Deutschland, der Sowjetunion und Frankreich, was den Frieden in einem Europa sichern würde, in dem die nationale Unabhängigkeit und das uneingeschränkte Selbstbestimmungsrecht aller unterdrückten Völker garantiert wären. " 393 Auf den ersten Blick scheint Dahlem hier die bisher ostentative Enthaltsamkeit der KPD im Europadiskurs aufzukündigen und ein kommunistisches Szenario für das Nachkriegseuropa zu entwerfen. Tatsächlich aber stand das spätere ZK-Mitglied der SED abseits der von der Komintern vorgegebenen Linie. Denn bei Kriegsausbruch hatte sich Dahlem entgegen der Komintern-Vorgabe freiwillig bei den französischen Behörden registrieren lassen und propagierte die Einbindung der KPD in die französische Armee - eine Position, die zwischenzeitlich von der nun in Moskau ansässigen KPD-Führung aufgegeben worden war. In der Folge wurde Dahlem bis auf weiteres von den ZK-Sitzungen suspendiert.

Vor diesem Hintergrund stellen sich seine Äußerungen hinsichtlich einer europäischen Friedens-Troika aus Frankreich, Deutschland und der Sowjetunion unter Wahrung der vollen Souveränität aller Länder als Randposition dar, die zu diesem Zeitpunkt nicht mehr die Unterstützung Moskaus genoß und deshalb von vornherein zum Scheitern verurteilt war. Doch verfehlte die von Dahlem skizzierte Idee eines Friedensbündnisses auf der Grundlage der nationalen Souveränität nicht ihre Wirkung, denn in einer Erklärung der deutschen, österreichischen und tschechoslowakischen KP vom November 1939 findet sich die versteckte Anregung, Europa nach dem Muster der Sowjetunion zu organisieren: „Die Sowjetvölker, viele Dutzende Nationen, leben, arbeiten, und kämpfen in freundschaftlicher Einheit und voller Gleichberechtigung im Rahmen des Sowjetlandes." 394 Zudem belegt Dahlems Engagement in Frankreich, daß es sich bei der KPD nicht um einen monolithischen Block handelte, sondern gerade auch aus den Reihen der deutschen Kommunisten der Moskauer Führung widersprochen wurde ${ }^{395}$.

$\mathrm{Daß}$ dies ein höchst gefährliches Spiel war, beweist der Fall Willi Münzenberg. Münzenberg hatte sich primär mit Blick auf die Moskauer Schauprozesse von der stalinistischen Ausrichtung der KPD distanziert und war Anfang 1939 als "Feind der Einheits- und Volksfrontpolitik“ aus der Partei

393 DAHLEM, ibid. S. 74.

394 Erklärung der Kommuniștischen Parteien Deutschlands, Österreichs und der Tschechoslowakei: Gegen den imperialistischen Krieg - für den Frieden und die Freiheit der Völker, November 1939, Typoskript, BAB, RY 1/I 2/707/80, Bl. 51-65 (51).

395 Dies beweist auch ein parteiinterner Bericht der KPD in Frankreich vom Dezember 1942, in dem festgestellt wurde: "Leider gab es auch in unseren Reihen [nach dem Abschluß des Hitler-Stalin-Paktes, B. S.] einige Schwankungen und Unklarheiten und höchst gefährliche Auffassungen." (Bericht der KPD-Frankreich: Rückblick auf die wichtigsten Fragen und Probleme aus der Zeit kurz vor Hitler bis zum Ende 1942, 15. 12. 1942, S. 16, BAB, RY 61/V 232/2, Bl. 100). 
ausgeschlossen worden ${ }^{396}$. Als „Spalter“397 und „trotzkistischer Verräter“ beschimpft, bemühte sich der Verleger um eine neue politische Heimat und gründete die politisch breit angelegte Union franco-allemande. Im Oktober 1939 fragte er sich verbittert, ob er vergeblich gekämpft habe und konstatierte: „Im Frieden ist die Einigung nicht gelungen, der Krieg hat die Spaltung vertieft. Je kleiner die Gruppe, um so berufener fühlt sie sich, das kommende Deutschland allein zu bestimmen. ${ }^{\text {398 }}$

\subsubsection{Annäherung durch Wandel}

Für den Europadiskurs des nichtkommunistischen Exils hatte der deutschsowjetische Nichtangriffspakt drei wesentliche Auswirkungen: eine durch die paradigmatische Wende vieler Linkssozialisten ermöglichte Annäherung der europapolitischen Motive, die Tabuisierung einer sowjetfreundlichen Position Europas und eine differenzierte Profilschärfung der Europakonzeptionen an der Föderalismusdebatte.

Im Zuge des „russischen Dolchstoßes“399 erfuhr das antikommunistische Motiv einer europäischen Einigung eine differenzierte Vertiefung und eine folgenreiche Ausweitung auf das linkssozialistische Exil. Auf der Basis dieses breitgefächerten Motivbündels sollten in der verbleibenden Zeit der Emigration mitunter detaillierte und konstruktive Lösungsvorschläge zur künftigen Positionierung Europas im weltpolitischen Machtgefüge sowie zur konkreten Institutionalisierung eines vereinten Europas erarbeitet werden. Mithin liegt eine wesentliche diskursive Bedeutung des 23. August 1939 darin, daß die Suche nach Identitäten eines gemeinsamen Europas mit dem nun weite Teile des linkssozialistischen Exils erfassenden Antikommunismus um ein weiteres wichtiges Motiv ergänzt wurde. Ein gruppenübergreifender antisowjetischer Grundton war seitdem nicht mehr zu überhören. Das europäische Motivbündel des deutschen Exils war im wesentlichen geschnürt, und die innereuropäische Rückbesinnung hatte einen vorläufigen Höhepunkt erreicht.

Hinsichtlich der Haltung der Sowjetunion rückten die Exilgruppen politisch zusammen, da sich die Europapläne nun mehrheitlich durch eine jeden-

396 In einem Rundbrief erklärte die Auslandsleitung der KPD ihr volles Einverständnis mit Münzenbergs Ausschluß, vgl. Kl[amm], Auslandsleitung der KPD an „Liebe Freunde!“" 16. 4. 1939, ANF, F7 15133. Ein anderes, typisches Beispiel für die alltägliche Kontrolle und die ständige Gefahr einer Parteiintrige (hier durch den insoweit besonders umtriebigen Walter Ulbricht) schildert der damalige Kommunist und Schriftsteller Gustav REGLER, Das Ohr des Malchus 1975, S. $228 \mathrm{ff}$.

397 Auslandsleitung der KPD an „Liebe Freunde“, 16. 4. 1939, ANF, F 15133.

398 MÜnZENbERG, Ein Jahr vergeblichen Kampfes?, in: Die Zukunft, II. Jg., Nr. 41 (13. 10. 1939), S. 5. Münzenberg war selbst nicht frei von einer gewissen Selbstüberschätzung. In einem Brief an Kurt Grossmann vom 8. 5. 1940 schrieb er: „Jeder Tag beweist mehr, wie recht wir mit unserer politischen Analyse hatten und wie die von uns propagierte sozialistisch-demokratische Sammlung der deutschen Kräfte der einzige Ausweg ist, den es für Deutschland und seine Arbeiter gibt.“, ANF, F7 15123, M. G. 399 MÜNZENBERG, in: Die Zukunft, II. Jg., Nr. 38 (22. 9. 1939), S. 1. 
falls momentane antisowjetische Grundtendenz auszeichneten. Frieden, Freiheit und Gerechtigkeit schienen von diesem Moment an auch für die Linkssozialisten eher mit Hilfe der westlichen Demokratien, zumindest der westlichen Arbeiterbewegungen, verteidigt werden zu können als durch die UdSSR. Der Wandel in der Beurteilung der SU führte zu einer in der Regel mit taktischen Erwägungen gerechtfertigten Annäherung der Linkssozialisten an den Westen, so daß sich selbst sozialistische Europakonzeptionen nun häufiger durch eine Westorientierung Europas auszeichneten. Dieser Prozeß wurde durch die restriktive Ausländerpolitik der Exilländer nach dem Ausbruch des Krieges intensiviert, zumal der deutsch-sowjetische Nichtangriffspakt die Gastländer zu einem kritischen Mißtrauen gegenüber linken, tendenziell sowjetfreundlichen Emigranten veranlaßte. Sicherlich spielte auch dieser Hintergrund eine Rolle, als Münzenberg im Namen der Union franco-allemande in einem Rundschreiben an führende französische Politiker wie Daladier, Herriot, Blum, Bonnet, Sarraut und Reynaud in heftigen Worten den Verrat der Sowjetunion an der antifaschistischen Front anprangerte: „Les membres allemands de l'Union Franco-Allemande regrettent que le Front de la Paix, dont la formation sembla imminente, et qui, d'après leur conviction, n'était pas seulement le moyen le plus sûr de garantir la paix, mais de préparer également l'Europe future, a échoué. Ils condamnent sévèrement la trahison de ce Front par la Russie, c'est-à-dire par une puissance qui réclamait, jusqu'ici, la première place, non seulement dans la lutte pour l'idée de la sécurité collective, mais aussi dans la représentation de la classe ouvrière contre le fascisme international. “400

Mit dem Hitler-Stalin-Pakt vom 23. August 1939 kollidierte erstmals der sowjetfreundliche Kurs deutscher Linkssozialisten mit dem Konzept des Widerstandes durch Planung. Dadurch erhielt auch die sowjetische Frage plötzlich eine ganz andere, aber nicht minder entscheidende Bedeutung für den Prozeß der innereuropäischen Rückbesinnung. Münzenberg bemerkte konsterniert: „Es ist der schwerste Schlag, den die Arbeiterbewegung und die Front des Friedens und der Freiheit erhalten hat." 401 Der Europadiskurs hatte seine zweite entscheidende Weichenstellung erreicht, die für den gesamten Diskurs des Exils und über 1945 hinaus auch für die beiden deutschen Nachkriegsgesellschaften und ihr Verhältnis zueinander bestimmend bleiben sollte.

400 Unbetitelte Erklärung der deutschen Mitglieder der Union franco-allemande an französische Minister, 29. 8. 1939, S. 1, ANF F7 15129, M. 2.

401 MünZenBerg, Der russische Dolchstoß, in: Die Zukunft, II. Jg., Nr. 38 (22. 9. 1939), S. 1. Mit unverhohlenem Blick auf seine eigene Biographie fügte der Verleger hinzu: "Jahrelang hat eine ausgehaltene Presse gehetzt und verleumdet, hat Hunderte von niederträchtigen Lügen verbreitet, Tausende tapfere Arbeiter verdächtigt, keine Nummer der ,Volkszeitung" erschien, die nicht hundertmal wiederholte: ,Nieder mit dem Schädling. Nieder mit dem Verräter'. Heute stehen in allen Ländern Millionen auf, sie recken den Arm und rufen, nach dem Osten deutend: ,Der Verräter, Stalin, bist $\mathrm{Du}^{\text {‘ }}$, ibid. 
Nachdem es die deutschen Sozialisten 1914 aus Uneinigkeit nicht vermocht hatten, den Kriegsausbruch zu verhindern, stellte der Hitler-StalinPakt das zweite große Trauma der sozialistischen Bewegung dar. Moskaus politisches Gebaren rief Verwirrung hervor, die sich schon bald in Bitterkeit und Enttäuschung entlud. Die Idee des sozialistischen Internationalismus war nicht mehr vereinbar mit der Außenpolitik der UdSSR ${ }^{402}$. Folglich war eine Abkehr von der Sowjetunion unvermeidbar, wollte man der sozialistischen Idee treu bleiben und die eigene Glaubwürdigkeit bewahren. Die Idee wurde der Realpolitik übergeordnet. Insofern nahm das sozialistische Exil eine idealistische Position ein, die aus der realpolitisch nahezu einflußlosen Position des Exils sicherlich leichter formuliert werden konnte. Einige wenige Sozialisten wie Eugen Brehm gingen noch einen Schritt weiter und sagten sich nicht nur von der UdSSR, sondern zugleich auch vom Prinzip des sozialistischen Internationalismus los.

Der ohnehin sowjetkritische Willi Eichler empfand das traumatische Ereignis als „Dolchstoß der Sowjetunion“ 403 und verkündete das Ende der sowjetischen Vorbildfunktion. Gemeinsam mit Neu Beginnen, der SAP und den RSÖ sprach der ISK der Auslandsleitung der KPD unter Ulbricht jede Solidarität mit der deutschen Arbeiterbewegung ab404, und Willi Münzenberg sah die KPD nach dem sowjetischen Einmarsch in Polen gezwungen, „sich selbst zu ohrfeigen und in das Gesicht zu speien" ${ }^{405}$.

Dagegen zeigte sich die Gruppe Neu Beginnen von der unerwarteten Wendung völlig überrascht, denn noch im April 1939 hatte man die „Märchen über eine deutsch-russische Verständigung " 406 als antikommunistische Propaganda abgetan. Nur vier Monate später sah sich die Gruppe einer Orientierungskrise ausgesetzt, die sie jedoch im Gegensatz zur SAP bald zugunsten einer taktischen, auf die Arbeiterbewegung beschränkten Westorientierung zu lösen vermochte. Ein unveröffentlichtes Manuskript zur „neuen Lage" offenbart den inneren Zwiespalt der Gruppe: Selbst eine kritische Solidarisierung mit dem stalinistischen Regime war nunmehr ausgeschlossen, das stalinistische Rußland fiel „als Faktor der sozialistischen Weltkräfte“

402 Neu Beginnen rief den Lesern des Sozialdemokratischen Informationsbriefs beschwörend zu: „Begreift, daß die Interessen des Stalinregimes nicht identisch sind mit den Interessen der sozialistischen Gesamtbewegung." aus: Die außenpolitische Wendung der Sowjetunion, in: SIB, Nr. 48 (Oktober 1939), S. 5-7 (7).

${ }^{403}$ Holz [d. i. EICHLER], Die Aufgabe, in: SW, 14. Jg., H. 36 (15. 9. 1939), S. 853-856 (853).

404 Sozialistische Arbeitsgemeinschaft London [RSÖ, ISK, Neu Beginnen, SAP], Die KPD und die Solidarität der Illegalen, in: SW, 15. Jg., H. 7 (28. 3. 1940), S. 199-203 (200 et passim).

${ }^{405}$ MUnzenderg, Die Partei, die sich selbst ohrfeigt, in: Die Zukunft, II. Jg., Nr. 45 (10.11. 1939), S. 8.

406 Die Vollstreckung von München - der Anfang vom Ende?, in: SIB, Nr. 45 (Anfang April 1939), S. 15. 
aus $^{407}$ - dem Wortlaut nach zunächst eine Beschränkung der Kritik auf den Stalinismus. Damit stand die Frage im Raum, ob eine insgesamt antisowjetische Wendung unvermeidlich sei oder die ideologische Vorreiterfunktion gegenüber vorübergehenden Verirrungen überwiege. Der Verfasser entschied sich für eine klare antisowjetische, ja antikommunistische Wendung, weil er keine andere Möglichkeit sah, den antifaschistischen Kampf glaubhaft fortzusetzen $^{408}$. Dennoch blieb das unkomfortable Gefühl dogmatischer Orientierungslosigkeit, das sich erst mit dem deutschen Angriff auf die UdSSR im Juni 1941 entspannen sollte. Nun glaubte nicht zuletzt Richard Löwenthal die Errichtung der lange ersehnten Anti-Hitler-Koalition unter Beteiligung der Sowjetunion und der westlichen Arbeiterbewegungen für greifbar nahe und stellte erleichtert wieder "klare Fronten" fest ${ }^{409}$.

Zeigte Neu Beginnen trotz der dogmatischen Orientierungskrise ein beachtliches Maß an Konfliktfähigkeit, so wurde die orthodox marxistische SAP durch den Nichtangriffspakt doch einer inneren Zerreißprobe ausgesetzt, die die Organisation nicht zu überwinden vermochte. Insbesondere die Anfang der 30er Jahre von der Kommunistischen Partei/Opposition (KPO) zur SAP gewechselten Mitglieder wie Jacob Walcher weigerten sich, das Kind mit dem Bade auszuschütten und propagierten eine vorübergehende politische Abstinenz, denn "die deutsche Revolution, dieses entscheidende Glied in der Kette der Entwicklung"410, sei unter diesen Umständen nicht realisierbar.

407 [Hertz?], Unsere Kriegsziele und ihre Propaganda in der neuen Lage, o. D. [Anfang 1940], S. 1, AsD, NL Schoettle, M. 51. Das ungezeichnete Manuskript findet sich erneut im IISG, Coll. Neu Beginnen, M. 42. Es könnte von dem europapolitisch aktiven NB-Mitglied Paul Hertz verfaßt und als Resolutionsentwurf an Schoettle und andere Mitglieder verschickt worden sein. Hierfür spricht der teilweise identische Wortlaut eines unzweifelhaft von Hertz geschriebenen Rundbriefs vom 21.2.1940, der sich in Hertz' Nachlaß befindet; vgl. Paul Hertz, NB, Analyse der allgemeinen politischen Situation. Rundbrief (NB), London, 21. 2.1940 (insb. S. 5-8), IISG, NL Hertz, S11, M. T, Nr. 10. Darin bezieht sich Hertz auf zwei Entwürfe zur Kriegszieldiskussion, die an einige Freunde (NB-Mitglieder) geschickt worden seien. Einer dieser Entwürfe sei als "Rohentwurf für eine kurze sozialistische Kriegszieldeklaration" gedacht und werde nun auch anderen Freunden zugehen. Hierzu zählte mit Sicherheit Erwin Schoettle. Letztlich sollte dieser Entwurf als Grundlage für eine gemeinsame Erklärung der Arbeitsgemeinschaft von Neu Beginnen und SAP sowie dem ISK dienen, vgl. ibid. S. $5 \mathrm{f}$. Mit Blick auf das Datum des Hertzschen Rundbriefes (21.2. 1940) erscheint eine Datierung des darin erwähnten Entwurfs auf Anfang 1940 plausibler als das von BEHRING, Demokratische Außenpolitik 1999, S. 451, Anm. 23 vorgeschlagene Datum Herbst/ Ende 1939.

408 [Hertz], Rundbrief (NB), London, 21. 2. 1940, S. 2, IISG, NL Hertz, S11, M. T, Nr. 10. In Übereinstimmung mit der Sopade lehnte Neu Beginnen nun jede Zusammenarbeit mit den Kommunisten strikt ab, vgl. Neu Beginnen. Was es will, was es ist und wie es wurde, hg. v. Auslandsbüro Neu Beginnen, London o. J. [1939], S. 38.

409 [LÖWENTHAL], Klare Fronten 1941, S. 1.

410 JACQUES [d. i. WALCHER] an Brandt, 27. 12. 1939, AsD-WBA, Allgemeine Korrespondenz 1939. 
Im Ringen um eine gemeinsame Linie einigte man sich im Dezember 1939 auf das Dokument „Unsere Stellung zum jetzigen Krieg“, in dem einerseits die Wende in der sowjetischen Außenpolitik scharf kritisiert und zu einer Frontstellung gegen die UdSSR aufgerufen, andererseits jedoch der Versuch unternommen wurde, in das Verhalten Stalins eine weitblickende sozialistische Zielsetzung hineinzulesen ${ }^{411}$. Das Dokument zeichnet sich durch einen unüberwindlichen Spagat $z$ wischen dogmatischer Orthodoxie und pragmatischer Kompromißbereitschaft aus. Unverändert verstand man sich im Klassenkampf als unerbittlicher Gegner des kapitalistischen Westens, obwohl man gleichzeitig dessen Hilfe im Kampf gegen die Endstufe des Kapitalismus, den Nationalsozialismus, in Anspruch nahm. Daraus resultierte ein weiterer, politischer Spagat, denn entgegen der weiterhin erwarteten Schlüsselposition der deutschen Arbeiterklasse für die sozialistische Revolution zeigte man sich zugleich überzeugt, daß die Bedingungen für den Klassenund Freiheitskampf der Massen in Großbritannien und Frankreich „unvergleichlich viel besser sind als in Hitler-Deutschland“412.

Im Gegensatz zu Walcher sahen sich andere SAP-Mitglieder wie Eugen Brehm veranlaßt, sich endgültig von der bisherigen sowjetfreundlichen, den Stalinismus als vorübergehendes Phänomen betrachtenden Einstellung zu verabschieden und näherten sich so der strikt antikommunistischen Position der Sopade: „Wer eine höhere Auffassung vom Sozialismus hat [...], der wird radikal Schluß machen müssen mit dem Stalinismus und allen seinen ideologischen Spielarten." ${ }^{113}$ Als Vorstandsmitglied der Volkssozialistischen Bewegung hielt Brehm der SAP vor, ihr erstarrtes Marxismusverständnis habe „dem Ansturm des Lebens nicht standgehalten" und sowohl 1933 als auch im Exil versagt ${ }^{414}$. Nachdrücklich warnte der Publizist vor einem „bolschewistische[n] Chaos“, dem die Errichtung einer „volkssozialistische[n] Ordnung" zuvorkommen müsse ${ }^{415}$. Aus der seit August 1939 evidenten Doppelgefahr von Nationalsozialismus und Bolschewismus schloß Brehm auf den ideologischen Charakter des Krieges, der primär um der europäischen Einigung willen geführt werden müsse ${ }^{416}$. Europa habe

411 [Auslandsvertretung der SAP], Unsere Stellung zum jetzigen Krieg, Dezember 1939, insb. S. 4-6.

412 Ibid. S. 8.

413 Herb [d. i. Brehm], Der Krieg, in: SW, 14. Jg., H. 39 (13. 10. 1939), S. 928-931 (930). Zur wiederholten Absage der Sozialdemokraten an Kommunismus und Marxismus vgl. F. ST[AMPFER], Die Internationale und der Krieg. Einigkeit und Verwirrung, in: NV, Nr. 330 (15. 10. 1939), S. 2.

414 [BREHM], Thesen der Deutschen Volkssozialisten, in: Volkssozialistische Blätter, Nr. 1 (November 1939), 5. These, S. 14 f. (14).

415 Ibid.

416 Nahezu wortgleich kam August Siemsen im lateinamerikanischen Exil zu derselben Einsicht, vgl. SIEMSEN, Vaterland Europa, in: La Otra Alemania. Das Andere Deutschland (1. 1. 1940), wieder abgedruckt in: Ders., Die Tragödie Deutschlands 1947, S. 98101 (98). 
sogar die Pflicht, sich dauerhaft zu vereinigen, um gemeinsam den Bolschewismus abzuwehren ${ }^{417}$.

Für die Sopade, die aus der traditionellen Auseinandersetzung mit den Kommunisten um die Führerschaft in der Arbeiterbewegung ohnehin eine antikommunistische Haltung eingenommen hatte, bewies der Hitler-StalinPakt die Unzuverlässigkeit der Sowjetunion als antifaschistischer Bündnispartner und die Offensichtlichkeit ihrer ideologisch verbrämten Zielsetzungen. Betont lakonisch kommentierte Hilferding den Pakt: „Es ist scheußlich, es ist infam [...] wir sind nicht überrascht". ${ }^{418}$

Ebensowenig zeigte sich die Sopade vom Ausbruch des Krieges überrascht und bemühte sich auffällig, der Öffentlichkeit die konsequente Haltung der sozialdemokratischen Politik vor Augen zu führen, indem der Vorstand einen Aufruf vom 14. September 1938 ein Jahr später nahezu unverändert publizieren ließ ${ }^{419}$. Symptomatisch für die zunächst selbstgefällige, dann taktisch begründete Zurückhaltung des Sopade-Vorstandes in der vermeintlich schon seit dem Heidelberger Parteitag geklärten Europafrage obsiegte hier nicht zum ersten Mal zunächst das parteipolitische Kalkül über den europapolitischen Planungsbedarf. Mit der griffigen Formel von der „Krönung des Verrats" ${ }^{420}$ versuchte der Parteivorstand der Sopade, die zahlreichen linkssozialistischen Exilgruppen in den Schoß der Sozialdemokratie zurückzuführen. Er nutzte die Chance, allen Bestrebungen einer Volksfront unter Einschluß der Kommunisten endgültig einen Riegel vorzuschieben und erneut seinen Führungsanspruch als offiziöser Stellvertreter des „Anderen Deutschland “ im Exil zu bekunden: „Angesichts der jetzt durch den Verrat Stalins geschaffenen internationalen Situation" weigere man sich, „in irgendeine Verbindung mit der Kommunistischen Partei Deutschlands zu treten“421. In

417 BREHM, Die Stellung der deutschen Volkssozialisten im Kriege, in: Volkssozialistische Blätter, Nr. 1 (November 1939), S. 17.

418 KERN [d. i. Hilferding], Die Krönung des Verrats. Stalin als militärischer Bundesgenosse Hitlers, in: NV, Nr. 327 (24. 09. 1939), S. 4.

419 Vorstand der Sozialdemokratischen Partei Deutschlands, An das deutsche Volk! Mit einem verbrecherischen Angriff Hitlers hat der Krieg begonnen, in: NV, Nr. 325 (10. 9. 1939), S. 1.

420 Ibid. Der Vorwurf des Verrats findet sich auch in Verlautbarungen des IGB zum Hitler-Stalin-Pakt, vgl. etwa: Der Hitlerkrieg, in: Neue Gewerkschaftszeitung, Nr. 9 (September 1939), S. 249-253 (251).

421 [Parteivorstand der Sopade], Zum Hitler-Stalin-Pakt. Die Sozialdemokratische Partei Deutschlands und der deutsch-russische Nichtangriffspakt, in: NV, Nr. 325 (10. 9. 1939), S. 3. Ultimativ erwartete der Parteivorstand „von allen Mitgliedern der Partei, daß sie im gleichen Sinne handeln“, ibid. Die breitangelegte Offensive der Sopade gegen den Kommunismus und die KPD fand in zahlreichen Aufsätzen ihren Niederschlag, vgl. z.B. SCHWARZ [d. i. Reinbold], Der Weg zum deutsch-russischen Pakt, in: SW, 14. Jg., H. 36 (15. 9. 1939), S. 861-867; DERS., Kommunisten und der deutsch-russische Pakt, in: SW, 14. Jg., H. 37 (29. 9. 1939), S. 882-885. GEYER, Die russische Machtpolitik, in: NV, Nr. 328 (1. 10.1939), S. 1-2 (2) brachte es auf den populistischen Nenner: „Wir wollen jedenfalls in einem neuen, anderen, besseren, freieren Deutschland nicht russisch reden!“ 
einer an die französische Öffentlichkeit gerichteten Erklärung verkündeten die Sozialdemokraten stolz: „Nous avons reconnu le danger de guerre! Nous avons résisté aux séductions de Moscou! Nous avons déclaré la guerre à la dictature hitlérienne! Et nous la mènerons jusqu’à la chute de celle-ci!" 422

Für konstruktive Vorschläge einer künftigen Neuordnung fand sich im Augenblick des Triumphes jedoch kein Raum, sieht man von der pauschalen Phrase von der "Schaffung eines freien Europa“ $a b^{423}$. Jedenfalls blieb diese Zurückhaltung bis Ende 1939 für die sozialdemokratischen Beiträge zum Europadiskurs charakteristisch, nur trat an die Stelle der traditionsbewußten Überlegenheit zunehmend die latent schon früher entwickelte Skepsis gegenüber dem realpolitischen Sinn visionärer Europakonzeptionen. In diesem Zusammenhang ist eine private Äußerung des Vorstandsmitglieds Erich Ollenhauer in einem Brief an ein befreundetes Ehepaar kennzeichnend: „Denn wir wissen nicht, unter welchen Bedingungen die neue deutsche Arbeiterbewegung in Deutschland erstehen wird und welche Aufgabe wir Emigranten dabei erfüllen können. Das ist auch nich[t] wesentlich. Jetzt haben wir nichts anderes zu tun als unsere Pflicht zu erfüllen[,] so gut wie wir es vermögen." 424

Dennoch war diese Linie nicht völlig unumstritten. So bemerkte Rinner in einem Brief an Erich Brost, man könne zur Frage der europäischen Nachkriegsordnung nicht schweigen: „Wir würden die große Geschichte der Partei verleugnen, wenn wir bei allem realpolitischem Skeptizismus doch nicht immer wieder neuen Glauben in die Idee und in den Fortschritt der Gesellschaftsorganisation aufbringen würden. Aber bevor wir uns in irgendeiner Form dazu erklären, müssen wir natürlich die Dinge sehr sorgfältig durchberaten, und das wird vielleicht noch einige Zeit beanspruchen. " ${ }^{425}$ Tatsächlich waren solcherlei Beratungen nur wenige Tage zuvor mit unveränderter Skepsis im Parteivorstand aufgenommen worden, ohne daß im Ergebnis eine offizielle Stellungnahme der Sopade zur europäischen Frage vorgelegt wurde ${ }^{426}$.

Noch kurz vor dem erzwungenen Ende des kontinentaleuropäischen Exils durch die deutsche Besetzung Frankreichs war die Sopade mehr mit ihrer

422 Vorstand der Sozialdemokratischen Partei Deutschlands, Connaissance claire des faits - but clair. La Lutte de la socialdémocratie allemande contre le régime hitlérien, o. D. [Okt. 1939], S. 2, AsD, Bestand PV-Emigration Sopade, M. 188.

${ }^{423}$ [Parteivorstand der Sopade], Zum Hitler-Stalin-Pakt, in: NV, Nr. 325 (10. 9. 1939), S. 3 .

424 Ollenhauer an „Lieber Edgar, liebe Anni“, 19.11. 1939, ANF, F7 14716.

425 Rinner an Brost, 20. 2. 1940, S. 3, AsD, Bestand PV-Emigration Sopade, RinnerKorrespondenz, M. 4.

426 Auch Brost hatte sich in seiner Antwort gegen die Aufstellung "solcher Dinge wie ,Vereinigte Staaten von Europa“, ,Aufhebung der Zollgrenzen“ und dergleichen " als realpolitische Programmpunkte verwahrt und wollte die offiziellen Stellungnahmen der Partei auf bloße Andeutungen der außenpolitischen Tendenz beschränkt wissen; vgl. Brost an Rinner, 26. 2. 1940, S. 3, AsD, Bestand PV-Emigration Sopade/Rinner-Korrespondenz, M. 4. 
eigenen Rolle im deutschen Exil beschäftigt als mit der Gestaltung von $\mathrm{Zu}-$ kunftsplänen. Man scheute sich nicht, auf die national und international "vielleicht entscheidende Rolle" der deutschen Sozialdemokraten nach dem Zusammenbruch des nationalsozialistischen Regimes zu verweisen und empfahl sich gegenüber dem amerikanischen Diplomaten Sumner Welles als Regierungsmannschaft für ein neues Deutschland ${ }^{427}$. Abgesehen von Stampfers europapolitischem Engagement in den USA nahm sich der seit Mitte 1940 durch den Atlantik zerrissene Parteivorstand bis Mitte 1943 Zeit, um schließlich mit einem aktualisierten Europaprogramm aufzuwarten, das seine Entstehung hauptsächlich der kompromißbereiten Haltung der Sopade in den Verhandlungen über die Union deutscher sozialistischer Exilgruppen in Großbritannien verdankte. Anders verhielt es sich mit früheren Veröffentlichungen und privaten Stellungnahmen namhafter Sozialdemokraten außerhalb des Parteivorstandes wie Gerhard Kreyssig, Paul Tillich, Paul Hertz, Rudolf Katz und Siegfried Marck, auf deren Bedeutung für den Europadiskurs noch einzugehen sein wird.

Das Trauma vom August 1939 veranlaßte selbst die bewußt allgemeinpolitisch abstinenten Gewerkschaften zu einer unmißverständlich antisowjetischen, ja antikommunistischen Stellungnahme. Typisch für diese Grundhaltung ist die Position von Fritz Tarnow, der in einem „Memorandum über die Aufgaben der Auslandsvertretung der deutschen Gewerkschaften während des Krieges" eine klare Trennung zwischen den klassischen Gewerkschaftsfragen und den allgemeinpolitischen Fragen vollzog, um sich auf die eigentliche Kernkompetenz der Gewerkschaften konzentrieren zu können und auf diese Weise ein ohnehin drohendes Auseinanderbrechen der exilierten Gewerkschaftsbewegung aufgrund politischer Differenzen abzuwenden ${ }^{428}$. Dementsprechend wurde die europäische Frage nicht diskutiert. Statt dessen zog man sich auf konsensfähige Allgemeinplätze zurück, die sich im Vergleich zu den zwischenzeitlich präzisierten Ergebnissen anderer Exilgruppen als Banalitäten ausnahmen. Dies ist nicht weiter verwunderlich, da Tarnow selbst in seinem "Memorandum" auf den restriktiven Aufgabenkreis der

427 [Parteivorstand der Sopade], Die Sozialdemokratische Partei Deutschlands und der Krieg. Für ein freies Deutschland in einem freien Europa, o. D. [handschriftlich: Endgültige Fassung April 1940], AsD, Bestand PV-Emigration Sopade, M. 178 sowie [Parteivorstand der Sopade], Memorandum, o. D. [März (handschriftlich:) 1940], AsD, Bestand PV-Emigration Sopade, M. 179; das Zitat ist dem letztgenannten Dokument entnommen, ibid. S. 3.

428 Vgl. Tarnow, Memorandum über die Aufgaben der Auslandsvertretung der deutschen Gewerkschaften während des Krieges, September 1939, abgedruckt in: MIELKE, FRESE (Bearb.), Gewerkschaften 1999, Dok. Nr. 47, S. 271-279. Ein Brief von Bruno Süß an Fritz Tarnow dokumentiert, daß innerhalb der deutschen Gewerkschaftsbewegung sogar Uneinigkeit über den Schwerpunkt der Exilsarbeit herrschte. Während Süß den Kampf gegen Hitler in den Vordergrund stellen wollte, widmete sich Tarnow vorrangig den Planungen für eine künftige Neuorganisation der Gewerkschaften in Deutschland; vgl. Süß an C. Frederek [d. i. Tarnow], 18.12. 1939, abgedruckt in: MiELKE, FrESE (Bearb.), Gewerkschaften 1999, Dok. Nr. 48, S. 279-288, insb. S. 279 f. 
Auslandsvertretung der deutschen Gewerkschaften verwies, wie er in den Leitsätzen vom 26./27. Juli 1935 definiert worden war ${ }^{429}$.

Hans Gottfurcht reflektierte im November 1939 pointiert den gewerkschaftlichen Standpunkt zur Auslandsarbeit: „Wir wünschen es klar zu machen, daß [über das Ziel des Sturzes der nationalsozialistischen Diktatur, B. S.] hinaus unsere Arbeit lediglich diktiert wird von den Interessen, für die wir als Sachwalter deutscher freier Gewerkschaftsarbeit zuständig sind. "430 Und Willy Kressmann ergänzte zwei Monate später in einer Aussprache von Gewerkschaftern in London, daß die gewerkschaftliche von der politischen Frage zwar nicht zu trennen sei, man aber keinesfalls beabsichtige, über ausgesprochen politische Fragen zu diskutieren ${ }^{431}$. Einzig die Ausgrenzung der Kommunisten aus der Londoner Auslandsvertretung der deutschen Gewerkschaften erzwang des öfteren eine dezidiert politische Stellungnahme ohne unmittelbar gewerkschaftlichen Hintergrund. So verurteilte Gottfurcht den Hitler-Stalin-Pakt als „eines der größten Verbrechen [...], die jemals begangen wurden" und sprach sich erneut gegen jede Aufnahme von Kommunisten in die Auslandsvertretung der deutschen Gewerkschaften (AdG) aus 432 .

Selbst die internationale Gewerkschaftsbewegung wagte sich nicht über eine verschämte Erwähnung ,des Rechts, der Freiheit und der Menschlichkeit" als den Grundsätzen einer neuen Ordnung hinaus ${ }^{433}$. Mitunter berief sich der IGB schlicht auf die Sopade und zitierte deren Stellungnahme zum Kriegsausbruch, um sich ihr ohne eigene Stellungnahme anzuschließen ${ }^{434}$. Lediglich die Ablehnung des Kommunismus veranlaßte den IGB, regelmäßig Abgrenzungserklärungen abzugeben. In seiner antikommunistischen Grundhaltung sah sich der IGB durch den Abschluß des deutsch-russischen

429 Leitsätze für die Gewerkschaftliche Auslandsvertretung Deutschlands (Geade), 26./ 27. 7. 1935, abgedruckt in: MIELKE, FrESE (Bearb.), Gewerkschaften 1999, Dok. Nr. 27, S. $192 \mathrm{ff}$.

430 Gottfurcht, Zum Standort und zu den Aufgaben der Londoner Vertretung, 30. 11. 1939, abgedruckt in: Mielke, FreSE (Bearb.), Gewerkschaften 1999, Dok. Nr. 209, S. $878 \mathrm{f} .(879)$.

431 Neuordnungsvorstellungen der Mitglieder der Londoner Vertretung der freien Arbeiter-, Angestellten- und Beamtengewerkschaften (ADGB-AFA-ADB), 29. 1. 1940, abgedruckt in: MielKe, FRESE (Bearb.), Gewerkschaften 1999, Dok. Nr. 212, S. 885888 (886).

432 Gottfurcht, Bericht über Organisation und Tätigkeit der Londoner Vertretung der freien Arbeiter-, Angestellten- und Beamtengewerkschaften (ADGB-AFA-ADB), 15. 5. 1940, abgedruckt in: Mielke, Frese (Bearb.), Gewerkschaften 1999, Dok. Nr. 215, S. 891-896 (894).

433 Der Hitlerkrieg, in: Neue Gewerkschaftszeitung, Nr. 9 (September 1939), S. 249 253 (253).

434 Kriegsziele, in: Neue Gewerkschaftszeitung, Nr. 10 (Oktober 1939), S. 289-291 (291). 
Nichtangriffspaktes bestätigt, den er als „Hochzeit des Teufels mit Beelzebub" charakterisierte ${ }^{435}$.

Für das nichtsozialistische Exil zählte ein dezidierter Antikommunismus in der Regel zum politischen Selbstverständnis. So erstaunt es nicht, daß das Bündnis des Bolschewismus mit dem Nationalsozialismus hier weder Überraschung noch Entsetzen auslöste. Zwar erkannten die nichtsozialistischen Exilgruppierungen den machtpolitischen Gehalt dieses Bündnisses, doch sah man auch die Chance, daß sich der Bolschewismus als Gesellschaftssystem dadurch langfristig selbst diskreditieren würde. Wenige Tage nach Kriegsausbruch formulierte diese Einsicht Hubertus Prinz zu Löwenstein für den politischen Katholizismus: „Der russische Pakt mit Hitler, durch den die Katastrophe ausgelöst wurde, mag für die Zukunft seine guten Seiten haben; der Kommunismus ist jetzt so innig mit dem Nationalsozialismus verflochten, daß der Sturz des letzteren jenem bestimmt nicht die Macht verschaffen wird." $" 436$

Der liberale Publizist Schwarzschild betonte auf dem Höhepunkt seines erst im Exil schrittweise entwickelten Antibolschewismus, daß die „nazistisch-bolschewistische ,Nichtangriffs'-Verschwörung " ${ }^{437}$ die prinzipielle Unterschiedslosigkeit der beiden nun verbündeten Diktaturen für jeden sichtbar aufgedeckt habe: „Sie sind, mit allem, was sie darstellen, ineinandergeflossen, Nazschewismus, Komfascismus. [...] Gleich abschreckend steht die $z$ wiefache Pest vor den Augen. “438

Zugleich wurden neue Perspektiven für eine verstärkte Zusammenarbeit innerhalb des deutschen Exils entdeckt, um, alle zur Mitarbeit bereiten und fähigen geistigen und politischen Kräfte des noch in Freiheit lebenden Deutschtums zu sammeln“439. Die DFP, die ihren eigenen Standpunkt als prädestiniertes Kompromißprogramm verstand, hielt angesichts der gemeinsamen Ablehnung der Kommunisten ${ }^{40}$ insbesondere eine Kooperation mit

435 Abschied von 1939, in: Neue Gewerkschaftszeitung, Nr. 12 (Dezember 1939), S. 345-351 (346). Zur antibolschewistischen Grundhaltung vgl. auch: Der Fortgang des Hitlerkrieges, in: Neue Gewerkschaftszeitung, Nr. 10 (Oktober 1939), S. 284-288, insb. S. 285.

436 LöwENSTEIN, Europas kommender Friede, in: Die Zukunft, II. Jg., Nr. 36 (6. 9. 1939), S. 3.

437 SChwarZSCHLD, Das zweite Brest-Litowsk, in: NTB, 7. Jg., H. 35 (26. 8. 1939), S. 825-827 (825).

438 DERS., Zwischen Krieg und Frieden, in: NTB, 7. Jg., H. 36 (2. 9. 1939), S. 849-851 (851).

439 Die Aufgaben der Deutschen im Ausland, in: Das Wahre Deutschland (Oktober/ Dezember 1939), S. 6-9 (9).

440 Ibid. S. 7; vgl. auch Strasser, Deutscher Situationsbericht, 10. 9. 1939, S. 2, IfZ, NL Strasser, ED 118/20. In dieser Schrift entwickelte Strasser das Bild einer zweigeteilten politischen Emigration: einerseits die Volksfrontgruppierung, der er die Kommunisten, Linkssozialisten, den linken Flügel der Sopade sowie vereinzelte Intellektuelle wie Georg Bernhard und Heinrich Mann zurechnete, und andererseits die nationale Gruppierung des rechten Flügels der Sopade, der DFP, den politischen Katholizismus, die 
den Sozialisten für möglich. Zugleich konstatierte sie eine neue Frontenbildung im Exil, einen „Riß zwischen denen, die nichts hinzulernten, und denen, die neue Wege bejahen "441. Ein Umlernen - im Sinne gesteigerter Kompromißbereitschaft, interpretiert als Annäherung an den Standpunkt der DFP - habe sich auf nahezu alle Lager erstreckt, wobei dem sozialistischen Exil durch den Hitler-Stalin-Pakt das bei weitem schwerwiegendste Damaskus beschert worden sei. Allerdings übersah dieser Standpunkt die Tatsache, daß die dem gesamten sozialistischen Exil unterstellte Abkehr vom Internationalismus nur bei den Volkssozialisten und dem konvertierten Volkssozialisten Brehm vorzufinden war ${ }^{442}$.

Unverändert rangierte für viele Bürgerliche die deutsche Frage in der Reihenfolge der außenpolitischen Prioritäten weit vor der europäischen. Ausgangspunkt vieler liberaler und konservativer Überlegungen zu Europa war die drohende Zerstückelung Deutschlands ${ }^{443}$. Unmißverständlich wurde das eigentliche Motiv in der Europafrage als ein nationales charakterisiert: „Dann ist unsere nationale Aufgabe nicht mehr, ein Großdeutschland zu schaffen, sondern all unsere Kräfte in den Dienst Europas zu stellen, weil ein gesundes und starkes Europa die Wohlfahrt und Sicherheit Deutschlands beinhaltet." 444 Man sprach sich also für Europa aus, um Deutschland zu retten. Daher sei das wahre Deutschland europäisch, menschlich und christlich ${ }^{445}$.

Volkskonservativen bis zu seiner eigenen Schwarzen Front. Diese Gruppen stünden in grundsätzlicher Opposition zueinander: „Auf jeden Fall muß mit der unversöhnlichen Existenz der beiden erwähnten Gruppen der deutschen Opposition gerechnet werden, da für entscheidende Faktoren der nationalen Gruppe jede Zusammenarbeit mit Kommunisten ausgeschlossen ist und gleichzeitig ein überstarker jüdischer Einfluß nicht anregbar erscheint." Durch die Identifizierung der jüdischen Emigration mit der seiner Ansicht nach kommunistisch dominierten Volksfrontgruppierung kehrte Strasser zur nationalsozialistischen Terminologie einer , jüdisch-bolschewistischen Weltverschwörung" zurück und entlarvte seine früheren Verurteilungen des hitlerschen Antisemitismus als bloße Manöver der tagespolitischen Taktik.

${ }^{441}$ Der Kampf um das künftige Deutschland, in: Das Wahre Deutschland (August 1939), S. 14-16 (14).

442 Úberspitzt sprach ein ungenannter Verfasser von "ehemalige[n] Sozialisten aller Schattierungen, die ohne ihren Idealen untreu zu werden, die gepredigte Vaterlandslosigkeit (genannt, Internationalismus') als Wegbereiterin des Nationalsozialismus [...] ansehen [...], den historischen Materialismus als eine Sünde wider den Geist, die Begrenzung auf die Arbeiterschaft aber als eine Torheit und als eine Schädigung des sozialistischen Gedankens verurteilen"; Der Kampf um das künftige Deutschland, in: Das Wahre Deutschland (August 1939), S. 16.

${ }^{443}$ In wütender Verzweiflung fragte ein ungenannter Verfasser in einem Beitrag mit dem Titel: Soll Deutschland vernichtet werden?, in: Das Wahre Deutschland (September 1939), S. 3-6 (5): „Das Herzstück Europas soll vernichtet werden, ohne daß die anderen Glieder unseres Erdteiles Schaden nehmen?"

${ }^{444}$ Nicht Großdeutschland, sondern Europa!, in: Das Wahre Deutschland (April 1940), S. 2-4; erneut abgedruckt in: LIPGENS (Hg.), Föderationspläne 1968, Dok. Nr. 142, S. $416 f$.

${ }^{445}$ Soll Deutschland vernichtet werden?, in: Das Wahre Deutschland (September 1939), S. 3-6 (6). 
Auch Strasser bekräftigte, „daß Hitler durch seinen Pakt mit Stalin nicht nur die Zukunft Europas gefährdet, sondern auch die Interessen Deutsch-

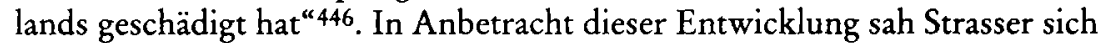
veranlaßt, die nationale deutsche Opposition im Exil unter dem gemeinsamen Dach eines Nationalrates für ein Freies Deutschland zu vereinen, um so dem Ausland einen Ansprechpartner des „Deutschland von Morgen“ zu bieten. Namentlich erwähnte Strasser die dem rechten Parteiflügel angehörenden Sozialdemokraten Sollmann und Jaksch, den ehemaligen Vorsitzenden der Deutschen Staatspartei August Weber, den einstigen Reichskanzler Brüning und dessen Kabinettskollegen Treviranus, den vormaligen national-sozialistischen Senatspräsidenten von Danzig, Hermann Rauschning, sowie sich selbst ${ }^{447}$. Strassers hauptsächliche Befürchtung war eine Bolschewisierung Europas, die nicht nur den Verfall des Abendlandes, sondern darüber hinaus den Verlust der deutschen Großmachtstellung zugunsten der Sowjetunion bedeuten würde ${ }^{448}$. Politischer Scharfsinn kann Strasser nicht abgesprochen werden, behauptete er doch, daß eine Zusammenarbeit dieser Personen viel leichter möglich erscheine und eine viel größere innere Einheit repräsentiere als die Addierung der Parteigruppen, denen sie entstammten ${ }^{449}$. Der bekennende Nationalsozialist hatte eine Entwicklung innerhalb der politischen Emigration beobachtet, die sich mit dem Ende des kontinentaleuropäischen Exils verschärfen sollte: die Individualisierung der politischen Konzepte durch eine nahezu alle Gruppen erfassende Loslösung einzelner aus der Loyalität ihrer jeweiligen Parteilinien ${ }^{450}$.

Aufgrund des Vorranges der deutschen Frage und mangels einer internationalistischen Tradition, die die nichtsozialistischen Kreise vehement ablehnten, blieb der Europagedanke - mit einigen Ausnahmen wie Edgar SternRubarth sowie den linkskatholischen Politikern Löwenstein und Thormann - auch 1939/40 oft noch eine leere Worthülse. Selten reichte er über die unverbindliche Umschreibung als Abwesenheit von Krieg oder als Gegnerschaft gegen eine nationalsozialistische Hegemonie hinaus ${ }^{451}$. Ein typisches

446 Strasser, Lage und Entwicklung, 1. 10. 1939, S. 1, IfZ, NL Strasser, ED 118/20.

447 Ders., Deutscher Situationsbericht, 10.9. 1939, S. 2 und 4, IfZ, NL Strasser, ED 118/20. In einem späteren Memorandum über Aufgaben und Möglichkeiten der Deutschen Opposition, o. D. [Oktober 1940], IfZ, NL Strasser, ED 118/20 griff Strasser erneut auf die Idee einer deutschen Exilregierung zurück, wobei Treviranus und Weber nicht mehr erwähnt und Jaksch durch Höltermann ersetzt wurde. Als Kabinettschef sah Strasser Brüning vor, der nach seiner Ansicht „zweifellos der Geeignetste wäre“ (S. 3). Brüning selbst lehnte jede Mitarbeit ab. In einem Brief an Löwenstein bezeichnete er Strassers Ansatz als falschen Weg: Brüning an Löwenstein, 7. 4. 1941, BAK, NL Löwenstein, N 1222, Bd. 11.

448 Strasser, Lage und Entwicklung, 1. 10. 1939, S. 2, IfZ, NL Strasser, ED 118/20.

449 Vgl. Strasser, Deutscher Situationsbericht, 10. 9. 1939, S. 2, IfZ, NL Strasser, ED $118 / 20$.

${ }^{450} \mathrm{Zu}$ diesem Charakteristikum des politischen Exils siehe Kapitel V.2.3.

451 Z. B. Soll Deutschland vernichtet werden?, in: Das Wahre Deutschland (September 1939), S. 3-6 (insb. S. 5); Nicht Großdeutschland, sondern Europa!, in: Das Wahre 
Beispiel ist der Otto Klepper zugeschriebene Beitrag in der Zukunft, der unter der vielversprechenden Überschrift „Kriegsziel Europa. Die föderalistische Idee" mit "tiefer Befriedigung" einen nicht näher bezeichneten Zeitungsartikel paraphrasierte, darüber hinaus jedoch nur eine nicht weiter ausgeführte europäische Konföderation andeutete. Am Ende des Beitrags läßt der Verfasser sein wirkliches Anliegen erkennen: „Bleibt Europa [...] das eigentliche Kriegsziel, so wird auch die Lösung der deutschen Frage keine unüberwindlichen Schwierigkeiten machen. ${ }^{452}$

\subsubsection{Ausfall der Ostoption}

Während sich die Westannäherung als europapolitische Option während des Krieges erst allmählich entwickelte, war die Option einer Ostorientierung im Sinne einer an die Sowjetunion gebundenen Gestaltung eines gemeinsamen Europas seit der Oktoberrevolution dogmatisch verankert gewesen. Der plötzliche Wegfall dieser jahrzehntelang als sozialistische Selbstverständlichkeit verstandenen außenpolitischen Orientierung traf das linkssozialistische Exil ins Mark. Nun war eine Zusammenarbeit mit der Sowjetunion nicht nur für die ohnehin antisowjetisch eingestellten bürgerlichen und nationalkonservativen Kreise undenkbar, sondern bis auf weiteres auch für das sozialistische Exil. Die aus linkssozialistischer Sicht schier unglaubliche Tatsache einer Kooperation des sozialistischen und damit erklärtermaßen antifaschistischen Repräsentationsstaates mit dem nationalsozialistischen Feind wurde als Triumph des russischen Nationalismus über den sozialistischen Internationalismus gewertet ${ }^{453}$. Münzenberg resümierte: „Die alte Ideologie, die Prinzipien der kollektiven Sicherheit und die nur als Tarnung mühselig mitgeschleppten sozialistischen und internationalistischen Doktrinen sind in Stalin-Rußland ein für alle Mal tot und begraben." 454 Damit hatte sich die UdSSR vorerst als Bündnispartner eines freiheitlichen Europas diskreditiert, wenngleich die Überzeugung vorherrschte, daß sie im europäischen Sicherheitsgefüge auch weiterhin eine wichtige Funktion wahrnehmen werde. In diesem Sinne ist auch Budzislawskis enttäuschte Bemerkung zu verstehen, es gehöre zur

Deutschland (April 1940), S. 2-4; erneut abgedruckt in: LIPGENS ( $\mathrm{Hg}$.), Föderationspläne 1968, Dok. Nr. 142, S. $416 f$.

452 Kriegsziel Europa. Die föderalistische Idee, in: Die Zukunft, II. Jg., Nr. 45 (10. 11. 1939), S. 1; abgedruckt in: VOIGT (Hg.), Friedenssicherung 1988, S. 135-137; englischer Abdruck bei LiPGENS (Hg.), Documents II 1986, Dok. Nr. 207, S. $562 \mathrm{ff}$.

453 Sozialistische Selbstverständigung. Nach dem deutsch-russischen Pakt. - Ein Diskussionsbeitrag, in: SW, 14. Jg., H. 35 (1. 9. 1939), S. 850-852 (852). Vgl. auch Rußlands Schwenkung - und die sozialistische Bewegung, in: SIB, Nr. 49 (Anfang Dezember 1939), S. 27: „Dieses [russische] Regime steht heute außerhalb der sozialistischen Bewegung; es ist der Verbündete ihrer Todfeinde."

454 MünzenberG, Der russische Dolchstoß, in: Die Zukunft, II. Jg., Nr. 38 (22. 9. 1939), S. 1. 
europäischen Tragödie, daß die große Sowjetmacht damit als Faktor zunächst ausgeschieden sei455.

Mit dem tiefgreifenden Wandel der linkssozialistischen Position ging eine vorsichtige Annäherung der Europakonzepte einher. Sie basierte auf dem von Sozialisten, Liberalen und Konservativen mitgetragenen Minimalkonsens, daß jedenfalls eine vorübergehende taktische $Z$ wecksolidarisierung mit den westlichen Demokratien Frankreich, Großbritannien und den USA der einzig gangbare Weg sei, um gegen die Doppelbedrohung des Nationalsozialismus und des Bolschewismus wirksam anzugehen. Umstritten war aber, welche langfristigen Konsequenzen diese Zwecksolidarisierung mit dem Westen für ein vereinigtes Europa nach sich zöge. Da die künftige Stellung der SU als europäischer und weltpolitischer Machtfaktor kaum mehr verkannt wurde, die Option einer einseitigen Bindung an den Osten jedoch entfiel, blieben im wesentlichen zwei Orientierungsmuster: Entweder würde sich Europa einer einseitigen Westbindung verschreiben, oder es müßte versuchen, sich zu einem unabhängigen Machtblock zwischen Ost und West zu entwickeln.

Notwendigerweise wurde die sich nun aufdrängende Frage nach einer möglichen taktischen oder gar grundsätzlichen Annäherung an den Westen vorrangig im linkssozialistischen Milieu des Exils geführt. Denn hier war der historische Ort, an dem das Trauma vom August 1939 verarbeitet werden mußte, hier setzte eine umfassende Abwendung von der $\mathrm{SU}$ als ideologisches Vorbild und damit als Orientierungspunkt eines vereinigten Europas ein. Über die Eigenständigkeit Europas in der Dichotomie des Ost-West-Konflikts aber wurde nicht nur bei den Sozialisten, sondern in allen Gruppen des deutschen Exils engagiert debattiert.

Das linkssozialistische Exil verweigerte sich einer einheitlichen Linie zur weltpolitischen Position Europas. Traf eine taktisch begründete, auf die Überwindung des Nationalsozialismus beschränkte Annäherung an den Westen auf nahezu uneingeschränkte Zustimmung, so wurde die langfristige Perspektive Nachkriegseuropas unterschiedlich skizziert. Ausschlaggebend war die durch den sowjetischen Frontenwechsel erzwungene axiomatische Substitution. Mit dem Wegfall der Sowjetunion als zentralem Bündnispartner war ein baldiger Sieg des Sozialismus in Europa in weite Ferne gerückt. Sollte der Anspruch der Realisierbarkeit aufrechterhalten bleiben, mußten die linkssozialistischen Europamodelle nun von einem Sieg der Westmächte ausgehen, ohne die der Nationalsozialismus nicht zu überwinden war.

Vor dem Hintergrund dieser Zwangslage bemühte sich der marxistische Dogmatiker Jacob Walcher vergeblich um ideologische Konsequenz. Zwar erkannte auch er die Ostoption als momentan unvertretbar, doch verweigerte er sich einer bloß taktisch motivierten Hinwendung zum Westen, dessen ka-

455 BuDZISLAwsKI, Die europäische Tragödie, in: Die neue Weltbühne, XXXV.Jg., Nr. 35 (31. 8. 1939), S. 1086. 
pitalistisch-imperialistisches Wesen er bisher so erbittert bekämpft hatte. Statt dessen erklärte er eine politische Auszeit, bis der richtige Augenblick für den weltrevolutionären Startschuß in Deutschland gekommen sei ${ }^{456}$. Seine theoretische Konsequenz hob Walcher in der Praxis sogleich wieder auf - und emigrierte in die USA, dem Flaggschiff des Kapitalismus.

Dagegen postulierte die nunmehr als Auslandsvertretung der Gesamtpartei auftretende Londoner SAP-Gruppe ihr taktisch „bedingtes Eintreten für die militärische englisch-französische Anti-Hitler-Front " ${ }^{457}$. Doch bestand sie darauf, daß ein später vereinigtes Europa „in voller Selbständigkeit und Unabhängigkeit sowohl vom englisch-französischen, wie russischen Staatsapparat" stehen müsse ${ }^{458}$.

Die Position der Londoner SAP war nachhaltig von Neu Beginnen beeinflußt, mit der man in einer Arbeitsgemeinschaft kooperierte. Neu Beginnen hatte schon zuvor die drohende Spaltung des europäischen Kontinents befürchtet und daraus die Konsequenz gezogen, daß Europa nur als eigenständiger Machtfaktor zwischen Ost und West politisch überleben würde. Wie viele Linkssozialisten, betonte auch Neu Beginnen, daß der Kampf gegen den Nationalsozialismus jetzt nur noch auf der Seite der Westmächte geführt werden könne, "weil wir nur mit ihr während des Krieges in einem Hauptpunkt [gemeint ist der Antifaschismus, B. S.] übereinstimmen und weil nur in ihrem Rahmen eine gewisse Manövrierfreiheit und die Möglichkeit gegeben sind, sich auf echte Bundesgenossen aus der Arbeiterbewegung zu stützen"459.

Damit war die entscheidende Umorientierung vollzogen, mit der sich $\mathrm{Neu}$ Beginnen an die Seite des ISK stellte. Durch die Arbeitsgemeinschaft mit Neu Beginnen war auch die SAP gezwungen, diesen Schritt nachzuvollziehen. In Übereinstimmung mit der Auslandsvertretung der SAP bemühte sich die Gruppe zugleich um eine Beschränkung der Zusammenarbeit mit dem Westen auf ein ideologisch vertretbares $\mathrm{Maß}$, mit anderen Worten: auf die Überwindung des Nationalsozialismus. Klarsichtig erkannte man die Gefahr, daß sich Europa und der europäische Sozialismus bei Kriegsende in einer politischen Zwangslage zwischen dem "kapitalistischen Westen und dem stalinistischen Osten" wiederfinden werde und sprach sich für eine unabhängige Balance zwischen den „potentiell feindlichen Machtfaktoren im Westen und Osten" aus ${ }^{460}$. Dahinter stand das Fernziel eines sozialistischen Europas, an

456 JACQues [d. i. WALCHER] an Brandt, 27. 12. 1939, AsD-WBA, Allgemeine Korrespondenz 1939.

457 [Auslandsvertretung der SAP], Unsere Stellung zum jetzigen Krieg, Dezember 1939, S. 8.

458 Ibid. S. 9.

459 [Hertz?], Unsere Kriegsziele und ihre Propaganda in der neuen Lage, o. D. [Anfang 1940], S. 2, AsD, NL Schoettle, M. 51.

460 Ibid. S. 1. 
dem man weiterhin festhielt, ohne dessen Realisierung alsbald erwarten zu können.

Für die Übergangsphase stellte sich mithin das Problem einer vorübergehenden Kooperation mit dem kapitalistischen Westen innerhalb einer europäischen Föderation. Waren solche Überlegungen noch vor kurzem als den Interessen der sozialistischen Bewegung widersprechend abgelehnt worden, sah sich Neu Beginnen nach dem sowjetischen Frontenwechsel gezwungen, unter dem Druck der realpolitischen Verhältnisse eine Föderation sozialistischer und kapitalistischer Staaten zu unterstützen. Dies mußte als momentan einziger umsetzbarer Schritt in Richtung einer letztlich sozialistischen Föderation hingenommen werden. Um so wichtiger war den führenden Köpfen von Neu Beginnen, daß die Idee einer europäischen Föderation nur unter bestimmten Bedingungen propagiert werde, „die uns im Fall einer starken revolutionären Bewegung in Mitteleuropa an einen reaktionären Westen nicht bindet" ${ }^{461}$. Auf diese Weise sollte die Unabhängigkeit Europas und die "sozialistische Selbständigkeit" 462 gegenüber Ost und West bewahrt werden, um das Fernziel einer sozialistischen Kontinentalrevolution zu ermöglichen ${ }^{463}$.

Eine deutlichere Abgrenzung zum Osten als Negativimplikation einer dauerhaften Westbindung findet man bei dem ehemaligen Kommunisten Willi Münzenberg. Im Kampf um das Überleben seiner Zeitung Die Zukunft beschwor er in einem Brief an Edouard Mounier die Rettung Deutschlands vor der Bolschewisierung: "Ce qui importe, c'est la nécessité de concentrer tous les efforts afin qu'au moins l'Ouest et le Sud de l'Allemagne soient sauvés du bolchevisme et que soit maintenue, dans ces territoires au moins, la possibilité de créer un état démocrate. " ${ }^{464}$ Als zentrale Figur der deutschen

\section{Ibid. S. 3.}

462 Rußland und die deutsche Revolution, o. D. [Mitte 1940], S. 7, IISG, Coll. Neu Beginnen, M. 41.

$463 \mathrm{Vgl}$. auch Rußlands Schwenkung - und die sozialistische Bewegung, in: SIB, Nr. 49 (Anfang Dezember 1939), S. 31: „Wir kämpfen heute um die selbständige Entwicklung der neuen sozialistischen Bewegung Deutschlands [...]. Wir werden morgen um die selbständige Entwicklung der deutschen und mitteleuropäischen Revolution gegenüber allen Kräften der Intervention kämpfen und damit um die Voraussetzung jenes Wiederaufstiegs der sozialistischen Weltkräfte, der auch die Sowjetunion von den Schlacken der Reaktionsperiode befreien wird." Ein "doppeltes Spiel“, wie es BEHRING, Demokratische Außenpolitik 1999, S. 453 der Gruppe Neu Beginnen unterstellt, findet in den Quellen keine hinreichende Stütze. Gerade die oben zitierte Stellungnahme benennt in aller Öffentlichkeit und ohne erkennbare Verdeckungsabsicht die von Neu Beginnen anvisierte Schrittfolge: erst sozialistische Revolution in Deutschland, dann Übergreifen auf die europäische Ebene und schließlich Durchbruch der Weltrevolution.

464 Münzenberg an "Monsieur Le Ministre" [Emmanuel Mounier], 25. 9. 1939, S. 3, ANF, $F^{7} 15124$, M. M. In einem Annex („Ma proposition“) schlägt Münzenberg vor, einige Männer, "qui sont prêts à risquer le tout", nach Dänemark oder in die Schweiz, wenn nicht gar direkt nach Deutschland ausreisen zu lassen. Offensichtlich sollte diese Aktion der Vorbereitung eines innerdeutschen Aufstandes dienen. Der Annex befindet sich in Mappe P desselben Bestandes. Ein gleichlautender Brief war unter dem Datum des 21. 9. 1939 an Palewski, den Chef de Cabinet du Ministre des Finances, geschickt 
Exilpublizistik durchlief Münzenberg einen beachtlichen „parcours politique" 465 : Er wandte dem Kommunismus, für den er sich so lange eingesetzt hatte, den Rücken zu und widmete sein politisches Engagement für die kurze ihm verbleibende Lebenszeit einer umfassenden, auf dem deutsch-französischen Ausgleich basierenden Europaföderation als Bollwerk gegen den kommunistischen Osten. Mit dieser mutigen Kehrtwende nahm er bewußt einen biographischen Bruch in Kauf, der nur auf den ersten Blick als Widerspruch erscheint. Tatsächlich war Münzenbergs Vorstellung vom Kommunismus nie gelebt worden, und die Hoffnung, dies nachzuholen, war mit dem August 1939 gründlich zerstört worden. Treffend beschrieb der Historiker Gilbert Badia die innere Zwangslage, der sich der emigrierte Verleger ausgesetzt gesehen haben muß: „Münzenberg semble bien de nouveau en 1939, avoir découvert les erreurs stratégiques d'un mouvement qui devaient entraîner, à terme, la mort de ce communisme pour lequel il s'était battu sa vie durant." 466

Durch die zunehmend konkreten Überlegungen anderer Exilgruppen und sicherlich auch die unverändert proeuropäischen Voten von Stampfer und Geyer ${ }^{467}$ sah sich der Parteivorstand der Sopade zu Beginn des Jahres 1940 veranlaßt, sich mit der politischen Rolle Europas in der Welt nach Kriegsende auseinanderzusetzen. Anstoß der parteitaktischen Wende war ein Referat des altgedienten Sozialdemokraten Rudolf Hilferding ,über die Frage der Kriegsziele und über das Problem der Vereinigten Staaten von Europa" 468 . Aufbauend auf einer vorab in der Weihnachtsausgabe des Neuen Vorwärts

worden; vgl. ANF, F7 15129, M. 2. Zu Münzenbergs Korrespondenz mit Palewski siehe Peterson, „Dieselben Debatten wie zu Hause" ? 1988, S. 901.

465 BADIA, De l'orthodoxie à la rébellion. Esquisse du parcours politique de Willi Münzenberg, in: Bibiothèque Méjanes/Institut de l'Image (Hg.), Willi Münzenberg (18891940). Un Homme Contre 1993, S. 23-32.

466 Ibid. S. 30.

467 Vgl. C. G[EYER], Kein Hitlerfrieden. Der Krieg für Frieden und Freiheit in Europa, in: NV, Nr. 330 (15. 10. 1939), S. 1 f. sowie F. ST[AMPFER], Die Internationale und der Krieg. Einigkeit und Verwirrung, ibid.

468 Hilferding, Anmerkungen des Genossen Dr. Rudolf Hilferding über die Frage der Kriegsziele und über das Problem der Vereinigten Staaten von Europa (Vorstandssitzung vom 29. 1. 1940), AsD, Bestand PV-Emigration Sopade, M. 3. Das Dokument, das bei VOIGT (Hg.), Friedenssicherung 1988, S. 50-55 abgedruckt ist, wird in der Literatur häufig überbewertet. So kann keine Rede davon sein, daß Hilferdings Referat einen den Europadiskurs des gesamten sozialistischen Exils betreffenden Einschnitt markiere, wie die Darstellung bei VoIGT (Hg.), Friedenssicherung 1988, S. 34f. nahezulegen scheint. Zwar ist dies ein Dokument von zentraler Bedeutung für die Parteigeschichte der Sopade; im Hinblick auf den gesamten Europadiskurs des Exils aber liegt seine Bedeutung nicht in dem europavisionären Gehalt, sondern in der realistischen Skizzierung der internationalen Nachkriegsverhältnisse: Hilferding erkannte früh die spätere Konstellation des Kalten Krieges mit all ihren außenpolitischen Implikationen. Darüber hinaus zeichnet sein Referat eine ebenso realistische Einschätzung der politischen Bedeutung des Exils aus. Der bloße Hinweis auf das andere, bessere Deutschland könne nicht als ernst zu nehmende Friedensgarantie betrachtet werden; ibid. S. 7. 
veröffentlichten Skizze ${ }^{469}$ trug Hilferding eine aktualisierte Fassung seines schon vor 1933 formulierten Ansatzes vor ${ }^{470}$. So erneuerte er sein Plädoyer für eine enge Zusammenarbeit mit den Westmächten und sprach sich langfristig für eine Resurrektion des Völkerbundes aus. Hilferding brachte ein hohes $\mathrm{Maß}$ an fatalistischem Realismus - nicht aber Resignation ${ }^{471}$ - auf, wenn er davon ausging, daß eine solche europäische Neuordnung ohnehin nicht unter Einbindung der Emigranten - auch nicht der exilierten Sozialdemokraten -, sondern allein von den Siegern des Krieges vorgenommen werde. Da Rußland sich aber spätestens mit dem Abschluß des Hitler-Stalin-Paktes als "barbarische Großmacht" offenbart habe, sei der Sieg der Westmächte die zentrale Vorbedingung einer europäischen Neuordnung.

In der wichtigen Frage der Behandlung Rußlands als europäischem Machtfaktor begnügte sich Hilferding mit der Feststellung, daß hierzu zweierlei Auffassungen vertreten würden: „Die einen [befürworten] eine Politik, die es vermeidet, Stalin noch mehr an die Seite Hitlers zu drängen, während die anderen, von der Unvermeidlichkeit des Zusammenschlusses überzeugt, Rußland als offenen Gegner anzusehen bereit sind. " 472 Für die Teilnahme an einer grundsätzlich erstrebenswerten europäischen Föderation habe sich die Sowjetunion jedenfalls endgültig diskreditiert ${ }^{473}$. Statt dessen betonte Hilferding die Notwendigkeit einer Teilnahme Englands als kriegführender Westmacht an einer späteren Föderation, obwohl dessen Interessen überwiegend außereuropäischer Natur seien. Hilferdings Referat zeichnet sich also weniger durch eine große europäische Vision als vielmehr durch einen realpolitischen Scharfsinn aus, der den Referenten schon Anfang 1940 die Konstellation des Kalten Krieges vorhersehen ließ: „In erster Linie wird [...] am Ende des Krieges die Regelung bestimmter Machtfragen stehen. [...] Der Frieden kann nur garantiert werden, wenn eine überlegene Macht auf der Seite vorhanden ist, die den Willen zum Frieden hat. [...] Die Stärke der Westmächte wird notwendig sein gegenüber den Drohungen, die auch nach dem Krieg in Europa bestehen bleiben und gegenüber der Entwicklung in dem Fernen Osten." 474

469 KERN [d. i. Hilferding], Zwischenakt in Genf, in: NV, Nr. 340 (24. 12. 1939), S. 1-2. ${ }^{470}$ Hilferding, Anmerkungen des Genossen Dr. Rudolf Hilferding, 29. 1. 1940, S. 1, AsD, Bestand PV-Emigration Sopade, M. 3 sowie KERN [d. i. Hilferding], Zwischenakt in Genf, in: NV, Nr. 340 (24. 12. 1939), S. 1.

${ }^{471}$ So die nicht weiter begründete Hypothese VoIGTS (Hg.), Friedenssicherung 1988, S. 35.

472 KERN [d. i. Hilferding], Zwischenakt in Genf, in: NV, Nr. 340 (24. 12. 1939), S. 2.

473 Hilferding, Anmerkungen des Genossen Dr. Rudolf Hilferding, 29. 1. 1940, S. 3, AsD, Bestand PV-Emigration Sopade, M. 3. LADEMACHER, Voraussetzungen und Probleme 1977, S. 377 weist darauf hin, daß der bisher latente Antikommunismus in weiten Teilen der deutschen Sozialdemokratie mit dem Hitler-Stalin-Pakt zum Durchbruch gelangte und "mit leichter Hand" eine Ost-Westpolarisierung vollzogen wurde, die auch europapolitische Auswirkungen zeitigte.

474 Ibid. S. 4 f. 
Hilferding erkannte in einer klaren Westorientierung die einzige realpolitisch sinnvolle Reaktion Europas auf die zu erwartende Machtkonstellation nach Kriegsende ${ }^{475}$. Dies ergibt sich zunächst aus seinem Bekenntnis zum europäischen Wertekatalog, dessen Repräsentanten er unzweifelhaft in den Westmächten $\mathrm{sah}^{476}$. Darüber hinaus ging er davon aus, daß die Westmächte als Sieger dann auch die europäische Neuordnung vornehmen würden ${ }^{477}$. Wenngleich Hilferding eine - durchaus wünschenswerte - britisch-französische Kooperation nicht für realistisch hielt, betrachtete er doch die Westmächte, namentlich Großbritannien und die USA, als die bestimmenden Faktoren eines neuen Völkerbundes und damit auch einer europäischen Neuordnung ${ }^{478}$.

An der Seite Hilferdings focht Eugen Brehm für eine dauerhafte Ausrichtung an den westlichen Demokratien. Die realpolitischen Mächteverhältnisse diktierten eine nach Kriegsende beizubehaltende Zwecksolidarisierung mit den Westmächten, denn: „Wir haben heute nur die Wahl, entweder impotent beiseite zu stehen, um nachher auch bei der Neugestaltung Europas nicht mitreden zu können, oder Herz und Waffen in die Wagschale jener Mächte zu werfen, die den Barbarismus bekriegen. “479

Dieses Ansinnen entsprach dem Grundverständnis des linken Katholizismus, dessen Weltbild im deutschen Exil von Hubertus Prinz zu Löwenstein und Werner Thormann aufrechterhalten wurde. Löwenstein und Thormann verfochten nach dem Abschluß des Hitler-Stalin-Paktes, den auch sie als „Katastrophe“ empfanden, eine europäische Föderation auf der Basis der sozialistisch-demokratischen Bewegung, wie sie die Weimarer Koalition aus Sozialdemokraten, Zentrum und Deutschen Demokraten repräsentiert habe ${ }^{480}$. Werner Thormann erblickte darin die europäische Aufgabe

475 Im Ergebnis übereinstimmend BEHRING, Demokratische Außenpolitik 1999, S. 483. Die klare Westorientierung ergibt sich darüber hinaus aus Geyers wiederholter Parole von der „europäischen Demokratie“ als auch aus Stampfers dezidiert prowestlichem Plädoyer.

476 Hilferding, Anmerkungen des Genossen Dr. Rudolf Hilferding, 29. 1. 1940, S. 1, AsD, Bestand PV-Emigration Sopade, M. 3: „Es geht dieses Mal nicht in erster Linie um wirtschaftliche Gegensätze, es geht auch nicht um territoriale Fragen. Im Mittelpunkt dieser Auseinandersetzung steht praktisch der Kampf um all das, was seit der Zeit der Renaissance zum Kulturbesitz der Menschheit geworden ist. Daher ist das allererste und wichtigste Kriegsziel der Sieg der Westmächte. Die Erreichung dieses Ziels ist noch um so wichtiger geworden, nachdem auch die andere barbarische Großmacht, Rußland, auf die Gegenseite getreten ist. "

477 Ibid.: "Teilt man diese [Hilferdings] Vorstellungen, dann muß man den Sieg der Westmächte als das primäre Kriegsziel betrachten und man kann dann über alle anderen Fragen, wie Neuordnung in Europa, Vereinigte Staaten von Europa usw. in Ruhe diskutieren."

478 Ibid. S. 4.

479 Ibid. S. 931.

480 LÖWENSTEIN, Europas kommender Friede, in: Die Zukunft, II. Jg., Nr. 36 (6. 9. 1939), S. 3: „Den Kräften des demokratischen Sozialismus wird schon jetzt große Bedeutung zufallen, denn seine Haltung, sein Evolutionsprogramm und seine gesunde 
schlechthin, denn es gehe um die Erhaltung der abendländischen Kulturtradition, die es vor Stalinismus und extremem Nationalismus gleichermaßen zu schützen gelte ${ }^{481}$. Zugleich handle es sich um eine vordringliche Aufgabe des deutschen Exils, denn: „Der abendländische Geist, der auf deutschem Boden die Leistungen hervorbrachte, auf denen die Rechtstitel des ,anderen Deutschland 'beruhen, wird aus dem inneren Exil in die Seele des deutschen Volkes hineinzutragen sein. " 482 Den abendländischen Geist aufrechterhalten hieß auch, das Abendland über die kulturellen Gemeinsamkeiten hinaus zu einer moralischen und politischen Einheit zu formen, die der „Entchristlichung des Völkerlebens" ein Ende bereiten müsse ${ }^{483}$. Mit den Westmächten wußten sie sich sowohl in der kurzfristig militärischen als auch in der langfristig ideologischen Zielsetzung einig, denn diese würden weder die Wiedererrichtung eines nationalistischen Deutschlands zulassen noch eine Bolschewisierung Mitteleuropas ${ }^{484}$.

\subsubsection{Profilschärfung in der Föderalismusdebatte}

Von nun an stand weniger das Warum einer europäischen Einigung im Vordergrund als vielmehr das Wie. Da nicht nur hinsichtlich der Motivationen für ein vereinigtes Europa, sondern nun auch in der Ablehnung einer europäischen Ostorientierung weitgehende Einigkeit zwischen den Exilgruppen herrschte, bot die Frage der Institutionalisierung, insbesondere die politische Evaluation der nationalen Souveränität, eine willkommene Plattform für die Schärfung des eigenen Europaprofils ${ }^{485}$. Hier war das nach dem Hitler-Stalin-Pakt letzte verbleibende Konzeptionsfeld, auf dem man die eigene Europakonzeption präzisierend von anderen Konzeptionen abgrenzen und sich als überlegener Europavisionär, teilweise auch als geeigneter Außenpolitiker des künftigen Deutschland empfehlen konnte.

Einschränkung der Souveränität Trotz des desolaten Zustandes der SAP waren es gerade zwei Mitglieder dieser ihres dogmatischen Fundamentes beraubten Partei, die mit deren europapolitischer Enthaltsamkeit brachen und sich mit auffallend konstruktiven Beiträgen in die Föderalismusdebatte einbrachten. Der junge Journalist Willy Brandt war nach Norwegen geflohen und gehörte dort einem kleinen Zirkel engagierter norwegischer und deut-

Mischung von Weltbürgertum und nationaler Verantwortung, werden dem kommenden Deutschland wohl zu dienen vermögen."

$481 \mathrm{Vgl}$. ThORMANN, Eine europäische Aufgabe. Demokratie und Sozialismus müssen neugedacht werden, in: Die Zukunft, III. Jg., Nr. 18 (3. 5. 1940), S. 1.

482 Ibid.

${ }^{483}$ LÖWENSTEIN, Europas kommender Friede, in: Die Zukunft, II. Jg., Nr. 36 (6. 9. 1939), S. 3.

484 ThormanN, Um den Frieden Europas, in: Die Zukunft, II. Jg., Nr. 42 (20. 10. 1939), S. 3.

485 Zur Föderalismusdebatte im Exil vgl. die vorzügliche Analyse von BECKER, Verfassungspläne 2001. 
scher Sozialisten an, bis er Ende April 1940 vor der Wehrmacht flüchten mußte und später die illegale Widerstandstätigkeit in Schweden fortsetzte. Der vier Jahre ältere Eugen Brehm, der schon 1938 einen bis ins Detail ausgearbeiteten europäischen Aufgabenkatalog entworfen hatte, führte seinen individualistischen Kurs fort und sah sich durch die Ereignisse vom August und September 1939 auf dem richtigen Weg.

Brehm begann zu dieser Zeit, sich von der letzten SAP-Position zu verabschieden: dem Prinzip des Internationalismus als außenpolitischer Pfeiler des sozialistischen Ideologiegebäudes. Kurz nach seiner Wahl in den Vorstand der Volkssozialistischen Bewegung sagte er sich los von „der betonten Beziehungslosigkeit zur Nation, dem gekünstelten Internationalismus, der Traditionslosigkeit und dem Materialismus, aus denen schließlich der kulturelle Nihilismus mit allen seinen Begleiterscheinungen erwuchs" ${ }^{486}$. Vorzuziehen sei eine freie Föderation der Staaten Europas, deren Aufgabe gerade die Bewahrung der nationalen Selbständigkeit ihrer Mitglieder und der Schutz der abendländischen Werte sein müsse ${ }^{487}$. Als Beratungsorgan regte der volkssozialistische Pazifist und SAPler ein Europäisches Forum an, das durch ein internationales Schiedsgericht unterstützt werden sollte ${ }^{488}$. Offen ließ Brehm, ob das Europäische Forum aus Vertretern der Mitgliedstaaten oder aus eigens gewählten Volksvertretern zusammenzusetzen sei.

Mit seinem 1940 auf norwegisch erschienenen Buch „Stormaktenes krigsmål og det nye Europa“ legte Brandt ein europapolitisches Dokument ersten Ranges vor, das hinsichtlich der Klarheit des föderalen Bekenntnisses und der logischen Schärfe bis ins Detail mit Brehms „Bemerkungen zur Außenpolitik“" vergleichbar ist. Brandt zeigte auf, daß es nur durch eine föderale Lösung der europäischen Frage möglich sei, größere soziale und wirtschaftliche Freiheit zu gewährleisten. Er pflichtete Eichler bei, daß einem europäischen Machtblock unbedingt die aggressiv-bellizistische Spitze gegen andere kontinentale Zusammenschlüsse genommen werden müsse $\mathrm{e}^{489}$. In aller Deutlichkeit nannte der junge Emigrant die entscheidende Weichenstellung beim $\mathrm{Na}$ men: „Die Europäer stehen vor der Wahl zwischen einer neuen imperialistischen Machtlösung und einer demokratischen, föderativen Neuordnung. " 490

Eingehender als Brehm beschäftigte sich Brandt mit dem Gedanken des internationalen Rechts, der entscheidend gestärkt und zur Grundlage jedes internationalen Zusammenschlusses erhoben werden müsse. Im Augenblick jedoch stehe das Völkerrecht in der Gefahr, von der europäischen Wirklichkeit des Nationalsozialismus überrollt zu werden.

486 [BREHM], Thesen der Deutschen Volkssozialisten, in: Volkssozialistische Blätter, Nr. 1 (November 1939), 7. These, S. 14.

487 Ibid. S. $15 \mathrm{ff}$. (17).

488 Ibid.

489 BRANDT, Stormaktenes krigsmål, abgedruckt in: VoIGT ( $\mathrm{Hg}$.$) , Friedenssicherung$ 1988, S. 56-70 (56f.).

490 Ibid. S. 57. 
In realistischer Einschätzung von Mensch und Staat wandte Brandt gegen die auf ein neues Völkerrecht fokussierten Bestrebungen des ISK ein, daß allein der Respekt vor internationalen Normen nicht ausreiche, um den Frieden dauerhaft zu sichern. Vielmehr sei internationale Politik gleichbedeutend mit dem Zusammenspiel verschiedener Gesellschaften, so daß einer Neuordnung Europas denknotwendig die gesellschaftliche Befreiung von der Profitgier einzelner voranzugehen habe ${ }^{491}$. Erst in einem zweiten, unerläßlichen Schritt müsse statt allgemeiner völkerrechtlicher Prinzipien vorzugsweise ein Grundgesetz der Vereinigten Staaten von Europa verabschiedet werden. Wichtigste Funktion eines solchen Grundgesetzes müsse sein, den Bürgern unabhängig von Sprache, Rasse oder Glaubensbekenntnis gemeinsame Grundrechte zu geben, die allgemeinverbindlich und einklagbar zu gestalten seien ${ }^{492}$ - denn „noch schlimmer als Verstöße gegen das Gesetz ist das Fehlen eines Gesetzes" 493 .

Eng verbunden mit dem Aspekt der Weiterentwicklung des Völkerrechts war die fortgesetzte Auseinandersetzung um den Stellenwert der nationalen Souveränität. Eichler begann, die alte Forderung des ISK nach einer Beschränkung der nationalen Souveränität zugunsten eines übernationalen Europas schärfer gegen andere Europakonzepte des Exils abzugrenzen. Im Januar 1940 kritisierte er die stereotyp wiederholte Parole OttoStrassers für nationale Freiheit, soziale Gerechtigkeit und europäische Zusammenarbeit als oberflächlich und wenig aussagekräftig. Sarkastisch bemerkte der umtriebige Leiter des ISK, solch ein proeuropäisches Bekenntnis sei „an sich erstaunlich im Munde von Nationalisten, denen das ,Völkische' eine Idee ist“", zumal der Grundgedanke der Solidarität der weißen Rasse einen bellizistischen Nukleus in sich trage ${ }^{494}$. Er wiederholte die vehement verfochtene These, daß ein vereinigtes Europa sinnvoll nur durch einen weitreichenden Souveränitätsverzicht der Mitgliedstaaten erreicht werden könne, da der Aberglaube an die Souveränität jedes wirkliche Völkerrecht unmöglich mache ${ }^{495}$.

Demgegenüber mahnte Hilferding einen zwar kritisch-distanzierten, aber für die kulturelle Autonomie von Minderheiten durchaus sinnvollen Rückgriff auf das Selbstbestimmungsrecht an. Da es jedoch für die politische Ordnung des Kontinents nur bedingt geeignet sei, eine den Frieden garantierende Lösung zu finden, solle man "nicht allzu viel“ mit dem Selbstbestimmungsrecht der Völker arbeiten ${ }^{496}$. Brandt wurde konkreter: Eine Einschränkung

491 Ibid. S. 65.

492 Ibid. S. 67.

493 Ibid. S. 62.

${ }^{494}$ Hart [d. i. Eichler], Zehn Thesen der deutschen Opposition, in: SW, 15. Jg., H. 1 (4. 1. 1940), S. 1-5 (4).

495 HART [d. i. Eichler], Europa als Aufgabe, in: SW, 14. Jg., H. 42 (23. 11. 1939), S. 985988 (987).

496 Hilferding, Anmerkungen des Genossen Dr. Rudolf Hilferding, 29. 1. 1940, S. 7, AsD, Bestand PV-Emigration Sopade, M. 3. 
der nationalen Souveränität sei notwendig, dürfe aber zur völligen Aufhebung der nationalen Unabhängigkeit führen ${ }^{497}$. Im Umkehrschluß folgt daraus die Erkenntnis, der sich Brandt keineswegs verschloß, daß eine Einschränkung (nicht Aufhebung) des Selbstbestimmungsrechts denknotwendig auch eine Einschränkung der nationalen Souveränität bedingt. Es ist Brandts Verdienst, auf die Vereinbarkeit des Selbstbestimmungsrechts mit dem Föderationsgedanken aufmerksam gemacht zu haben. Als integraler Bestandteil einer föderativen Rechtsordnung habe das notwendig relativierte Selbstbestimmungsrecht die Aufgabe, die Bevölkerung der einzelnen Staaten sowohl über den Beitritt als auch über einen möglichen Austritt aus der Völkergemeinschaft entscheiden zu lassen ${ }^{498}$. Innerhalb der Föderation werde ein ständiger Ausgleich zwischen der nationalen Unabhängigkeit und den Interessen der Gesamtorganisation erforderlich sein, als dessen effektives Werkzeug der Verfasser das Subsidiaritätsprinzip andeutete: „Dann wird bei Angelegenheiten, die von entscheidender Bedeutung für den Nutzen der Allgemeinheit sind, die nationale Souveränität kein unüberwindliches Hindernis mehr sein. “499

(Kon)Föderale Binnenstruktur Nach der grundsätzlichen Erörterung einer völkerrechtlich legitimierten Einschränkung des Souveränitätsprinzips galt es, die Ausgestaltung der europäischen Binnenstruktur zu konkretisieren und den Umfang der föderativen Integration zu bestimmen. Angesichts eines inflationären Gebrauchs des Föderationsbegriffs für bundesstaatliche, konföderale sowie bloß multilaterale Europakonzeptionen warnte Willy Brandt in Oslo vor einer "imperialistischen Verdrehung des Föderativgedankens“ und einer drohenden Beliebigkeit der Begriffe: „Inzwischen besteht die Gefahr, daß die ganze föderative Idee kompromittiert wird. Sie ist dabei, zu einer Zauberformel zu werden, zu einem neuen Schlagwort, dem jeder den Inhalt gibt, der ihm am besten paßt, abgesehen davon, daß viele etwas anderes sagen, als sie eigentlich meinen." 500

Tatsächlich wurde für die europäische Binnenstruktur oft ein Staatenbund mit zukünftigem Integrationspotential bevorzugt; die sofortige Errichtung eines Bundesstaates im Sinne einer Föderation mit einer starken Zentralgewalt konnten sich bei weitem nicht alle Beteiligten vorstellen. Im Grundsatz aber sah man im Föderalismus das einzig erfolgversprechende Ordnungsprinzip zur Lösung der europäischen Frage. Dies galt um so mehr für die Minderheitenprobleme und Nationalitätenkonflikte, die insbesondere in

497 Vgl. BRANDT, Stormaktenes krigsmål, abgedruckt in: VOIGT (Hg.), Friedenssicherung 1988 , S. 56-70 (63).

498 Ibid. S. 66. Brandt sprach sich zugleich gegen das Prinzip der unbedingten Neutralität aus, das sich „schwerlich mit den Erfordernissen der europäischen und internationalen Gemeinschaft vereinen" lasse; ibid. S. 63.

499 Ibid. S. 68.

500 Ibid. S. $56 \mathrm{f}$. 
Ost- und Südosteuropa einer Antwort harrten. Daher beurteilten viele Diskursteilnehmer eine Balkanföderation sowie eine ost- und mitteleuropäische Föderation als vordringliche Aufgabe zur föderativen Befriedung einer von ethnischen Auseinandersetzungen zerrissenen Region ${ }^{501}$. Es liege gerade im Interesse Deutschlands, sein Verhältnis zu den östlichen Nachbarn innerhalb einer mitteleuropäischen Teilföderation zu lösen, um auf diese Weise zugleich die vielfältigen ethnischen Gegensätze in einem größeren Rahmen aufzuheben ${ }^{502}$. Voraussetzung sei jedoch die vorherige Überwindung des deutschen Imperialismus und die Verhinderung einer erneuten deutschen Hegemonie, insbesondere in wirtschaftlicher Hinsicht.

Zwar konnte man sich auf eine weitreichende Wirtschaftsunion einigen, doch schon die in einigen Europakonzepten vorgesehene Währungsunion stieß auf nur verhaltene Zustimmung. Statt dessen wurde ein Währungsleitsystem mit festen Wechselkursen und einem einheitlichen Goldstandard angeboten. Auch über die Erforderlichkeit einer bundeseinheitlichen Außenpolitik wurde kontrovers diskutiert.

Die Auslandsleitung der SAP mußte erkennen, daß der zuletzt praktizierte bequeme Verweis auf die föderative Ordnung der Sowjetunion als Vorbild für ein föderiertes Europa nun endgültig seine Überzeugungskraft eingebüßt hatte ${ }^{503}$. Daher mußte ein eigenes Konzept entwickelt werden, das sich am Ende der internen Debatte als Konföderationsmodell darstellte. Mit Blick auf die Abgrenzungsschwierigkeiten zu anderen Konzepten einer europäischen Föderation, die „in Worten sogar von Chamberlain und anderen kapitalistischen Staatsmännern genannt wird" ${ }^{504}$, erhob die SAP die sozialistische Ausrichtung ihres Entwurfes zum wesentlichen Unterscheidungsmerkmal: Es sei klar, daß eine solche Föderation „nur unter sozialistischer Ordnung endgültig durchführbar und lebensfähig sein kann"505. War die föderal-sozialistische Position für Neu Beginnen und ISK in den langen Jahren der Emigration zur Selbstverständlichkeit gewachsen ${ }^{506}$, mußte sich die SAP, die den

501 Mit der ost- und/oder mitteleuropäischen Föderation wurde in der Regel an die alte Idee der mitteleuropäischen Donauföderation angeknüpft, die mit Stern-Rubarths „Western Slav Federation“ gleichzusetzen ist; vgl. z.B. das einflußreiche Gemeinschaftswerk von Neu Beginnen, SAP und RSÖ: HAGEN [d. i. Frank] et al., Der kommende Weltkrieg 1939, S. 29 ff.; des weiteren: Hilferding, Anmerkungen des Genossen Dr. Rudolf Hilferding, 29. 1. 1940, S. 7, AsD, Bestand PV-Emigration Sopade, M. 3; Stern-RubarTh, Exit Prussia 1940, S. 145-152.

$502 \mathrm{Vgl}$. BRANDT, Stormaktenes krigsmål, abgedruckt in: VOIGT (Hg.), Friedenssicherung 1988, S. 56-70 (60).

503 Noch in der gemeinsam mit Neu Beginnen und RSÖ herausgegebenen Broschüre: Der kommende Weltkrieg 1939 (insb. S. 33) wurde die Sowjetunion als Musterföderation gepriesen.

504 [Auslandsvertretung der SAP], Unsere Stellung zum jetzigen Krieg, Dezember 1939, S. 9, IfZ, Slg. W. Röder, ED 200/2.

505 Ibid.

506 Als zeitlich vergleichbares Dokument sei das Bekenntnis von Neu Beginnen zur ge- 
Europadiskurs mit Ausnahme von Brehm bisher stets ignoriert hatte, dem föderalen Gedanken erst allmählich nähern.

Sehr weitgehende, nahezu radikal anmutende Binnenföderationspläne wurden insbesondere von Grossmann, Löwenstein und Arnold Brecht präsentiert. Unter dem unmittelbaren Eindruck des Kriegsausbruchs hatte der Pazifist und Sozialdemokrat Kurt Grossmann in den USA beschlossen, auf eigene Faust eine partei- und gruppenübergreifende Interessenvertretung des deutschen Exils zu organisieren, der er den umständlichen, aber programmatischen Namen „Komitee für einen gerechten Frieden, ein demokratisches Deutschland und ein föderatives Europa " gab ${ }^{507}$. Ein Rundschreiben, das er mit Datum vom 6. November 1939 an die Sozialdemokraten Hertz, Aufhäuser, Tillich, Sollmann und Seger ebenso wie an die Linkskatholiken Hubertus Prinz zu Löwenstein und Carl Spiecker sowie namhafte Intellektuelle wie Thomas Mann und Albert Einstein verschickte, wurde nur mäßige Resonanz entgegengebracht ${ }^{508}$. Dennoch erlebte das Grossmann-Komitee neben der Initiierungsphase eine kurze aktive Phase, während der in nicht weniger als fünf Sub-Komitees engagierte Debatten um ein europäisches Zukunftsprogramm geführt wurden. Schon im Herbst 1940 aber schliefen die Aktivitäten ein, bis schließlich die Zusammenarbeit der Gründer wegen interner Zerwürfnisse im März 1941 ein Ende fand ${ }^{509}$. Nach April 1940 ist lediglich ein weiteres Dokument des Komitees aus dem Herbst desselben Jahres überliefert.

Zunächst aber gelang es Grossmann unter erheblichem persönlichen Engagement, am 5. Januar 1940 die erste Sitzung des „Komitees für einen gerechten Frieden, ein demokratisches Deutschland und ein föderatives Europa“ einzuberufen. Der Name war Programm: Man wollte Vorschläge

samteuropäischen Föderation genannt: Zur Diskussion über die Kriegsziele, in: SIB, Nr. 48 (Oktober 1939), S. 9-13 (12 f.).

507 Dem von Grossmann initiierten Komitee für einen gerechten Frieden, ein demokratisches Deutschland und ein föderatives Europa hat die Forschung bislang kaum Beachtung beschenkt. Trotz seiner kurzen und im Ergebnis fruchtlosen Arbeitsphase enthält der Nachlaß Grossmann im Münchener Institut für Zeitgeschichte doch einige bemerkenswerte Dokumente zur Geschichte des politischen Exils, insbesondere zum Europadiskurs im Exil.

$508 \mathrm{Vgl}$. Grossmanns maschinengeschriebenen Verteiler mit handschriftlichen Randbemerkungen über die jeweilige Reaktion des Adressaten; IfZ, ED 201/1, NL Grossmann. Bemerkenswert ist die höflich-reservierte, möglicherweise sarkastisch intendierte Antwort Albert Einsteins an Grossmann vom 6. 12. 1939, IfZ, NL Grossmann, ED 201/1: „Sehr geehrter Herr Grossmann, ich muß die Schaffung der politischen Formen der Zukunft vertrauensvoll Ihnen und Ihren Freunden überlassen, da es mir auf dem Gebiete der Menschen-Beeinflussung - soll ich sagen Gott sei Dank? - an jeglicher Erfahrung fehlt. Freundlich grüßt Sie, Ihr A. Einstein.“

509 Die internen Auseinandersetzungen hatten sich an dem von Gregory Feige (Catholic Association, Washington, D. C.) gegenüber Grossmann geäußerten Plagiatsvorwurf entzündet und gipfelten in einem mit persönlicher Kritik gespickten Brief vom 21. 3. 1941. Dies stellt zugleich das letzte Dokument zur Geschichte des Grossmann-Komitees dar. 
entwickeln für eine möglichst umfassende Regelung der europäischen Nachkriegsordnung und der künftigen Rolle Deutschlands. Als Fernziel hatte Grossmann einen Zusammenschluß europäischer Emigranten unterschiedlicher Nationalitäten hinter dem Banner einer gemeinsamen Europavorstellung vorgegeben 510 .

Maßgebliche Orientierung verlieh den Diskussionen des Grossmann-Komitees ein Thesenpapier, das Grossmann selbst noch im Dezember 1939 erstellt hatte und das von dem Ko-Initiator Erwin Kraft um die ökonomischen Aspekte ergänzt worden war ${ }^{511}$. Grossmann trat für eine möglichst weitgehende Einschränkung der nationalen Souveränität ein und favorisierte eine starke europäische Föderation: „Die Mitgliedstaaten übertragen der Europäischen Föderation ihre juristische Souveränität in allen Fragen, die die Föderation direkt oder indirekt angehen." 512 Damit hatte auch Grossmann das der katholischen Sozialphilosophie entstammende Subsidiaritätsprinzip umschrieben, demzufolge die Zuständigkeit der nächsthöheren Handlungsebene nur dann begründet ist, wenn ein Eingreifen der unteren Handlungsebene unmöglich oder zumindest unzweckmäßig wäre. Erwin Kraft wurde noch deutlicher: „The ultimate goal of the Federation should be a form of super-national government in which will be vested most of the functions which are now being exercised by the separate national governments. ${ }^{\text {" }} 513$

Wenngleich der Zeitplan für die Kompetenzenübertragung in der Sitzung des Federation Sub-Committees am 8. Februar 1940 kontrovers diskutiert wurde ${ }^{514}$, hat doch kaum eine andere Gruppe des deutschen Exils zu diesem relativ frühen Zeitpunkt des Europadiskurses solch ein unzweideutiges Bekenntnis zur supranationalen Struktur und zur weitestgehenden Aufhebung der nationalen Souveränität abgegeben. Vielmehr waren viele Emigranten ge-

510 Vgl. [Grossmann], Thesen zur Kriegszieldiskussion am 5. 1. 1940, IfZ, NL Grossmann, ED 201/1.

511 Vgl. [Grossmann], Europäische Föderation, o. D. [November/Dezember 1939], IfZ, NL Grossmann, ED 201/1 sowie Erwin Kraft, Some thoughts on a scheme for a federated Europe, Januar 1940, IfZ, NL Grossmann, ED 201/1. Zur Datierung: Da Grossmann am 6.11.1939 mit der Organisation des Komitees begann und Krafts ergänzender Entwurf vom Januar 1940 datiert, muß Grossmanns Thesenpapier im November oder Dezember 1939 erarbeitet worden sein. Die vom Komitee letztlich verabschiedete Version vom Herbst 1940 wich kaum von den Vorschlägen Grossmanns und Krafts ab; vgl. GrossmaNN et al., European Federation. Essay agreed upon by a group of Anti-Nazi German-Americans during the Fall of 1940, Herbst 1940, IfZ, NL Grossmann, ED 201/1. Dieses Dokument wurde am 20.3. 1941 verschickt. Wie sich aus einem Schreiben Grossmanns an die Catholic Association for International Peace in Washington, D. C. vom 27. 7. 1942 ergibt, wurde diese endgültige Fassung von Veit Valentin, Paul Tillich, Gregory Feige, Erwin Kraft u. Kurt R. Grossmann selbst angefertigt, so daß die nahezu unveränderte Übernahme der beiden Entwürfe nicht verwundert.

512 Ibid. S. 3.

$513 \mathrm{Kraft}$, Some thoughts on an scheme for a federated Europe, Januar 1940, S. 1, IfZ, NL Grossmann, ED 201/1.

$514 \mathrm{Vgl}$. Minutes of the Federation Sub-Committee Meeting, February 8, 1940, IfZ, NL Grossmann, ED 201/1. 
genüber einer allzu forschen Integration aus Rücksicht auf die spezifisch deutschen Interessen skeptisch, insbesondere wollte man sich die Festlegung der deutschen Grenzen für die späteren Friedensverhandlungen offenhalten. Man scheute sich, ohne Not die diesbezüglichen Einflußmöglichkeiten aus der Hand zu geben.

Nach Grossmanns Ansicht sollte die föderative Exekutivgewalt vor allem auf ihrer militärischen Überlegenheit gegenüber den Mitgliedstaaten beruhen $^{515}$. Faktisch lief Grossmanns Ansatz auf eine völlige militärische Entmachtung der Nationalstaaten hinaus. Neben der Ausgestaltung der militärischen Binnenstruktur beschäftigte sich Grossmann mit dem Problem der europäischen Minderheiten, für die er einklagbare Rechtspositionen wie uneingeschränkte Kulturautonomie, Wiedergutmachung und Einbürgerung der Staatenlosen verlangte ${ }^{516}$.

Grossmanns umfassender Föderalismus stieß bei linkskatholischen Föderalisten wie Löwenstein auf lebhafte Unterstützung. In einer Rede vor dem International Relations Club in San Diego, Kalifornien, skizzierte Löwenstein einen Europäischen Bund, der auf den staatsrechtlichen Prinzipien der Demokratie, des Rechtsstaates und des Bundesstaates fußte und die moralische Weltordnung des Christentums anzuerkennen habe ${ }^{517}$. Nicht die Souveränität der Mitgliedstaaten, sondern die Souveränität der Mitgliedsvölker gelte es zu bewahren, um ihnen "unter der Herrschaft des Bundesprinzips“ ein kulturelles Eigenleben zu ermöglichen ${ }^{518}$. In allen wesentlichen politischen Bereichen wollte der ehemalige Leiter katholischer Jugendorganisationen dem Bund eine eigene Kompetenz einräumen. Unklar blieb jedoch, ob er die Bundeskompetenz als ausschließliche, konkurrierende oder parallele Kompetenz neben denjenigen der Mitgliedstaaten verstand. Nur für den Bereich der Außenpolitik erachtete Löwenstein ausdrücklich eine konkurrierende Kompetenzregelung für zweckmäßig519. Die Einrichtung von Bundesministerien schlug er namentlich für die Bereiche Außenpolitik, Verteidigung, Finanzen, Justiz, Handel, Arbeit, Wissenschaft und Unterricht vor ${ }^{520}$. Löwenstein verstand das föderale Bundesprinzip als funktionale und zugleich juristische Ordnung. Keinen Zweifel ließ er an der Ernsthaftigkeit seiner bundesstaatlichen Konzeption, die in juristischer Hinsicht durch den Grundsatz „Bundesrecht bricht Staatsrecht" untermauert werden müsse ${ }^{521}$.

515 [Grossmann], Europäische Föderation, o. D. [November/Dezember 1939], S. 1, IfZ, NL Grossmann, ED 201/1.

516 Ibid. S. 3.

517 Löwenstein, Die Zukunft Europas. Rede, gehalten am 3.11. 1939 vor dem „International Relations Club “ in San Diego, Kalifornien, ANF, F7 15126, M. 2. Der Hinweis auf die moralische Weltordnung des Christentums findet sich auf S. 8.

518 Ibid. S. 12.

519 Ibid. S. 15.

520 Ibid.

521 Ibid. 
In den wesentlichen Elementen stimmte Löwensteins Europabild mit den Gedanken des liberalen Politikprofessors Arnold Brecht überein, der ebenfalls in die USA emigriert war. So wollte auch Brecht eine Föderation im Sinne eines Bundesstaates, scheute sich jedoch vor einer Orientierung an dem weitgehenden amerikanischen Föderalismus, der in Ermangelung einer vergleichbaren Homogenität zwischen den europäischen Staaten nicht übertragen werden könne ${ }^{522}$. Insbesondere ein Verzicht Großbritanniens und Frankreichs auf die nationale Kompetenz in der Außen- und Sicherheitspolitik erschien dem ehemaligen Reichsministerialbeamten als unrealistisch. Andererseits müsse eine starke Bundesgewalt mit gewichtigen politischen $\mathrm{Zu}$ ständigkeiten geschaffen werden, die zur Sicherung ihrer Effizienz auf das Einstimmigkeitsprinzip zu verzichten habe. Brecht suchte daher nach "something in between the United States and the League models " 523 .

Das bürgerlich-konservative Exil tat sich häufig schwer mit einem klaren Bekenntnis zum Föderalismus. Oft erschöpften sich die europaföderalistischen Bekundungen in Lippenbekenntnissen, hinter denen sich tatsächlich konföderalistische Vorstellungen verbargen. Diese orientierten sich meist am Paneuropagedanken, den Coudenhove im Oktober 1939 aus seiner Außenseiterposition heraus dem Exil ins Gedächtnis zurückzurufen versuchte ${ }^{524}$. Wie der Sozialdemokrat Hilferding hofften auch viele bürgerliche Emigranten mitunter auf eine britisch-französische Kernsolidarität, insbesondere in wirtschaftlicher Hinsicht ${ }^{525}$.

Unter den konservativen Beiträgen zum Europadiskurs ist Edgar SternRubarths „Exit Prussia“ von herausragender Bedeutung. In seinem Anfang 1940 edierten Werk entwarf der Publizist einen genauen Plan zur Auslöschung Preußens, das er als Wurzel deutscher Fehlentwicklungen betrachtete. Herausragend ist Stern-Rubarths Buch deshalb, weil damit ein durchdachter Verfassungsentwurf für eine europäische Föderation vorlag, der zahlreiche Details wie Mehrheitsquoten und juristische Verfahrensfragen enthielt ${ }^{526}$. Stern-Rubarth, der sich regelmäßig in der Contemporary Review zu Wort meldete, äußerte sich zur Europafrage zwar relativ selten, aber pointiert. Eine dauerhafte Befriedung des europäischen Brandherdes versprach sich der langjährige Streiter für die deutsch-französische Versöhnung allein von der "creation of political entities sufficiently equivalent to each other to justify such an equal voting right in affairs concerning several or all of

522 Brecht, Political Basis of a durable peace, Rede vor dem International Institute of Cultural Relations des Wells College in Aurora, N. Y., 26. 4.1940 (Niederschrift vom 5. 10. 1940), S. 2, BAK, NL Brecht, N 1089, Bd. 111.

523 Ibid. S. 3.

524 Coudenhove-Kalergi, Europa von morgen, in: NTB, 7. Jg., H. 44 (28. 10. 1939), S. 1016-1020. Es handelt sich dabei um einen teilweise wörtlichen Auszug aus Coudenhoves Schrift Kommen die Vereinigten Staaten von Europa? 1938.

525 Das europäische Wirtschaftsproblem der Zukunft, in: Das Wahre Deutschland (April 1940), S. 8-12 (insb. S. 11).

526 Stern-Rubarth, Exit Prussia 1940. 
them"527. Um ein in diesem Sinne „well-balanced Europe“ zu gewährleisten, sollten den Großmächten Frankreich, Deutschland, Italien und Großbritannien innerhalb eines gesamteuropäischen Zusammenschlusses vier Regionalföderationen - eine Iberische, eine Westslawische, eine Oslo- und eine Balkanföderation - als gleichberechtigte Mitglieder gegenübergestellt wer$\operatorname{den}^{528}$. Nach Grossmanns Konzept dagegen waren nur Einzelstaaten mitgliedsfähig, nicht aber Föderationen. Die ursprünglich vorgesehene Bestimmung, die innerhalb der bestehenden Europaföderation einen Zusammenschluß mehrerer Mitglieder ermöglichte, hatte Grossmann in seinem Manuskript wieder gestrichen, um den Einigungsprozeß Gesamteuropas nicht durch Teilföderationen zu gefährden ${ }^{529}$.

Als ersten Schritt auf dem Weg zu einem europäischen Patriotismus betrachtete Stern-Rubarth die Einführung einer europäischen Staatsangehörigkeit, die zunächst den Soldaten der europäischen Bundesarmee zu verleihen sei ${ }^{530}$. Dies entsprach Stern-Rubarths Ansicht, daß der Patriotismus nicht starr an die Nation gebunden, sondern einem Prozeß stetiger Erweiterung unterworfen sei: "To those who are afraid of having their patriotic loyalty infringed by such new and larger entities, let it be said that patriotism never was, or is, confined [Hervorhebung im Original, B. S.] to a limited geographical unit. Our loyalty, our love for the community to which we belong has widened with the times. From the tribe, the town, the duchy, it has expanded to the nation, the empire; and there is no earthly reason why it should stop there. " 531

Im Rückgriff auf Weimarer Diskussionsansätze erwiesen sich die Konzeptionen einer europäischen Wirtschaftsunion als verhältnismäßig konvergent. Erörterungswürdig waren vor allem drei Problemkreise: die ordnungspolitische Gestaltung der Wirtschaftsunion als Plan- oder Marktwirtschaft, die Alternative zwischen Währungsunion und einem festen Wechselkurssystem sowie das Integrationstempo der allgemein geforderten Zollunion.

Für die Errichtung einer europäischen Planwirtschaft nach sozialistischem Modell führte Willy Brandt drei Gründe an ${ }^{532}$ : Erstens setze ein dauerhafter Friede die zeitgleiche Lösung der ökonomischen Probleme voraus. Zweitens sei ein Bedürfnis der Völker nach Wirtschaftsplanung im Frieden und „wirtschaftlicher ,Abrüstung “"533 nicht zu leugnen. Und drittens müsse der

527 Ibid. S. 146.

528 Ibid. S. 145-152 sowie S. 210 (Art. 2/II).

529 [Grossmann], Europäische Föderation, o. D. [November/Dezember 1939], S. 5, IfZ, NL Grossmann, ED 201/1.

530 Stern-Rubarth, Exit Prussia, S. 200 f. sowie S. 210 (Art. $2 / \mathrm{N}$ c).

531 Ibid. S. 164. Eben dieser Gedanke wurde auch in der französischen Résistance kolportiert, vgl. etwa LIPGENS (Hg.), Europäische Verfassung 1986, Dok. 20, S. 91: „Die Geschichte lehrt uns eine ständige Ausweitung der Grenzen.“

532 Vgl. BrandT, Stormaktenes krigsmål, abgedruckt in: VOIGT (Hg.), Friedenssicherung 1988, S. 56-70 (69).

533 Ibid. 
Mensch in den Mittelpunkt rücken, statt die staatlichen Institutionen um ihrer selbst willen aufrecht zu erhalten. Brandt teilte die von Neu Beginnen vertretene Auffassung, daß zunächst auf europäischer Ebene eine Planwirtschaft mit national definierter Arbeitsteilung zu errichten sei, die später dann zu einem weltumfassenden System ausgebaut werden könne ${ }^{534}$. Erste Voraussetzung für eine europäische Planwirtschaft sei der schrittweise Abbau von Trusts. Nach dieser Übergangsphase würde sich die Wirtschaftsunion durch die Beiträge der Mitgliedstaaten finanzieren, die nach Einwohnerzahl, Volkseinkommen und Nationalvermögen zu staffeln seien ${ }^{535}$.

Naturgemäß lehnten die liberalen und konservativen Exilanten eine sozialistische Planwirtschaft ab und propagierten statt dessen ein marktwirtschaftlich orientiertes Freihandelsmodell. Angesichts der politischen und militärischen Präsenz der Sowjetunion auf dem europäischen Kontinent befürchteten sie jedoch nur geringe Realisierungschancen der europäischen Wirtschaftsunion, „solange die russische Sphinx als drohender Koloß auf Europa lastet" 536 .

In der Frage der Zollunion vertrat eine Minderheit die Ansicht, die Binnenzölle müßten mit Beginn der Föderalisierung Europas beseitigt werden, um von Anfang an eine uneingeschränkte Zollunion zu gewährleisten ${ }^{537} . \mathrm{Zu}-$ mindest sollten unverzüglich regionale Zollunionen ats Vorstufe einer gesamteuropäischen Zollunion errichtet werden ${ }^{538}$.

Dem wurde entgegen gehalten, eine uneingeschränkte Zollunion sei aus politischen und ökonomischen Gründen nur schrittweise zu erreichen. So verfocht Hilferding das Ziel eines möglichst weitgehenden Freihandels innerhalb einer europäischen Zollunion, die auf der Grundlage einer engen britisch-französischen Wirtschaftskooperation errichtet werden sollte und sodann in einer gemeinsamen Schrittfolge und nach einem verbindlichen Plan die Binnenzölle reduzieren müsse ${ }^{539}$. Anschließend könne eine einheitliche Goldwährung eingeführt und schließlich ein grundsätzliches Zollerhöhungsverbot erlassen werden. Auf der letzten Stufe sollte der europäische Freihan-

534 Resolutionsentwurf für Neubeginnen. Die Friedensziele der deutschen Sozialisten, Dezember 1939, abgedruckt in: VolGT (Hg.), Friedenssicherung 1988, S. 46-50 (insb. S. 47 u. 50).

535 Vgl. BRANDT, Stormaktenes krigsmål, abgedruckt in: VoIGT (Hg.), Friedenssicherung 1988, S. 56-70 (68f.).

536 Das europäische Wirtschaftsproblem der Zukunft, in: Das Wahre Deutschland (April 1940), S. 11.

537 Stern-Rubarth, Exit Prussia 1940, S. 208 f. (Art. 1/V).

538 So der Resolutionsentwurf für Neubeginnen. Die Friedensziele der deutschen Sozialisten, Dezember 1939, abgedruckt in: VorGT (Hg.), Friedenssicherung 1988, S. 4650 (50). Einen weiteren, englischsprachigen Abdruck enthält LIPGENS (Hg.), Documents II 1986, Dok. Nr. 208, S. 564 ff. Das Original befindet sich im IISG, NL. Hertz, S9/10, M. J, Nr. 11.

539 Hilferding, Anmerkungen des Genossen Dr. Rudolf Hilferding, 29. 1. 1940, S. 5 f., AsD, Bestand PV-Emigration Sopade, M. 3. 
del einer Meistbegünstigungsklausel unterworfen werden ${ }^{540}$. Ebenso zeigten sich Grossmann und Kraft überzeugt, daß eine uneingeschränkte Zollunion nur schrittweise erreicht werden könne. Kraft schlug daher eine umgehende Senkung der Zölle um ein Viertel oder gar ein Drittel vor, die in den folgenden Jahren mit weiteren $15-20 \%$ p. a. fortzusetzen sei ${ }^{541}$.

Einer die Wirtschaftsföderation begleitenden Währungsunion standen einige Emigranten skeptisch, aber in der Regel nicht ablehnend gegenüber. Während Stern-Rubarth ein gemeinsames Währungssystem auf der Grundlage eines einheitlichen, nicht weiter spezifizierten Standards mit festen Wechselkursen für ausreichend hielt ${ }^{542}$, bekannten sich sowohl Sozialdemokraten als auch Linkskatholiken zum Fernziel einer einheitlichen europäischen Währung. Hilferding sprach sich für eine gemeinsame Goldwährung aus, und der Kreis um Grossmann dachte an die Errichtung kleinerer Währungsunionen, etwa in Skandinavien oder zwischen den Ländern des Bal$k_{k a n}{ }^{543}$. Auch Löwenstein trat für ein einheitliches Zoll- und Wirtschaftsgebiet mit allgemeingültiger Währung ein ${ }^{544}$.

Europäische Gewaltenteilung Seit das Schreckensszenario eines unter dem Hakenkreuz vereinigten Kontinentaleuropas Wirklichkeit geworden war, bemühten sich die politischen Flüchtlinge sichtbar um Abgrenzung und Konkretisierung ihrer alternativen Europakonzeptionen. Zu erkennen ist der Konkretisierungsbedarf auch an der nun aufgenommenen Debatte um wichtige Detailfragen der institutionellen Ausgestaltung eines föderativen Europas. Seit 1940 äußerte sich das Exil vermehrt zur Zusammensetzung föderaler Organe, zu Wahl- und Abstimmungsmodi in gemeinsamen Gremien. Während sich viele föderalistische Exilanten auf den Ausbau einer effizienten Exekutive konzentrierten, setzten diejenigen, die einem umfassenden Föderalismus das Wort redeten - etwa Kurt Grossmann, Willy Brandt oder Hubertus Prinz zu Löwenstein - den Schwerpunkt ihrer institutionellen Erörterungen nicht nur auf eine starke Exekutive, sondern ebenso auf die effektive Gestaltung der Judikative und einer demokratisch legitimierten Legislative. Essentielle Basis solcher Überlegungen war das Prinzip der Gewaltenteilung auf europäischer Ebene, flankiert und ergänzt durch die Grundsätze der Demokratie und der Rechtsstaatlichkeit ${ }^{545}$.

540 Ibid. S. 6.

$541 \mathrm{Kraft}$, Some thoughts on an scheme for a federated Europe, Januar 1940, S. 3, IfZ, NL Grossmann, ED 201/1.

542 STERn-RubarTh, Exit Prussia 1940, S. 208 f. (Art. 1/V).

$543 \mathrm{Kraft}$, Some thoughts on an scheme for a federated Europe, Januar 1940, S. $3 \mathrm{f}$., IfZ, NL Grossmann, ED 201/1.

544 Löwenstein, Die Zukunft Europas, 3. 11. 1939, ANF, F7 15126, M. 2, S. 14.

545 Solch ein weites Föderalismusverständnis vertrat auch der Schriftsteller Emil Ludwig, der sich Anfang 1940 mit einem eigenen Verfassungsentwurf für ein föderiertes Europa zu Wort meldete; vgl. LUDwIG, Die Vereinigten Staaten von Europa. Entwurf einer Verfassung, in: NTB, 8. Jg., H. 3 (20. 1. 1940), S. 66-71. Ein ergänzender Nachtrag 
Übereinstimmend teilte das politische Exil die Ansicht, daß die Verankerung einer starken Bundesexekutive unabdingbar sei für den inneren Frieden und die Gewährleistung einer stabilen Binnenstruktur des künftigen Europas. Der konservative Publizist Stern-Rubarth macht sich Gedanken über die erforderlichen Mehrheitsquoten ${ }^{546}$ : Rechtsverbindliche Beschlüsse sollten einer Zweidrittelmehrheit bedürfen, Grenzänderungen der Einstimmigkeit. Bei Konflikt zwischen zwei Mitgliedern sollten die Betroffenen selbst kein Stimmrecht haben. Stern-Rubarth kam den frühen Erörterungen von Neu Beginnen aus dem Jahre 1934 recht nahe, indem er die nationale Polizeistärke auf das notwendige Minimum reduzieren wollte und für die Entscheidung über einen Einsatz der statt dessen einzurichtenden Bundespolizei eine stabile Dreiviertelmehrheit vorschlug ${ }^{547}$. Alle drei Jahre sollte die Stärke der Bundesarmee überprüft und einstimmig neu festgelegt werden. Die nationalen Luftwaffen und U-Boot-Flotten würden von der Föderation konfisziert und in den kleinen, über die vier Regionalföderationen nur mittelbar dem gesamteuropäischen Verband angehörenden Staaten deponiert werden ${ }^{548}$. Für die gemeinsame Außenpolitik schlug Stern-Rubarth die Einrichtung eines ständigen obersten Organs vor, das proportional zu Bevölkerung und Regierungen der Mitglieder zusammengesetzt sein müsse ${ }^{549}$.

Aus der verbreiteten Kritik am Völkerbund, ihm fehle eine starke Exekutive, zogen viele Emigranten die Konsequenz, daß gegen die Umsetzungsverweigerung von Föderations- oder Gerichtsbeschlüssen der Gemeinschaft ein bestimmter Sanktionskatalog beschlossen werden müsse. Über die allgemein als unzureichend empfundene Option der Verhängung von Wirtschaftssanktionen hinaus sollte sich das Instrumentarium repressiver $Z$ wangsmittel nach Stern-Rubarths Ansicht über das Einfrieren von Bankkonten und die Unterbrechung der Kommunikation bis zur ultima ratio des Einsatzes der Bundespolizei steigern lassen ${ }^{550}$.

In der Diskussion um eine europäische Judikative war schon in den 1920er Jahren vielfach der Ruf nach einem internationalen Schiedsgericht laut geworden. Aufbauend auf der Idee der Schiedsgerichtsbarkeit, wurden nun

findet sich in: Krieg gegen Preußen (II), in: NTB, 8. Jg., H. 7 (17. 2. 1940), S. 164-168. Ludwigs Entwurf gerät allzu idealistisch, realitätsfern und gespickt mit sarkastischen Spitzen gegen allgemeinpolitische Erscheinungen seiner Zeit. Dies rechtfertigt aber noch keine pauschale Verurteilung des Beitrags als pure „Ansammlung von Kuriositäten", wie sie VoIGT ( $\mathrm{Hg}$.), Friedenssicherung 1988, S. 128 vornimmt.

546 Stern-Rubarth, Exit Prussia 1940, S.,211 (Art. 2/IV).

547 Ibid. S. 213 (Art. $2 / \mathrm{V}$ d und $2 / \mathrm{VI}$ ).

548 Ibid. S. 212 (Art. $2 / \mathrm{V} \mathrm{b}$ ).

549 Ibid. S. 208 f. (Art. $1 / \mathrm{V})$.

550 Ibid. S. 212 (Art. 2/V d). Brandt bezeichnete bloße Wirtschaftssanktionen ebenfalls als ungenügend, beließ es jedoch bei einem Verweis auf den von Neu Beginnen und ISK schon früh erörterten Vorschlag einer internationalen Militärmacht oder Polizeitruppe als Vollstreckungsorgan; vgl. BRANDT, Stormaktenes krigsmål, abgedruckt in: VOIGT (Hg.), Friedenssicherung 1988, S. 56-70 (64). 
weitergehende Kompetenzen eines ständigen europäischen Gerichts angeregt, das nach überwiegender Auffassung möglichst alle Streitigkeiten von Mitgliedstaaten untereinander sowie $z$ wischen einzelnen Mitgliedstaaten und dem Bund regeln sollte ${ }^{551}$. Löwenstein legte darüber hinaus die Zuständigkeit des Obersten Bundesgerichts für die Prüfung der Vereinbarkeit von Mitgliedstaatenrecht mit Bundesrecht nahe. Sein Konzept sah insoweit sogar die Möglichkeit einer Individualklage für diejenigen Bundesbürger vor, die in den gesetzlich $\mathrm{zu}$ definierenden gemischtsprachigen Gebieten ansässig $\operatorname{seien}^{552}$. Im Vordergrund der Entwürfe stand regelmäßig das gerichtliche Entscheidungsmonopol, die Verbindlichkeit der Beschlüsse und Urteile sowie deren zuverlässige Vollstreckung.

Die beiden Publizisten Grossmann und Stern-Rubarth widmeten sich eingehender dem Gerichtsverfahren, wobei sie insbesondere die Notwendigkeit einer Appellationsinstanz uneinheitlich beurteilten. Während Grossmanns Entwurf eine Berufungsmöglichkeit jedenfalls in den Fällen vorsah, die das "Leben und Lebensgrundsätze der Europäischen Föderation" berührten 553 , konzipierte Stern-Rubarth die erstinstanzlichen Gerichtsurteile als abschlieBende Entscheidungen ${ }^{54}$. Der Mitgründer des Europäischen Zoll-Vereins wies auch auf die Möglichkeit einer pragmatischen Institutionalisierung des Bundesgerichts hin: Die schon bestehende Europakammer des Ständigen IGH könne zu einem Europäischen Gericht mit acht Richtern (entspr. Mitgliedern) umfunktioniert werden, wobei die Anzahl der Richter der Anzahl der Mitglieder - Einzelstaaten und Teilföderationen - entsprach ${ }^{555}$.

Im Gegensatz zu den Bereichen einer europäischen Exekutive und Judikative war die Einrichtung einer bundeseigenen Legislative umstritten. Abhängig war dies zunächst von der föderalen oder konföderalen Ausgestaltung der europäischen Binnenstruktur, denn einem Staatenbund kann per definitionem keine Gesetzgebungskompetenz gegenüber Mitgliedstaaten zustehen. Radikale Föderalisten wie Löwenstein und Grossmann fochten für ein unabhängiges, durch unmittelbare Wahlen legitimiertes Europaparlament als Vertretung der Völker statt der Regierungen ${ }^{556}$. Im Sinne einer gegenseitigen demokratischen Kontrolle und einem sinnvollen Ausgleich der Interessen

551 Vgl. etwa Resolutionsentwurf für Neubeginnen. Die Friedensziele der deutschen Sozialisten, Dezember 1939, abgedruckt in: VoIGT (Hg.), Friedenssicherung 1988, S. 46-50 (50); Stern-Rubarth, Exit Prussia 1940, S. 208 f. (Art. 1/V).

552 Löwenstein, Die Zukunft Europas, 3. 11. 1939, ANF, F7 15126, M. 2, S. 15.

553 [Grossmann], Europäische Föderation, o. D. [November/Dezember 1939], S. 4, IfZ, NL Grossmann, ED 201/1.

554 Stern-Rubarth, Exit Prussia 1940, S. 208 f. (Art. 1/V).

555 In Art. 2/V c seines Europaplanes regte Stern-Rubarth die für die Rechtsstaatlichkeit bedeutsame Regelung der Wiederaufnahme des Verfahrens an, soweit neue Tatsachen vorlägen oder ein entsprechender Beschluß der Föderation einstimmig gefaßt worden sei.

556 Löwenstein, Die Zukunft Europas, 3. 11. 1939, ANF, F7 15126, M. 2, S. 14; [Grossmann], Europäische Föderation, Typoskript, S. 5, IfZ, NL Grossmann, ED 201/1. 
zwischen Regierungen und Volksvertretern beabsichtigte Löwenstein zusätzlich die Einberufung eines Bundesrates als Vertretung der Mitgliedstaaten, dem sowohl in Verwaltungsangelegenheiten als auch im Gesetzgebungsverfahren Mitwirkungsrechte zustünden. Grossmanns Entwurf sah vor, daß die Föderationsregierung sogar aus der Mitte des Parlamentes gewählt werde ${ }^{557}$. Da er anders als Löwenstein ein Zweikammersystem ablehnte, kam der Zusammensetzung des europäischen Parlamentes eine gesteigerte Bedeutung zu. Hier wollte Grossmann die Zahl der auf einen Mitgliedstaat entfallenden Delegierten in Abhängigkeit von der Bevölkerungszahl und dem ProKopf-Durchschnittseinkommen des jeweiligen Mitgliedstaates fixieren.

In gewissem Kontrast zu Löwensteins und Grossmanns Ausführungen steht das Konzept Arnold Brechts, der in einer Rede vom April 1940 das Problem einer europäischen Legislative eingehend analysierte ${ }^{558}$. Er entwickelte ein „Minimum Program of Common Principles“, in dem er Vorstellungen eines Zweikammersystems als unrealistisch ablehnte und aus Gründen der politischen Praktikabilität zunächst ein der Völkerbundsversammlung vergleichbares Gremium nationaler Regierungsvertreter mit imperativem Mandat vorschlug. Im Gegensatz zum Völkerbund sei für alle Abstimmungen das Mehrheitsprinzip festzulegen. Brecht bedachte auch das Problem der Stimmenverteilung vor dem Hintergrund erheblich divergierender Bevölkerungszahlen, das er durch einen zweifachen Wahlmodus zu lösen versuchte: Im ersten Wahlgang sollte jedes Land für eine Million europäischer Einwohner je eine Stimme erhalten, während im zweiten Wahlgang jedem Land ungeachtet seiner Größe eine einzige gleichwertige Stimme zustehe.

Als zusammenfassendes Beispiel für den institutionellen Forderungskata$\log$ vieler Europaföderalisten im Exil sei Heinrich Georg Ritzels Aufsatz "Wir müssen nicht untergehen!“ erwähnt, der viele der zentralen Elemente wirklich föderalistischer Europapläne in sich vereint. Ritzel, der sich engagiert um eine Perspektive für die europäische Zukunft bemühte, forderte die Niederlassungsfreiheit, das europäische Bürgerrecht und die verbindliche Beachtung der Menschenrechte als konstitutive Elemente eines neuen Europas ein. 1935 aus dem Saarland über Lothringen in die Schweiz emigriert, war Ritzel zum Generalsekretär der Schweizer Europa-Union avanciert und entfaltete in dieser Funktion eine rege Publikationstätigkeit. Zusammen mit Wilhelm Hoegner hatte er die Leitlinien der Europa-Union vom 4. Februar 1940 in die Form einer europäischen Verfassung gegossen ${ }^{559}$, die er in einer

557 [Grossmann], ibid.

558 Brecht, Political Basis of a durable peace, 26. 4. 1940, BAK, NL Brecht, N 1089, Bd. 111. Die folgenden Zitate finden sich auf S. 7 des Dokumentes.

559 Europa-Union Schweiz (Hg.), Entwurf zur Verfassung der Vereinigten Staaten von Europa, abgedruckt in: LIPGENS (Hg.), Europäische Verfassung 1986, Dok. Nr. 22, S. 94-102. Es handelt sich um die maßgeblich von Ritzel und Hoegner geprägte Ausarbeitung des Verfassungsausschusses der Europa-Union. 
gemeinsam mit Hans Bauer veröffentlichten Schrift kommentierte ${ }^{560}$. Der Kommentar liest sich wie ein Katalog der wesentlichen Forderungen europäischer Föderalisten: Ziel war ein an der schweizerischen Eidgenossenschaft orientierter europäischer Bundesstaat ${ }^{561}$ ohne Austrittsoption für die Mitgliedstaaten. Als oberste Bundesorgane sah der Entwurf ein Zweikammerparlament, eine Bundesregierung und ein Schiedsgericht vor. Darüber hinaus sollte für Fragen des Kulturlebens und der Wirtschaft je ein weiteres Bundesorgan geschaffen werden. Kernkompetenzen des Bundes sollten in der gemeinsamen Außen-, Zoll-, Wirtschafts- und Währungspolitik mit einer einheitlichen Währung und einer bundeseigenen Finanzhoheit liegen. Eine Bundesarmee würde als starke Bundesexekutive den Schiedsurteilen zur Durchsetzung verhelfen und sämtliche internen Konflikte zwischen Mitgliedstaaten unterbinden.

Außenverbältnis zum Völkerbund Neben der Frage der föderativen Binnenstruktur wurde die Föderalismusdebatte 1939/40 von der Erörterung des europäischen Verhältnisses zu einer umfassenderen Weltorganisation bestimmt. Während eine Minderheit einen europäischen Bund ohne ergänzende Weltorganisation oder einen Völkerbund ohne europäische Regionalföderation bevorzugte, trat die deutliche Mehrheit für eine Eingliederung des europäischen Zusammenschlusses in einen weltweiten Völkerbund ein.

Auch die Linkssozialisten favorisierten nun mehrheitlich das Modell einer europäischen Föderation oder Konföderation innerhalb des Völkerbun$\mathrm{des}^{562}$. Vorausgegangen war eine taktische Kurskorrektur der SAP und von Neu Beginnen. Die SAP stellte nach dem deutsch-sowjetischen Nichtangriffspakt die sofortige Inszenierung der sozialistischen Weltrevolution zugunsten des Zwischenschritts einer europäischen Föderation zurück und glich ihr Revolutionskonzept insofern anderen linkssozialistischen Visionen an. Neu Beginnen hatte schon zuvor einer europäischen Föderation das Wort

560 RITZEL, Wir müssen nicht untergehen!, in: DERS., BAUER, Von der eidgenössischen zur europäischen Föderation 1940, S. 81-156. Daraus (insb. S. 142-149) die folgenden Zitate.

561 Ritzel nimmt allerdings eine falsche Zuordnung der juristischen Begrifflichkeiten vor, wenn er den Bundesstaat mit der Konföderation und den Staatenbund mit der Föderation gleichsetzt; vgl. ibid. S. 142.

562 In [Hertz?], Unsere Kriegsziele und ihre Propaganda in der neuen Lage, o. D. [Anfang 1940], S. 7, AsD, NL Schoettle, M. 51 findet sich die sachlich unzutreffende Behauptung, Souveränitätsaufgabe sei gleichbedeutend mit dem juristischen Begriff der Föderation im Sinne eines Bundesstaates, während mit einer Konföderation die bloße Beschränkung der Souveränität im Sinne eines Staatenbundes gemeint sei. Vielmehr unterscheidet sich die Föderation von der Konföderation durch eine gemeinsame Exekutive mit Weisungsrecht gegenüber den Mitgliedstaaten und einer eigenen Völkerrechtssubjektivität. Der Konföderation dagegen fehlt eine solche zentrale Gewalt. Eine Beschränkung der Souveränität setzen beiden Formen des Zusammenschlusses voraus; die völlige Aufgabe der nationalen Souveränität aber würde die Errichtung eines gemeinsamen Einheitsstaates ohne föderative Untergliederungen bedeuten. 
geredet, aber eine Teilnahme kapitalistischer Staaten kategorisch ausgeschlossen. Diese Grundposition mußte angesichts der strategischen Abhängigkeit von den westlichen Mächten zumindest interimistisch revidiert werden.

Dem Leitbild einer europäischen Föderation im Rahmen eines weltweiten Völkerbundes schlossen sich zahlreiche Stimmen der linkskatholischen, liberalen und konservativen Emigration an. Löwensteins Konzept eines Europäischen Bundes enthielt das Bekenntnis zum Gedanken eines universalen Völkerbundes ${ }^{563}$. Brecht hielt zwar eine Ausdehnung der europäischen Föderation auf außereuropäische Staaten für inopportun, befürwortete aber ebenfalls die parallele Existenz eines Weltvölkerbundes, dem Europa entweder als europäische Föderation oder über ihre einzelnen Mitglieder angehören sollte ${ }^{564}$. Stern-Rubarth stimmte mit der linkssozialistischen Mehrheitsposition insofern überein, als er die von ihm entworfene achtköpfige Föderation als erste Instanz für europäische Angelegenheiten in den Völkerbund integrieren wollte ${ }^{565}$. Und selbst Strasser hatte sich mittlerweile durchgerungen, seine in diesem Punkt bisher unklare Position zugunsten einer Europäischen Föderation innerhalb eines erneuerten Welt-Völkerbundes aufzugeben ${ }^{566}$.

Dagegen klingt bei Grossmann eine Abschottung der europäischen Föderation gegen Nichtmitglieder an, die eine Einbindung in den größeren Verband des Völkerbundes ausschließen. Grossmann schweigt sich über diesen Punkt jedoch aus: „Die Europäische Föderation wird gegen diejenigen Staaten, die ihr nicht angehören, präventiv alle jene militärischen oder wirtschaftlichen Maßnahmen ergreifen, die eine Gefahr der Lebensfähigkeit der Europäischen Föderation von vorneherein ausschließen. "567 Auch in Krafts ergänzender Ausarbeitung erscheint die Europaföderation als Substitut, nicht aber als Supplement des Völkerbundes: „The League [of Nations] was chiefly an organization to outlaw the aggressor, whereas the Federation should have as its first aim an arrangement of Europe under which aggression should be generally recognized to be both useless and purposeless. "568 Nach mehreren engagierten Diskussionen in den verschiedenen Unterkomitees hieß es in einer gemeinsamen Verlautbarung der Gruppe vom Frühjahr 1940 in paneuropäischer Einfärbung: „Wenn wir uns die Entwicklung der Welt etwa so vorstellen, wie wir sie nach dem Krieg haben werden: 1. die Panamerikani-

563 Löwenstein, Die Zukunft Europas, 3. 11. 1939, ANF, F7 15126, M. 2, S. 15.

564 Brecht, Political Basis of a durable peace, 26. 4. 1940, S. 8, BAK, NL Brecht, N 1089, Bd. 111.

565 Stern-Rubarth, Exit Prussia 1940, S. 210 (Art. 2/I).

566 Strasser, Deutscher Situationsbericht, 10. 9. 1939, S. 3, IfZ, NL Strasser, ED 118/20.

567 [Grossmann], Europäische Föderation, o. D. [November/Dezember 1939], S.6, IfZ, NL Grossmann, ED 201/1.

$568 \mathrm{Kraft}$, Some thoughts on an scheme for a federated Europe, Januar 1940, S. 4, IfZ, NL Grossmann, ED 201/1. 
sche Union, 2. die Europäische Föderation, 3. ein noch nicht ablesbares Gebilde der mongolischen Welt, 4. die englischen Dominions mit Indien, 5. das gesamte Rußland [...], so hätten wir fünf große Gruppen, die nun den sogenannten Völkerbund als höchste Einheit der Völkerkooperation bilden könnten. " 569

Die Sopade war in der Frage einer europäischen Regionalföderation uneinig. Während Stampfer sich seit jeher für eine europäische Föderation innerhalb eines weltweiten Völkerbundes eingesetzt hatte, lehnte Hilferding einen Völkerbund allein für Europa strikt ab und nannte gegen dieses Modell zwei Gründe: Erstens sei England keine rein europäische Macht, müsse aber dennoch unter allen Umständen einer Föderation angehören, und zweitens müsse es das Ziel jeder auswärtigen Politik bleiben, die Vereinigten Staaten von Amerika zur Mitarbeit heranzuziehen ${ }^{570}$.

Somit sprach sich Hilferding gegen die im sozialistischen Exil vorherrschende Tendenz für einen modifizierten Völkerbund ohne eine eigene europäische Untergliederung aus und reagierte damit unmittelbar auf einen Artikel von Siegfried Marck, der in der sozialdemokratisch dominierten Neuen Volkszeitung für einen rein europäischen Völkerbund geworben hatte ${ }^{571}$. Zentrum dieses Europabundes sollte nach Marcks Ansicht ein enger Schulterschluß Deutschlands, Frankreichs, Italiens und Großbritanniens sein. Jede der vier Großmächte würde Regierungsvertreter in ein Direktorium entsenden, das als Bundesexekutivorgan fungieren sollte. Um dieses Zentrum würden sich sodann die kleineren europäischen Staaten gruppieren. Marcks Vorstellung einer binären Struktur widersprach der Linie des Parteivorstandes, der sich für eine unbedingte Gleichstellung aller Mitgliedstaaten verwandte: „Wir vertreten die Sache der Freiheit, und die Sache der Freiheit ist immer die Sache der Kleineren und Schwächeren und der Aufstrebenden." 572 Als Wilhelm Sollmann zwei Monate später an Rinner schrieb, Deutschland müsse erhalten bleiben, nahm er auch auf Marcks Ansatz eines Viererbundes Bezug: In einem gemeinsamen Europa sei es unmöglich, Deutschland zu ignorieren, „ob das ein Dreibund oder Vierbund der westlichen Mächte einschließlich England wird, ob es eine europäische Föderation gibt oder was immer" ${ }^{\text {"573. }}$. Im Ergebnis konnten sich weder Marck noch Hilferding im Parteivorstand durchsetzen. Ein Memorandum, das dem US-amerikanischen Unterstaatssekretär im Außenministerium Sumner Welles anläßlich dessen Besuchs in

569 Europa-Komitee: Europäische Föderation oder demokratische Union?, o. D. [Feb./März 1940], S. 2. Zur Datierung: Das Papier wurde vermutlich auf dem folgenden Meeting des Federation Sub-Committees am 5. 3. 1940 diskutiert.

570 Hilferding, Anmerkungen des Genossen Dr. Rudolf Hilferding, 29. 1. 1940, S. 4, AsD, Bestand PV-Emigration Sopade, M. 3.

571 MARCK, Vom alten zu einem neuen Genf, in: NVZ, 9. Jg., Nr. 1 (6. 1. 1940), S. 1.

572 C. G[EYER], Was Deutschland gebührt, in: NV, Nr. 282 (13. 11. 1938), S. 1.

573 Sollmann an Rinner vom 8. 3. 1940, S. 2, AsD, Bestand PV-Emigration Sopade, Rinner-Korrespondenz, M. 34. 
Paris im März 1940 überreicht werden sollte, griff zwar Hilferdings Vorschlag für eine enge britisch-französische Kooperation als Grundstein einer europäischen Neuordnung auf. Im übrigen aber machte man sich das mehrheitsfähige, im Parteivorstand vor allem von Stampfer vertretene Modell einer europäischen Föderation innerhalb eines weltweiten Völkerbundes zu eigen $^{574}$.

\section{3. „Wir müssen nicht untergeben!" - Flucht aus der „Festung Europa“ (1940/41)}

Mit der Besetzung Frankreichs und dem Fall von Paris, der heimlichen Hauptstadt des deutschen Exils, am 14. Juni 1940 wurde ein neuer Abschnitt sowohl für das Leben der Emigranten und Exilgruppen als auch für den Europadiskurs eingeläutet. Die Unterzeichnung des deutsch-französischen Waffenstillstandsabkommens in dem bekannten Salonwagen im Wald von Compiègne stieß im Exil auf Verzweiflung und Fassungslosigkeit: „Der Moloch hat ein weiteres Land verschlungen. ${ }^{575}$

Vor dem Hintergrund der traumatisierenden Ereignisse des Jahres 1940 erhält Heinrich Georg Ritzels Appell aus dem gleichen Jahr eine besonders dramatische Note: „Wir müssen nicht untergehen!“, rief er den Europäern zu und erinnerte daran, daß die Not "die große Lehrmeisterin der Völker“ sei $^{576}$. Aus dem puren Selbsterhaltungstrieb heraus werde sich der europäische Kulturkreis zu den Vereinigten Staaten von Europa zusammenfinden ${ }^{577}$.

Für den Europadiskurs des deutschen Exils, zu dessen Zentrum sich bis 1940 die Stadt an der Seine entwickelt hatte, war die Besetzung Frankreichs in dreierlei Hinsicht bedeutsam: Erstens veränderten sich schlagartig die Lebensbedingungen in der Emigration, und mit dem Ende des kontinentaleuropäischen Exils wurde ein nachhaltiger Individualisierungsprozeß ausgelöst. Zweitens war durch die veränderte machtpolitische Situation ein faktisch geeintes Kontinentaleuropa entstanden, das in Verbindung mit der pervertierten Europaidee der Nationalsozialisten politische und programmatische Ab-

574 [Parteivorstand der Sopade], Memorandum, o. D. [März 1940], S. 2, AsD, Bestand PV-Emigration Sopade, M. 179. Ausweislich des im Annex befindlichen Begleitbriefs sollte das Memorandum einem amerikanischen Politiker überreicht werden, der sich 1940 in Paris aufhielt. Somit muß das Dokument noch im Pariser Exil vor der Flucht des (Rumpf)Vorstandes nach London verfaßt worden sein. Im März 1940 weilte Sumner Welles im Auftrag Roosevelts in Paris und hatte am 9.3. 1940 dem französischen Ministerpräsidenten Paul Reynaud die amerikanischen Vorstellungen für eine internationale Nachkriegswirtschaft erläutert. Daraus ergibt sich die Datierung der Quelle auf März 1940. Zur Bewertung des US-Vorschlages aus der Sicht des bürgerlich-liberalen Exils vgl. SCHWARZSCHILD, Zukunftsthesen des amerikanischen Besuchers, in: NTB, 8. Jg., 11. H. (16. 3. 1940), S. 249-251.

575 Die Festung der Freiheit, in: Das Wahre Deutschland (Juli 1940), S. 1-4 (1).

576 RITZEL, Wir müssen nicht untergehen!, in: DERS., BAUER, Von der eidgenössischen zur europäischen Föderation 1940, S. 105.

577 Ibid. S. 106. 
grenzungsschwierigkeiten aufwarf. Drittens begann zunächst zaghaft die Suche nach einer außereuropäischen Antwort auf die europäische Frage. Die allmähliche Erkenntnis um den schleichenden, doch seit längerem schon evidenten Bedeutungsverlust Europas hatte mit Verzögerung nun auch das deutsche Exil erreicht.

Die Exilpublizistik des Zeitraums zwischen Juni 1940 und Juni 1941 ist quantitativ zwangsläufig eingeengt, so daß verstärkt auf unveröffentlichte Dokumente zurückzugreifen ist. Die Ursachen liegen auf der Hand: Die vorrangigen Sorgen der Emigranten galten zunächst der Organisation der neuerlichen Flucht, der häufig völligen Mittellosigkeit, der Unterkunft und dem täglichen Lebensunterhalt im neuen Exilland sowie der permanenten Gefahr der Entdeckung, Internierung oder gar Auslieferung. Zudem widmeten sich die meisten Exilgruppen in dieser Zeit hauptsächlich der Flüchtlingshilfe, besorgten Ausreisepapiere oder Einreisegenehmigungen und arrangierten die Unterstützung durch internationale Hilfswerke oder persönliche Fürsprache, so daß die Arbeit an den politischen Programmen zeitweise zurücktrat.

\subsubsection{Individualisierungsprozeß des politischen Exils}

Abgesehen von den Zufluchtsorten in der Schweiz und in Schweden hatte die Niederlage Frankreichs und die Kapitulation von Paris die Zeit des kontinentaleuropäischen Exils brutal beendet. Aus Paris als der bisherigen Hochburg des deutschen Exils flohen die Emigranten zumeist über Lissabon nach Großbritannien, in die USA und nach Lateinamerika. Für die nicht rechtzeitig Geflohenen erwies sich der weitere Aufenthalt in den nunmehr von den Deutschen besetzten Exilländern bald als akute Lebensbedrohung: Gemäß Artikel 19 des deutsch-französischen Waffenstillstandsvertrages vom 22. Juni 1940 war Frankreich zur Auslieferung an Deutschland verpflichtet ${ }^{578}$.

Durch die weltweite Verstreuung der deutschen Emigration erhöhten sich die ohnehin bestehenden Organisations- und Kommunikationsschwierigkeiten auch innerhalb der Gruppen. Auf diese Weise entwickelte sich in der Gesamtschau der Diskurssplitter ein buntes Kaleidoskop an Neuordnungsansätzen, sowohl hinsichtlich der Axiome im allgemeinen als auch bezüglich der Implementierungsvorschläge im einzelnen. Charakteristisch ist dabei die zunehmende Individualisierung der politischen Konzeptionen infolge einer schleichenden Aufweichung, teilweise sogar Auflösung der parteiinternen Kommunikationsstrukturen. Der Gedanke der parteipolitischen Solidarität büßte an Integrationskraft ein, je länger sich das Exil hinzog.

Strasser hatte diese Entwicklung frühzeitig erkannt und versucht, daraus Kapital zu schlagen. Wie gezeigt, appellierte er an den individualistischen Geist bestimmter Politiker, die er für einen Deutschen Nationalrat im Exil

${ }^{578}$ Zur Auslieferungspflicht nach dem deutsch-französischen Waffenstillstandsvertrag, insbesondere zu dem genauen Hergang der Auslieferung Breitscheids und Hilferdings vgl. DELACOR, „Auslieferung auf Verlangen“? 1999. 
auserkoren hatte, und äußerte die Auffassung, daß diese Einzelpersönlichkeiten eher zu einer Kooperation fänden als ihre Parteien ${ }^{579}$. Beispielhaft ist die Individualisierungstendenz an der Organisationsgeschichte der SAP im Exil abzulesen. Ebenso wie die Auslandsleitung in London schon in der Arbeitsgemeinschaft mit Neu Beginnen an Profil verlor und schließlich in der Union deutscher sozialistischer Organisationen in Großbritannien aufging, definierte sich die SAP-Gruppe in Schweden zunehmend über das Engagement einzelner wie Willy Brandt und löste sich als Partei faktisch im Stockholmer Kreis internationaler Sozialisten auf, bis im Oktober 1944 der Beitritt zur SPD erklärt wurde. In ähnlicher Weise übernahmen ab 1940 im Parteivorstand der Sopade einzelne Emigranten die intellektuelle Führung und vernachlässigten den parteiinternen Solidaritätskonsens.

Für das liberale und konservative Exil war der Individualismus von Beginn an charakteristisch gewesen, denn es war nie gelungen, im Exil eine gemeinsame Plattform zu schaffen, zumal die DFP an dieser Aufgabe gescheitert war. Erst recht gilt dies für das nationalkonservative Lager, da Strasser mal offen, mal kaschiert für das Führerprinzip eintrat, als dessen geborenen Führer er sich selbst zu stilisieren versuchte. Doch bleibt festzuhalten, daß viele Exilorganisationen durch die erneute Flucht nach Großbritannien oder in außereuropäische Länder häufig bis in das Jahr 1941 hinein mit dem Neuaufbau ihrer Kommunikationsstrukturen beschäftigt waren und weder die Kraft noch die Zeit hatten, den Faden des Europadiskurses wieder aufzunehmen.

Durch die nach der Niederlage Frankreichs einsetzende Teilung des sozialdemokratischen Exils in eine US-amerikanische und eine britische Gruppe spielte der Individualisierungsprozeß für die politische Grundlinie der Sopade eine besondere Rolle. Erste sichtbare Auswirkung dieser Entwicklung war das deutlich gestiegene Interesse an Lösungsmodellen für die europäische Zukunft, das hauptsächlich von den in die USA emigrierten SopadeMitgliedern getragen wurde. Bemerkenswerterweise entwickelte sich seit der Teilung des Sopade-Vorstandes Friedrich Stampfer gegenüber Curt Geyer zu dem aktiveren der beiden Europapolitiker. Geyer hingegen entfremdete sich zusehends von seiner Partei, bis er 1942 im Zusammenhang mit der Fight Freedom-Affäre aus dem Parteivorstand ausschied und posterior aus der Partei ausgeschlossen wurde.

Eine wachsende Entfremdung der beiden sozialdemokratischen Exilgruppen, die auch grundlegende Fragen nicht ausschloß, war unübersehbar. Dies war sicherlich auch dadurch bedingt, daß der nach London geflüchtete Rumpfvorstand einerseits und die in die USA emigrierten Vorstandsmitglieder andererseits sich völlig unterschiedlichen Umfeldern ausgesetzt sahen und sich persönlichkeitsbedingt unterschiedlichen Aufgaben widmeten.

579 Strasser, Deutscher Situationsbericht, 10. 9. 1939, S. 2, IfZ, NL Strasser, ED 118/20. In diesem späteren Dokument nannte Strasser die Namen Sollmann, Jaksch, Weber, Brüning, Treviranus, Rauschning und Strasser. 
Während Vogels und Ollenhauers Herz eher der Innenpolitik gehörte und sie sich deshalb erfolgreich der Rückführung der verlorenen linkssozialistischen Söhne in den Schoß der Sozialdemokratie zuwandten, hatte sich vor allem Stampfer in den USA der außenpolitischen Thematik verschrieben und bemühte sich um die Aufrechterhaltung einer außenpolitischen Kontinuität der Partei.

Wie grundlegend unterschiedlich die sozialdemokratische Grundtendenz in den USA gegenüber der Londoner Situation war, beweist das Unverständnis der amerikanischen Emigranten gegenüber der Gründung einer Union mit Linkssozialisten, insbesondere mit Neu Beginnen und SAP. Stellvertretend für die in die USA emigrierte Sozialdemokratie schloß Rudolf Katz ein vergleichbares Vorgehen in den USA aus und konstatierte: „Außerordentlich gewundert, ja befremdet, hat uns der Beschluß der Koalition mit den sog. Splittergruppen. Wie erklärt sich das? [...] Mit Leuten, mit denen man keine praktische Politik treiben kann, sich in offiziellen Koalitionsgruppen zusammenzutun, erscheint uns in keiner Weise sinnvoll." 580

Auf den nach Großbritannien geflüchteten Teil der Sopade wirkte sich der Individualisierungsprozeß in besonderer Weise ambivalent aus. Einerseits trat eine zunehmende Diskrepanz zu führenden Mitgliedern wie Geyer, Menne oder Loeb auf, die sich bald auch in grundsätzlichen Angelegenheiten wie der Frage nach den künftigen deutschen Staatsgrenzen, der gleichberechtigten Einordnung Deutschlands in der europäischen Neuordnung und der Aufgabe der Emigration überhaupt niederschlugen ${ }^{581}$. Andererseits fand der Londoner Rumpfvorstand gerade in dieser Zeit bedeutsame Anknüpfungspunkte mit den linkssozialistischen Gruppen, mit denen im März 1941 die Union deutscher sozialistischer Organisationen in Großbritannien gegründet wurde.

\subsubsection{Nationalsozialistische Usurpation der Europaidee}

Mit der Niederlage Frankreichs hatte Hitler Kontinentaleuropa unter dem deutschen Hegemonieanspruch zur „Einheit“ gezwungen. Deutlicher denn je stand den Emigranten nun die Alternative vor Augen: „Adolf Hitler Kaiser von Europa und damit Mitherrscher, wenn nicht gar übermorgen Beherrscher [Hervorhebung im Original, B. S.] des Planeten - oder die Zerstörung seines Regimes“582. Für den Europadiskurs erwiesen sich zwei Momente der neuen Lage von herausragender Bedeutung: der Zusammenbruch des euro-

$580 \mathrm{Katz}$ an Ollenhauer zur Bildung der Union deutscher sozialistischer Organisationen in Großbritannien, 25. 5. 1941, abgedruckt in: MIELKE, FRESE (Bearb.), Gewerkschaften 1999, Dok. Nr. 27, S. 1012.

$581 \mathrm{Vgl}$. die von persönlichen Spannungen überlagerte Diskussion im Anschluß an Ollenhauers Grundsatzreferat auf der SPD-Konferenz vom 10./11. 5. 1941, abgedruckt in: EIBER (Hg.), Union 1998, Dok. Nr. 210, S. 499-513.

582 Hiller, Die Zukunft des Erdteils, Rede vom 18. Januar 1941, in: DeRs., Ratioaktiv 1966, S. 116-34 (119f.). 
päischen Nationalstaatensystems unter dem Ansturm des Nationalsozialismus ${ }^{583}$ und die erzwungene Einigung Kontinentaleuropas unter dem Haken$\mathrm{kreuz}^{584}$. Der realpolitischen Vereinheitlichung Europas zu einem nationalsozialistischen Machtblock ließ das Hitler-Regime noch im selben Jahr eine Europaideologie folgen, die gezielt den Europabegriff, ja die Europaidee usurpierte. Auf ausdrücklichen Wunsch der Deutschen wurde die Neuordnung Europas in den ebenfalls noch 1940 abgeschlossenen Dreimächtepakt aufgenommen. Damit wurden die Europaplanungen des politischen Exils mit der Konkurrenz der real existierenden nationalsozialistischen „Festung Europa " konfrontiert. Auf die dadurch verursachten schwerwiegenden Abgrenzungsprobleme des emigrierten Widerstandes durch Planung ist bereits hingewiesen worden ${ }^{585}$.

Aus der neuen Machtkonstellation ergaben sich für den Europadiskurs des deutschen Exils zwei aktuelle Herausforderungen: Einerseits mußten die eigenen Europakonzepte von dem Realität gewordenen NS-Konzept deutlich abgegrenzt und die grundlegenden Unterschiede aufgedeckt werden, andererseits stellte sich die Frage, ob eine spätere Anknüpfung an die von Hitler geschaffenen Einigungsansätze zulässig sei.

Zunächst wurden nun weitere Konkretisierungen notwendig, um der Abgrenzungsaufgabe ebenso gerecht $\mathrm{zu}$ werden wie dem Anspruch eigener Glaubwürdigkeit als das ernst zu nehmende „andere Deutschland“. Knoeringen faßte es in die selbstkritische Mahnung: „Um mehr als Mode zu sein, muß dieser Gedanke [d. i. der Europagedanke, B. S.] so konkretisiert werden, $\mathrm{da}$ er den wirtschaftlichen und nationalen Problemen Rechnung trägt. Ohne solche inhaltliche Konkretisierung bleibt die schönste Europaverfassung leeres formales Gerede." 586 Knoeringens Ruf nach einer Konkretisierung des antifaschistischen Europamodells fand Widerhall in den Reden und Kriegszielerklärungen führender westlicher Entscheidungsträger. Insbesondere in der britischen und US-amerikanischen Politik hatte die europäische Einigung in den ersten Kriegsjahren einen hohen Stellenwert ${ }^{587}$. Dies ver-

$583 \mathrm{Vgl}$. dazu auch LOTH, Sozialismus und Internationalismus 1977, S. 11.

584 In einem unveröffentlichten Manuskript vom September 1940, das v. Knoeringen zuzuschreiben ist, heißt es: „Hitler hat die Einheit des europäischen Kontinents in Form der Militärdespotie hergestellt. [...] Der allgemeine Kriegsverlauf hat gezeigt, daß das Zeitalter der souveränen Nationalstaaten [...] vorbei ist.“; [Knoeringen], Sinn und Grenzen europäischer Zielpropaganda, September 1940, S. 1, AsD, NL Knoeringen, M. 137.

585 Siehe dazu das Kapitel IV.1.

586 [Knocringen], Sinn und Grenzen europäischer Zielpropaganda, September 1940, S. 1, AsD, NL Knoeringen, M. 137. Zustimmend Paul Hertz, der in einem ungezeichneten Beitrag auf die Notwendigkeit eines konkreten außenpolitischen Programms hinweist, das den inhaltlosen Pazifismus weit hinter sich lasse und die Schaffung der europäischen Föderation anvisiere; [Hertz], Zwei Linien. Demokratische Revolution in Deutschland, o. D. [1940], S. 3, IISG, NL Hertz, S7/8, M. B, Nr. 4.

587 Vgl. dazu Lipgens (Hg.), Föderationspläne 1968, S. 19-26 sowie die Dokumente Nr. 139-176, S. 405-521. 
leitete den Linkskatholiken Spiecker zu der hoffnungsvollen Bemerkung: „Europa wird wieder als Aufgabe erkannt. ${ }^{\text {"588 }}$

Neben der konzeptionellen Abgrenzung stellte sich die essentielle Frage, ob eine Anknüpfung an das NS-Europa überhaupt zulässig sei. Schon die Fragestellung beweist, daß der Europadiskurs der politischen Emigration seit 1940 wesentlich an der Reibung mit der erdrückenden Wirklichkeit der Hitlerschen „Festung Europa“ wuchs. Je deutlicher sich die NS-Expansionspolitik manifestierte, je erfolgreicher das nationalsozialistische Deutschland Europa Landstrich für Landstrich, Staat für Staat unter das Hakenkreuz zwang, desto mehr wuchs der Druck auf die politischen Emigranten, brauchbare Gegenentwürfe vorzulegen: Gegenentwürfe für eine Frieden sichernde Gestaltung des europäischen Kontinents, um den alle Widerstände rücksichtslos einreißenden Politpanzer zum Stillstand zu bringen und seine Wiederkehr zu verhindern. Die europäische Orientierung der politischen Emigration wuchs also an den außenpolitischen Erfolgen des "Dritten Reichs" und verdankte ihnen mittelbar entscheidende Konkretisierungsimpulse.

Selbst die KPD sah sich gezwungen, aus dem Abseits des politischen Exils gegen den von Hitler angekündigten Neuaufbau Europas zu Felde zu ziehen, ohne jedoch eine Alternativkonzeption vorzulegen ${ }^{589}$. Man hatte den Sprengstoff der Europaidee erkannt, auch wenn man sie sich nicht zu eigen machen wollte. Gegen die wachsende politische Überzeugungskraft eines vereinigten Europas, wie es sich unter der nationalsozialistischen Hegemonie entfaltet hatte, mußten daher auch die Kommunisten Stellung beziehen.

Grundsätzlich aber hielt die KPD entsprechend den Vorgaben der Komintern an der absoluten staatlichen Unabhängigkeit auf der Grundlage des uneingeschränkten Selbstbestimmungsrechts fest. Sie lehnte jede europaspezifische Konstruktion ab und beschränkte im Sinne der von Ulbricht eingeleiteten parteipolitischen Wende von 1939 ihr gesamtes außenpolitisches Programm auf die „Verstärkung und Vertiefung der Freundschaft zwischen dem deutschen Volke und dem Sowjetvolke und allen anderen Völkern", wobei man sich mit dem "mächtigen Sowjetvolk [...] aufs engste verbunden" fühlte ${ }^{590}$. Im übrigen beließ es die Auslandsleitung der KPD bei den gewohnten Angriffen auf die "chauvinistisch verseuchten, im Dienste des britischen Imperialismus stehenden Führern der II. Internationale", forderte die nationale und soziale Befreiung der europäischen Völker und verwies auf den pro-

588 [SPIECKER], Die gemeinsame Aufgabe, in: Das Wahre Deutschland (August 1940), S. 1-5 (4).

589 Vgl. z.B. die Erklärung der KPD zum deutsch-französischen Waffenstillstandsabkommen: Gegen das Diktat von Compiègne. Erklärung der KPD von Anfang Juli 1940, $\mathrm{BAB}, \mathrm{RY} 1 / \mathrm{I}$ 2/707/80, Bl. 82-86. Auch die Berliner KPD verteilte etwa zur gleichen Zeit ein Flugblatt mit der Überschrift: Das Freie Wort! Die Deutschen marschieren siegreich durch Europa!, Juni 1940, Faksimiledruck in: PIKARSKI, UEBEL (Hg.), Widerstandskampf der KPD 1978, Dok. Nr. 142.

590 Wir wollen Frieden!, September 1940, 21 seitiges Typoskript, BAB, RY 1/I 2/707/ 80, Bl. $23-43(43)$. 
letarischen Internationalismus als weltweit Frieden stiftendes Prinzip ${ }^{591}$. Bezeichnend für das verzweifelte Ringen der KPD um politische Aufmerksamkeit in den westlichen Exilländern ist die ausführliche Kritik an den Europaplänen anderer Gruppierungen, ohne ein eigenes Konzept anzubieten. Viel zu sehr mit der Suche nach dem eigenen Selbstverständnis beschäftigt, verfiel das ZK-Mitglied der KPD Herbert Wehner 1940 in einer 21seitigen Denkschrift zur "Politik der Sozialdemokratie im europäischen Krieg" erneut in die Terminologie der These vom Sozialfaschismus ${ }^{592}$. Seit die Komintern auf Grund des Hitler-Stalin-Paktes Hoffnung geschöpft hatte, innerhalb Deutschlands wieder eine legale Parteistruktur aufbauen zu können, war der bisherige Referent für deutsche und mitteleuropäische Fragen in der Presseabteilung der Komintern als künftiger Inlandsleiter der KPD vorgesehen. Vor dem Hintergrund einer solchen biographischen Perspektive überrascht es nicht, daß Wehner in der erwähnten Denkschrift unverändert auf die $\mathrm{Pa}$ role vom Hitler-Stalin-Pakt als wahrer Friedenspolitik der Sowjetunion zurückgriff und den Sozialdemokraten entgegenhielt: „Wer diesen Krieg, der ein imperialistischer Krieg ist, dadurch maskieren hilft, daß er ihn als ,Krieg gegen den Hitlerismus' und ,Krieg zur Verteidigung der Demokratie' ausgibt, arbeitet der Bourgeoisie in die Hände und leistet ihr Hilfsdienste auf Kosten der Werktätigen und der unterdrückten und mißbrauchten Kolonialvölker." 593

Auch sozialdemokratische Stimmen wandten sich gegen eine Anknüpfung an die von Hitler geschaffene Einheit Europas. Der Weg zu Freiheit und Rechtsgleichheit führe statt dessen über den status quo ante ${ }^{594}$.

Eine andere gruppenübergreifende Tendenz erkannte in dem Zusammenschluß Europas unter dem Hakenkreuz eine im Ergebnis positive Errungenschaft, die lediglich von ihrem nationalsozialistischen Gepräge als „Einheit der Knechtung und des Todes" 595 befreit und einem freiheitlichen Selbstverständnis zugeführt werden müsse. Stellvertretend für diese Ansicht brachte Spiecker den Beschleunigungseffekt zur Sprache, den der faschistische Vormarsch auf die Renaissance der Europaidee ausgeübt habe: „Was in normaler, gleichmäßiger Entwicklung vielleicht noch Jahrzehnte erfordert hätte, ist durch Hitlers unbezähmbaren Machtdrang fast über Nacht der Entscheidung zugeführt worden, allerdings einer Entscheidung auf Tod und Le-

591 [KPD], Gegen das Diktat von Compiègne, Anfang Juli 1940, BAB, RY 1/I 2/707/ $80, \mathrm{Bl} .85$.

$592 \mathrm{Vgl}$. Funk [d. i. Wehner], Die Politik der Sozialdemokratie im europäischen Krieg, 1940, BAB, RY 1/I 2/707/59, Bl. 266-294.

593 Ibid. Bl. 274.

594 GEYER, [Skizze über den kommenden Frieden], S. 1, AsD, Bestand PV-Emigration Sopade, M. 44. Die Skizze befindet sich im Annex eines Briefes an Erich Ollenhauer vom 21. 4. 1941.

595 So TILLICH in einer Radioansprache vom September 1942, Die Welt nach dem Krieg, in: Ders., An meine deutschen Freunde 1973, S. 104-108 (106). 
ben." 596 Waldemar von Knoeringen plädierte für die Anknüpfung an die von Hitler geschaffene europäische Einheit bei gleichzeitiger Zerstörung der faschistischen Elemente ${ }^{597}$. Dem Neu Beginnen-Mitglied erschien dies nur deshalb möglich, weil Hitler bislang allein die militärische Einheit Europas geschaffen habe, die wirtschaftliche und soziale Einheit aber im wesentlichen noch ausstehe.

Ein möglicherweise von Erwin Schoettle verfaßtes Memorandum forderte „eine andere gesamteuropäische Lösung anstelle der Hitlerschen ,Neuordnung " und appellierte an die Solidarität der von Hitler unterdrückten Völker als gemeinsamer Ausgangsposition für eine friedliche Zukunftsgestaltung ${ }^{598}$. Sarkastisch spekulierte ein Verfasser im Wabren Deutschland, Hitler sei das Werkzeug der Vorsehung, das erst alles Morsche und Faule in Europa hinwegzufegen habe, damit eine neue und bessere Welt entstehen könne ${ }^{599}$.

Im Tenor erinnert diese Interpretation der historischen Gegebenheiten an Strassers Terminologie der "Männer von Morgen“, die Europa von einem morschen System befreien würden. So verwundert es kaum, daß Strasser die europäische Einheit durch Hitler verwirklicht sah - nur sei sie in ein neues Ordnungssystem umzuwandeln. Folglich verzichtete Strasser nach dem Sommer 1940 auf die bisher typischen kritischen Ermahnungen zur europäischen Einigung. Es fällt auf, daß Strasser weder in den nach Juni 1940 verfaßten Grundsatzmemoranden noch in seinem Buch „Germany Tomorrow" auf die bisher so eindringlich penetrierte Parole von der europäischen Zusammenarbeit als Gipfel seines programmatischen Dreiklanges einging ${ }^{600}$. Einzig der Entwurf für eine Broschüre der Frei-Deutschland-Bewegung nimmt zum Programmpunkt der Europäischen Föderation Stellung und offenbart Strassers Schwierigkeiten, sich gegen Hitlers Nationalsozialismus abzugrenzen, gleichzeitig aber den von Hitler herbeigeführten Zusammenschluß Europas grundsätzlich zu begrüßen: „Hitlers Schlagwort von der ,Neuen Ordnung in Europa' kommt einer allgemeinen Empfindung der europäischen Völker entgegen - nur kann diese Neuordnung nicht basiert sein auf

596 [SPIECKER], Die gemeinsame Aufgabe, in: Das Wahre Deutschland (August 1940), S. 4 .

597 [Knoeringen], Sinn und Grenzen europäischer Zielpropaganda, September 1940, S. 2, AsD, NL Knoeringen, M. 137.

598 Vgl. [Schoettle?], Deutsche und europäische Revolution. Eine Diskussionsgrundlage, o. D. [Sommer 1940-Sommer 1941], S. 1, AsD, NL Schoettle, M. 64.

599 Deutschlands europäische Aufgabe, in: Das Wahre Deutschland (September 1940), S. $1-4(2)$.

$600 \mathrm{Vgl}$. etwa Strasser, Memorandum über Aufgaben und Möglichkeiten der deutschen Opposition, o. D. [Oktober 1940]. Die Datierung dieses Dokumentes geht ausdrücklich aus Strassers Memorandum Nr. 3 hervor, das als Ergänzung dieses Dokumentes und eines weiteren Memorandums bezeichnet wird (IfZ, NL Strasser, ED 118/20). Vgl. auch Strasser, „2. Versailles“ heißt „3. Weltkrieg“, o. D. [März/April 1941], IfZ, NL Strasser, ED 118/20 sowie die Veröffentlichung Germany Tomorrow 1940, die sich im Anhang mit einer unkommentierten Wiedergabe der "European Collaboration" begnügt (S. 254). 
der Herrschaft eines einzigen Volkes über die anderen, wie es das Ziel des Nazismus ist. “601

\subsubsection{Außereuropäische Lösung der europäischen Frage?}

„Frankreich ist tot - es lebe Frankreich!“ titelte die sozialdemokratische Neue Volks-Zeitung und versicherte, daß die Ideen von 1789 nie untergehen würden ${ }^{602}$. Tatsächlich setzte mit der Niederlage Frankreichs im Sommer 1940 der letzte Prozeßabschnitt des spätestens seit 1917/18 zu beobachtenden Bedeutungsverlustes Europas auf dem globalen Parkett ein. Mit Blick auf die bisher passive Rolle der USA stellte der nach New York emigrierte Rechtsanwalt Rudolf Katz im Juni 1940 nüchtern fest: „Der Krieg rückt näher."603

Die Änderung der außenpolitischen Koordinaten wirkte sich axiomatisch auf die Neuordnungspläne des Exils aus und setzte einen Erkenntnisprozeß in Gang, der sich mit dem Einschwenken der Sowjetunion in die Reihen der Anti-Hitler-Koalition, dem Kriegseintritt der USA und schließlich der Konferenz von Teheran fortsetzte. Immer klarer wurde den deutschen Emigranten, daß nicht nur die bisher erörterten Motive einer europäischen Einigung für die Konzeptionalisierung eines vereinigten Europas ausschlaggebend waren, sondern die rasanten Änderungen des weltpolitischen Szenarios sich unvermeidlich in den Vordergrund der Europadiskussionen drängten. Strategische und machtpolitische Momente gewannen gegenüber ideologischen Wertvorstellungen innerhalb des Europadiskurses an Gewicht.

Die Ereignisse von 1940 setzten das politische Exil einer von nun an bestimmenden Zwangslage aus: einerseits Konzeptionen für ein eigenständiges, vereinigtes Europa, andererseits mußte dem die Befreiung Europas vorangehen. Hitler mußte so schnell wie möglich vernichtend geschlagen werden der verträumten Hoffnung auf eine alles beendende innerdeutsche Revolution wollte sich kaum mehr jemand hingeben. Es drängte sich die Frage auf, wem man nun die Führung im Kampf gegen Hitler zutraute. Für das deutsche Exil hatte diese Frage, die machtpolitisch nur die drei Optionen Großbritannien, USA und UdSSR zuließ, eine entscheidende grundsatzpolitische Dimension. Bekannte man sich zu den USA als Anführer der Anti-HitlerKoalition, war damit zugleich eine Erklärung für den westlichen Kapitalismus und für eine außereuropäische Macht abgegeben. Demgegenüber stand die UdSSR in den Augen einiger Sozialisten noch immer für den verwirklich-

601 Strasser, Was will die Frei-Deutschland-Bewegung?, o. D. [Februar-Juni 1941], IfZ, NL Strasser, ED 118/20. Zur Datierung: Das Dokument muß verfaßt worden sein nach dem im Text erwähnten 30.1. 1941, aber vor dem deutschen Angriff auf die Sowjetunion, da Strasser dieses herausragende Ereignis - im Gegensatz zu nahezu allen folgenden Stellungnahmen - mit keinem Wort erwähnt.

602 MarcK, Frankreich ist tot - es lebe Frankreich!, in: NVZ, 9. Jg., Nr. 28 (13. 7. 1940), S. 1.

${ }^{603}$ KATZ, Der Krieg rückt näher, in: NVZ, 9. Jg., Nr. 24 (15. 6. 1940), S. 4. 
ten Sozialismus, wenngleich die Ostoption selbst für die Linkssozialisten vorerst nicht mehr in Betracht kam und darüber hinaus auch die UdSSR als überwiegend außereuropäischer Staat angesehen wurde.

Das politische Wohlwollen des deutschen Exils galt nun Großbritannien. Das Land schien einen Kompromiß zu bieten: ein im Kern europäisches Land von beachtlicher militärischer Stärke, das zwar kapitalistisch geführt, aber demokratisch organisiert war und über eine gewichtige sozialistische Arbeiterbewegung verfügte. Des weiteren lag Großbritannien durch seine Insellage in einer strategisch günstigen Position für einen im ureigensten Interesse des Inselvolkes liegenden Abwehrkampf gegen die potentielle deutsche Weltmacht. Der sozialistische Schriftsteller Hiller schilderte die Wahrnehmung des europäischen Hoffnungsträgers Großbritannien in der Retrospektive in heroischen Worten: „Großbritannien in prachtvoll harter, aber reiner Defensivstellung, auf die deutsche Invasion (die dann nicht kam) wohlvorbereitet"604. Vor allem symbolisierte Großbritannien die letzte Chance einer europäischen Selbstbefreiung, denn jedenfalls das Mutterland des Commonwealth gehörte traditionell dem abendländischen Kulturkreis an. Viele Emigranten setzten ihre Hoffnungen daher auf Großbritannien als die letzte verbliebene Großmacht Europas. An der „Festung der Freiheit“ werde die Barbarei zerschellen ${ }^{605}$. In der Folge richtete sich der Fokus des Europadiskurses auf Großbritanniens europäisches Führungspotential sowohl in der militärstrategisch bestimmten Gegenwart als auch in der politischen Zukunft: „Heute ist das europäische Festland der Naziherrschaft unterworfen. Ein einziges einsames Bollwerk ist übriggeblieben, in dem noch offen von der Sehnsucht nach einem freien und geeinten Europa gesprochen werden darf, das britische Inselreich." ${ }^{\text {606 }}$ Dementsprechend bedurfte es eines konzeptionellen Umdenkens insbesondere derjenigen, die bisher Großbritannien von der künftigen Gestaltung Europas ausgeschlossen hatten.

Dennoch darf die allseitige Konzentration auf Großbritannien als rettende Hand in ihrer europapolitischen Dimension nicht überbewertet werden. Sicherlich sahen einige Exilgruppen, wie Neu Beginnen, in Großbritannien tatsächlich primär den Kopf einer innereuropäischen Selbstrettung. Viele andere probritische Stellungnahmen resultierten aber schlicht aus der momentanen Kriegssituation heraus, in der die USA noch nicht in den Krieg eingetreten waren, die UdSSR sich durch den Hitler-Stalin-Pakt gebunden hatte

${ }^{604}$ Hiller, Die Zukunft des Erdteils, Rede vom 18. Januar 1941. Nachwort, in: Ders., Ratioaktiv 1966, S. 116-34 (133).

605 Die Festung der Freiheit, in: Das Wahre Deutschland (Juli 1940), S. 1-4 (4).

606 [SPIECKER], Die gemeinsame Aufgabe, in: Das Wahre Deutschland (August 1940), S. 2. Das Dokument, als dessen Verfasser in der Tat Carl Spiecker vermutet werden darf, findet sich auch in der kleinen Quellensammlung von VOIGT (Hg.), Friedenssicherung 1988, S. 184-187. Für die Verfasserschaft des Linkskatholiken spricht nicht nur seine Stellung als Herausgeber von Das Wabre Deutschland, sondern auch das typische Bekenntnis zur Notwendigkeit einer reinigenden europäischen Revolution (ibid. S. 2). 
und allein Großbritannien als verbleibende Großmacht aktiv gegen das faschistische Deutschland kämpfte. Vielfach ahnte man, daß sich Europa nicht mehr aus eigener Kraft würde befreien können, obwohl die politischen Emigranten die längst vollzogene Ablösung Großbritanniens durch die USA als führender westlicher Weltmacht 1940/41 noch nicht in ihrer Totalität erkannt hatten. Also begann allmählich die Suche nach einer nur vordergründig paradox anmutenden außereuropäischen Antwort auf die europäische Frage. Als außereuropäische Befreier des europäischen Kontinents kamen nur die beiden neuen Weltmächte USA und UdSSR in Betracht, von denen letztere sich durch den Abschluß des Ribbentrop-Molotow-Vertrages für die Aufgabe der antifaschistischen Abwehr vorerst diskreditiert hatte. Übrigblieben damit die USA. Naheliegend war dieser Gedankengang auch deshalb, weil die USA zwar noch nicht aktiv in den Krieg eingetreten waren, aber Großbritannien ebenso wie die UdSSR finanziell unterstützten. Überlegungen zur Rettung Europas mit Hilfe der UdSSR wurden hingegen vertagt und erst nach dem deutschen Angriff auf die Sowjetunion wieder zur Diskussion gestellt.

In den Erörterungen einer möglicherweise außereuropäischen Hilfestellung zugleich ein größtmögliches Maß an europäischer Autonomie gegenüber Ost und West zu erhalten ${ }^{607}$ stellte sich für die meisten Emigranten als eine Gratwanderung dar, deren Bewältigung sich durch das Einschwenken der UdSSR in die Anti-Hitler-Koalition und den Kriegseintritt der USA 1941 noch schwieriger gestaltete, bis schließlich die schlimmsten Befürchtungen für die Zukunft eines vereinigten Gesamteuropas nach den Konferenzen von Moskau und Teheran bestätigt wurden. Die Position Europas zwischen Ost und West entwickelte sich zu einer der entscheidenden Grundsatzfragen jedes Europamodells und stellte sich in der letzten Diskursphase 1944/45 gar als Überlebensfrage eines selbständigen Gesamteuropas dar. Diese fatale Entwicklung zu erkennen und zur richtigen Zeit mit jeweils adäquaten Lösungsvorschlägen zu begleiten sollte von nun an die zentrale Aufgabe des Europadiskurses im Exil sein.

All diese neuen Aspekte, die durch das Zerrbild einer nationalsozialistisch pervertierten europäischen Einheit provoziert worden waren, mußten nun in die Europakonzeptionen des Exils eingearbeitet werden. In diesem Zusammenhang von Bindungen an den Osten oder Westen zu sprechen, entspräche nicht dem tatsächlichen Anliegen der Emigranten. Wohl aber können die grundlegenden Änderungen als Ost- oder Westorientierung bezeichnet werden. Flexibler als die feste Bindung, meint Orientierung eine eher den einen oder anderen Pol als politisches Entscheidungsfeld akzeptierende Ausrichtung, die jedoch weder mit blindem Gehorsam noch mit übereifrigem Integrationswillen gleichzusetzen ist. Demnach läßt sich die außenpolitische Orientierung definieren als die jeweils gewählte Option eines Gesellschafts- 
musters, dessen staatlichem Träger folglich auch ein Mehr an politischer Entscheidungsgewalt zugedacht wurde.

Erwartungsgemäß und unverändert empfahl die KPD als einzige deutsche Exilgruppe eine prosowjetische Nibelungentreue und wandte sich gegen eine europäische Struktur unter der Führung kapitalistischer Demokratien, denn: „Sind nicht die in so bunten Farben angepriesenen, Vereinigten Staaten von Europa' nur eine verschlimmerte Neuauflage des unter englischer Vorherrschaft stehenden, Völkerbundes'?" ${ }^{608}$ Auf dem linken Auge blind, aber dennoch cum grano salis blickte Wehner in die Zukunft: „Es läßt sich nicht leugnen, daß hinter diesen, ideellen' Kriegszielen [der Westmächte und der Sozialdemokratie, B. S.] höchst materielle Beweggründe stecken. Die kapitalistischen Staaten wollen den Kampf um die Vorherrschaft in der Welt, den Kampf um Einflußsphären und koloniale Ausbeutungsplätze, den sie während des ersten imperialistischen Weltkrieges 1914-1918 führten, jetzt in einem zweiten Waffengang zu Ende führen." 609

Im Verlaufe des Frühjahrs aber kamen angesichts umfangreicher Truppenbewegungen an der deutschen Ostgrenze ernste Zweifel an der Bündnistreue des nationalsozialistischen Regimes auf, und die Kommunisten versuchten, möglicherweise zu erwartende Widersprüche in der sowjetischen Außenpolitik schon im Vorfeld zu erklären: Das "Licht im Osten"610, das positive Vorbild der sowjetischen Gesellschaft schüre den Neid der kapitalistischen Staaten, so daß ständig die Gefahr eines Angriffs auf die Sowjetunion drohe. Daher: „Tretet ein für die Einhaltung des Nichtangriffspakts mit der Sowjetunion. Wir fordern Ausbau der Freundschaft mit den Völkern der Sowjetunion. [...] Keinen Schuß gegen die Rote Armee, keine Granate, kein Flugzeug gegen die 193 Millionen Völker der Sowjetunion. Dann lautet die Parole: Waffen herum' [...]. Hände weg von der Sowjetunion!"611 Es bedarf kaum einer Erwähnung, daß nach dem Schockerlebnis des Hitler-Stalin-Paktes eine so unkritisch prosowjetische Haltung allein bei den Kommunisten vorzufinden war. An diesem Grundtatbestand hatten auch die Ereignisse von 1940 nichts geändert.

Eine intensive und zielgerichtete Westkooperation betrachtete der extreme Individualist Kurt Hiller als strategisch geboten, mit Blick auf die umfassendere Idee eines Weltbundes gar für unerläßlich. Doch war Hiller nicht an einem eigenständigen Europa als dritter Machtkomponente zwischen Ost und West interessiert, sondern verfolgte das Ziel einer kontinental geglieder-

608 Funk [d. i. Wehner], Die Politik der Sozialdemokratie, 1940, BAB RY 1/I 2/707/59, Bl. 293.

609 Ibid.

610 So die Umschreibung Kurt Hillers für die bedingungslose Unterwerfung der KPD unter die Parameter sowjetischer Politik: HiLler, Die Zukunft des Erdteils, 18. 1. 1941, in: DERS., Ratioaktiv 1966, S. 118.

611 Achtung! Achtung! Hände weg von der Sowjetunion!, 5. 5. 1941, Faksimiledruck bei: Pikarski, Uebel (Hg.), Widerstandskampf der KPD 1978, Dok. Nr. 146. 
ten Weltstaatenföderation, für die eine enge Westkooperation die erste wichtige Voraussetzung darstelle. Aus der momentanen Kriegssituation zu Beginn des Jahres 1941 folgerte er die Abwehr des deutschen Angriffs als Englands große strategische Aufgabe - die größere strategische Aufgabe aber sei die Europäische Revolution des freiheitlichen Sozialismus, für die ein multinationaler Generalstab unter britischer Führung eingerichtet werden müsse ${ }^{612}$. Dabei dachte er an eine zentral gelenkte Résistance der unterdrückten Völker Europas gegen die nationalsozialistische Tyrannei. Das ideale Fundament für die Verwirklichung des freiheitlichen Sozialismus in Europa bot seiner Ansicht nach die Paneuropaidee, deren Schöpfer für ihn der „Meister, der genialste, am meisten erleuchtende Verkünder, der Klassiker des paneuropäischen Gedankens" war613. Allerdings bedürfe Coudenhoves Ansatz einer Erweiterung um den „Erdstaatsgedanken“: Notwendig sei ein alle kontinentalen Gruppen umfassender Weltbund, der im bewußten Gegensatz zum Völkerbund universal zu organisieren, kontinental zu gliedern und mit einer machtvollen Exekutive zu versehen sei614. Für die Verwirklichung dieses Erdstaates betrachtete Hiller einen engen Zusammenschluß des Britischen Empires mit den USA und dem künftigen paneuropäischen Bund als einzig erfolgversprechenden Weg. Denn angesichts einer solchen Westkooperation wäre der Gegenspieler Rußland möglicherweise eher geneigt, „sich mit der Westwelt zu verständigen" und sich gesellschaftlich zu liberalisieren, ohne dem Kapitalismus anheim fallen zu müssen ${ }^{615}$. Den bevölkerungsreichen Staaten Asiens und Vorderasiens sowie den afrikanischen Völkern bleibe die Wahl: Ob sie sich letztlich dem Sowjetstaat oder dem Westblock anschlössen oder die kontinentale Eigenständigkeit bevorzugten, bleibe abzuwarten.

Hillers Bedeutung für den Europadiskurs des Exils liegt vor allem in seiner schon 1921 entwickelten „Logokratie“, der Theorie von der Herrschaft des Geistes als intellektuelles und moralisches Prinzip, in dem er ab 1940/41 das gedankliche Verbindungselement zwischen dem Europagedanken und der Idee des freiheitlichen Sozialismus sah ${ }^{616}$. So bemühte sich der „eigenwillige Verkünder eines revolutionären Pazifismus"617 um eine politiktheoretische Legitimation der Symbiose zwischen dem Europagedanken und der Idee des

612 Hiller, Die Zukunft des Erdteils, Rede vom 18. Januar 1941, in: DERS., Ratioaktiv 1966, S. $120 \mathrm{f}$.

${ }^{613}$ Ibid. S. 124. Zum Erdstaatsgedanken erläuterte Hiller, ibid.: "Natürlich hört der föderative Gedanke bei Europa nicht auf; wie er die Völker eines Kontinents zu einer lebendigen und friedlichen Einheit zusammenschließen will, so will er auch die Kontinente zusammenschließen - zu einem die Erde umspannenden, die ganze Menschheit umfassenden Friedensstaat. “

614 Ibid. S. 125.

615 Ibid.

616 Ibid.: „Der paneuropäische und Erdstaatsgedanke geht Hand in Hand mit dem Gedanken eines freiheitlichen Sozialismus."

617 Vgl. VOIGT (Hg.), Friedenssicherung 1988, S. 126. 
freiheitlichen Sozialismus. In einem „Abriß eines Systems der gesollten $\mathrm{Zu}$ kunft" bekannte er sich zur logokratischen Durchbrechung des absoluten Souveränitätsprinzips, um Europa in zollpolitischer, währungspolitischer, produktionspolitischer, militärischer und rechtlich-moralischer Hinsicht unter der Gesetzgebung des Geistes zu vereinen ${ }^{618}$.

Angesichts ihrer antisowjetischen Grundhaltung sah die Sopade keine Notwendigkeit, auf ihre Befürwortung einer Kooperation mit dem Westen erneut hinzuweisen. Dies um so mehr als man die ausführlichere Debatte um eine Aktualisierung und Konzeptionalisierung der Europavorstellungen erst Anfang 1940 aufgenommen hatte. So wirken die verhältnismäßig wenigen Ausarbeitungen des sozialdemokratischen Parteivorstandes zur veränderten Lage nach „Frankreichs Katastrophe "619 farblos. In nur neun Stichworten skizzierte Erich Rinner Ende 1940 das europapolitische Programm seiner Partei ${ }^{620}$ und bediente sich dabei offenkundig der Vorlagen des Heidelberger Parteiprogramms sowie des Memorandums an Sumner Welles vom März 1940621. Diese Vorgehensweise machte sich auch der Innenpolitiker Ollenhauer zu eigen, als er auf der Londoner Parteikonferenz vom Mai 1941 ein nicht minder blasses Grundsatzreferat zum Thema „Der kommende Friede und das kommende Deutschland" hielt ${ }^{622}$. Rinners Sammelsurium unverbindlich zeitloser Parolen erwähnt mit keinem Wort die veränderte strategische Situation Europas und stieß in den eigenen Reihen auf Widerspruch, so insbesondere von Curt Geyer, Albert Grzesinski und Karl Höltermann. Die teilweise konfusen Aufzeichnungen des nach Großbritannien geflüchteten Höltermann lassen jedoch kaum ein Mehr an konzeptioneller Vorstellungskraft erkennen. Unter der Bezeichnung Free German Committee hatte Höltermann im Februar 1941 in England lebende deutsche Parlamentarier als

618 Hiller, Die Zukunft des Erdteils, 18. 1. 1941, in: Ders., Ratioaktiv 1966, S. 123 und $127 \mathrm{f}$

619 KATZ, Frankreichs Katastrophe und die U.S.A., in: NVZ, 9. Jg., Nr. 25 (22. 6. 1940), S. 4.

620 [Rinner], Beitrag zur Diskussion über die Friedensziele. Entwurf zu einem Katalog der Probleme, o. D. [1940/41], AsD, Bestand PV-Emigration Sopade, M. 179, insb. S. 3. 621 [Parteivorstand der Sopade], Memorandum, o. D. [März 1940], S. 2, AsD, Bestand PV-Emigration Sopade, M. 179.

622 Dies trifft ebenso auf Ollenhauers frühere Rede über die Aufgaben der Union vom 4. 4. $1941 \mathrm{zu}$, abgedruckt in: EIBER (Hg.), Union 1998, Dok. Nr. 10, S. 26-29. Ollenhauer, der sich in der außenpolitischen Dimension seines Vortrages vom Mai 1941 auf wenige Sätze beschränkte, versuchte gar nicht erst, den Anschein der Originalität zu erwecken: „Ich habe nicht das Amt, eine bestimmte Auffassung zu vertreten. [...] Als Grundlage für meine Vorlage dienen die früheren Veröffentlichungen des PV.“ Dies veranlaßte Walter Loeb zu der Bemerkung, die geistigen Probleme seien in Ollenhauers Vortrag in den Hintergrund getreten, und der Konferenzleiter Hans Vogel resümierte am Ende der Sitzung: „Die Aussprache hat sich größtenteils in luftleerem Raume bewegt.“; Protokoll der SPD-Konferenz „Der kommende Friede und das kommende Deutschland" am 10./11.5. 1941, abgedruckt in: EIBER (Hg.) Union 1998, Dok. Nr. 210, S. 499-513 (500, 506 und 511). 
Kern einer „Repräsentativen Körperschaft“ des deutschen Exils, mithin einer Art Exilregierung um sich gesammelt ${ }^{623}$. Man warb in Übereinstimmung mit dem in den USA exilierten Sollmann für ein Europa unter britischer Führung und amerikanischer Tolerierung ${ }^{624}$ und begnügte sich im übrigen mit dem pauschalen Seufzer: „Es wird sehr schwer sein, eine neue Karte von Europa zu planen." 625 Karten und Grenzen waren für Höltermanns politisches Grundverständnis von außerordentlicher Bedeutung. Für den Verbandsfunktionär war Politik „Denken in Grenzen, wie Mathematik ein Denken in Maßen und Zahlen"626. Mit diesen Axiomen war eine verbindliche Rechtsordnung in einem föderativen Europa schlicht unvorstellbar, so daß auf konkretere Erfahrungshorizonte zurückgegriffen werden mußte: „Zu den Spielregeln für Fußball gehören die Linien auf dem Spielfeld. Zum Internationalen Recht gehört ein System von Staatengrenzen. [...] Wir bedürfen der Linienkonstruktionen auf dem Fußballfeld und der Staatengrenzen auf dem Kontinent, um überhaupt Regeln oder Gesetze anwenden zu können. ${ }^{\text {"627 }}$

Albert Grzesinski dagegen sah sich zu einer ausführlicheren Auseinandersetzung mit der Friedensproblematik der Nachkriegszeit veranlaßt und entwarf Richtlinien für einen Bund demokratischer Nationen als Nachfolgeorganisation des Völkerbundes. Mit der europäischen Frage beschäftigte sich der ehemalige Polizeipräsident von Berlin bewußt nur im Rahmen einer weltweiten Neuordnung, um sich nicht dem Vorwurf der Inkompatibilität mit den Nachkriegsplänen der Alliierten aussetzen zu müssen. Insgesamt finden sich in Grzesinskis Richtlinienentwurf viele Gedanken aus Hilferdings Referat von Anfang 1940 wieder, insbesondere hinsichtlich der ökonomischen Ausgestaltung. Doch bleibt das Dokument hinter den recht detaillierten Institutionalisierungsplänen anderer Emigranten aus dieser Diskursphase weit zurück ${ }^{628}$. Auch Curt Geyer, den Rinner in seinem Manuskript mit

623 Der Gruppe gehörten nach Höltermanns eigenen Angaben an: Arthur Arzt, Max Braun, August Weber, der bayrische Landtagsabgeordnete Franz Aenderl sowie die sächsischen MdL Paul Heide, Hans Geisser und Curt Weckel. Als ständige Mitarbeiter waren daneben Otto Lehmann-Russbueldt und der Jurist Heinz Braun benannt; vgl. [Karl Höltermann], Memorandum über die künftigen Grenzen Deutschlands, z. Hd. des Herrn Präsidenten der Republik Čzechoslovakia, 18. 3. 1941, S. 1, AsD, NL Höltermann, M. 1.

${ }^{624}$ Ibid. Zu Sollmanns parallelem Vorschlag einer europäischen Einigung unter dem anglo-amerikanischen Schutzschild vgl. seinen Brief an Stampfer vom 3. 4. 1941, AsD, NL Stampfer, M. 13.

625 [Höltermann], Europa - ohne Hitler (Entwurf), o. D., AsD, NL Höltermann, M. 7. 626 [Ders.], Grenzen 4, Manuskript, o. D., AsD, NL Höltermann, M. 7.

627 [Ders.], Staatengrenzen und Internationales Recht, o. D., AsD, NL Höltermann, M. 7. Ein besonders hartes Urteil über Höltermann als Mensch und Politiker findet sich in einem privaten Brief Löwensteins an Hermann Rauschning vom Karfreitag 1941, BAK, NL Löwenstein, N 1222, Bd. 11: „Höltermann, den ich recht gut kenne, halte ich für einen der unfähigsten Männer überhaupt, halbgebildet, arrogant und hohl. Das ist natürlich vertraulich."

${ }^{628}$ Grzesinski, Gedanken über die Zusammenarbeit der Nationen nach dem Siege der 
zahlreichen abweichenden Voten erwähnt, fertigte im April 1941 eine eigene Skizze über den kommenden Frieden an und ließ sie Ollenhauer in London zukommen $^{629}$. In einigen zentralen Punkten erwies sich Geyer zwar als der überlegene Außenpolitiker und Europavisionär, stieß gerade damit aber auf Widerstand im Londoner Rumpfvorstand 630 . So erteilte der langjährige außenpolitische Vordenker des exilierten Parteivorstands den linkssozialistischen Vorstellungen einer europäischen Planwirtschaft eine Absage, weil die Aufstellung des Planes nur auf diktatorischem Wege dekretiert werden könne ${ }^{631}$. Darüber hinaus definierte Geyer den freien Personen- und Warenverkehr, die ungehinderte Wanderung und Niederlassung als die vier elementaren europäischen Grundfreiheiten, die allein mit Zustimmung des modifizierten Völkerbundes eingeschränkt werden könnten ${ }^{632}$. Damit nahm Geyer gedanklich die vier justiziablen Grundfreiheiten der Europäischen Gemeinschaft vorweg und redete im Vergleich zu den zurückhaltenderen Anmerkungen Hilferdings vom Januar 1940 einer stärker interventionistischen Zentralgewalt das Wort.

Für den in die USA emigrierten Teil der Sopade sprach sich Rudolf Katz zugunsten einer Militärintervention seines Gastlandes aus: „Es ist eine Ironie der Geschichte, daß gerade das Land, das durch Tradition, Erziehung, geographische Lage und Machtposition sozusagen von der Vorsehung dazu berufen ist, zum Retter der bedrohten großen Menschheitsideen der Freiheit und der Demokratie zu werden, im Augenblick durch seine demokratischen Einrichtungen selbst, durch die bevorstehende Präsidentenwahl, aktionsunfähig gemacht wird."633 Ähnliche Ansichten, wenngleich häufig auf Großbritannien bezogen, finden sich in linkskatholischen und liberalen Stellungnahmen. Eine Ostoption war in diesen politischen Kreisen gar nicht erst erörtert worden. Ganz im Gegenteil zeigte man sich bemüht, die drohende Degradierung Europas zu einem bloßen Annex des sowjetischen Macht-

demokratischen Mächte, 2. 3. 1941, IfZ, Slg. Kurt Glaser, ED 202/1. Die Quelle ist abgedruckt bei VoIGT (Hg.), Friedenssicherung 1988, S. 70-73 sowie auf englisch bei LIPGENS (Hg.), Documents II 1986, Dok. Nr. 212, S. 572-575. In institutioneller Hinsicht dachte Grzesinski insbesondere an ein europäisches Bundesgericht für Personalangelegenheiten der Föderation sowie ein Schiedsgericht für internationale Streitigkeiten.

629 Geyer an Ollenhauer, 21. 4. 1941 mit Annex: [Skizze über den kommenden Frieden], AsD, Bestand PV-Emigration Sopade, M. 44.

630 Geyer an Ollenhauer, 22. 5. 1941, AsD, Bestand PV-Emigration Sopade, M. 44: "Daß Ihr nicht mit allen Punkten meiner Skizze einverstanden seid, verstehe ich ganz gut - das sind eben die Punkte, über die ernstlich diskutiert und beraten werden muß." 631 Geyer an Ollenhauer, 21. 4. 1941, AsD, Bestand PV-Emigration Sopade, M. 44.

632 Geyer, [Skizze über den kommenden Frieden], 21. 4. 1941, S. 2, AsD, Bestand PVEmigration Sopade, M. 44. Bemerkenswert ist der innenpolitische Vorschlag Geyers, zum Schutz der neuen freiheitlichen Verfassung Deutschlands öffentliche Ämter nur an "grundsätzliche Anhänger der neuen Verfassungsgrundsätze" zu übertragen, vgl. ibid. 633 KATZ, Frankreichs Katastrophe und die U.S.A., in: NVZ, 9. Jg., Nr. 25 (22. 6. 1940), S. 4. Die angesprochene Präsidentenwahl ist die erste Wiederwahl F. D. Roosevelts zum Präsidenten der Vereinigten Staaten. 
blocks gerade durch die Einigung Europas zu verhindern. Leitlinie war die Solidarität des christlichen Abendlandes: "Jetzt endlich muß die große europäische Idee sich verwirklichen und zur Reife gelangen, die Idee der schicksalhaften Verbundenheit der europäischen Völker, der tief reichenden Verwurzeltheit in gemeinsamem Erleben, in gemeinsamem Leid und gemeinsamer Hoffnung, die Idee des christlichen Abendlandes im Gewand des zwanzigsten Jahrhunderts." 634

Unverdrossen erhob Neu Beginnen zugunsten einer europäischen Eigenständigkeit zwischen Ost und West seine Stimme. Hierfür war in der momentanen Situation eine strategische Einbindung in den Westen unvermeidbar, um unter der kritisch beäugten, aber aus taktischen Erwägungen geduldeten Observanz des britischen Kapitalismus Europa als west-östlichen Diwan des Weltfriedens zu konzipieren.

Mehr denn je zeigte man sich überzeugt, daß die virulente Gefahr einer Teilung Europas in konträre weltpolitische Einflußbereiche das zentrale Problem sei, als das es sich in der Tat schon bald erweisen sollte: „Die Wahl steht zwischen dem Weg zur sozialistischen Föderation und dem Untergang. Und der ungeheure Druck dieser Alternative bietet die einzige Chance, daß die Schwierigkeiten einer jahrzehntelangen Fehlentwicklung noch überwunden werden." 635

Mit der abschreckenden Umwandlung Europas in einen einheitlichen nationalsozialistischen Herrschaftsraum sah man sich gezwungen, auf Großbritannien als die einzig verbliebene europäische Karte zu setzen, wollte man Europa in den späteren Verhandlungen über seine Zukunft ein Stimmrecht erhalten. In einer rasch vollzogenen Abkehr von der antibritischen Position der Jahre 1938/39 fand sich Großbritannien seit der Niederlage Frankreichs als militärpolitischer Grundstein der Europakonzeption von Neu Beginnen wieder ${ }^{636}$. Dies zeigt nicht nur das ernsthafte Bemühen der Gruppe um ein selbständiges Europa als dritte Kraft in der Ost-West-Konfrontation, sondern auch das Einschätzungsvermögen des politisch Machbaren. Die Grundeinstellung förderte den Verzicht auf einen europäischen Weltführungsanspruch ebenso wie den Verzicht auf die sozialistische Weltrevolution, um das politisch machbare Projekt eines sozialistischen Europas nicht zu gefähr$\operatorname{den}^{637}$.

Um dem überlieferten Mißtrauen gegen den englischen Imperialismus aber dennoch Rechnung tragen zu können, schloß man Großbritannien von

634 [SPIECKER], Die gemeinsame Aufgabe, in: Das Wahre Deutschland (August 1940), S. 2.

635 [Schoettle?], Deutsche und europäische Revolution, o. D. [Sommer 1940-Sommer 1941], S. 11, AsD, NL Schoettle, M. 64.

636 Rußland und die deutsche Revolution, o. D. [Mitte 1940], S. 8, IISG, Coll. Neu Beginnen, M. 41 .

637 [Schoettle?], Deutsche und europäische Revolution, o. D. [Sommer 1940-Sommer 1941], S. 10, AsD, NL Schoettle, M. 64. 
allen weiteren Integrationsschritten wie der wirtschaftlichen und allgemein politischen Föderation aus, zumal es kein wirklich europäisches Land sei. Dogmatisches Fernziel war unverändert ein sozialistisches Gesamteuropa. In realistischer Einschätzung der tatsächlichen Machtverhältnisse aber begnügte man sich vorerst mit der Schaffung eines selbständigen nichtsozialistischen Europas, das in sicherheitspolitischer Hinsicht mit den Flügelmächten Großbritannien und UdSSR verbündet sein sollte, nach innen aber eine rein binneneuropäische Föderation zu entwickeln habe ${ }^{638}$. Für den Aufbau der letztlich sozialistischen Binnenstruktur wurde eine gelungene Verbindung der sozialen Revolution mit der allgemeinen Friedenssehnsucht als erfolgversprechend angesehen ${ }^{639}$. In diesem Zusammenhang verwies Waldemar von Knoeringen auf das unterschiedlich gewichtete soziale Revolutionspotential in Europa. Im Gegensatz zum industriellen Nordwesteuropa stehe im agrarischen Südosten auf Grund der ungelösten Nationalitätenprobleme die soziale Revolution nunmehr auf der Tagesordnung; zentrales Anliegen jeder Europakonstruktion müsse daher die schrittweise Angleichung dieser Unterschiede $\operatorname{sein}^{640}$.

Die Differenzierung zwischen einem sicherheitspolitisch definierten äußeren Kreis und einem umfassend föderalistisch orientierten inneren Kreis bot den Vorteil, daß ein nach außen militärisch abgesichertes Kontinentaleuropa mit Bedacht eine erst föderative, dann sozialistische Binnenstruktur aufbauen könnte, ohne die Mißgunst der ehemals gefährlichen Flügelmächte fürchten zu müssen. Somit barg das Konzept von Neu Beginnen ein konzentrisches Europamodell mit einem stärker föderal orientierten inneren Kreis und einem auf die Sicherheitspolitik beschränkten, intergouvernementalen äußeren Kreis, der über Großbritannien indirekt auch die USA umfassen würde ${ }^{641}$. Auf diese Weise würde selbst ein sicherheitspolitisch erweitertes Europa seine Unabhängigkeit bewahren, bevor es sich nach sozialistischem Muster organisieren würde: „Wir sehen die Sicherung gegen den Stalinismus und die Befriedigung der englischen Interessen in der Bildung eines Sicherheitssystems des revolutionären Europas unter englischer Führung, die Sicherung gegen den kapitalistischen Interventionismus und die Befriedigung der russischen Interessen in der Anerkennung der russischen Territorialgewinne [...], in der rein defensiven Gestaltung des Sicherheitssystems und in der Sicherung dieses defensiven Charakters durch den sozialistischen Einfluß auf dem Kontinent, durch den Einfluß der englischen Arbeiterpartei und durch intensiven Austausch des neuen europäischen Wirtschaftsgebiets mit

638 Ibid. S. $8 \mathrm{ff}$.

639 Ibid. S. 6.

640 [Knoeringen], Sinn und Grenzen europäischer Zielpropaganda, September 1940, S. $2 \mathrm{f}$, AsD, NL Knoeringen, M. 137.

641 [Schoettle?], Deutsche und europäische Revolution, o. D. [Sommer 1940-Sommer 1941], S. 9, AsD, NL Schoettle, M. 64. 
Rußland.“642 Damit ging Neu Beginnen deutlich über die vage Kompromißformel im Gründungskommuniqué der Union deutscher sozialistischer Organisationen in Großbritannien vom 19.3. 1941 hinaus. Dort hatte man ursprünglich statt einer Stellungnahme zur europäischen Frage eine Abgrenzung zu anderen Exilgruppen und Emigranten vorgesehen. Erst nach mehrfacher Intervention aller linkssozialistischen Gruppen, die in jeder der vier Vorbesprechungen auf die Bedeutung der europäischen Dimension für einen dauerhaften Frieden hinwiesen, wurde auf Schoettles Vorschlag noch am Tag der Veröffentlichung des Kommuniqués ein Satz ergänzt ${ }^{643}$ : „[Die beteiligten Organisationen, B. S.] werden sich gleichzeitig bemühen, an der Vorbereitung eines demokratischen Friedens mitzuwirken, der einem neuen Deutschland die Möglichkeit gibt, als freies Glied der europäischen Völkergemeinschaft seinen Beitrag zum Wiederaufbau Europas zu leisten." 644

Entgegen der allgemeinen Tendenz in der politischen Emigration, die jedenfalls 1940/41 noch von der Realisierbarkeit eines gesamteuropäischen Integrationsprozesses ausging, waren vereinzelt kritische Stimmen zu vernehmen, die zwar dem Projekt Europa wohlwollend gegenüberstanden, an der baldigen Umsetzung aber machtpolitisch begründete Zweifel hegten. Zu den Kritikern zählt auch der ehemalige sozialdemokratische Finanzsenator der Freien Stadt Danzig, Bernhard Kamnitzer, der im Rahmen seiner Mitarbeit in Grossmanns Komitee für einen gerechten Frieden, ein demokratisches Deutschland und ein föderatives Europa ein Thesenpapier zur europäischen Frage erarbeitete. Einer Verwirklichung der europäischen Idee standen seiner Ansicht nach vorerst sechs wesentliche Hindernisse entgegen: Sowohl Großbritannien als auch die Sowjetunion müßten als nur teilweise europäische Mächte ausgeschlossen bleiben. Dies aber würde ihre machtpolitische Stellung auf dem europäischen Kontinent nachhaltig schwächen, so daß sie einer europäischen Föderation keinesfalls ihr Plazet erteilen würden. Auch seien die monarchistischen und kolonialistischen Gegenkräfte in Europa selbst

642 Rußland und die deutsche Revolution, o. D. [Mitte 1940], S. 7, IISG, Coll. Neu Beginnen, M. 41. Zur Föderalstruktur des Sicherheitssystems vgl. [Schoettle?], Deutsche und europäische Revolution, o. D. [Sommer 1940-Sommer 1941], S. 6, AsD, NL Schoettle, M. 64. Die Idee eines europäischen Militärbündnisses auf der Grundlage eines anglo-russischen Nukleus wurde 1942 erneut aufgegriffen, vgl. Draft Statement on Peace Guarantees, o. D. [Herbst 1942], IISG, Coll. Neu Beginnen, M. 42.

643 Eichler wandte sich in der ersten Vorbesprechung am 25.2. 1941 gegen eine allzu vage Formulierung zur europäischen Dimension des antifaschistischen Kampfes und beantragte eine entsprechende Änderung der Gründungserklärung. In der letzten Vorsprechung am 19. 3. 1941 intervenierte der neu ernannte SAP-Vertreter Schuricht gegen die nur geringfügig geänderte Fassung und verlangte eine Ergänzung der Erklärung, um der europäischen Frage einen eigenen Satz zu widmen. Daraufhin schlug Schoettle als Vertreter von Neu Beginnen die letztlich einstimmig beschlossene Formulierung vor; Eiber (Hg.), Union 1998, Dok. Nr. 1, S. 3-7 (7) sowie Dok. Nr. 5, S. 16 f. (16).

644 Gemeinsame Erklärung über die Gründung der Union deutscher sozialistischer Organisationen in Großbritannien vom 19. 3. 1941, abgedruckt in: EIBER (Hg.), Union 1998, Dok. Nr. 6, S. 18 f. (19). 
nicht zu unterschätzen. Des weiteren sei nach Kriegsende mit einem stark ausgeprägten $\mathrm{Haß}$ auf Deutschland und die Deutschen zu rechnen, der die für einen dauerhaften Frieden notwendige Beteiligung Deutschlands unmöglich erscheinen lassen werde. Schließlich stünde die europäische Vielfalt in Sprache, Kultur und Geschichte einer übereilten Föderation entgegen ${ }^{645}$.

Trotz allem hielt Kamnitzer am Fernziel einer europäischen Föderation fest und schlug für die schrittweise Annäherung an dieses Ziel die Bildung von vier ethnisch-sprachhistorisch definierten Staatengruppen vor, die im Idealfall als Bundesstaaten zu konzipieren seien und nur bei vehementem Widerstand gegen den Föderationsgedanken auf die Konstruktion des Staatenbundes zurückgreifen sollten. Die Föderationen zeichneten sich durch ein einheitliches Zollgebiet, eine einheitliche Wirtschafts- und Geldpolitik mit einer gemeinsamen Währung sowie eine einheitliche Außenpolitik aus. Um eine wirtschaftliche Übermacht Deutschlands auszuschließen, kreierte Kamnitzer eine deutsche Staatengruppe, die lediglich aus Deutschland und Österreich bestehen sollte ${ }^{646}$.

\section{4. „Klare Fronten“? - Europa zwischen West und Ost (1941-1943)}

Hitlers unerwarteter Angriff auf die UdSSR am 22. Juni 1941 leitete im Zusammenspiel mit der Verkündung der Atlantikcharta vom 14. August 1941 und dem Kriegseintritt der USA Anfang Dezember desselben Jahres eine neue Phase des Europadiskurses ein. Die Sowjetunion meldete sich gezwungenermaßen als aktiver Faktor im europäischen Machtpoker zurück und wurde in den Nachkriegskonzeptionen des deutschen Exils verstärkt berücksichtigt.

Für Richard Löwenthal und einige andere Linkssozialisten bedeutete die Eingliederung der Sowjetunion in die Reihen der antifaschistischen Kriegsgegner die Restauration weltpolitisch „klare[r] Fronten“ zwischen Faschisten und Antifaschisten ${ }^{647}$. Tatsächlich aber bewirkte die Änderung der machtpolitischen Situation eine andere, für das gesamte politische Exil bedeutsame Front: den Interessenkonflikt zwischen West und Ost auf europäischem Boden. Die politische und konzeptionelle Handhabung dieser Konfrontation war längst nicht so klar wie das gemeinsame Kriegsziel der Überwindung des Nationalsozialismus. In den Worten des Historikers Walter Lipgens spiegelt sich die übergeordnete Bedeutung des Ost-West-Konfliktes $^{648}$ für den Europadiskurs auch der deutschen Exilgruppen wider: „[Die

${ }^{645}$ Kamnitzer, Europa nach dem Kriege. Ein Vorschlag, 11. 1. 1941, S. If., IfZ, Slg. Glaser, ED 202/1.

646 Ibid. S. 2 f.

647 [LÖWENTHAL], Klare Fronten 1941.

648 Der Verfasser ist der Ansicht, daß die konkreten Umstände des Ost-West-Konflikts, die die weltpolitische, europäische und deutsche Nachkriegsgeschichte bestimmten, tatsächlich erst seit 1941 mit dem Kriegseintritt der beiden Weltmächte des 
deutsche Form des Faschismus] erzwang unter Zusammenbruch aller anderen kontinentalen Staaten erstmals eine effektive wirtschaftliche und militärische Einigung des Kontinents, jedoch mit solcher Diktatur, daß alle restlichen europäischen Lebenskräfte und Überzeugungen dagegen in Widerstand traten, das Regime selbst aber nicht mehr durch europäische Koalitionen, sondern nur noch durch den diesmal endgültigen Einmarsch der beiden neuen Weltmächte besiegt werden konnte." 649 Seit der französischen Niederlage im Juni 1940 hatte die Wahrscheinlichkeit einer europäischen Selbstrettung schrittweise abgenommen. Die einzige Hoffnung der deutschen Exilanten hatte auf Großbritannien geruht, obwohl man die starken außereuropäischen Interessen und die daraus resultierende Zurückhaltung der Briten in der Konzipierung einer rein europäischen Lösung durchaus gesehen hatte. Ohnmächtig hatten die deutschen Emigranten mit ansehen müssen, wie zunehmend außereuropäische Einflußfaktoren den Kriegsverlauf und damit auch die Nachkriegsüberlegungen bestimmten. Nun, nach Hitlers überraschendem Angriff auf die UdSSR am 22. Juni 1941, drohte die spezifisch europäische Frage endgültig ihre bisher zentrale Position in den Neuordnungsplänen der kriegführenden Regierungen zu verlieren. Bedingt und beschleunigt durch die weltweite Ausdehnung des Krieges, geriet zusehends die Alternative einer ebenfalls weltweiten Lösung der Nachkriegsproblematik in den Blick der Alliierten.

Auch in der Konstellation der Kriegsgegner Deutschlands zeichnete sich eine Verlagerung der Interessen auf die globale Ebene ab. 1941 provozierte Hitlers Vertragsbruch und Angriff auf die UdSSR das russische Bündnis mit Großbritannien, das am 12. Juli 1941 vertraglich fixiert wurde. Dadurch wurde die Perspektive der gegen Deutschland kämpfenden Front nun sichtbar von der europäischen auf die weltweite Ebene verlagert. Dies implizierte andere, von den rein europäischen Problemen losgelöste Überlegungen, zumal die UdSSR mit dem nur vorübergehend unterdrückten russisch-japanischen Konflikt eine asiatische Dimension in die strategischen Erörterungen des Bündnisses einfließen ließ. Es ging längst nicht mehr nur um den Krisenherd Europa, sondern um die Neuverteilung der weltweiten Machtinteressen. Noch einmal verstärkt wurde diese Entwicklung durch den aktiven Eintritt der USA in den Krieg am 8. Dezember 1941, womit das außereuropäische Gewicht und die globale Interessenlage der nunmehr verwirklichten Anti-Hitler-Koalition erneut erhöht und zum bestimmenden Maßstab der alliierten Nachkriegsplanungen erhoben wurde.

20. Jahrhunderts politisch virulent wurden; vgl. dazu die Studie von LOTH, Teilung der Welt ${ }^{71989, ~ S . ~} 13$ et passim (DÜLFFER, Jalta 21999 , S. 238 et passim setzt den Beginn des Ost-West-Konflikts erst mit der Konferenz von Jalta an). Dabei soll jedoch keineswegs bestritten werden, daß die Ost-West-Konfrontation ihre politisch-ideologischen Wurzeln bereits in der Oktoberrevolution und dem Eintritt der USA in den Ersten Weltkrieg 1917 hat.

${ }^{649}$ LIPGENS, Anfänge 1977, S. 6. 
Gleichzeitig wurde den Emigranten mehr und mehr einsichtig, daß ihre Einflußmöglichkeiten auf die Regierungen der Anti-Hitler-Koalition als verschwindend gering bis nicht existent bezeichnet werden mußten. Bis Ende 1943 reifte allmählich die Erkenntnis heran, daß weder eine deutsche oder gar europaweite sozialistische Revolution noch eine andersartige innereuropäische Integrationskraft über die Zukunft Europas entscheiden werde ${ }^{650}$, und daß eine Rettung Europas aus eigener Kraft in den Überlegungen der Alliierten überhaupt nicht mehr vorkam. Die eher der Verzweiflung als einem realpolitischen Verständnis entsprungene Hoffnung auf eine europazentrische Schwerpunktverlagerung der britischen Politik zu Lasten ihrer außereuropäischen Interessen war zerschellt. Die drei Großmächte England, Rußland und Amerika zeigten kaum ernsthaftes Interesse an einer Erörterung der europäischen Zukunft mit den betroffenen Ländern oder gar den Emigranten.

Wenngleich die über den unmittelbaren militärischen Sieg hinausgehenden Friedensziele der Alliierten bis zur Moskauer Außenministerkonferenz vom Oktober 1943 unklar blieben, kam bald die Befürchtung auf, daß die konventionelle Machtpolitik fortgesetzt und das der Selbsthilfe unfähige Europa als Ganzes dem machtpolitisch geleiteten Einfluß der außereuropäischen Großmächte ausgesetzt werde 651 .

In dieser Situation begannen die Emigranten, erbittert um jede verbliebene Chance einer europäischen Lösung zu ringen und den Bedeutungsverlust Europas als die weltpolitischen Geschicke lenkenden Machtfaktor doch noch aufzuhalten. Denn durch den Kriegseintritt der USA war dieser Bedeutungsverlust faktisch manifestiert und durch die Teheraner Konferenz schließlich offen ausgesprochen worden. Das Ringen um eine europäische Lösung erschien gerade denjenigen Exilanten als zwingend notwendig, die das bedrohliche Szenario eines zwischen dem sowjetisch dominierten Osten und dem anglo-amerikanischen Westen zerrissenen Europas vorausahnten. Folglich stand seit dem durch Hitler provozierten russisch-britischen Kriegsbündnis das Ziel der europäischen Eigenständigkeit Europas als wirtschaftlicher, politischer und kultureller Einheit in der aufziehenden Dichotomie der Weltpolitik im Vordergrund des Europadiskurses.

Am ehesten versprach der Ansatz eines europäischen Föderativmodells dem Ziel deutscher Befriedung und europäischer Eigenständigkeit zu entsprechen. Da vor dem Hintergrund der weltpolitischen Situation alternative, vergleichbar erfolgversprechende Lösungen nicht in Sicht waren, erreichte die Föderalismusdebatte bald einen Punkt, an dem - ungeachtet zahlreicher Differenzen in den Einzelheiten - mehrheitlich die Idee einer souveränitätsbeschränkenden Europaföderation als einzige Möglichkeit angesehen wurde,

650 Vgl. z. B. STAMPFER, Weder Hitler noch Stalin!, in: NVZ, 10. Jg., Nr. 26 (28. 6. 1941), S. 1.

651 So Willi Eichlers Befürchtung in dem von ihm verfaßten Rundschreiben des Bundesvorstandes an die ISK-Funktionäre vom Januar 1943, auszugsweise abgedruckt in: EIBER (Hg.), Union 1998, Dok. Nr. 310, S. 759-765 (762). 
Europa vor der endgültigen Bedeutungslosigkeit zu bewahren und dem Kontinent langfristig wieder zu einem globalen Mitbestimmungsrecht zu verhelfen. Nun ging es nicht mehr um die Frage, ob die Föderation überhaupt die zukunftsweisende Form Europas sei. Erörtert wurde vielmehr die Frage, unter welchen Konditionen eine europäische Föderation in der Lage wäre, den Frieden langfristig zu sichern, ohne Deutschland in zehn oder zwanzig Kleinstaaten zerlegen und den europäischen Kontinent in weltpolitisch definierte Einflußsphären der Alliierten auseinanderfallen zu lassen. Darüber hinaus bot eine europäische Föderation die einzige überzeugende Chance, einer seit 1941 vermehrt diskutierten politischen Zerstückelung und wirtschaftlichen Entmachtung Deutschlands die konstruktive Alternative der Einbindung Deutschlands in einen größeren internationalen Zusammenhang entgegenzusetzen.

Den erfolgversprechendsten Ansatz, das ehrgeizige Ziel einer europäischen Föderation möglichst zügig und homogen umzusetzen, sahen die politischen Flüchtlinge in einer nunmehr konkret zu konzipierenden Wirtschaftsunion als erstem Integrationsschritt. Daher können zwischen 1941 und 1943 intensive Auseinandersetzungen mit den Voraussetzungen und Gestaltungsoptionen eines ökonomischen Zusammenschlusses Kontinentaleuropas beobachtet werden. Durchgängig wurde der wirtschaftliche Zusammenschluß unter dem übergeordneten Ziel der langfristigen Friedenssicherung durch Entschärfung des politischen und sozialen Konfliktpotentials betrachtet.

\subsubsection{Rückkehr der Sowjetunion}

Die Rückkehr der Sowjetunion in die Phalanx der antifaschistischen Mächte stieß bei der KPD auf große Erleichterung, vermochte die durch den HitlerStalin-Pakt verursachte politische Isolierung jedoch nicht aufzuheben. Diejenigen linkssozialistischen Stimmen, die das Ereignis zum Anlaß nahmen, einer ideologischen und politischen Wiederannäherung an die Sowjetunion das Wort zu reden, befanden sich letztlich in der Minderheit. Als selbstverständlich betrachtete es aber auch die Minderheit, daß zwischen der Sowjetunion als sozialistischem Vorbildstaat einerseits und den kommunistischen Machtapparaten, namentlich der Komintern und der KPD, andererseits unterschieden werden müsse. Eichler sprach in diesem Zusammenhang von einem „unüberbrückbaren Gegensatz" und stellte klar: „Nur klare Trennung kann hier die Parole sein. “652

Für den SAP-Vertreter im Exekutivkomitee der Londoner Union, Paul Walter, war klar, daß der Krieg mit dem Überfall auf die Sowjetunion ein neues Stadium erreicht habe, da es der einzigen neutralen Großmacht Europas allen Bemühungen zum Trotz nicht gelungen sei, von den Verwüstungen

652 Rußland und die Komintern 1943, S. 55. Vgl, auch die SAP-Veröffentlichung: Sozialistische Revolution gegen Nazi-Imperialismus 1943, S. 34. 
des zweiten Weltkrieges verschont zu bleiben ${ }^{653}$. Getreu der marxistischen Tradition der Partei hielt die Londoner SAP-Auslandsleitung an der doktrinären Zielsetzung eines europäischen Sozialismus marxistischer Prägung fest ${ }^{654}$ und propagierte nach Hitlers Überfall auf die UdSSR eine kritische Wiederannäherung an die Sowjetunion als Quelle sozialistischer Kampfkraft. Zwar sei die „sklavische Kritiklosigkeit der Kominternanhänger“ zu vermeiden, doch müsse die Kritik an der Sowjetunion hinter dem Respekt für ihre revolutionären Leistungen zurückstehen, zumal in diesem Krieg auch mit Ideen gekämpft werde ${ }^{65}$. Man war überzeugt: „Seit dem Überfall der Naziheere auf die SU hat der russische Staat der Arbeiter und Bauern wieder die Sympathien der Arbeiter der ganzen Welt." 656

Ähnlich sowjetfreundlich äußerte sich ein Arbeitskreis Internationaler Sozialisten in Stockholm, der unter dem beherrschenden Einfluß der SAP-Mitglieder Brandt, Szende und dem Ehepaar Enderle stand. Man bewunderte den "heldenhaften Kampf der Roten Armee und des russischen Volkes" 657 und war gewillt, der Sowjetunion volle Unterstützung für den sozialen Neuaufbau zuteil werden zu lassen ${ }^{658}$.

Die Rückkehr der Londoner SAP zu einer positiven Grundeinschätzung der Sowjetunion als revolutionärer Kraft des internationalen Sozialismus stieß im Exekutivkomitee der Union auf ein differenziertes Echo659. Während sich Neu Beginnen - wenn auch in abgeschwächter Form - der sowjetfreundlichen Kehrtwende der SAP anschloß, begrüßten ISK und Sopade lediglich den militärischen Aspekt des britisch-russischen Bündnisses und behielten im übrigen ihre antisowjetische Grundhaltung bei.

Der Neu Beginnen-Theoretiker Richard Löwenthal verfaßte im August 1941 für das Auslandsbüro Neu Beginnen die programmatische Schrift „Klare Fronten“. Darin begrüßte er die Klarstellung der weltpolitischen Konfliktlinien: „Auf der einen Seite die angelsächsischen Demokratien, die Sowjetunion und China, unterstützt von den unterdrückten Nationen Europas [...], auf der anderen Seite Hitlerdeutschland mit seinen faschistischen und halbfaschistischen Trabanten."660 Die akute Bedrohung der UdSSR durch den nationalsozialistischen Imperialismus verlange von jedem Soziali-

653 Walter, Vorschlag für eine Stellungnahme im Newsletter zum deutschen Angriff auf die Sowjetunion vom 8. 7. 1941, abgedruckt in: EIBER (Hg.), Union 1998, Dok. Nr. 33, S. $77 \mathrm{f}$.

654 Sozialistische Revolution gegen Nazi-Imperialismus 1943, S. 29.

655 Ibid. S. 32 f.

656 Ibid. S. 29.

657 [Arbeitskreis Internationaler Sozialisten in Stockholm], Friedensziele der demokratischen Sozialisten, März 1943, S. 6, AsD, Bestand PV-Emigration Sopade, M. 180.

658 Ibid.

659 Vgl. das Protokoll der Exekutivkomiteesitzung vom 17. 7. 1941, abgedruckt in: EIBER (Hg.), Union 1998, Dok. Nr. 37, S. 85 f.

660 [LÖWENTHAL], Klare Fronten 1941, S. 1. 
sten die Rückbesinnung auf die einmaligen Leistungen der Sowjetunion ${ }^{661}$, die Wiederaufnahme des solidarischen Verteidigungskampfes und den rückhaltlosen Einsatz für die Überwindung der russischen Isolation nach dem Sieg über Hitler ${ }^{662}$. Löwenthal ging sogar so weit, den Hitler-Stalin-Pakt in der Retrospektive als bloße Sicherheitsmaßnahme „zum Schutz der zarten Pflanze des russischen Sozialismus" zu relativieren ${ }^{663}$ und die sowjetische Außenpolitik von weltpolitischen Ambitionen freizusprechen ${ }^{664}$. An dieser Einschätzung hielt er prinzipiell fest ${ }^{665}$, wenngleich er wie Eichler strikt zwischen dem förderungswürdigen Rußland einerseits und einer abzulehnenden Kooperation mit den Kommunisten andererseits unterschied: „The important thing is Russia and not the Communists." ${ }^{666}$

Zurückhaltender als Löwenthal gaben sich die Neu Beginnen-Mitglieder Schoettle in London und Frank in den USA, gingen aber ebenfalls von geklärten Fronten aus. Schoettle beschränkte sich im übrigen auf parteitaktische Schlußfolgerungen. Entscheidend sei nun die Ausnutzung der wieder erwachenden Rußland-Sympathien für eine revolutionär-demokratische Bewegung der deutschen Arbeiterschaft. Die Voraussetzungen hierfür seien nun günstig, wenn man vergleichbaren Bestrebungen der Kommunisten zuvorkomme ${ }^{667}$. Karl Frank, der sich ab 1942/43 intensiver in die Europadebatte einbrachte, teilte die Einschätzung, daß mit der russischen Eingliederung in die antifaschistische Front „der Nazi-Überfall [...] eine prinzipielle Wendung der Lage und der Politik erzwungen" habe ${ }^{668}$. Auf diese Weise sei

661 Ibid. S. 9: „Der Gedanke, daß diese materiellen Voraussetzungen [gemeint ist das erreichte technische Niveau von Landwirtschaft, Industrie und Transportsystem der SU als kriegswichtige Wirtschaftsbereiche, B. S.] in nur zwei Jahrzehnten, auf rückständigster Grundlage und unter den unerhörten Schwierigkeiten der Isolierung von einem Staat ohne Kapitalisten geschaffen worden sind, muß jeden Sozialisten mit Stolz erfüllen."

662 Ibid. S. 12.

663 Ibid. S. 11

664 Ibid. S. 2.

665 Sering [d. i. Löwenthal], Unsere Taktik gegenüber den Kommunisten, 6. 6. 1942, S. 2, IISG, Coll. Neu Beginnen, M. 40: „Wir müssen, wo irgend möglich, in praktischen Gegenwartsfragen und nicht nur in prinzipiellen Diskussionen unser Interesse an der Verteidigung der Sowjetunion aktiv zum Ausdruck bringen."

666 Löwenthal an Frank, 28. 10. 1942, abgedruckt in: EIBER (Hg.), Union 1998, Dok. Nr. 322, S. 822-827 (825).

667 Schoettle, Vorschlag für eine Stellungnahme im „New Letter“ zum deutschen Angriff auf die Sowjetunion, vorgelegt am 8. 7. 1941, abgedruckt in: EIBER (Hg.), Union 1998, Dok. Nr. 31, S. 70-73.

${ }^{668}$ Hagen [d. i. Frank], Entwurf: Die Sowjetunion im Kriege [Januar 1942], S. 14, IfZ, NL Frank, ED 213/3. Bei der handschriftlich vermerkten Datierung "Januar 1941“ (die ursprüngliche Monatsbezeichnung „April“ ist durchgestrichen) handelt es sich sicherlich um einen Schreibfehler Franks. Gemeint ist wohl Januar 1942, denn Frank bezieht sich unmißverständlich auf den deutschen Angriff auf die Sowjetunion vom 22. 6. 1941. Dafür spricht auch die Datierung eines zweiten Exemplars in Franks Nachlaß im IfZ, ED 213/2, das von November 1942 datiert. 
die UdSSR erneut zu einem bedeutenden fortschrittlichen Faktor der gegenwärtigen Welt geworden ${ }^{669}$. Hinsichtlich der künftigen Position der Sowjetunion im weltpolitischen Machtgefüge aber wollte sich Frank vorerst nicht festlegen, da dies vom Ausgang des Krieges abhängig sei670.

Eindeutig fiel dagegen Eichlers Votum aus. Der Vorsitzende des ISK legte Wert auf die Feststellung, daß nun alle in den Kampf eintreten müßten - England, Rußland und auch Amerika. Dabei war Eichler der russische Verbündete ausschließlich aus strategischen Gesichtspunkten willkommen. Eine ideologisch-moralische Auseinandersetzung hielt er zu diesem Zeitpunkt für überflüssig: "Wer lieber der Illusion huldigt, ein Arbeiterstaat sei in Gefahr und er möchte deshalb zu Aktionen kommen, sollte sein Steckenpferd nicht zerstört bekommen. Man sollte über den ,Arbeiterstaat' also möglichst gar nichts sagen, sondern sich darauf beschränken, den blindgläubigen Huldigern Moskaus zu sagen: Also auch Euer Vaterland ist nun in Gefahr." ${ }^{671}$

Während sich der Londoner Rumpfvorstand der Sopade mit der blassen Formel begnügte, der unersättliche Machtwille Hitlers habe Rußland in die Front zurückgezwungen, in der es einst gestanden habe ${ }^{672}$, nahmen die Vertreter des amerikanischen $\mathrm{Z}$ weiges der Sopade eine härtere Abwehrhaltung gegenüber jeder das notwendige Maß überschreitenden Zusammenarbeit mit der Sowjetunion ein. Ungeachtet früherer Aussagen als führendes Mitglied der oppositionellen SPD-Gruppe Paris titelte Siegfried Marck unmittelbar nach dem deutschen Überfall auf die Sowjetunion: „Keine ,Appeasement'Politik gegenüber dem Stalinismus - Keine Wiederbelebung der ,Volksfront'-Ideologie!"673 Solange Rußland selbst nicht zu den sozialen Demokratien gezählt werden könne, sei eine - langfristig wünschenswerte - Eingliederung Rußlands in eine Föderation der Weltdemokratien nicht denkbar $^{674}$. Auch Rudolf Katz fürchtete die Neubelebung vergangener Debatten.

669 Ibid. S. 15.

670 Ibid. S. 23.

671 Eichler, Vorschlag für eine Stellungnahme im „New Letter“ zum deutschen Angriff auf die Sowjetunion vom 1.7. 1941, abgedruckt in: EIBER (Hg.), Union 1998, Dok. Nr. 32, S. $74 \mathrm{ff}$.

672 Ollenhauer, Vogel, Vorschlag für eine Stellungnahme im „New Letter“ zum deutschen Angriff auf die Sowjetunion vom 10. 7. 1941, abgedruckt in: EIBER (Hg.), Union 1998, Dok. Nr. 34, S. 79 f. (79).

${ }^{673}$ MARCK, Einheitsfront oder Zweck-Allianz?, in: NVZ, 10. Jg., Nr. 26 (28. 6. 1941), S. 1.

674 Ibid. Die Hoffnung auf einen innerrussischen Demokratisierungsprozeß teilten viele Sozialisten. So äußerte der Gewerkschafter Hans Gottfurcht die Ansicht, daß die Sowjetunion als Partner der westlichen Demokratien im Kampf gegen Hitler jede erdenkliche militärische Hilfe verdiene, obwohl sie selbst eine diktatorische Struktur aufweise. $\mathrm{Ob}$ diese militärische Zusammenarbeit im Kampf für demokratische Werte innenpolitische Wirkung in der UdSSR selbst zeitigen werde, hänge von der Einsichtsfähigkeit der sowjetischen Führung in ihre Fehler ab (Gottfurcht, Vorschlag für eine Stellungnahme im "News Letter" zum deutschen Angriff auf die Sowjetunion, vorgelegt am 8. Juli 1941, abgedruckt in: EIBER (Hg.), Union 1998, Dok. Nr. 29, S. 65 f.). 
Er warnte vor falschem Optimismus über den Ausgang und die Auswirkungen des Ostkrieges und prophezeite einen nachhaltigen Einfluß der deutschsowjetischen Auseinandersetzung auf den Kriegsausgang - „und zwar, worüber man sich nicht täuschen darf, sicherlich nicht nur zugunsten der [westlichen] Demokratien"675. In dieselbe Richtung argumentierte Stampfer, der im Juli 1942 vor dem ideologischen Imperialismus der Sowjetunion warnte und in der Ausdehnung des russischen Einflußbereichs eine unmittelbare Gefahr für Deutschland und Europa sah ${ }^{676}$.

Allein Paul Tillich wich von der Linie der in den USA ansässigen deutschen Sozialdemokraten ab. Ebenfalls auf eine Demokratisierung der russischen Binnenstrukturen hoffend, kam Tillich zu dem Schluß, daß seit dem deutsch-russischen Krieg die Frage nach der Teilnahme Rußlands an einer europäischen Föderation positiver beantwortet werden könne ${ }^{677}$. So befand sich Tillich in krassem Gegensatz zu Stampfer, Katz und Marck, wenn er die Emigration aufforderte, „die Glut der antirussischen Propaganda [zu] dämpfen", zumal sie den europäischen Untergrundbewegungen eine ungeheure Ermutigung bedeute 678 .

Kaum verwunderlich ist die extreme Position Otto Strassers, der selbst eine militärische Allianz mit Rußland strikt ablehnte. Der Rechtsextremist bemängelte, daß das Militärbündnis mit dem Bolschewismus die geistige Auseinandersetzung im demokratischen Gesamtlager wieder getrübt habe. „Es war ganz erstaunlich und oft peinlich zu beobachten, mit welch charakterlicher Schnelligkeit sich sogenannte Verteidiger für Christentum und Demokratie plötzlich dem roten Bundesgenossen an den Hals warfen, wobei sie in übergroßer Nächstenliebe vergaßen, daß der gesamte Krieg Hitlers überhaupt nur möglich geworden war durch die aktive Beihilfe des bolschewistischen Rußland." ${ }^{779}$ Es bleibe aber der Trost, daß sich die beiden Todfeinde der kommenden europäischen Neuordnung gegenseitig in die Haare geraten seien ${ }^{680}$. Strasser hoffte in dieser Auseinandersetzung zunächst auf eine möglichst zügige Vernichtung des Bolschewismus und eine damit einhergehende entscheidende Schwächung des Nationalsozialismus ${ }^{61}$. Warnend skizzierte

${ }^{675}$ KATZ, Hitlers Feldzug gegen Rußland, in: NVZ, 10. Jg., Nr. 26 (28. 6. 1941), S. 4. 676 Stampfer, What Labor can do to win the war and the peace. From a German point of view, Rede vom 6.7. 1942, abgedruckt in: MaTThIAS (Hg.), Mit dem Gesicht nach Deutschland 1968, Dok. Nr. 131, S. 554 ff. (555): „There can be no doubt that Moscow will make every effort to extend its ideological predominance over Germany and the whole old continent."

677 TIlliCH, Wessen Kriegsziele?, Herbst 1941, in: DERS., Impressionen und Reflexionen 1972, S. 264-269 (266).

678 Ibid. S. 268.

679 Strasser, FDB-Rundschreiben Nr. 3/Juli 1941, S. 1, IfZ, NL Strasser, ED 118/20.

680 Ibid.

681 Die damit zusammenhängenden militärischen Spekulationen legte Strasser in einem eigenen Rundschreiben dar: Die Frei Deutschland Bewegung zur Rußland-Frage, o. D. [Juli/August 1941], IfZ, NL Strasser, ED 118/20. 
der überzeugte Antikommunist das Szenario eines „Russian peace for Europe" und umschrieb damit die Ängste nicht nur des nationalkonservativen Exils vor einer politischen Bolschewisierung Europas auf der Grundlage der sich stetig ausweitenden militärischen Dominanz Rußlands in Osteuropa ${ }^{682}$. Sein bekanntes Gegenkonzept definierte Strasser 1942/43 als „European Federation, born in the spirit of Christianity and the conception of the unity of all European culture" 683 .

\subsubsection{Relativierung der europäischen Frage}

Die Einschätzung der Sowjetunion nach Hitlers Militäroperation vom 22. Juni 1941 sowie der wenige Monate später vollzogene Kriegseintritt der USA führten den Emigranten vor Augen, daß immer stärker außereuropäische Interessen den weiteren Kriegsverlauf und damit auch die alliierten Nachkriegspläne bestimmten. Ohnmächtig mußten sie beobachten, daß nicht nur eine europäische Selbstrettung höchst unwahrscheinlich geworden war, sondern darüber hinaus die gesamte europäische Frage ihre bisher absolut beherrschende Stellung verlor und durch die weltpolitischen Interessengegensätze innerhalb der Anti-Hitler-Koalition relativiert wurde. Die Chancen für eine eigens europäische Lösung verdüsterten sich. Um so dringlicher hoffte man auf eine alliierte Europapolitik, die dem Kontinent freiwillig seine Eigenständigkeit beließ und den Integrationsprozeß in Gang setzte.

Von diesem allgemeinen Trend des politischen Exils nahm sich die KPD erwartungsgemäß aus. Ihrer Überzeugung nach erübrigte sich auch in den Jahren 1941 bis 1943 ein gesondertes Europakonzept. Der Wunsch nach dauerhaftem Frieden und wirtschaftlicher Blüte für Europa werde schließlich durch die kommunistische Weltordnung auf der Grundlage nationaler Gerechtigkeit erfüllt ${ }^{684}$. Im Vordergrund europapolitischer Erörterungen stand gemäß der antiföderalen, ja antiintegrativen Grundeinstellung die künftige deutsche Außenpolitik, die Paul Merker gemäß der Sprachregelung vom Dezember 1942 auf „den Frieden und die internationale Zusammenarbeit der Völker und Staaten" unter Anerkennung der vollen nationalen Selbständigkeit angelegt wissen wollte ${ }^{685}$. Naturgemäß wurden sowohl die von der Sowjetunion am 14. September 1941 unterschriebene Atlantikcharta als auch der britisch-russische Bündnisvertrag regelmäßig positiv erwähnt, ohne wei-

682 Strasser, A Russian Peace for Europe?, o. D. [1942/43], IfZ, NL Strasser, ED 118/ 23.1.

683 Ibid. S. 8.

684 [KPD-ZK], Wahrheit über den „Deutschen Sozialismus“, hektographiertes Typoskript, 1941/42, S. 23, BAB RY 1/I 2/707/80, Bl. 201 und 204.

685 Friedensmanifest der westdeutschen Beratung der nationalen Friedensbewegung, 6. 12. 1942, abgedruckt in: LASCHITZA, VIETZKE, Arbeiterbewegung 1964, S. 389-395 (394). MERKER griff das Zehn-Punkte-Programm der Friedensbewegung nur wenige Monate später in seinem Buch: Was wird aus Deutschland? 1943, S. 55 f. uneingeschränkt auf. 
tergehende Rückschlüsse auf die Entwicklung der europäischen Nachkriegsordnung zu ziehen 686 .

Um so wortreicher fiel die Polemik gegen die nationalsozialistische "Neue Ordnung" Europas aus. Mangels eigener Alternativkonzepte ist das Verhalten der KPD primär als propagandistisch motivierte Reaktion auf die öffentlichen Exildebatten über das Nachkriegseuropa zu werten, die nicht länger ignoriert werden konnten ${ }^{687}$. Bezeichnenderweise erfuhr die europäische Neuordnung selbst auf der Gründungskonferenz der gruppenübergreifend gedachten, faktisch kommunistisch beherrschten Freien Deutschen Bewegung in Großbritannien am 25. September 1943 keinerlei Erwähnung688. Lediglich das Schlagwort der Unabhängigkeit wurde dem öffentlichen Diskurs entliehen, um es auf die nationale Ebene zu begrenzen und den Köder der „Unabhängigkeit des Reiches“ den Wehrmachtssoldaten als Zielgruppe der Bewegung Freies Deutschland für den Westen hinzuhalten ${ }^{689}$.

Hatten die Kommunisten von Anfang an eine Fremdbefreiung des europäischen Kontinents durch die Sowjetunion mit dem Ziel struktureller Ostorientierung angestrebt, wurde vielen nichtkommunistischen Emigranten nach Hitlers „Unternehmen Barbarossa“ und der deutschen Kriegserklärung an die USA die Befürchtung einer Fremdbestimmung Europas zur bitteren Gewißheit.

In der konzeptionellen Verarbeitung des Kriegseintritts der beiden neuen Weltmächte können drei Tendenzen unterschieden werden. Eine kleine Gruppe klammerte sich verzweifelt an die Option einer kraftvollen europäischen Eigendynamik. Der weitaus größere Teil des Exils sah sich jedoch gezwungen, die willenlose Ohnmacht Europas als weltpolitisches Faktum zu akzeptieren und appellierte an die Alliierten, konstruktiv zusammenzuarbeiten und eine am Wohl des Kontinents orientierte, speziell auf Europa zugeschnittene Nachkriegsordnung zu entwickeln. Dabei kann wiederum differenziert werden zwischen denjenigen, die mit dem Herzen in Moskau waren und mit dem Verstand die USA mitzuerfassen suchten, sodann denjenigen Emigranten, die sich politisch und kulturell stärker dem Westen verbunden

686 MERKER, Was wird aus Deutschland? 1943, S. 55. Wortgleich äußerte sich der KPDFunktionär Wilhelm Koenen in einem Interview mit Heinrich Fraenkel, in: FrAENKEL (Hg.), Der Weg zu einem neuen Deutschland 1943, S. 23 f. (23).

${ }^{687}[\mathrm{KPD}-\mathrm{ZK}]$, Wahrheit über den „Deutschen Sozialismus“, hektographiertes Typoskript, 1941/42, S. 26f., BAB RY 1/I 2/707/80, Bl. 204 f.: „Denn das ,neue Europa 'ist in Wirklichkeit das alte kapitalistische Europa der Unterdrückung und Ausbeutung - so alt und verblichen, daß es schon in den letzten Atemzügen liegt. [...] Wirtschaftlich reduziert sich das ,neue Europa' auf die rücksichtslose Ausplünderung der besetzten Länder. ${ }^{*}$

${ }^{688}$ Freie Deutsche Bewegung in Großbritannien (Hg.), Konferenzbericht, September 1943. An der Konferenz beteiligten sich u.a. der ehemalige Fraktionsvorsitzende der Deutschen Staatspartei, August Weber, und der Mitgründer der Deutschen Volkssozialistischen Bewegung, Arthur Arzt.

689 Das freie Deutschland formiert sich, in: Volk und Vaterland, Nr. 1 (Oktober 1943), S. 2. 
fühlten und sich aus strategischen Gründen bemühten, den sowjetischen Machtfaktor mit zu berücksichtigen, sowie den Befürwortern einer gleichgewichtigen Ost-West-Kooperation. Da alle drei Untergruppen auf ein am Wohl Europas orientiertes alliiertes Nachkriegskonzept hofften, bewiesen sie mehr Idealismus als es auf den ersten Blick erscheint, denn letztlich verlangten sie von den Alliierten den Verzicht auf die Fortsetzung der konventionellen Machtpolitik.

Eine dritte Gruppe schließlich konnte in der Entwicklung detaillierter Europapläne keinen Sinn mehr erkennen und fokussierte sich auf die Neuordnung der Welt und die Sicherung des Weltfriedens.

Unter den wenigen Emigranten, die weiterhin auf eine europäische Eigendynamik warteten, befanden sich der Sozialdemokrat Arno Seidel und der überzeugte Europäer Willi Eichler. Seidel, der innerhalb der Sopade eine Minderheit vertrat, hoffte auf ein neues Gleichgewicht der Kräfte in Europa. Zwar verkannte auch er nicht die unverzichtbare Mitwirkung Großbritanniens und der UdSSR im Rahmen ihrer explizit europäischen Verpflichtungen, doch „der Hauptanteil an den europäischen Aufgaben fällt [...] den Völkern dieses Erdteils selbst zu." 690

Konkreter äußerte sich Eichler, der zu der Erkenntnis gelangt war, daß die USA, Großbritannien und die Sowjetunion keinerlei Interesse an einem selbständig organisierten Europa hätten ${ }^{691}$. Auf einer Veranstaltung der britischen Schwesterorganisation des ISK, der Socialist Vanguard Group, bäumte sich Eichler vergebens gegen die sich allmählich abzeichnende drohende Spaltung des Kontinents in Einflußsphären auf: Europa müsse die Chance gewährt werden, sich selbst zu organisieren ${ }^{692}$. Unmißverständlich lehnte der ISK-Vorsitzende jede einseitige Bindung an Großbritannien, die USA oder die Sowjetunion ab und propagierte statt dessen den dritten Weg für ein eigenständiges Europa: „In their dealings with all forces, even those of good

690 UHLMANN [d. i. Seidel], Vorstellungen über die soziale Demokratie 1943, S. 8. Seidels Studie stellte innerhalb der Sopade eine Mindermeinung dar. Dies läßt sich unmittelbar an der deutlichen Distanzierung der Sopade in dem eigens für diesen Zweck vorangestellten Vorwort des Herausgebers ablesen.

691 Eichler, in: Towards European Unity 1943, S. 12-19 (17). Die Broschüre diente der Veröffentlichung der auf der Veranstaltung vom 12.12.1942 gehaltenen Reden. Eichler bemerkte in seiner Rede: „Whence can we expect help and inspiration for this [European] revolution? From the non-continental powers? I must admit that I cannot see many signs of help forthcoming from these quarters."

692 Eichler, in: Calling All Europe 1942, S. 8-13 (8). Das Dokument ist auszugsweise erneut abgedruckt in: LIPGENS (Hg.), Föderationspläne 1968, Dok. Nr. 154, S. 456f. sowie in englisch bei LIPGENS (Hg.), Documents II 1986, Dok. Nr. 243, S. 666-672. Die Broschüre umfaßt die Reden des ersten Sitzungstages der Osterkonferenz 1942 der britischen Socialist Vanguard Group, der dem Thema Europa gewidmet war. Vgl. auch das von Eichler verfaßte Rundschreiben des Bundesvorstandes an die Funktionäre vom Januar 1943, auszugsweise abgedruckt in: EIBER (Hg.), Union 1998, Dok. Nr. 310, S. 759765 (762): „Ich halte insbesondere jede Lösung in Europa für falsch, die in irgendeiner Weise eine Verteilung nach Einflußsphären begünstigt." 
will in the victorious states, the united European people must put forward their own European representation and their own European plans. ${ }^{\alpha 693} \mathrm{Da}$ hinter stand Eichlers axiomatische Erwartung, daß eine europäische Föderation selbstverständlich nicht von außereuropäischen Kräften errichtet würde ${ }^{694}$, sondern durch das Revolutionspotential der französischen Arbeiterbewegung695. Ohnehin brachte Eichler dem europäischen Sozialismus noch mehr Vertrauen entgegen als andere Linkssozialisten und rief die europäischen Sozialisten zur Solidarität auf: „Es ist gewiß weise, nicht mit dem Kopf gegen die Wand zu rennen. Aber es ist töricht, nicht zu sehen, daß die Zusammenarbeit der europäischen Sozialisten die Wand der Vorurteile [gegenüber dem Föderativgedanken, B. S.] oder der Vorrechte wirklich niederreißen könnte. Aber nur wenige bedenken, daß das Schicksal Europas und der Welt von der Aktivität oder der Trägheit der Sozialisten mit abhängt. ${ }^{6} 696$ Dennoch zeigten sich die Teilnehmer des internationalen ISK-Symposiums Calling All Europe in dem neun Punkte umfassenden Abschlußkommuniqué mehrheitlich überzeugt, daß Großbritannien, Amerika und Rußland einen entscheidenden Einfluß auf die europäische Nachkriegsordnung ausüben würden ${ }^{697}$.

Überwiegend aber hatte man die Hoffnung auf die Eigendynamik Europas fahren lassen und erwartete eine von den Alliierten mehr oder weniger oktroyierte europäische Nachkriegsordnung. Dabei rechnete man neben den beiden seit Juli 1941 verbündeten Flügelmächten Europas auch die USA hinzu, die sowohl Großbritannien als auch die UdSSR nach Kräften unterstützte, bevor sie schließlich selbst am Ende dieses ereignisreichen Jahres in den Krieg gezogen wurde.

Stellvertretend für viele Emigranten dieser Gruppe konstatierte Stefan Szende resigniert: „Europa hat für lange Zeit, vielleicht für immer, die führende Stellung in der Wirtschaft und in der Weltpolitik verloren. "698 Szende mahnte daher dringend eine aktive Beteiligung des deutschen Exils an der Neuordnungsdebatte an, denn die allgemeine Desorientierung zwinge zur Stellungnahme, auch wenn die Entwürfe noch nicht formvollendet seien ${ }^{699}$.

In vergleichbarer Enttäuschung notierte Hubertus Prinz zu Löwenstein nach dem 22. Juni 1941, daß die bisherige Kriegsperiode eine Periode der verpaßten Chancen gewesen sei, da die Westmächte mehrere Möglichkeiten einer Überwindung des Nationalsozialismus hätten verstreichen lassen. Nun

693 Eichler, in: Calling All Europe 1942, S. 10 f.

${ }^{694}$ Eichler, in: Towards European Unity 1943, S. 19: „A federated Europe will certainly not be created by forces from without."

695 EICHLER, in: Towards European Unity 1943, S. 17.

696 Rußland und die Komintern 1943, S. 62.

697 Calling All Europe 1942, S. 29.

698 SZENDE, Europäische Revolution 1945, S. 10. Das Dokument ist sowohl bei VOIGT (Hg.), Friedenssicherung 1988, S. 78-86 abgedruckt als auch bei LiPGENS (Hg.), Documents II 1986, Dok. Nr. 216, S. $583 \mathrm{f}$.

699 Ibid. S. 12. 
bedürfe die politische Geographie Europas einer um so sorgfältigeren Betrachtung 700 . Doch könne man nur einen Appell zu vorausschauendem Handeln an die künftigen Siegermächte richten, denn allein diese Mächte würden bei Kriegsende den Frieden in ihren Händen halten ${ }^{701}$.

Unter den Emigranten und Exilgruppen, die ihre Blicke nun auf eine alliierte Nachkriegsplanung für Europa richteten und hierfür möglichst realistische Vorschläge zu unterbreiten suchten, wiesen insbesondere die Londoner SAP und der Neu Beginnen-Vordenker Löwenthal eine gewisse Osttendenz auf, die die Freundschaft mit der Sowjetunion in den Mittelpunkt der außenpolitischen Betrachtungen stellte. Daher überrascht auf den ersten Blick der Aufruf der Londoner SAP an die Sozialisten deutscher Sprache, in allen mit den USA zusammenhängenden Fragen vordringlich zu einer Klärung zu kommen: "Wir zweifeln nicht daran, daß sie möglich ist. Sie ist vordringlich und notwendig, weil von ihr viel, wenn nicht alles abhängt." 702 Auf den zweiten Blick jedoch erweist sich der Aufruf der marxistischen Linkssozialisten als Einsicht in die realen Gegebenheiten der Weltpolitik. Zwar sah man sich noch außerstande, die langfristige europapolitische Bedeutung des Kriegseintritts der USA zu überblicken, aber man war überzeugt, daß das enorme wirtschaftliche Potential der westlichen Weltmacht sowie ihre militärische und politische Dominanz nachhaltig die europäische Neuordnung beeinflussen würde ${ }^{703}$. Ungeachtet der Einsicht in die Notwendigkeit einer Westverständigung blieb für die Londoner Vertretung der SAP die kritische Freundschaft eines sozialistischen Deutschlands mit der Sowjetunion das Leitbild künftiger Außen- und Europapolitik ${ }^{704}$. Dies um so mehr, als nach Hitlers Vertragsbruch vom 22. Juni 1941 der intellektuelle Spagat zwischen der Bewunderung für das Land des verwirklichten Sozialismus einerseits und der politisch-moralischen Verwerfung der ideologischen Inkonsequenzen andererseits entfallen war.

Innerhalb von Neu Beginnen warb Richard Löwenthal für eine enge OstWest-Kooperation und engagierte sich mehr als andere für eine Rehabilitierung der UdSSR im Lichte ihrer neuen Rolle als Opfer des nationalsozialistischen Imperialismus. Ungeheuer viel hänge davon ab, „daß in England und Amerika rechtzeitig alle Vorurteile und Hemmungen überwunden werden, die der maximalen möglichen Hilfeleistung an die Sowjetunion im Wege stehen."705 Während Neu Beginnen in einem Rundschreiben weiterhin davon

700 Löwenstein, Europe Tomorrow. The shape of things to come, [2. Jahreshälfte] 1941, S. 2 und 4, BAK, NL Löwenstein, N 1222, Bd. 42.

701 Löwenstein, Is peace possible in Europe. An address delivered at the Institute of Arts and Sciences of Columbia University, N. Y., 7. 4. 1943, S. 18, BAK, NL Löwenstein, N 1222, Bd. 40.

702 Sozialistische Revolution gegen Nazi-Imperialismus 1943, S. 39.

703 Ibid. S. $37 \mathrm{f}$.

704 Ibid. S. 34.

705 [LÖWENTHAL], Klare Fronten 1941, S. 7. 
ausging, daß der Krieg im Westen entschieden werde, hielt Löwenthal diese Position für überholt ${ }^{706}$. Für Europa werde die rechtzeitige Verständigung zwischen Ost und West der bestimmende Faktor der Zukunftsgestaltung sein. Für eine solche Verständigung der Alliierten über die europäische Neuordnung sah Löwenthal gute Chancen, denn durch das britisch-russische Bündnis sei die Gefahr einer Ost-West-Konfrontation vorerst gebannt, so $\mathrm{da} ß$ nun ein dauerhaftes Friedensszenario entwickelt werden könne. Er forderte die strukturelle Einbindung der Sowjetunion in die europäische Nachkriegspolitik, um auf diesem Wege die drohende „anglo-amerikanische Herrschaft über Europa" zu verhindern ${ }^{707}$. Damit wandte er sich vor allem gegen die aus seiner Sicht übertriebene Furcht vor einer russischen Vereinnahmung Europas, die seit dem Hitler-Stalin-Pakt viele Linkssozialisten veranlaßt hatte, ihre Nachkriegsvorstellungen allein oder vorrangig auf den bestimmenden Einfluß der westlichen Demokratien zu stützen. Löwenthal sollte sich angesichts der sowjetischen Polenpolitik, die auf der Teheraner Konferenz eingehend erörtert wurde, ab Ende 1943 jedoch wieder von der UdSSR als europäischem Impulsgeber abwenden und sich endgültig für eine enge Zusammenarbeit mit den westlichen Arbeiterbewegungen aussprechen.

Zu der Emigrantengruppe, die von den Alliierten eine tendenziell westorientierte Nachkriegskonzeption für Europa erhofften, zählte neben dem Hauptvertreter dieser Ansicht, Friedrich Stampfer, zunächst auch das Auslandsbüro von Neu Beginnen, wenngleich Richard Löwenthal als der maßgebliche Außenpolitiker der Gruppe in den Jahren 1941 bis 1943 in eine andere Richtung tendierte. In ihrer Einschätzung der strategischen Lage nach dem Juni 1941 kam die Auslandsleitung der Organisation zu dem Schluß, daß nicht der sowjetische, sondern der amerikanische Kriegseintritt den Krieg entscheiden werde und deshalb die Entschlossenheit der anglo-amerikanischen Kräfte um so wichtiger sei ${ }^{708}$. Für das sozialistische Nachkriegsdeutschland bedeute dies die notwendige Zusammenarbeit mit West und Ost, ohne daß man "sich einseitig an Rußland anlehnen oder eine Haltung des revolutionären Messianismus gegenüber der westlichen Welt einnehmen ${ }^{*}$ würde ${ }^{709}$. Mit der größeren historischen Distanz des Jahres 1942 wurde diese Einstellung zugunsten eines internationalen Sicherheitssystems auf der Grundlage des anglo-russischen Militärpotentials korrigiert ${ }^{710}$.

706 Ibid.

707 Ibid. S. 14.

708 Rundschreiben [NB], 15. 7. 1941, S. 6, IISG, NL Hertz, S. 9, M. E, Nr. 4.

709 Entwicklungsbedingungen der deutschen Revolution, o. D. [August 1941], S. 10, AsD, NL Knoeringen, M. 137.

710 Draft Statement on Peace Guarantees, o. D. [Herbst 1942], IISG, Coll. Neu Beginnen, M. 42. Hinsichtlich der Datierung verweist BEHRING, Demokratische Außenpolitik 1999, S. 465 zutreffend auf den handschriftlichen Vermerk "Herbst 1942“ auf einem Zweitexemplar im Nachlaß Eberhard, IfZ, ED 117/8a. Für Behrings Datierung spricht auch der enge zeitliche Zusammenhang mit den Anmerkungen zur Diskussion der Friedensziele vom November/Dezember 1942. 
Friedrich Stampfer hatte sich seit Beginn des Exils konsequent für eine am Westen ausgerichtete, antibolschewistisch motivierte Europakonzeption eingesetzt. Daran hatte das britisch-sowjetische Militärbündnis vom Juli 1941 nichts geändert, nur war Stampfers Vorhersage einer gefährlichen Ohnmacht Europas zur bitteren Gewißheit geworden: „Bei alledem sind wir uns dessen bewußt, daß in diesem Augenblick unser Wille nicht zu den ausschlaggebenden Faktoren der Weltgeschichte gehört. Wir sind nicht stark und bedürfen der Hilfe. Wir hoffen sie nun erst recht und in erhöhtem Maße zu finden bei der britischen und bei der amerikanischen Arbeiterbewegung, die in ihrem Bekenntnis zur Demokratie und in ihrer grundsätzlichen Ablehnung des Bolschewismus mit uns übereinstimmen." 711

Stampfer hatte durchaus erkannt, daß eine Rettung Europas aus eigener Kraft schon lange nicht mehr realistisch war. Einigten sich die Alliierten auf eine schlichte Fortsetzung traditioneller Machtpolitik, würde dies das Ende des politischen Europas bedeuten ${ }^{712}$. Einen Ausweg sah Stampfer in einem anglo-amerikanisch geführten Europabund und suchte deshalb Großbritannien und vor allem sein Gastland zu bewegen, sich als Geburtshelfer einer Europaorganisation zur Verfügung zu stellen. In einem umfangreichen Manuskript zum „Kampf um Deutschland“ modifizierte der Sozialdemokrat des rechten Parteiflügels sein bekanntes Konzept einer Europaföderation als Unterorganisation des zu überarbeitenden Völkerbundes und unterstellte es dem direkten Vorsitz der beiden westlichen Großmächte ${ }^{713}$. Basierend auf dem Axiom der Kulturgemeinschaft Europas mit den USA wünschte sich Stampfer die verantwortliche Inkorporation der Vereinigten Staaten nicht nur in die Weltorganisation, sondern auch in die europäische Föderation. Indem er die USA in den Dienst der europäischen Einheit stellte, hoffte er, die Eigenständigkeit Europas bewahren zu können. Er glaubte, daß jedenfalls die Legitimation eines angloamerikanischen Europabundes als eines die Sowjetunion respektierenden und zugleich in Schach haltenden Partners die Amerikaner überzeugen müsse ${ }^{714}$. Gerade vor diesem Hintergrund sei eine Beteiligung Rußlands an dem Europabund wünschenswert, wenn auch nicht notwendig715.

Die Befürworter einer gleichberechtigten Ost-West-Kooperation strebten nach einem dauerhaften Ausgleich zwischen den westlichen Demokratien und der Sowjetunion zum Wohle beider Seiten sowie des zwischen ihnen liegenden europäischen Puffers. Dabei setzte Willy Brandt auf allmähliche strukturelle Veränderungen der drei Großmächte, deren Rückkopplungen

\footnotetext{
711 STAMPFER, Weder Hitler noch Stalin!, in: NVZ, 10. Jg., Nr. 26 (28. 6. 1941), S. 1. 712 Ibid.

713 Stampfer, Kampf um Deutschland (o. D.) [1943], S. 204 f., AsD, NL Stampfer, Box 9, M. 44. Stampfer selbst sprach von dem Europabund als dem "Council of Europe", ibid. passim.

714 Ibid. S. 206.

715 Ibid. S. 205.
} 
die europäische Nachkriegsordnung positiv beeinflussen würden. Von den west-östlichen Wechselwirkungen erhoffte er sich einerseits eine Demokratisierung der Sowjetunion und andererseits die Ergänzung der westlichen Demokratien um eine soziale Komponente ${ }^{716}$. Im Gegensatz zur Londoner Vertretung seiner Partei war der junge SAP-Funktionär überzeugt, daß weder die Westmächte noch die UdSSR allein entscheidend sein würden, sondern eine lange Übergangsperiode mit zahlreichen ,inneren Umbrüchen“ in den kriegsbeteiligten Ländern zu erwarten sei ${ }^{717}$. Gerade deshalb erachtete er die konstruktive Kooperation zwischen West und Ost als elementar, ohne die Augen vor der andernfalls drohenden Gefahr einer Teilung Europas zu verschließen: „Aber wir können auch nicht davon absehen, daß die Sowjetunion eine stärkere Anziehungskraft auf [...] Ost- und Südosteuropa, besonders die slawischen Völker ausüben wird."718

Hoffnungsfroher klingen die Worte Erwin Schoettles, der gerade in einem von Großbritannien, den USA und der UdSSR gemeinsam durchgeführten Wiederaufbau nach dem Krieg eine reelle Chance erblickte, dem demokratischen Sozialismus in Europa zum Durchbruch zu verhelfen und der europäischen Stimme dadurch ihr Eigengewicht zu bewahren ${ }^{719}$. Schoettle betonte, daß der demokratische Sozialismus als dritter Weg zwischen britischem Kapitalismus und sowjetischem Totalitarismus im Falle einer Ost-West-Konfrontation niemals zu realisieren gewesen wäre. Nun aber, mit dem Einschwenken der Sowjetunion in die antifaschistische Phalanx, stehe Europa die Option des dritten Weges offen ${ }^{720}$.

Angesichts der schwindenden Hoffnung auf eine gesonderte Lösung der europäischen Frage vollzogen einige Emigranten frühzeitig eine Kehrtwende und widmeten sich von nun an nahezu ausschließlich der Neuordnung der Welt. Klarsichtiger als andere umriß der Neu Beginnen-Repräsentant in den Vereinigten Staaten, Karl Frank, 1943 den west-östlichen Wettlauf um den

716 Brandt an den außenpolitischen Berater des norwegischen Außenministers, Ording, 11. 3. 1942, abgedruckt in: Grebing, SCHÖllgen, WINKLER (Hg.), Berliner Ausgabe 2000, Dok. Nr. 3, S. 72-82 (73).

717 Brandt an den außenpolitischen Berater des norwegischen Außenministers, Ording, 27. 12. 1941, abgedruckt in: GREBING, SCHÖLLGEN, WINKLER (Hg.), Berliner Ausgabe 2000, Dok. Nr. 2, S. 64-72 (69).

718 Brandt an den außenpolitischen Berater des norwegischen Außenministers, Ording, 11. 3. 1942, abgedruckt in: GrEBING, SCHÖllgeN, WINKLER (Hg.), Berliner Ausgabe 2000, Dok. Nr. 3, S. 73.

719 Schoettle, Vorschlag für eine Stellungnahme im Nezvsletter zum deutschen Angriff auf die Sowjetunion, vorgelegt am 8. 7. 1941, abgedruckt in: EIBER (Hg.), Union 1998, Dok. Nr. 31, S. 70-73.

720 Auf Schoettles Vorschlag hin wurde der Verweis auf den demokratischen Sozialismus als drittem Weg in ein von Eichler verfaßtes Kompromißpapier der Londoner Union aufgenommen, das zur Veröffentlichung im News Letter bestimmt war: Eichler, Entwurf für eine Stellungnahme im „News Letter" zum deutschen Angriff auf die Sowjetunion unter Berücksichtigung der bisherigen Vorschläge vom 15.7. 1941, abgedruckt in: EIBER (Hg.), Union 1998, Dok. Nr. 36, S. 83 f. (84). 
vorherrschenden Einfluß in Europa. Die Leistungen der russischen Revolution und des praktizierten Sozialismus einerseits und die wirtschaftliche Wiederaufbauhilfe sowie der demokratische Impetus der USA andererseits würden sich bald reiben und einen Kräftekonflikt in der Einwirkung auf das neue Europa auslösen ${ }^{721}$. Frank ging davon aus, daß dieser weltmachtpolitische Wettlauf auf europäischem Boden das politische Europa für lange Zeit prägen würde und spezifisch europäischen Befindlichkeiten keinen Raum ließe: "Nothing else will be." 722

In der Absicht, einen gemeinsamen Entwurf der internationalen Sozialisten für die künftige Neuordnung der Welt zu erarbeiten, konstituierte sich 1941 an der New Yorker Rand School of Social Research eine Gruppe amerikanischer, russischer, österreichischer und deutscher Sozialisten, die Wert auf die Feststellung legten, daß sie sich als demokratische Sozialisten der internationalen sozialistischen Bewegung verbunden fühlten. Von deutscher Seite waren mit Grzesinski, Katz, Ernst Hamburger und Hedwig Wachenheim ausschließlich Parteimitglieder der Sopade vertreten, und auch die übrigen Teilnehmer gehörten überwiegend sozialdemokratischen Parteien an ${ }^{723}$. Insbesondere Albert Grzesinski konnte in diesem Forum seine im März 1941 niedergeschriebenen, global ausgerichteten „Gedanken über die Zusammenarbeit der Nationen nach dem Siege der demokratischen Mächte" einbringen und in wesentlichen Grundzügen durchsetzen ${ }^{724}$. Die von der Gruppe Anfang August 1941 veröffentlichten Kriegs- und Friedensziele decken sich in weiten Teilen mit den Positionen von Grzesinski und Katz ${ }^{725}$. Die neue Weltordnung müsse auf Freiheit, sozialem Fortschritt und wirtschaftlichem Aufbau begründet sein und bedürfe einer Weltorganisation mit sozial- und wirtschaftspolitischen Befugnissen zur Sicherung des Friedens und der De-

721 Hagen [d. i. Frank], Entwurf: Die Sowjetunion im Kriege [Januar 1942], S. 25, IfZ, NL Frank, ED 213/3.

722 Hagen [d. i. Frank], What to do with Germany after the war?, [Januar] 1943, S. 32, If'Z, NL Frank, ED 213/3.

723 Die am 1.7. 1941 veröffentlichte Broschüre „War aims, peace terms, and the world after the war" nennt als weitere Unterzeichner den österreichischen Sozialdemokraten Alfred Braunthal, die russischen Sozialdemokraten Peter Garvy und Boris Nicolaevsky, die amerikanischen Sozialdemokraten John L. Afros, William E. Bohn, Sergius M. Ingerman, Herman Kobbe, Algernon Lee und Bela Low sowie die russischen Revolutionären Sozialisten N. Avxentieff, S. Soloveitchik und Mark Vishniak. Angesichts dieser Zusammensetzung ist die Feststellung von VOIGT (Hg.), Friedenssicherung 1988, S. 204, das Manifest der Gruppe sei von sozialdemokratischem Gedankengut geprägt, kaum verwunderlich.

724 Grzesinski, Gedanken über die Zusammenarbeit der Nationen nach dem Siege der demokratischen Mächte, 2. 3. 1941, IfZ, Slg. Glaser, ED 202/1.

725 Unsere Kriegs- und Friedensziele, in: NVZ, 10. Jg., Nr. 31 (2. 8. 1941), S. 1 f. und Nr. 32 (9.8. 1941), S. 1f. Das zweiteilige Dokument ist auch abgedruckt in: VoIGT (Hg.), Friedenssicherung 1988, S. 217-222 und auf englisch bei LIPGENS (Hg.), Documents II 1986, Dok. Nr. 242, S. 663 ff. 
mokratie ${ }^{726}$. Im Prinzip dachte man wie gehabt an eine Neuauflage des Völkerbundes, der dieses Mal unbedingt die Vereinigten Staaten einbinden müsse. Mit einer unverkennbaren Spitze gegen die Sowjetunion verlangte die Gruppe eine internationale Polizeigewalt, die von den beiden Westalliierten zu stellen sei und als Exekutivorgan mit „echten Machtmitteln“ ausgestattet werden müsse. Wirtschaftlich wurde das Bild durch ein System internationaler Arbeitsteilung, die Beseitigung der Zollschranken, freien Austausch der Arbeitskräfte, freien Zugang zu den internationalen Verkehrswegen und zu den globalen Rohstoffreserven abgerundet ${ }^{727}$.

Im wesentlichen trugen die internationalen Sozialisten die zuvor in der Europadebatte sowie in der damit zumeist verbundenen Völkerbundsdebatte erarbeiteten Forderungen zusammen. Dies gilt für den beschränkten Souveränitätsverzicht für Rüstungsindustrie und Waffenhandel ebenso wie für die Gewährleistung und den Schutz verbindlicher Grundrechte, und die Einrichtung eines Weltgerichtshofes als Schiedsgericht und erkennende Instanz. Auch die Idee eines im Rahmen des Völkerbundes regional eigenständig organisierten Europas ${ }^{728}$ war im politischen Exil längst Gemeingut, so daß dem Dokument inhaltlich kaum neue Impulse entnommen werden konnten. Dennoch spielte es eine nicht unerhebliche Rolle als eine der ersten Zusammenstellungen eines kompromißfähigen sozialistischen Forderungskataloges, so daß in der Folgezeit recht häufig auf die "Kriegs- und Friedensziele“ verwiesen wurde.

\subsubsection{Im Zeichen des Ost-West-Konflikts: Föderation statt Division}

$\mathrm{Ob}$ alliierte Nachkriegsplanung oder europäische Eigendynamik - das Ziel all der Überlegungen zur europäischen Neuordnung war die Bewahrung der europäischen Selbständigkeit zwischen den Weltmächten des Ostens und des Westens. Einig war man sich auch, daß die kontinentale Selbständigkeit ein ungeteiltes Gesamteuropa voraussetzte. Denn die Teilung Europas in ein anglo-amerikanisch beeinflußtes Westeuropa und ein sowjetisch dominiertes Osteuropa würde es den Europäern unmöglich machen, mit einer Stimme zu sprechen und sich in der Dichotomie der Weltpolitik als unabhängige Kraft zu behaupten ${ }^{729}$. Nachdrücklich warnte der Sozialdemokrat Gerhard Kreys-

726 Unsere Kriegs- und Friedensziele, in: NVZ, 10. Jg., Nr. 31 (2. 8. 1941), S. 1. Daraus die folgenden Zitate.

727 Unsere Kriegs- und Friedensziele, in: NVZ, 10. Jg., Nr. 32 (9. 8. 1941), S. 2.

728 Ibid. S. 1.

729 Besonders eindringlich Kreyssig, Memorandum zu Problemen und Aufgaben des Nachkriegs-Europa, 15. 7. 1942, S. 50, AsD, NL Kreyssig, M. 20: „Die Gefahr besteht und ist nicht von der Hand zu weisen, daß die Großmächte (USSR, England und USA) sich auf europäischem Gebiet ,Einflußsphären' schaffen könnten oder wollten, also eine Art wirtschaftliche Dominions, mit deren Errichtung die wirtschaftliche und politische Bevormundung der Sphären parallel laufen würden. Ich sehe eine der hervorragendsten Aufgaben der europäischen Gewerkschaftsbewegung darin, solche Pläne und Absichten rechtzeitig zu bekämpfen und sich dagegen zur Wehr zu setzen." 
sig ebenso wie der Linkskatholik Löwenstein vor einer Kolonisierung Europas zugunsten der Siegermächte, die mit der Teilung des Kontinents in Einflußsphären unweigerlich verbunden wäre ${ }^{730}$.

Das deutsche Exil war sich weitgehend einig, daß sich als einzige Alternative zu diesem Szenario eines geteilten Europas ein möglichst enger Verbund der europäischen Staaten anbot. Ein solcher Verbund müßte stark genug sein, sich als Puffer oder Brücke, als Vermittler zwischen Ost und West behaupten zu können. Unter diesem Blickwinkel erfuhr die Föderalismusdebatte eine neue Dimension. Mit der Einsicht, nur durch eine europäische Föderation Europa als eigenständigen Macht- und Wirtschaftsblock erhalten zu können und an der eigenen Nachkriegsordnung mitwirken zu dürfen, erhielt der $\mathrm{Ge}$ danke der Föderation eine deutliche Aufwertung als propagandistisches Mittel und politische Waffe des Exils gegen tatsächliche Teilungspläne und unterstellte Teilungsabsichten in den alliierten Staaten ${ }^{731}$. Die mehrfach vorgeschlagene Errichtung europäischer Teilföderationen stieß nun öfter auf Ablehnung, da man die besondere Anfälligkeit solcher Konstruktionen für politische Einflußnahmen stärkerer Nachbarn erkannt hatte. Die UdSSR würde sich solcher Regionalföderationen in Ost- und Südosteuropa ebenso annehmen wie Großbritannien und die USA westeuropäische Teileinheiten in ihren politischen Bann ziehen würden ${ }^{732}$.

Für das deutsche Exil sprach ein weiteres zentrales Argument für eine europäische Föderation: die Verhinderung einer Teilung Deutschlands. Je offener auf den Konferenzen der Alliierten seit 1941 eine Teilung Deutschlands in mehrere Kleinstaaten oder eine endgültige Entmachtung Deutschlands durch seine völlige Agrarisierung erwogen wurde, desto verzweifelter klammerte sich das deutsche Exil an die Idee einer europäischen Föderation unter Einbindung eines entmilitarisierten Deutschlands, die doch im Ergebnis ebenso effektiv den europäischen Frieden zu gewährleisten versprach. Mit besonderer Dringlichkeit wurde diese Aufgabe an die in London versammelten Vertreter des deutschen Exils herangetragen, da dort der diplomatische Chefberater der britischen Regierung, Lord Robert Gilbert Vansittart, eine seit Karl dem Großen historisch nachweisbare Anfälligkeit des deutschen

730 Vgl. z.B. Kreyssig an Rimsberger, 22. 8. 1942, S. 3, AsD, NL Kreyssig, N. 59: „Wer vorzieht, sich einer westlichen oder östlichen ,Einflußsphäre' einzugliedern, dürfte wohl klar darüber sein, daß er sich damit in freiwillige Kolonisierung gibt." Zustimmend auch Löwenstein, Is peace possible in Europe, 7. 4. 1943, S. 2 f., BAK, NL Löwenstein, N 1222, Bd. 40 .

${ }^{731}$ Eine der wenigen Ausnahmen bildet das Wiederaufbauprogramm der deutschen Sozialisten in der Schweiz, das zunächst die bloße Förderung und Mitarbeit Deutschlands bei allen Bestrebungen zu internationaler Zusammenarbeit als ausreichend ansah und die wirtschaftliche, kulturelle und politische Föderation als Fernziel einstufte: Wiederaufbauprogramm der deutschen Sozialisten in der Schweiz, 16. 10. 1943, IfZ, Slg. Hoegner, ED 120/15.

732 Vgl. etwa Kreyssig, Memorandum zu Problemen und Aufgaben des NachkriegsEuropa, 15. 7. 1942, S. 50, AsD, NL Kreyssig, M. 20. 
Volkscharakters für aggressiven Nationalismus und Militarismus behauptete $^{733}$. In mehreren Rundfunk- und Oberhausreden erläuterte Vansittart seit Anfang 1941 seine Grundthese, daß das deutsche Volk in seiner überwiegenden Mehrheit mit dem Nationalsozialismus als geistiger Strömung konform gehe. Deshalb müsse es für die Verbrechen seiner Führer zur Verantwortung gezogen werden. Auch die deutsche Arbeiterbewegung blicke auf eine lange "nationalistische und militaristische Tradition" zurück, zumal die Revolution von 1918 lediglich eine „Revolte gegen die Verlierer des Krieges ${ }^{\alpha 734}$ gewesen sei. Im Fahrwasser der bald als "Vansittartismus" bezeichneten Bewegung fanden auch extrem deutschfeindliche Tendenzen Zugang zu einer breiteren Öffentlichkeit ${ }^{735}$. Deren Nachkriegsvorstellungen beruhten auf der endgültigen Zerschlagung Deutschlands in kleinere regionale Einheiten und die möglichst langfristige Ausschaltung jedes militärischen Einflusses Deutschlands.

Auf dem weiten Weg zu einer europäischen Föderation als Garant der kontinentalen Selbständigkeit bedurfte es machtvoller Unterstützung und hoher Geschwindigkeit, da die Zeit gegen die Europäer arbeitete. Je länger man zuwartete, je länger sich der Krieg hinzog, desto wahrscheinlicher würden die bestimmenden Mächte der außereuropäisch orientierten Anti-HitlerKoalition ohne Rücksicht auf europäische Stimmen eine an ihren jeweiligen nationalen Interessen ausgerichtete Nachkriegsordnung favorisieren, die einen schnellen Frieden bei bestmöglicher Sicherung des eigenen weltpolitischen Einflusses versprach. Dies aber würde auf eine Fortsetzung der Machtpolitik alten Stils hinauslaufen, die für eine europäische Föderation weder Raum noch Verständnis aufböte. Es galt also, der politischen Entwicklung zuvorzukommen und diejenigen Kräfte, die bei Kriegsende die Nachkriegsordnung für Deutschland, Europa und die Welt festlegen würden, so zügig und nachhaltig wie möglich für die Idee einer europäischen Föderation einzunehmen. Zwei Faktoren waren nun entscheidend und sollten dem Europadiskurs zwischen 1941 und Ende 1943 unverkennbar prägen: Soweit man nicht auf eine europäische Eigendynamik vertraute, mußte zumindest eine der alliierten Großmächte als starker Partner für eine europäische Föderation

733 Zum Verhältnis des deutschen Exils zum Vansittartismus vgl. RaDKaU, Exil-Ideologie 1970 sowie RÖDER, Sozialistische Exilgruppen ${ }^{2} 1973$, S. 143-146. Der Vansittartismus erreichte 1942 auch die USA und fand in dem Schriftsteller Emil Ludwig, unter dessen Vorsitz sich Ende 1943 die Society for the Prevention of World War III konstituierte, einen wortgewaltigen Fürsprecher. Doch war dem amerikanischen Vansittartismus ein weitaus geringeres Echo in der Öffentlichkeit beschieden, so daß sich das deutsche Exil in den USA eher mit dem britischen Original auseinandersetzte als mit Ludwigs Organisation.

734 Zit. n. RÖDER, Sozialistische Exilgruppen 21973, S. 144.

735 Nach JAEGER, Vansittart and Vansittartism, in: Wiener Library Bulletin, Bd. 11 (1957), Nr. 1/2, S. 14 f. wurde der Begriff „vansittartistisch“ zuerst von Gottfurcht in einem Beitrag für die Zeitschrift Die Arbeit, Nr. 1 (März 1941) in die Diskussion eingeführt. 
gewonnen werden. Zugleich mußte ein überzeugendes Föderativkonzept vorgelegt werden. Überzeugen konnte ein Europakonzept aber nur, wenn es imstande war aufzuzeigen, $\mathrm{da}$ ß und inwieweit ein föderativer Zusammenschluß der europäischen Staaten auch im Interesse Großbritanniens, der USA und der UdSSR lag und wenn das Konzept eine stringente, zügige Umsetzung versprach ${ }^{736}$.

Auf der Suche nach einem starken Partner der Europaföderalisten ruhten die Hoffnungen vorrangig auf Franklin D. Roosevelt. Präsident eines föderalen Staates und Förderer der Panamerikanischen Union schien er als Fürsprecher einer europäischen Union geradezu prädestiniert. Man hoffte, in ihm einen machtvollen Mitstreiter für das europäische Föderationsmodell zu haben, zumal die amerikanische Debatte eine föderationsfreundliche Tendenz aufwies und sich zahlreiche Intellektuelle fanden, die das Modell der Vereinigten Staaten von Europa begrüßten. Viele deutsche Emigranten erinnerten sich in diesen Tagen an Woodrow Wilsons weitsichtige, vielleicht sogar idealistische Friedenspolitik in Versailles und waren nur allzu gern bereit, darin eine Tradition US-amerikanischer Europapolitik zu sehen. Hinzu kam, daß Roosevelt selbst einer föderativen Lösung anfangs nicht abgeneigt war. In diesem Sinne wurde auch sein Freiheitsbekenntnis gewertet, das er im Januar 1941 mit den bekannten „Vier Freiheiten“ umschrieben hatte: Meinungsfreiheit, Gewissensfreiheit, Freiheit von Not und Freiheit von Furcht. Aufbauend auf diesen „Vier Freiheiten" hatten sich Churchill und Roosevelt am 14. August 1941 auf die Atlantikcharta geeinigt, die in acht Punkten die Konturen einer Nachkriegsordnung der Welt zeichnete. Für die europäischen Widerstandskämpfer war vor allem die Garantie des Selbstbestimmungsrechts bedeutsam, die von den deutschen Emigranten dahingehend interpretiert wurde, daß sowohl Deutschland als auch dem europäischen Kontinent das Recht zur selbstverantwortlichen Neuordnung nach dem Kriege zugestanden werden sollte ${ }^{737}$. So ging man von einem kontinentalen Selbstbestimmungsrecht Europas aus, das zumindest Großbritannien als auch die USA zu unterstützen schienen. Dabei wurde zumeist übersehen, daß die Atlantikcharta nicht viel mehr bot als eine politische Absichtserklärung, die auch für die Kriegspropaganda bestimmt war. Keinesfalls war damit eine verbindliche Zusicherung gemeint, erst recht nicht für den Kriegsgegner Deutschland. Dessen ungeachtet dachten sich die Exilanten bis zu den Konferenzen von Moskau und Teheran 1943 in grundsätzlicher Übereinstim-

736 In diesem Zusammenhang stelite schon der Zeitgenosse SZENDE, Europäische Revolution 1945, S. 11, für den Europadiskurs des linkssozialistischen Exils fest: „Die Diskussionen über den Verlauf der europäischen Revolution und über ihre durch einzelne und ganze Menschengruppen beeinflußte Gestalt werden einerseits zwar immer leidenschaftlicher. Sie werden seit einiger Zeit aber auch immer sachlicher und realistischer."

737 Vgl. etwa Stampfer, Erklärung „Die acht Punkte“, 24. 8. 1941, abgedruckt in: MATTHIAS (Hg.), Mit dem Gesicht nach Deutschland 1968, Dok. Nr. 117, S. $512 \mathrm{f}$. 
mung mit Großbritannien und den USA. Tatsächlich aber wandte sich die US-Regierung seit dem Washington-Pakt vom 1. Januar 1942 zusehends der Idee einer Weltorganisation zu, die sie als substituierende Alternative eines Europabundes betrachtete. Entscheidend für den amerikanischen Sinneswandel war letztlich der erhebliche Druck Stalins, der sich erfolgreich gegen jeden europäischen Sonderweg wehrte und statt dessen die Nationalstaaten von 1918/19 wiedererrichten wollte. Stalin gab sich kaum Mühe, seine territorialen und machtpolitischen Interessen in bezug auf Ost- und Südosteuropa zu kaschieren. Zudem war der an einigen internationalen Kriegskonferenzen beteiligte Tschiang Kai Tschek als Vertreter Chinas kaum an rein europäischen Lösungsmodellen interessiert, und auch der US-japanische Konflikt hatte mit den europäischen Befindlichkeiten wenig zu tun. Trotz der widrigen Umstände bemühte sich das politische Exil um Europakonzepte, die hinreichend realistisch waren, um die Alliierten möglicherweise überzeugen zu können, wobei ihnen als ständiges Damoklesschwert die Teilung ihres Kontinents in Einflußsphären vor Augen war.

Um die Erarbeitung eines überzeugenden Föderativkonzepts des deutschen Exils bemühte sich eine Gruppe deutscher Sozialisten um den Gewerkschafter Walter Auerbach. 1943 publizierten sie die programmatische Schrift „The Next Germany“, die ausweislich des Untertitels als Diskussionsgrundlage zum europäischen Frieden zu verstehen war ${ }^{738}$. Darin beschäftigten sich die Verfasser vorrangig mit der sozialistischen Revolution in Deutschland, von der sie sich unverändert eine Initialwirkung für den gesamten Kontinent erhofften, und den Chancen einer europäischen Integration. Europa sei eine Schicksalsgemeinschaft, die der Nationalsozialismus nicht nur in wirtschaftlicher und technischer Hinsicht geeint habe, sondern auch in der gemeinsamen Ablehnung von Ausbeutung, Imperialismus und Aggres$\operatorname{sion}^{739}$.

Schon aus diesem Grund hielt das sozialistische und sozialdemokratische Exil die Föderierung Europas für dringend geboten, denn andernfalls befürchtete man einen Rückfall in die Fehler von Versailles, also der europäischen Kleinstaaterei und der Verabsolutierung des Souveränitätsgedankens $^{740}$. Tillich sah darin die "größte Gefahr einer Teilung des Kontinents, und dies wäre gleichbedeutend mit dem endgültige[n] Todesurteil für Europa " 741 . Sein Aufsatz "Nicht Nation, sondern Föderation" war aufrüttelnd gemeint und sollte den exilierten Sozialisten den unmittelbaren Zusammenhang zwischen sozialistischer Revolution und europäischem Föderalis-

738 Auerbach et al., The Next Germany 1943.

739 Ibid. S. 113.

740 Tillich, Nicht Nation, sondern Föderation. Radioansprache an deutsche Hörer über "Die Stimme Amerikas“, 17.7. 1942, in: DERS., An meine deutschen Freunde 1973, S. 69-73.

741 DERS., Wessen Kriegsziele?, Herbst 1941, in: DERS., Impressionen und Reflexionen 1972 , S. 265 f. 
mus in Erinnerung rufen. Der Föderalgedanke sei der revolutionäre Ansatz, der sich gegen die konventionell bürgerliche Auffassung von der uneingeschränkten nationalen Souveränität durchsetzen müsse $e^{74}$. Tillich versuchte auf diese Weise, den Sozialisten die Europaföderation als ureigenes Projekt des europäischen Sozialismus zu präsentieren. Darüber hinaus sei die Errichtung der Vereinigten Staaten von Europa die einzige verbleibende Chance, der kontinentalen Zersplitterung und damit auch der Zersplitterung der europäischen Arbeiterbewegung zu entgehen. Tillichs Ziel war deshalb eine militärische und politische Föderation als "tätige, ausgleichende Mitte" zwischen Ost und West: „Nur als solche kann Europa leben. “" zur allgemeinen Einschätzung des sozialistischen Exils betrachtete der Theologieprofessor aber eine sofortige Einigung Europas im Herbst 1941 für verfehlt: „Sie würde Europa in einen westlichen und östlichen Teil spalten und den westlichen Teil der angelsächsischen Kontrolle unterwerfen, während der östliche dem Zerfall und dem Übergang in die Barbarei überlassen bliebe." 744

Anders als Tillich prophezeiten die beiden nach Amerika emigrierten Sozialdemokraten Gerhart Seger und Siegfried Marck eine Teilung des europäischen Kontinents nicht in zwei, sondern in drei Blöcke: den englisch(-französischen) Block mit Nord- und Westeuropa, den Mitteleuropablock zwischen Rußland und Deutschland und den Balkanblock mit Österreich ${ }^{745}$. Dahinter vermuteten Seger und Marck die europäische Basis der Auseinandersetzungen zwischen dem Westen und der ebenbürtigen Sowjetunion in der Nachkriegszeit ${ }^{746}$. Zur Lösung dieses konfliktträchtigen Kräftefeldes schlugen die Sozialdemokraten vor, den vorhersehbaren Ost-West-Konflikt dadurch zu relativieren, daß unter Hintanstellung antikommunistischer Empfindungen Deutschland als Brücke zwischen Ost und West installiert werden sollte ${ }^{747}$. Als unerläßliche Voraussetzung für eine solche weltpolitische Funktion betrachteten die Sozialdemokraten die gleichzeitige Einbindung Deutschlands in ein System europäischer Kooperation, da sich andernfalls jede Irritation zwischen dem Westen und dem Osten schicksalhaft auf die innerdeutschen Verhältnisse auswirken würde. Wichtig sei daher die Befriedung der Ost-West-Konfrontationen durch eine Befriedung Deutschlands ${ }^{748}$.

742 Ders., Nicht Nation, sondern Föderation, 17. 7. 1942, in: Ders., An meine deutschen Freunde 1973, S. 69.

743 DERS., Die Bedingungen für eine europäische Einigung. Radioansprache, 11.5. 1943, in: Ders., An meine deutschen Freunde 1973, S. 194-202 (201).

744 DERS., Wessen Kriegsziele?, Herbst 1941, in: DERS., Impressionen und Reflexionen 1972, S. 266.

745 Seger, Marck, Germany: To be or not to be? 1943, S. 132.

746 Ibid. S. 132.

747 Ibid. S. 137.

748 Ibid.: „Germany's inner tensions will be supplied, once the battle between the East and the West is settled within her own soul." 
Auch Karl Franks hauptsächliches Anliegen war die künftige Einbettung Deutschlands in ein neues Europa. In seinem Memorandum "What to do with Germany after the war?" näherte sich Frank mit Rücksicht auf sein Gastland dem Thema einer europäischen Föderation auf deduktive Weise und stellte zunächst einen Weltrat in Aussicht, der aus der britisch-russischamerikanischen Koalition, im Idealfall möglichst noch um den Bündnispartner China ergänzt, entstehen sollte. Unter dem Schutz und der Kontrolle dieses Weltrates würde sodann eine europäische Föderation zu bilden sein, um den Wiederaufbau der Alten Welt zu bewerkstelligen ${ }^{74}$. Auf der Basis der nationalen Souveränität würde die Föderation, die Frank aus realpolitischen Gründen als Konföderation skizzierte ${ }^{750}$, Deutschland als gleichberechtigtes Mitglied aufnehmen und es damit der gemeinsamen Kontrolle der europäischen Staaten unterwerfen ${ }^{751}$. Dahinter stand der Gedanke, den deutschen Widerstandskämpfern im In- und Ausland ein Mitspracherecht bei der Neugestaltung Deutschlands zu sichern. Nähere Angaben verweigerte Frank jedoch bewußt, um dieses erste unabdingbare $Z$ wischenziel der Inkorporation Deutschlands in ein vereinigtes Europa nicht durch Fernzielproklamationen zu gefährden und ihm das angemessene Gewicht beizumessen ${ }^{752}$.

Doch schon im Mai 1943 äußerte der amerikanische Vertreter von $\mathrm{Neu} \mathrm{Be-}$ ginnen ernste Zweifel an der Realisierungschance einer europäischen oder gar weltweiten Föderation: „Aber obgleich eine solche Föderation die vernünftige und natürliche Lösung des Krieges wäre, und obgleich wir sie anstreben müssen, wäre es illusionär, sie zu erwarten. Es gibt zu starke Kräfte gegen die europäische Föderation und gegen eine Weltföderation. " ${ }^{753} \mathrm{Um}$ so mehr, als die zukünftigen Siegermächte Grund hätten, eine europäische Föderation aus Eigeninteresse und Selbstschutz heraus abzulehnen. Die Sowjetunion und Großbritannien seien auf Grund ihrer „zentrifugalen Tendenzen“ nur mittelbar an einer europäischen Föderation interessiert, während die USA in einem enger verbundenen Europa möglicherweise einen zu starken

749 Hagen [d. i. Frank], What to do with Germany after the war?, [Januar] 1943, S. 30, IfZ, NL Frank, ED 213/3.

${ }^{750}$ Hagen [d. i. Frank], Deutschland nach Hitler. Um die Vollendung der demokratischen Revolution, Mai 1943, i. A. abgedruckt in: VOIGT (Hg.), Friedenssicherung 1988, S. 86-89 (87).

751 Hagen [d. i. Frank], What to do with Germany after the war?, [Januar] 1943, S. 31, IfZ, NL Frank, ED 213/3; erneut in: DERS., What are the principles that will guarantee security?, in: New Europe and World Reconstruction III, Nr. 7-8 (Juli/August 1943), S. $10 \mathrm{f} .(11)$.

752 So formulierte Frank in dem Artikel: What are the principles that will guarantee security?, in: New Europe and World Reconstruction III, Nr. 7-8 (Juli/August 1943), S. 10f. (11): „Without the emergence of a vital and militant democratic regime in Germany, there is no lasting security for Europe. It seems to us premature to discuss details so long as this basic principle has not been established."

753 Hagen [d. i. Frank], Deutschland nach Hitler, Mai 1943, i. A. abgedruckt in: VoIGT (Hg.), Friedenssicherung 1988, S. 87. 
und damit gefährlichen Konkurrenten auf dem Weltmarkt, vielleicht sogar in der Weltpolitik sehen könnten ${ }^{754}$.

Zum selben Zeitpunkt, als Frank erste Zweifel an der Realisierbarkeit des europäischen Projektes äußerte, beschäftigte sich der Sopade-Vorsitzende Hans Vogel erstmals explizit mit der europäischen Neuordnung im Sinne einer demokratischen Föderation, deren sinnfälligste Gestaltung auch er auf dem wirtschaftlichen Sektor sah755. Dabei stützte er sich unverändert auf Hilferdings Referat von Anfang 1940, ohne erkennbare Anpassungen an die aktuelle Situation vorzunehmen. Zuvor hatte sich Vogel mehrfach zur Notwendigkeit eines modifizierten Völkerbundes geäußert, doch hatte er sich auch insoweit auf bereits bekanntes sozialdemokratisches Gedankengut beschränkt. Neu war lediglich sein Appell, daß „die Politik der Zukunft und die des Völkerbundes im besonderen stärker als bisher mit ethisch-rechtlichen Erwägungen durchdrungen" werde. Darin sah der Vorsitzende der Londoner Union eine Möglichkeit, den Antiföderalisten das Argument aus der Hand zu schlagen, die Übertragung staatlicher Souveränität auf eine übergeordnete Organisation könne von niemandem erwartet werden, solange nicht deren rechtlicher Charakter geklärt sei 756 .

Wie Frank beurteilten auch die ISK-Vertreter in London, Willi Eichler und Mary Saran, die Chancen für eine Weltföderation bei Kriegsende äußerst skeptisch und setzten sich damit in diametralen Gegensatz zu Vogels pauschalem Verweis auf die Notwendigkeit eines modifizierten Völkerbun$\operatorname{des}^{757}$. Dagegen bewies der ISK hinsichtlich der Europaföderation mehr Optimismus als der amerikanische Neu Beginnen-Vertreter. Ein eigenständiges Europa als Scharnier zwischen Ost und West wäre zugleich Antriebskraft eines stabilen Weltsicherheitssystems ${ }^{758}$. Während Saran jedoch einen strikt gesamteuropäischen Ansatz verfocht und folgerichtig jegliche europäische Regionalföderation wegen der kontinentalen Zersplitterungsgefahr ablehnte ${ }^{759}$, hielt Eichler solche Teilföderationen innerhalb einer umfassenderen europäischen Gesamtföderation für empfehlenswert, soweit dadurch der Integrationsprozeß beschleunigt werden könne ${ }^{760}$.

Eichler und Saran legten Wert auf die supranationale Struktur der Föderation unter strenger Beachtung des Subsidiaritätsprinzips ${ }^{761}$. In dem vermut-

754 Ibid.

755 VOGEL, Deutschlands Zukunft in der Weltmeinung von heute, in: SM, Nr. 51 (Juli 1943), S. 1-14 (8f.). Hierbei handelt es sich um die Zusammenfassung einer Rede, die Vogel am 18.6. 1943 vor der Londoner Gruppe deutscher Sozialdemokraten gehalten hatte.

756 Vogel, Die Zukunft der Demokratie, o. D. [Mitte Oktober 1941], S. 11, AsD, Bestand PV-Emigration Sopade, M. 140.

757 Eichler, Zum Problem Europa, o. D. [1943], S. 1, AsD, Bestand IJB/ISK, Box 50.

758 SARAN, The Future Europe 1942, S. 27.

759 Ibid. S. 6-9.

760 Eichler, Zum Problem Europa, o. D. [1943], S. 1, AsD, Bestand IJB/ISK, Box 50.

761 Ibid. S. 2; SARAN, The Future Europe 1942, S. 25. 
lich von Eichler verfaßten ${ }^{762}$ allgemeinpolitischen Teil des Buches von Walter Fliess, „Die Wirtschaft im neuen Europa“, wurde das Subsidiaritätsverständnis des ISK erläutert: „Überall, wo solche Rechte und Pflichten einzelner und der einzelnen Völker in Frage stehen, die die internationale Organisation der Gesellschaft unmittelbar berühren, da soll eine internationale Organisation mit eigener Regierungsvollmacht eingreifen können. Wo das nicht notwendig ist, da soll den Einzelstaaten die Freiheit gelassen werden, zu tun, was ihnen gut und richtig erscheint." ${ }^{763}$ In einer europäischen Verfassung müßten die Bundesaufgaben abschließend geregelt werden ${ }^{764}$.

Die unterschiedlichen Entwicklungsstufen der sozialdemokratischen und sozialistischen Exilgruppen in der europäischen Frage lassen die zum Teil harten Verhandlungen erkennen, die innerhalb der Londoner Union um jedes einzelne Dokument geführt wurden. Insofern erklärt sich die Tatsache, daß die Union bis 1945 lediglich eine einzige Stellungnahme zur außenpolitischen Programmatik vorlegen konnte. Als typisches Kompromißpapier blieb die Erklärung vom 23. Oktober 1943 „Über die internationale Politik deutscher Sozialisten " weit hinter dem damaligen Stand des Europadiskurses zurück $^{765}$. Einig waren sich die in London versammelten deutschen Sozialisten in der plakativen Forderung einer „Föderation aller europäischen Völker“, $\mathrm{da}$ die uneingeschränkte Souveränität der Nationalstaaten nicht länger mit den wirtschaftlichen und politischen Existenzbedingungen in Europa vereinbar sei ${ }^{766}$. Gerade dieser Passus sollte in einer späteren Aussprache mit Vertretern der europäischen Arbeiterparteien über die Erklärung der deutschen Sozialisten auf vehemente Kritik des belgischen Sozialisten Louis de Brouckère stoßen. De Brouckère erklärte sich zwar mit der Errichtung einer internationalen Organisation einverstanden, lehnte die parallele Gründung einer europäischen Föderation jedoch ab. Sein eigentliches Motiv war wohl nicht die vorgeschobene weltwirtschaftliche Verflechtung Europas, sondern das

762 Vgl. etwa den Passus über die „vier Gruppen von Menschen“, S. 26-30, der wörtlich Eichlers Rede in: Towards European Unity 1943, S. 12-17 entspricht.

763 FLIESS, Wirtschaft im neuen Europa 1943, S. 25.

764 Ibid. S. 35. An anderer Stelle nannte Eichler als alleinige Bundeskompetenzen jedenfalls Außenpolitik, Verteidigung des Bundesgebietes nach außen, Zollpolitik, Außenhandel, fiskalische Abgaben, Münzrecht, Anleihewesen, Verkehr (Bahn-, Wasser-, Luftverkehr) und Telekommunikation (Post, Telegraph, Telefon): Eichler, Zum Problem Europa, o. D. [1943], S. 2, AsD, Bestand IJB/ISK, Box 50.

765 Erklärung der Union deutscher sozialistischer Organisationen in Großbritannien über die Internationale Politik deutscher Sozialisten vom 23. 10. 1943, in: SM, Nr. 55/ 56 (Mitte November 1943), S. 1 f.; erneut veröffentlicht in: Zur Politik deutscher Sozialisten 1945. Die Quelle ist auch abgedruckt in: EIBER (Hg.), Union 1998, Dok. Nr. 127, S. 296-298 sowie bei VOIGT (Hg.), Friedenssicherung 1988, S. 105-107 und bei LIPGENS (Hg.), Europäische Verfassung 1986, Dok. Nr. 33, S. 144 f. Eine englische Übersetzung findet sich bei LiPGENS (Hg.), Documents II 1986, Dok. Nr. 224, S. $602 \mathrm{f}$.

766 Ibid. Die Erklärung traf auf die uneingeschränkte Zustimmung Stampfers in den USA, die er öffentlichkeitswirksam unter der Schlagzeile „Das andere Deutschland spricht ${ }^{\alpha}$ in der NVZ, 12. Jg., Nr. 48 (27. 11. 1943), S. 1 bekundete. 
befürchtete politische Übergewicht der europäischen Großmächte zu Lasten kleinerer Staaten wie Belgien ${ }^{767}$.

Erneut wurde neben der europäischen Föderation ein weltumfassendes System kollektiver Sicherheit mit einer eigenen starken Exekutivgewalt und weitreichenden Schiedsbefugnissen eingefordert ${ }^{768}$. Bemerkenswert ist dabei die These, der Frieden Europas sei essentiell auf die konstruktive Kooperation mit dem britischen Commonwealth, den USA und der Sowjetunion angewiesen: „Nur in der freundschaftlichen Zusammenarbeit mit allen diesen Mächten, nicht in Anlehnung nur an eine oder die andere Seite, kann sich ein einiges und freiheitliches Europa entwickeln. ${ }^{469}$ Die Erkenntnis basierte weniger auf einer gemeinsamen Zielvorstellung der beteiligten Exilgruppen als vielmehr auf den indirekten Vorgaben der Moskauer Außenministerkonferenz, die im Oktober 1943 die Errichtung einer Weltorganisation auf der Grundlage der anglo-amerikanisch-sowjetischen Zusammenarbeit angedacht hatte. Dies belegt die Tatsache, daß in dem gemeinsamen Erklärungsentwurf von Eichler und Vogel mit Eingangsdatum vom 6. August 1943, also vor der Moskauer Konferenz, das Verhältnis zu den drei Staaten überhaupt nicht erwähnt worden war ${ }^{770}$. Der stärker innenpolitisch geprägte Entwurf hatte sich zwar ebenfalls für eine europäische Föderation als Teil einer Weltorganisation ausgesprochen, sich aber mit keinem Wort mit der europäischen Eigenständigkeit zwischen den drei alliierten Großmächten beschäftigt. Daraus kann jedoch nicht der Schluß gezogen werden, die gesamte Erklärung sei als Antwort auf das Außenministertreffen konzipiert worden ${ }^{771}$, denn die übrigen zentralen Gedanken wurden von Eichler und Vogel schon vor Moskau festgehalten.

Wiederholt und unabhängig voneinander wiesen Richard Löwenthal für die Londoner NB-Gruppe und Stefan Szende für die schwedische SAP-Vertretung auf die Hebelwirkung des europäischen Sozialismus für eine freiheitliche Zukunft Europas zwischen den beiden Machtblöcken hin. Löwenthal erwartete, „daß sich der Wiederaufbau Europas in der doppelten Abhängigkeit von der Wirtschaftsmacht und Luftmacht der Westmächte und von der

767 Vgl. die Einlassung Louis de Brouckères, in: Protokoll der Aussprache mit Vertretern europäischer Arbeiterparteien über die Erklärung „Zur internationalen Politik deutscher Sozialisten“ am 16. 11. 1943, abgedruckt in: EIBER (Hg.), Union 1998, Dok. Nr. 131, S. 302 ff.

768 Erklärung der Union deutscher sozialistischer Organisationen in Großbritannien über die Internationale Politik deutscher Sozialisten vom 23. 10. 1943, in: SM, Nr. 55/ 56 (Mitte November 1943), S. 2.

769 Ibid. S. 1.

770 Eichler, Vogel, Vorschlag für die Programmberatung über die internationale Politik, eingegangen am 6. 8. 1943, abgedruckt in: EIBER (Hg.), Union 1998, Dok. Nr. 117, S. 275 f.; erneut abgedruckt in: VOIGT (Hg.), Friedenssicherung 1988, S. 89 f. und bei RÖDER, Sozialistische Exilgruppen 21973, S. 271 sowie auf englisch bei LIPGENS (Hg.), Documents II 1986, Dok. Nr. 221, S. $594 \mathrm{ff}$.

771 So aber VOIGT (Hg.), Friedenssicherung 1988, S. 44. 
Militärmacht der Sowjetunion vollziehen" werde 772 . Darum dürften die Europäer nicht davon ablassen, auch im Interesse der eigenen politischen Stabilität eine neue Qualität der Zusammenarbeit zu entwickeln, die in freundschaftlicher Distanz zum demokratischen Kapitalismus sowie zur kommunistischen Parteidiktatur den Aufbau eines freiheitlich europäischen Sozialismus ermögliche ${ }^{773}$. Mit Blick auf die bei Löwenthal zeitweilig vertretene Osttendenz kann gesagt werden, daß der NB-Theoretiker der gesellschaftssystematischen Distanz zur westlichen Welt sicherlich größeres Gewicht bei$\mathrm{maß}$ als der nur die stalinistische Interpretation des Sozialismus betreffenden Distanz zur Sowjetunion. Als zentrale Kraft des europäischen Befreiungsprozesses erachtete Löwenthal weiterhin die europäische Arbeiterbewegung ${ }^{774}$. Löwenthals Konzept des europäischen Sozialismus, zu dem er sich im Juni 1942 erneut bekannte, wurde von der Mehrheit von Neu Beginnen durchgängig mitgetragen 775 .

Von dem SAP-Mitglied Szende stammte der Hinweis, daß im Sinne des europäischen Sozialismus eine gemeinsame Identität Europas sozial zu definieren sei. Darin sah der nach Schweden geflüchtete ehemalige Leiter des Prager Auslandsbüros die einzige Möglichkeit, sich zwischen West und Ost zu behaupten ${ }^{776}$. In diesem Rahmen setzte er sich für die Auflösung der identifikationsstiftenden Symbiose von Nation und Staat zugunsten des nationslosen Staates ein und umschrieb diesen Prozeß als "Entnationalisierung“ der Staaten ${ }^{777}$. Nur so sei die endgültige Abkehr vom nationalen Selbstbestimmungsrecht gewährleistet. Für die europäische Föderation beabsichtigte Szende eine Substitution des nationalstaatlichen Prinzips durch umfangreiche Föderationen und Staatengemeinschaften, die aus gesellschaftlichen, politischen und wirtschaftlichen Rechtsorganisationen bestehen sollten ${ }^{778}$. Ergänzend definierte er das europäische Erziehungsideal der Loyalität gegenüber dem nationalen Föderativstaat, der europäischen Föderation und einer Weltgemeinschaft als gemeinsamen Wertekonsens, der aktiv gefördert werden müsse 779 .

772 [LÖWENTHAL], Klare Fronten 1941, S. 12 f.

773 Ibid. S. 12.

774 Ibid. S. 15.

775 Sering [d. i. Löwenthal], Unsere Taktik gegenüber den Kommunisten, 6. 6. 1942, S. 1, IISG, Coll. Neu Beginnen, M. 40. Daß diese Einschätzung innerhalb der Gruppe mehrheitsfähig war, beweist eine Zuschrift an Paul Hertz im Rahmen einer Diskussion über die Aktualisierung der 1939 verabschiedeten Friedensziele der deutschen Arbeiterbewegung, November/Dezember 1942, IISG, NL Hertz, S8, M. C, Nr. 4: Die zu erwartende Besatzungszeit in Deutschland müsse positiv auch für den Aufbau einer europäischen Föderation genutzt werden, dessen Erfolg jedoch „vom Grade des Einverständnisses zwischen den Vereinigten Staaten, England und Rußland abhängig “ sei.

776 SZENDE, Europäische Revolution 1945, S. 365.

777 Ibid. S. 361-375.

778 Ibid. S. 374.

779 Ibid. S. 375. 
Szendes Gedanken fanden ansatzweise Eingang in die Schrift „Friedensziele der demokratischen Sozialisten" vom März 1943, für die der Arbeitskreis Internationaler Sozialisten in Stockholm verantwortlich zeichnete ${ }^{780}$. Die Gruppe aus 60 Sozialisten aus zwölf Ländern ${ }^{781}$ hatte das Dokument als internationale Diskussionsgrundlage an alle der SAI angehörenden deutschen Gruppen verschickt. Kompromißformeln nötigten auch die schwedische Gruppe zu eher vagen Aussagen ${ }^{782}$, die im Vergleich zu anderen Dokumenten dieser Diskursphase durch fehlenden Pragmatismus und nur geringe Konkretisierungsdichte auffallen, insbesondere mit Blick auf Willy Brandts eigene Schriften. Doch sollte nicht unberücksichtigt bleiben, daß der Arbeitskreis im Gegensatz zur Londoner Union kein Abschlußkommuniqué, sondern eine erste Grundlage für weiterführende Diskussionen vorlegen wollte. Tendenziell dogmatischer veranlagt, wurzelten die „Friedensziele der demokratischen Sozialisten" noch spürbar in den alten Grabenkämpfen der internationalen Arbeiterbewegung.

Entlang der acht Punkte der Atlantikcharta skizzierten die Sozialisten ein System internationaler Zusammenarbeit auf europäischer und globaler Ebene und konzipierten den Internationalen Gerichtshof als höchste streitschlichtende Instanz und weltumfassende Rechtsorganisation ${ }^{783}$. Während man für den Weltfrieden an einen Ausbau des englisch-russischen Bündnisses dachte ${ }^{784}$, wurde für Europa ein Föderativsystem, namentlich für den militärischen und ökonomischen Bereich ${ }^{785}$, zur unabdingbaren Voraussetzung des europäischen Friedens erklärt.

Vor dem Hintergrund öffentlich diskutierter Pläne zur Aufteilung Deutschlands als Mittel des Friedens und der kollektiven Sicherheit betonten die Sozialisten ebenso wie die bürgerlichen Emigranten immer wieder, daß Deutschlands Abrüstung eine viel bessere Friedensgarantie darstelle als

780 [Arbeitskreis Internationaler Sozialisten in Stockholm], Friedensziele der demokratischen Sozialisten, März 1943, AsD, Bestand PV-Emigration Sopade, M. 180. Dieses bedeutendste politische Dokument des schwedischen Exils ist abgedruckt in: VOIGT (Hg.), Friedenssicherung 1988, S. 222-235 und auf englisch auszugsweise bei LIPGENS (Hg.), Documents II 1986, Dok. Nr. 245, S. 677-680. Vorsitzender des Arbeitskreises war der sudetendeutsche Sozialdemokrat Ernst Paul, die Aufgabe des Sekretärs hatte Willy Brandt übernommen. Zum inneren Kreis zählten ferner Stefan Szende, Fritz Tarnow, der österreichische Sozialist Bruno Kreisky und zahlreiche Schweden und Norweger. Zur Geschichte des Arbeitskreises vgl. BRANDT, Links und frei 1982, S. 336-346 sowie MISGELD, Die „Internationale Gruppe demokratischer Sozialisten“ in Stockholm 1976.

781 Vgl. LIPGENS (Hg.), Documents II 1986, S. 677.

782 Zustimmend MISGELD, Die „Internationale Gruppe demokratischer Sozialisten“ in Stockholm 1976, S. 65, 67.

783 [Arbeitskreis Internationaler Sozialisten in Stockholm], Friedensziele der demokratischen Sozialisten, März 1943, S. 5 f., AsD, Bestand PV-Emigration Sopade, M. 180.

784 Ibid. S. 6.

785 Ibid. S. 5. 
Deutschlands Zerstückelung ${ }^{786}$. Dabei wurde Deutschlands einverständliche Entwaffnung in der Regel als do ut des für die Integration Deutschlands in eine demokratische europäische Staatenunion angesehen ${ }^{787}$. Stampfer behauptete sogar, daß die Idee einer Zerstückelung Deutschlands in viele kleine Territorien schon dadurch obsolet werde, „daß keine Macht der Sieger imstande wäre, eine Kleinstaaterei aufrechtzuerhalten, die niemand will und eine Wiedervereinigung zu verhindern, die alle wollen. ${ }^{\text {"788 }}$ Als Alternative zur Zerstückelung Deutschlands bot sich nach allgemeiner Ansicht der Sozialisten wiederum die Europaföderation an, in die Deutschland möglichst von Beginn an eingebunden werden müsse. Immer deutlicher wurde in Veröffentlichungen zur Europafrage die Einschätzung unterstrichen, daß das mildere Mittel der Abrüstung Deutschlands und seiner internationalen Einbindung ebenso effektiv den europäischen Frieden sichern könne wie die Teilung Deutschlands. Im Oktober 1943 schließlich wurde die deutsche Mitwirkung am Wiederaufbau Europas gar als "Ehrenpflicht" und die "sofortige militärische Abrüstung Deutschlands" als erster Beitrag des neuen, demokratischen Deutschlands bezeichnet ${ }^{789}$.

Nicht ohne Einfluß auf die zentrale Betonung der deutschen Frage innerhalb der Londoner Union dürfte die nationale Fokussierung ihres Vorsitzenden, des Sopade-Vorsitzenden Hans Vogel, gewesen sein, für den die Verhinderung der deutschen Teilung allerhöchste Priorität hatte. Insofern war Vogels außenpolitischer Blick merklich innenpolitisch gelenkt. Sein Hauptinteresse galt fraglos der Bewahrung eines einheitlichen Deutschlands, auf die er in all seinen programmatischen Reden in der Regel recht zügig zu sprechen kam. Für weitergehende Überlegungen hinsichtlich der Konzeption einer europäischen Föderation im einzelnen ließ Vogel selten Raum, sondern beließ es vorzugsweise bei althergebrachten Schlagworten, ohne auf die aktuellen Veränderungen der weltpolitischen Lage einzugehen ${ }^{790}$. Als Beispiel mag ein Manuskript dienen, das Vogel mit Datum vom 12.10. 1941 Yates zur

786 So stellvertretend die Gruppe internationaler Sozialisten an der Rand School of Social Research, Unsere Kriegs- und Friedensziele, in: NVZ, 10. Jg., Nr. 31 (2. 8. 1941), S. 2.

787 Vgl. stellvertretend für viele SIEMSEN, Deutschland und Frankreich, in: La Otra Alemania. Das Andere Deutschland (1. 8. 1943); erneut abgedruckt in: Ders., Die Tragödie Deutschlands 1947, S. 106-112 (111).

788 Stampfer, Kampf um Deutschland, o. D. [1943], S. 211, AsD, NL Stampfer, Box 9, M. 44.

${ }^{789}$ Erklärung der Union deutscher sozialistischer Organisationen in Großbritannien über die Internationale Politik deutscher Sozialisten vom 23. 10. 1943, in: SM, Nr. 55/ 56 (Mitte November 1943), S. 2. Dieser Passus ist nahezu wortgleich der gemeinsamen Entschließung der Union und der Landesgruppe deutscher Gewerkschafter in Großbritannien vom 16. 12. 1941 entlehnt; vgl. Die deutschen Sozialisten und Gewerkschafter und die Überwindung der Nazidiktatur, Entschließung der Union, angenommen am 16. 12. 1941, abgedruckt in: EIBER (Hg.), Union 1998, Dok. Nr. 54, S. $116 \mathrm{ff.}$

790 VOGEL, Deutschlands Zukunft in der Weltmeinung von heute, in: SM, Nr. 51 (Juli 1943), S. 1-14. 
Korrektur zukommen ließ: „Der Streit beim Friedensschlusse darf deshalb nicht darum gehen, einige Länder größer und andere kleiner zu machen, als sie vor dem Kriege waren. Je weniger Stacheldraht, Hochschutzzölle und Paßrevisionen es in Zukunft gibt und je mehr sich die Lebensverhältnisse der einzelnen Länder angleichen, eine desto geringere Rolle wird es spielen, wie die Ländergrenzen laufen. Das Primäre bei der Neuordnung der Welt muß sein, in allen Ländern den Geist des Friedens zu stärken und den Ungeist des Krieges auszurotten. "791 Vogel bediente sich hier aus dem politischen Schlagwort-Repertoire von Geyer und Hilferding, ohne sich um eine Differenzierung zwischen der europäischen und der globalen Ebene zu bemühen, und stellte den Überlegungen erneut die verklausulierte Ablehnung der deutschen Teilung voran. In der innenpolitischen Präferenz wußte sich Vogel mit Ollenhauer einig, der das Schwergewicht seiner unermüdlichen politischen Arbeit ebenfalls auf die Regierungsfähigkeit der in Gründung befindlichen einheitlichen sozialistischen Partei legte 792 .

Als entschiedener Gegner einer politischen Fremdbestimmung Deutschlands und Europas präsentierte sich der Volkssozialist und Pazifist Eugen Brehm. Bei Kriegsende müsse schnellstmöglichst eine handlungsfähige deutsche Bewegung die Führung übernehmen und augenblicklich eine neue Außenpolitik für Deutschland deklarieren. Andernfalls werde das außenpolitische Schicksal Deutschlands von der Machtpolitik der siegreichen Alliierten fremdbestimmt, und das gelte es als Patrioten und Weltbürger zu vermeiden $^{793}$. Brehm knüpfte an seine detaillierten Überlegungen aus dem Jahr 1938 an und beschrieb das künftige Europa als Wertegemeinschaft auf der doppelten Basis der Atlantikcharta und einer modernen Formel des Freiheitsbekenntnisses von $1789^{794}$. Hinsichtlich der Verwirklichung der europäischen Gemeinschaft zeigte sich Brehm recht flexibel. Falls eine gesamteuropäische Föderation im west-östlichen Spannungsfeld zunächst nicht zu realisieren sei, dann sollten seiner Ansicht nach jedenfalls temporäre Regionalföderationen geschaffen werden ${ }^{795}$. Und wenn eine Beteiligung Deutschlands am organisierten Europa zunächst nicht erwünscht sei, sollte zumindest eine Ring-

791 Vogel, Die Zukunft der Demokratie, o. D. [Mitte Oktober 1941], S. 11, AsD, Bestand PV-Emigration Sopade, M. 140.

${ }_{792}$ In einem Grundsatzreferat zu: Möglichkeiten und Aufgaben einer geeinten sozialistischen Partei in Deutschland, das Ollenhauer am 6. 12. 1942 vor der Mitgliederversammlung der Union in London hielt, beschränkte er sich im wesentlichen auf die außenpolitische Bemerkung, daß mit dem Übergang Deutschlands vom faschistischen zum demokratischen System der Weg für die Eingliederung in die Gemeinschaft der europäischen demokratischen Völker wieder frei werde; Ollenhauer, Möglichkeiten und Aufgaben einer geeinten sozialistischen Partei in Deutschland, Referat gehalten am 6.12. 1942 in einer Mitgliederversammlung der Union in London, abgedruckt in: Dowe, Klotzbach (Hg.), Programmatische Dokumente ${ }^{3} 1990$, S. 227-243 (236).

793 BREHM, Principles of a constructive German foreign policy, in: DERS., Towards a new German Policy o. D. [1943], S. 1-6 (1).

794 Ibid. S. 5.

795 Ibid. S. 1. 
föderation um Deutschland herum gebildet werden, um den Frieden zu gewährleisten ${ }^{796}$. Die weitere Ausgestaltung der europäischen Föderation überließ Brehm bewußt den Alliierten, deren Aufgabe als Sieger des Krieges es sein werde, die Nachkriegsordnung festzulegen 797 .

Im bürgerlichen Exil nahm Arnold Brecht die Entstehung des russischen Kraftfeldes im Lager der Hitlergegner zum Anlaß, sich ausführlich mit den Voraussetzungen einer europäischen Föderation als von den Siegermächten unabhängiger demokratischer Alternative zu beschäftigen. In einem Artikel für die Harvard Law Review, den Brecht im September/Oktober 1941 ausarbeitete, stellte er ein strikt am tatsächlich Machbaren orientiertes Minimalprogramm für eine „föderative Rechtsgemeinschaft mit entsprechenden Institutionen" auf ${ }^{98}$. Kern seiner Überlegungen war das Konstrukt einer losen Föderation mit zumindest einem ständigen Legislativorgan, einem obersten Föderationsgericht und einem mit weitreichenden Vollstreckungsbefugnissen ausgestatteten Exekutivausschuß. Da die Forderung des an sich wünschenswerten Maximums gleich zu Beginn unrealistisch, ein Minimum dagegen nicht nur wünschenswert, sondern auch unentbehrlich sei, verzichtete Brecht vorläufig auf eine in allen Einzelheiten bundesstaatliche Struktur im Sinne eines „Super-Staats" und bemühte sich um die Beschreibung des unbedingt Notwendigen 799 .

Anders als Stampfer, der auch die USA in die europäische Föderation einbinden wollte, legte Brecht in Artikel 5.2 seines Minimalprogramms fest, daß außereuropäische Länder nur ausnahmsweise der Föderation beitreten dürften, wenn sie „angemessene Erfahrung innerhalb der europäischen Grenzen gesammelt ${ }^{\text {" hätten }}{ }^{800}$. Offensichtlich zielte diese Formulierung auf die europäische Weltmacht Großbritannien ab, nicht aber auf die andere europäische Flügelmacht UdSSR, denn dem kommunistischen Totalitarismus erklärte Brecht eine unmißverständliche Absage ${ }^{801}$. Die Tatsache, daß sich Brecht in Artikel 5 explizit mit dem Verhältnis der Föderation zu außereuropäischen Ländern auseinandersetzte, beweist, daß er sich der Gefahr eines bipolaren

796 Ibid. S. 6.

797 BREHM, Germany and the small states, in: DERS., Towards a new German Policy o. D. [1943], S. 7-13 (12).

798 BRECHT, European Federation - The Democratic Alternative, in: Harvard Law Review, 55, Nr. 4 (Februar 1942), S. 561-595; in deutscher Übersetzung auszugsweise abgedruckt in: VOIGT (Hg.), Friedenssicherung 1988, S. 137-146. Kleinere Auszüge finden sich auch bei LIPGENS ( $\mathrm{Hg}$.), Europäische Verfassung 1986, Dok. Nr. 16, S. 82-84 und Ders. (Hg.), Documents II 1986, Dok. Nr. 214, S. 578-581. Die folgenden Zitate sind Voigts deutscher Übersetzung entnommen, hier: S. 137. Daß Brecht den Artikel schon im September/Oktober 1941 konzipiert haben muß, beweist ein am 20.10.1941 verfaßtes Manuskript: Rights of Individuals under a federal world government, BAK, NL Brecht, N 1089, Bd. 93, das mehrfach auf den zu erwartenden Artikel in der Harvard Law Review verweist (z. B. S. 2 ff.).

799 Ibid. S. 138, 142.

800 Ibid. S. 140.

801 Ibid. 
Spannungsfeldes in Europa durchaus bewußt war. Fand er für die notwendige Ausschaltung des sowjetischen Einflusses in den europäischen Nachkriegsdemokratien deutlichere Worte als bezüglich des Westeinflusses ${ }^{802}$, so impliziert der Ausschluß außereuropäischer Staaten doch den Willen des Verfassers, die Föderation ebenso von anglo-amerikanischer Dominanz freizuhalten.

Unabhängig von der Debatte um eine Europaorganisation sollte nach Brecht die Diskussion um die Reform des Völkerbundes, der grundsätzlich weiterbestehen sollte, wieder aufgenommen werden ${ }^{803}$. Doch enthielt er sich jedes weiteren Kommentars zum Verhältnis zwischen der europäischen und der globalen Ebene. Offenbar empfand Brecht diese Lücke schon bald als ein Manko seines Konzepts, denn im Oktober 1941 verfaßte er ein Manuskript, das sich unverkennbar mit dem bisher fehlenden Konnex zur globalen Ebene befaßte und viele der Kerngedanken aus dem europazentrierten HarvardArtikel schlicht übertrugg04. Ausdrücklich bekannte sich der Autor zu seinen persönlichen und politischen Präferenzen und bemerkte, daß die europäische Einigung in jedem Fall der Erörterung einer Weltorganisation voranzugehen habe ${ }^{805}$.

Der ehemalige geschäftsführende Vizepräsident des Deutschen Komitees der Paneuropa-Bewegung, Erich Koch-Weser, stand in regem Briefkontakt zu Brecht und ließ sich durch dessen Aufsatz in der Harvard Law Review zu einem eigenen Nachkriegskonzept inspirieren. Bereits in einem Brief an Brecht vom 21. Mai 1942 konnte Koch-Weser die weitgehende Übereinstimmung seiner Überzeugungen mit Brechts Ansatz einer entwicklungsfähigen losen Föderation feststellen, die er anschließend in mehreren Manuskripten weiterentwickelte ${ }^{806}$. Die Unterschiede zu Brechts Entwurf beschränkten sich im wesentlichen auf graduelle Schwerpunktverschiebungen in der institutionellen Gestaltung der Föderation. So betrachtete Koch-Weser die Einrichtung einer zentralen Bundesarmee als unerläßlich, um Bundesentscheidungen gegenüber den Mitgliedstaaten durchsetzen zu können ${ }^{807}$, und sah

802 Ibid.

803 Ibid.

${ }^{804}$ Brecht, Rights of Individuals under a federal world government, 20. 10. 1941, BAK, NL Brecht, N 1089, Bd. 93.

805 Ibid. S. 4.

806 Koch-Weser, Satzung des Europabundes, o. D. [Herbst 1942-Frühjahr 1943], abgedruckt in: VOIGT (Hg.), Friedenssicherung 1988, S. 149-155, auf englisch auszugsweise bei LiPGENS (Hg.), Documents II 1986, Dok. Nr. 217, S. 585-589. Eine Art Satzungskommentar findet sich in dem Manuskript Paneuropa, o. D. [Sommer 1943], BAK, NL Koch-Weser, N 1012, fiche 65.1, das posthum in den Deutschen Blättern, 3. Jg., H. 25 (Mai-Juni 1945), S. 26-34 abgedruckt wurde. Die Veröffentlichung entsprach KochWesers Wunsch, den er Arnold Brecht gegenüber in einem Brief vom 3. 8. 1944 äußerte: „Aber mindestens das über Paneuropa Geschriebene ist vielleicht noch irgendwie und teilweise die Veröffentlichung durch ein Buch oder in Zeitschriften wert." (S. 2, BAK, NL Brecht, N 1089, Bd. 11).

807 So bereits in seinem Brief an Brecht, 21. 5. 1942, S. 6 f., BAK, NL Koch-Weser, N 1012, fiche 64.2. 
für die Konstituierung des föderativen Mindeststandards eine Frist von drei Jahren vor ${ }^{808}$. Im übrigen sprach sich auch Koch-Weser für eine möglichst starke Exekutive aus und war sich mit Brecht jedenfalls in der prinzipiellen Ablehnung eines Austrittsrechts einig: „Wenn jeder, wie bei einer Kindergesellschaft, beleidigt seine Sachen zusammenpacken oder auch nur mit seinem Fortlaufen drohen kann, ist jede konsequente Zusammenarbeit unmöglich." ${ }^{809}$ Stärker als Brecht betonte Koch-Weser die Bedeutung des Präsidenten der Föderation, der Unabhängigkeit mit Hingebung für Europa vereinen müsse und von dessen Persönlichkeit die Macht und Durchsetzungskraft der Bundesexekutive wesentlich abhängen werde ${ }^{810}$.

Koch-Weser war die Unabhängigkeit Europas im bipolaren Weltmachtgefüge ein zentrales Anliegen. Die Entscheidung europäischer Fragen durch Nichteuropäer sei fast unmöglich ${ }^{811}$. Doch war auch ihm bewußt, daß die Entscheidungsbefugnis über Europas Zukunft nicht mehr bei den Europäern lag, denn „Europa, das einst die Welt regierte, muß sich heute durch die Welt regieren lassen. ${ }^{\circ 12}$ Eine erneute Unterwerfung, diesmal unter ein Protektorat der Weltmächte, sei den europäischen Staaten nach der nationalsozialistischen Tyrannei jedoch nicht zuzumuten. Die Entscheidung über die europäische Nachkriegsordnung müsse vielmehr von der „am Frieden interessierten Gesamtheit der Staaten, das heißt einem autonomen Völkerbund oder einem näher beteiligten Europabund" vorgenommen werden ${ }^{813}$. Ob England und der Sowjetunion ein Beitrittsrecht zur europäischen Föderation einzuräumen sei, überließ der ehemalige DDP-Vorsitzende der Weltpolitik, deutete jedoch an, daß er lediglich Großbritannien als „Bollwerk Europas in der Welt" integriert sehen wollte ${ }^{814}$. Einer Einbindung Rußlands hingegen stand der liberale Jurist skeptisch gegenüber, da dann eine klare Grenzziehung zwischen dem europäischen und dem asiatischen Kontinent unmöglich würde 815 .

Auch die nun häufiger ventilierte Teilung Deutschlands lehnten Koch-Weser und Brecht rigoros $\mathrm{ab}$ und hofften, sie durch die Gründung des Europa-

808 Koch-Weser, Satzung des Europabundes, o. D. [Herbst 1942-Frühjahr 1943], abgedruckt in:

VolGT (Hg.), Friedenssicherung 1988, S. 149-155 (154).

809 Koch-Weser an Brecht, 21. 5. 1942, S. 3, BAK, NL Koch-Weser, N 1012, fiche 64.2. Während Brecht jedoch den Austritt aus dem Bund kategorisch verbieten wollte, schwankte Koch-Weser zwischen einem absoluten Verbot einerseits (so in Art. 2 seiner Europabund-Satzung und auf S. 3 seines Briefes an Brecht vom 21. 5. 1942) und einem Austrittsrecht bei Zustimmung von der Stimmen andererseits (so in: Paneuropa, o. D. [Sommer 1943], S. 10, BAK, NL Koch-Weser, N 1012, fiche 65.1).

810 Koch-Weser an Brecht, 21. 5. 1942, S. 5, BAK, NL Koch-Weser, N 1012, fiche 64.2. 811 Ibid. S. 3.

812 Koch-Weser, Paneuropa, o. D. [Sommer 1943], S. 1, BAK, NL Koch-Weser, N 1012, fiche 65.1.

813 Ibid. S. 3.

814 Ibid. S. 9 f.

815 Ibid. S. 9. 
bundes obsolet erscheinen zu lassen. Koch-Wesers Argumentation stellte vor allem auf den historischen Aspekt ab, daß die deutsche Einheit gerade nicht von den konservativ-militaristischen Kreisen, sondern von den demokratischen und liberalen Gruppen erkämpft worden sei und dieser Kampf sich von vornherein als ein Kampf um die Freiheit dargestellt habe816. Eine Zerstückelung Deutschlands würde folglich diejenigen um die Frucht ihrer historisch-politischen Leistung bringen, die sich auch nun wieder auf der Seite der Freiheit wiederfänden. Darüber hinaus wäre in einem geteilten Deutschland die europäische Idee nicht mehr vermittelbar ${ }^{817}$. Schließlich sprach für Koch-Weser auch das übergeordnete Sicherheitsbedürfnis für die Einbindung Deutschlands: „Man kontrolliert und erzieht die Schuldigen besser, wenn sie im Bunde mitarbeiten, als wenn sie beiseite stehen." 818

In Anbetracht kursierender Pläne einer Teilung des Kontinents in Einflußsphären oder eine von der Sowjetunion favorisierte Wiederherstellung der kleinen Nationalstaaten in Ost- und Südosteuropa hielt Hubertus Prinz zu Löwenstein die rasche Vorlage konkreter Europapläne für unbedingt erforderlich, um antiföderalen Nachkriegsvorstellungen außereuropäischer Mächte frühzeitig die Grundlage zu entziehen: „We have no time to lose, for if we hesitate the initiative will be taken over by entirely different concepts. "819 Andernfalls drohe die Kolonisierung Europas zugunsten der Siegerstaaten ${ }^{820}$. Dies sei ebensowenig geeignet, Frieden zu stiften, wie eine militärische Besetzung des Kontinents oder der Ausbau zu einem antikommunistischen Bollwerk ${ }^{821}$. Vielmehr wollte Löwenstein das künftige Europa von der befreiten europäischen Bevölkerung selbst regiert sehen ${ }^{822}$. Es gelte deshalb, sich die historische Einheit Europas als abendländischer Kulturkreis in Erinnerung zu rufen und nach diesem Vorbild den Kontinent nicht nur als lose Konföderation, sondern als eigenständigen, supranationalen „European Commonwealth" neu zu gestalten ${ }^{823}$. Für Löwenstein war dieser Verbund ohne Deutschland schlicht nicht vorstellbar, da die deutsche Frage untrenn-

816 Koch-Weser an Brecht, 21. 5. 1942, S. 8, BAK, NL Koch-Weser, N 1012, fiche 64.2. 817 Ibid.

818 Koch-Weser, Paneuropa, o. D. [Sommer 1943], S. 10, BAK, NL Koch-Weser, N 1012, fiche 65.1.

${ }^{819}$ Löwenstein, Is peace possible in Europe, 7. 4. 1943, S. 11, BAK, NL Löwenstein, N 1222, Bd. 40.

820 Ibid. S. 2f. Löwenstein bezog sich auf die bekannt gewordenen Pläne deutscher Reparationszahlungen in Form von industrieller Demontage, die sich seiner Ansicht nach nicht auf Deutschland beschränken, sondern bald die gesamte europäische Industrie in Mitleidenschaft ziehen werde.

821 Ibid. S. 3.

822 Ibid.: „Peace cannot come if the attempt should be made after the war to rule Europe by foreign Gauleiters. Instead, it must be ruled by the liberated people of Europe themselves."

${ }^{823}$ Ibid. S. 5. Auf der folgenden Seite findet sich der terminus technicus der „supranational organs". 
bar mit der europäischen Frage gekoppelt sei ${ }^{824}$. In Anerkennung der Tatsache, daß die beiden entscheidenden außereuropäischen Alliierten in solchen rein europäischen Nachkriegsplänen ihre nationalen Interessen kaum würden wiedererkennen können, bemühte sich Löwenstein um eine komplementäre globale Perspektive. Der europäische Commonwealth müsse mit den anderen Kontinentalunionen einer organischen Weltrepublik beitreten, die auf dem Prinzip globaler Gerechtigkeit zu fußen habe ${ }^{825}$.

Nach dem deutschen Angriff auf die Sowjetunion war der emigrierte Nationalsozialist Strasser anfänglich in einen erneuten ideologischen Konflikt geraten, da er Hitlers „Kreuzzug gegen den Bolschewismus“ $z$ war als propagandistische Tarnung entlarvte, im Ergebnis jedoch völlig übereinstimmte ${ }^{826}$. Doch besann er sich rechtzeitig auf die alte Formel der dritten Front zwischen Nationalsozialismus und Bolschewismus, für die allein Großbritannien die Federführung übernehmen könne. Mithin hielt er an dem Konzept einer britisch geführten Europaföderation fest. Dies setze die Ergänzung der militärischen Kriegsführung Englands um eine politische Komponente voraus, deren innerdeutsche Öffentlichkeitsarbeit Strassers Frei Deutschland Bewegung zu übernehmen gedachte: „England kann den europäischen Völkern - einschließlich des deutschen und italienischen Volkes - viel mehr bieten als Hitler! “ 827

Das auch von der Sopade propagierte Schlagwort vom „unteilbaren Frieden" 828 griff 1943 der bekannte Völkerrechtler Hans Wehberg auf und verlieh seiner Überzeugung Ausdruck, daß eine künftige Organisation nur dann die Gewähr des Bestandes in sich trage, wenn sie im Sinne wahrhafter Universalität alle Staaten der Erde umfasse ${ }^{829}$. Dies folge aus der mittlerweile dominierenden Kriegsbeteiligung außereuropäischer Mächte ${ }^{830}$. Dementsprechend überging der Hochschullehrer und Mitherausgeber des Kommentars der Völkerbundssatzung die europäische Frage nahezu völlig und widmete

824 Ibid. S. 9.

825 Ibid. S. 4, 8 und 19 sowie Ders., Europe Tomorrow. The shape of things to come, [2. Jahreshälfte] 1941, S. 5, BAK, NL Löwenstein, N 1222, Bd. 42.

826 Strasser, Memorandum, Mitte Juli 1941, S. 2, IfZ, NL Strasser, ED 118/20: „Hitler zeigte sich hierin wiederum als überaus geschickt in jener Mischung von militärischen und politischen Gesichtspunkten, die seiner Kriegsführung von Anfang an einen revolutionären Charakter gegeben hat."

827 Ibid. S. 5.

828 Ollenhauer, Vogel, Vorschlag für eine Stellungnahme im Newsletter zum deutschen Angriff auf die Sowjetunion vom 10.7.1941, abgedruckt in: EIBER (Hg.), Union 1998, Dok. Nr. 34, S. 80.

${ }^{829}$ H. WeHBERG, Zum gegenwärtigen Stande des Problems einer künftigen Weltorganisation. Die zentrale Frage der Schaffung einer internationalen Autorität, in: Die Friedens-Warte, 43. Jg., Nr. 5 ([September] 1943), S. 205-220 (211); erneut abgedruckt in: VOIGT (Hg.), Friedenssicherung 1988, S. 157-169 und auf englisch bei LIPGENs (Hg.), Documents II 1986, Dok. Nr. 222, S. $597 \mathrm{ff}$.

830 Ibid. S. 211. 
sich um so eingehender den Anforderungen an eine Weltorganisation, wie sie seitens der Alliierten angedacht wurde.

$\mathrm{Da}$ Wehberg axiomatisch von der Unteilbarkeit der internationalen Sicherheit ausging, konnte es für ihn allein um die Gründung eines Weltbundes gehen, der "den Frieden in der Welt mit starker Hand aufrechtzuerhalten" vermochte und möglichst alle Staaten der Welt einbinde ${ }^{831}$. Solch eine weltumspannende Einigung bedürfe der Zustimmung und des Mitspracherechts aller Völker, auch der Kriegsverlierer. Diese Grundvoraussetzung sah Wehberg einen Monat vor der Moskauer Konferenz der alliierten Außenminister durch die drohende Omnipräsenz und politische Dominanz der künftigen Siegermächte gefährdet: „Wenn sich die in diesem Kriege siegreichen Mächte nicht als Diener einer neuen internationalen Ordnung betrachten, dann haben sie den Krieg in Wahrheit verloren." 832 Unter Rückgriff auf ältere Reformideen für den Völkerbund, die zum Teil von ihm selbst entwickelt worden waren, stellte Wehberg das Erfordernis einer starken internationalen Autorität in den Vordergrund seiner Betrachtungen. Dabei müsse es sich um eine Zentralgewalt handeln, „die nicht nur auf dem Papiere steht, sondern die Zügel der internationalen Politik zur Aufrechterhaltung des Friedens auf der Basis der Gerechtigkeit und der Menschlichkeit fest in der Hand hält." "833 Damit sprach sich der Völkerrechtsexperte gegen den bisherigen Vermittlungsgrundsatz und für eine autoritäre Regelung aus. Eine starke Autorität erfordere den Ausbau einer internationalen Regierung, die der demokratischen Kontrolle eines zumindest teilweise direkt zu wählenden Zweikammerparlamentes zu unterwerfen sei ${ }^{834}$. Entscheidungen seien mit qualifizierter Mehrheit zu treffen. Konflikte juristischer sowie politischer Art und den Menschen seien vor dem Internationalen Gerichtshof auszutragen, der verbindliche Urteile zu fällen befugt sein und sich dabei auf einen verbindlichen Katalog der Rechte und Pflichten der Menschen berufen müsse. Für die Lösung spezifisch kontinentaler Konflikte dachte Wehberg an die Einrichtung kontinentaler Ad-hoc-Gremien.

Der eigenwillige Radikalpazifist Friedrich Wilhelm Foerster äußerte sich in der europäischen Frage seit 1943 ausgesprochen resignativ, ja fatalistisch. In einem Brief an Paul Hagen [d. i. Karl Frank] sprach sich Foerster, der 1937 noch eine Föderation des christlichen Abendlandes als einzige Rettung vor dem Niedergang Europas bezeichnet hatte, nun ausdrücklich gegen die Idee einer Europaföderation aus, sei sie nun sozialistisch oder bürgerlich-liberal inspiriert. Verbittert meinte der Pädagoge den "geistigen Bankrott der modernen Menschheit" zu erkennen ${ }^{835}$ : Weder die "Sowjet-Maske“ des Sozialismus noch der westliche Liberalismus noch die christliche Kirche hätten

831 Ibid. S. 207.

832 Ibid. S. 215.

833 Ibid. S. 212.

834 Ibid. S. 216-220.

835 Foerster an Hagen [d. i. Frank], 10. 2. 1943, S. 2, IISG, NL Hertz, S. 9, M. G. 
bisher auch nur den Ansatz einer wirklichen Lösung der politischen Probleme gefunden. Insbesondere die verkürzende „Klassenkampfweisheit“ des Sozialismus werde sich nach dem Krieg als völlig ungeeignet erweisen, Frieden zu schaffen, denn: „Aus Rußland selber und aus dem gesamten Asien werden neue Geisteskräfte kommen, die Fragen lösen werden, die mit keinem Klassenkampfschema oder anderen menschenfeindlichen Schemen zu lösen sind. "836 Doch sei der von vielen propagierte Lösungsansatz einer europäischen Föderation auch in der bürgerlich-liberalen Variante schon im Prinzip abzulehnen. Mit der gleichberechtigten Einbindung Deutschlands in einen solchen Staatenverband wäre man gezwungen, die historische Schuld der Deutschen schlicht zu ignorieren, „als sei irgendwo in Sachsenhausen ein kleines Eisenbahnunglück passiert, wobei zwei Kälber umkamen“" 837 . Fern jeder Realität liege die Annahme, die europäischen Staaten würden bei Kriegsende gerade mit dem Volk föderieren wollen, das sie jahrelang gefoltert habe. Denn dies liefe auf eine „Föderation der Gangster mit der Polizei und mit den Opfern" 838 hinaus. Foerster erklärte sich statt dessen solidarisch mit den Vansittartisten in London und sprach sich dafür aus, während einer möglicherweise lange andauernden Periode Deutschland unter internationale Kontrolle zu stellen. Das für den neuerlichen Kriegsausbruch verantwortliche Deutschland solle in jeder Hinsicht politisch entmündigt werden, bis es die notwendige Reife erlangt habe, einer internationalen Gemeinschaft als gleichberechtigtes Mitglied beizutreten ${ }^{839}$. Als weiteres Sicherungsinstrument schlug er die Umformung Deutschlands in einen losen Staatenbund voneinander unabhängiger Kleinstaaten vor, die an keinerlei zentrale Autorität gebunden sein durften ${ }^{840}$.

1943 unternahm der nach Chile emigrierte Rechtsanwalt Udo Rukser in mehreren Beiträgen für die von ihm mit herausgegebenen Deutschen Blätter den Versuch, zwischen Foersters fatalistischer Auffassung und den Befürwortern einer Europaföderation zu vermitteln. Rukser, der in engem Kontakt zu Koch-Weser stand, befürwortete im Grundsatz den politischen Ansatz der föderativen Selbstverwaltung, da dieser allein imstande sei, die beiden wichtigsten Problemkreise Europas, nämlich die deutsche Frage und die

836 Ibid.

837 Ibid.

838 Ibid. Einige Monate später benutzte Foerster diese bildhafte Umschreibung auch öffentlich. In New Europe and World Reconstruction III, Nr. 7-8 (Juli/August 1943), S. 5-9 (7) mit dem Titel: Germany and the coming peace fragte er rhetorisch: „But who has ever heard [of] a federation between gangsters and police and the victims proposed after a successful police raid on a gangster mob and its accomplices?"

839 FoERSTER, Germany and the coming peace, in: New Europe and World Reconstruction III, Nr. 7-8 (Juli/August 1943), S. 6 sowie ders. an Hagen [d. i. Frank], 10. 2. 1943, S. 2 f., IISG, NL Hertz, S. 9, M. G.

840 FOERSTER, Germany and the coming peace, in: New Europe and World Reconstruction III, Nr. 7-8 (Juli/August 1943), S. 9. 
osteuropäischen Nationalitätenkonflikte, befriedigend zu lösen ${ }^{841}$. Für die deutsche Frage schlug er die Integration eines nach dem Vorbild des Norddeutschen Bundes dezentralisierten Deutschlands in eine europäische Konzeption vor ${ }^{842}$. Ergänzt um eine stabile Donauföderation versprach sich der konservative Publizist davon die langfristige Sicherung des Friedens.

Unabhängig von der Notwendigkeit eines europäischen Staatenverbundes räumte Rukser dessen tatsächlicher Errichtung bei Kriegsende nur vage Realisierungschancen ein. Europa selbst sei zur Erfüllung dieser großen Aufgabe momentan nicht in der Lage. Die Initiative für eine europäische Föderativordnung müsse statt dessen von Großbritannien und der bald vielleicht "größte[n] Macht des Erdballs ${ }^{843}$, der UdSSR, ausgehen, die als Sieger des Krieges „die Möglichkeit dazu erkämpft haben und den Neubau künftig zu verteidigen haben werden "844. Inhaltlich würde man sich an Churchills Vorstellungen zur europäischen Neuordnung zu orientieren haben, wie er sie in seiner Rede vom 21. März 1943 skizziert habe ${ }^{845}$. Gleichwohl werde eine von den Alliierten wohlwollend oktroyierte Föderation voraussichtlich an der Uneinigkeit der Anti-Hitler-Koalition scheitern ${ }^{846}$. Rukser erwartete daher eine recht lange Übergangszeit, innerhalb derer sich zunächst kleinere Staatengruppen $\mathrm{zu}$ Interessengemeinschaften zusammenfinden würden, um in unbestimmter Zukunft vielleicht einen europaweiten Bund einzugehen ${ }^{847}$. Bei Kriegsende müsse aber jedenfalls der bisherige Konsens in einer magna carta europea fixiert werden, um ihn einem späteren Zusammenschluß zugrunde zu legen. Für die Zeit des Übergangs forderte der Publizist unter der Parole „Weltordnung erfordert Weltinformation!“ einen vom Völkerbund unabhängigen „International Information Service“, der die öffentliche Weltmeinung zu einer moralischen Kraft erstarken lassen sollte, die "den widerstrebenden Völkern und auch den Großmächten das Gesetz der internationalen Solidarität" aufzuerlegen habe ${ }^{848}$. Die fundierte Unterrichtung der Weltöffentlichkeit unter Vermeidung jeder Geheimdiplomatie hielt Rukser für ein geeignetes Mittel zur Überwachung der internationalen Politik und hoffte, auf diesem Wege Kriege künftig vermeiden zu können.

841 RUKSER, Europäische Phantasien, in: Deutsche Blätter, 1. Jg., H. 5 (Mai 1943), S. 3$8(6)$.

842 Ibid. S. 7.

843 Ibid. S. 5.

844 RuKSER, Neue Methoden! I. Souveränität und Weltordnung, in: Deutsche Blätter, 1. Jg., H. 8 (August 1943), S. 8-11 (11).

$845 \mathrm{Vgl}$. Churchill, Radiobotschaft über die künftige Friedens-Organisation, 21.3. 1943, abgedruckt in: LIPGENS (Hg.), Föderationspläne 1968, Dok. Nr. 164, S. 474-477. 846 RuKSER, Europäische Phantasien, in: Deutsche Blätter, 1. Jg., H. 5 (Mai 1943), S. 3. 847 Ibid. S. 4.

848 RuKSER, Neue Methoden! II. Weltordnung erfordert Weltinformation!, in: Deutsche Blätter, 1. Jg., H. 9 (September 1943), S. 12. 


\subsubsection{Wirtschaftsföderation als supranationaler Auftakt}

Als vorrangig geeignetes Feld für einen supranationalen Auftakt eines europäischen Einigungsprozesses wurde der Wirtschaftsbereich angesehen, da insoweit die Notwendigkeit eines engeren europäischen Zusammenschlusses allseits anerkannt wurde. Darüber hinaus versprach die Anknüpfung an die vom Nationalsozialismus geschaffenen strukturellen Voraussetzungen eine vergleichsweise zügige Umsetzung des Einigungsprozesses, zumal es den Konzeptionalisten des Exils auch um die Schaffung möglichst unumkehrbarer Fakten ging, um nicht im Machtpoker zwischen West und Ost unterzugehen und Europa zu einem unselbständigen Spielball der weltpolitischen Dichotomie degradiert sehen zu müssen. Um jeden Zeitverzug bei Kriegsende zu verhindern, wurde nunmehr von sozialistischen Wirtschaftsföderalisten wie Walter Fliess, Gerhard Kreyssig und Hilda Monte ebenso wie von bürgerlichen Ökonomen wie August Weber oder Wilhelm Röpke mehrheitlich die Anknüpfung an das NS-Wirtschaftssystem bei gleichzeitiger Ausrichtung auf eine gleichberechtigte, integrative Binnenstruktur als sinnvoll erachtet. Die Wirtschaftstheoretiker des deutschen Exils hatten bald das politische Potential des wirtschaftsföderalen Projektes erkannt und beschäftigten sich seit 1941/42 intensiver mit den Einzelheiten, insbesondere der institutionellen Ausgestaltung. Dies um so mehr, als wegen der größeren Überzeugungskraft bloße Absichtsbekundungen oder die Formulierung wirtschaftspolitischer Selbstverständlichkeiten nun nicht mehr ausreichten, um auf die Stimmen des deutschen Exils aufmerksam zu machen und gegenüber den Alliierten die Fahne der europäischen Einigung hochzuhalten.

Im bürgerlichen Lager wurde das Verhältnis von politischer und ökonomischer Vereinigung nicht einheitlich beurteilt. Lehnte man die für die sozialistische Sicht charakteristische Fokussierung auf den ökonomischen Faktor $\mathrm{ab}^{849}$, sah man gleichwohl in der ökonomischen Föderation überwiegend eine notwendige Ergänzung und Absicherung der politischen Einigung850. Der in Genf ansässige Nationalökonom Wilhelm Röpke faßte diese nunmehr von vielen politischen Emigranten geteilte Erkenntnis in die eine Selbstverständlichkeit suggerierenden Worte: „Es ist klar, daß eine solche föderative Vereinigung nach allen bisherigen Erfahrungen und gemäß allen Überlegungen eine entsprechende wirtschaftliche Vereinigung voraussetzt, da ihr sonst eines der allerwichtigsten Bindemittel fehlen würde. "851 Entgegen den weni-

$849 \mathrm{Vgl}$ z. B. RöPKE, Wirtschaftsverfassung und politische Weltordnung, in: Die Friedens-Warte, 43. Jg., Nr. 1 (1943), S. 24-35 (25): „Wir haben uns vor einem einseitigen Ökonomismus zu hüten, indem wir das Wirtschaftliche zur alleinigen oder auch nur zur überragenden Ursache eines kriegerischen oder friedlichen Charakters der Völkerbeziehungen machen."

850 Vgl. etwa Koch-Weser, Paneuropa, o. D. [Sommer 1943], S. 4, BAK, NL Koch-Weser, N 1012, fiche 65.1 und BRECHT, Europäische Föderation - Die demokratische Alternative, in: VOIGT (Hg.), Friedenssicherung 1988, S. 137-146 (138).

851 RÖPKE, Wirtschaftsverfassung und politische Weltordnung, in: Die Friedens-Warte, 
gen Stimmen, die der politischen Einigung sogar eine Vorrangstellung gegenüber dem wirtschaftlichen Zusammenschluß einräumten ${ }^{852}$, rechnete Röpke für die nähere Zukunft mit einem wirtschaftsideologischen Dualismus zwischen Liberalismus und Kollektivismus. Obsiegen müsse letztlich dasjenige Wirtschaftskonzept, das den friedlichen Ausgleich nach innen und außen ermögliche ${ }^{853}$. Der Wirtschaftsprofessor ließ keinen Zweifel daran aufkommen, daß diese Aufgabe allein der Liberalismus erfüllen könne, den Röpke im Sinne eines Wirtschaftshumanismus verstand. Dies sei der tragische Irrtum der Sozialisten, die „im Namen des Friedens und der internationalen Gerechtigkeit die Marktwirtschaft verdammen und den Kollektivismus preisen"854. Tatsächlich führe ein kollektivistisches Wirtschaftssystem unweigerlich zur Sprengung der Föderation, entweder durch Zentralisation von oben oder durch regionalen Interventionismus und Zerfall von unten ${ }^{855}$. Diese Erkenntnis über das Verhältnis von Föderalismus und Kollektivismus transferierte Röpke unverändert von der nationalen auf die internationale Ebene und lehnte den kollektivistischen Ansatz für eine europäische Föderation kategorisch $\mathrm{ab}^{856}$.

Für die sozialistischen Emigranten stellte die Herbeiführung der wirtschaftlichen Einheit Europas eine ideologisch unerläßliche Voraussetzung für das Gelingen des politischen Föderationsprojektes dar ${ }^{857}$. Repräsentativ für das Ideal einer sozialistischen Wirtschaftsföderation sind - unbesehen der Divergenzen im einzelnen - die zwischen 1941 und 1943 entstandenen Konzeptionen von Hilda Monte ${ }^{858}$, Gerhard Kreyssig ${ }^{859}$ und Walter Fliess ${ }^{860}$.

43. Jg., Nr. 1 (1943), S. 33. Im gleichen Sinne antwortete August Weber auf die Frage, wie er zu politischer und wirtschaftlicher Demokratie stehe: "Ich betone das Wort ,wirtschaftlich': denn es gibt in Zukunft keine wirkliche politische Demokratie, wenn nicht ein gut Teil Wirtschaftsdemokratie fest darin verankert ist. “; A. Weber, Interview, in: FraENKEL (Hg.), Der Weg zu einem neuen Deutschland 1943, S. 48f. (49).

852 So etwa STERN-RubarTH, Germany defeated - What then?, in: Cont. Rev., Nr. 929 (Mai 1943), S. 265-270 (268).

853 Vgl. z.B. RöpKE, Wirtschaftsverfassung und politische Weltordnung, in: Die Friedens-Warte, 43. Jg., Nr. 1 (1943), S. 25.

854 Ibid. S. 29.

855 Ibid. S. 34.

856 Ibid. S. 35.

857 Vgl. etwa BreHM, Germany and the small states, in: Ders., Towards a new German Policy o. D. [1943], S. 12: „The recovery of Europe is not a political or an economic or a strategic problem [Hervorhebungen im Original, B. S.]. "In diesem Sinne auch die im folgenden näher erläuterten Konzeptionen von Kreyssig, Fliess und Monte, wobei Kreyssig zunächst ausschließlich die Schaffung der Wirtschaftseinheit und erst später eine politische Föderation anregte (Memorandum, S. 34).

858 MONTE, Unity of Europe 1943, S. 27. Das Werk ist auszugsweise erneut abgedruckt in: VOIGT (Hg.), Friedenssicherung 1988, S. 110-120 sowie bei LIPGENS (Hg.), Föderationspläne 1968, Dok. Nr. 168, S. 492-498, auf englisch auch bei LiPGENS (Hg.), Documents II 1986, Dok. Nr. 226, S. 605-609.

859 Kreyssig, Memorandum zu Problemen und Aufgaben des Nachkriegs-Europa, 
Kreyssigs Entwurf einer sozialistischen Wirtschaftsgemeinschaft Europa basierte ebenso wie die Ausarbeitungen von Monte und Fliess auf dem Wunsch nach Friedenssicherung durch wirtschaftliche Gleichberechtigung, Vollbeschäftigung, friedliche Arbeitsteilung und die Sicherung eines gehobenen Lebensstandards für alle Völker ${ }^{861}$. Als vorrangiges Problem erwiesen sich auch in wirtschaftlicher Hinsicht die Bewahrung einer selbständigen Position Gesamteuropas zwischen den Weltmächten USA und UdSSR sowie die Verhinderung einer kontinentalen Teilung: „Europa muß um den Preis seines Unterganges oder seiner Verarmung (was nur der Anfang des Unterganges wäre) diesmal so solidarisch nach Kriegsende zusammenhalten, wie es - gegen seinen Willen - heute unter der Diktatur der Hitlerschen ,Festung Europa zusammengehalten wird." 862 Auf keinen Fall dürfe man dem „Souveränitätsfimmel“ nachgeben und die Fehler von 1918/19 wiederholen. Der Leiter der wirtschaftspolitischen Abteilung des IGB erkannte in Hitlers Zwangsvereinheitlichung der europäischen Rüstungsindustrien die Chance, die Schicksalsverbundenheit der vom Nationalsozialismus unterdrückten Völker „durch freien Entschluß umzuwandeln in eine freiwillig gewollte echte Wirtschaftszusammenarbeit auf demokratischer Basis" 863 .

Souveränitätsbeschränkung auf dem Wirtschaftsgebiet müsse zunächst die Enteignung der Monopolkräfte bedeuten, denn der Faschismus sei nichts anderes als die politische Ausdrucksform des Monopolkapitalismus ${ }^{864}$. Um aber einen gegeneinander gerichteten Wettlauf der nationalen Wirtschaftsplanungen zu verhindern, sei ein weiterer Schritt unverzichtbar: die „europäische Kollaboration auf entnationalisierter Grundlage“, also die Europäisierung der Monopolpositionen in den kriegswichtigen Bereichen Kohle, Eisen/Stahl und Transportwesen ${ }^{865}$. Folglich strebte Kreyssig auf der europäischen Ebene eine supranationale Koordination in allen wichtigen und entscheidenden Wirtschaftsfragen an. Etwa zeitgleich beschäftigte sich Willi Eichler mit einem vergleichbaren Enteignungsplan zugunsten des Bundes-

15. 7. 1942 sowie ders., Europäisches Waren-Clearing durch eine Europäische Handels-Korporation, 10. 11. 1942, beide AsD, NL Kreyssig, M. 20.

860 FLIESS, Wirtschaft im neuen Europa 1943, S. 11. Das Dokument findet sich in Auszügen erneut abgedruckt in: VOIGT (Hg.), Friedenssicherung 1988, S. 91-105 sowie auf englisch bei LiPGENS (Hg.), Documents II 1986, Dok. Nr. 223, S. 599 ff.

861 Vgl. auch Kreyssig, Vorschlag für die Programmberatung über Wirtschaftsfragen, eingegangen am 6.5. 1943, abgedruckt in: EIBER (Hg.), Union 1998, Dok. Nr. 99, S. $217 \mathrm{f}$. Die Gemeinsamkeiten dieser drei sozialistischen Entwürfe hat REGIN, Wirtschaft im neuen Europa 1996, S. 69 f. herausgearbeitet.

862 Kreyssig an Rimsberger, 22. 8. 1942, S. 2, AsD, NL Kreyssig, N. 59.

863 Kreyssig, Memorandum, 15. 7. 1942, S. 7, AsD, NL Kreyssig, M. 20 sowie ders., Europaeisches Waren-Clearing, 10.11. 1942, S. 14, AsD, NL Kreyssig, M. 20. Zur Anknüpfung an die nationalsozialistische Wirtschaftsordnung Europas vgl. auch REGIN, Wirtschaft im neuen Europa 1996, S. 67 f.

864 Ders., Memorandum, 15. 7. 1942, S. 33 und 36, AsD, NL Kreyssig, M. 20.

865 Ibid. S. 35 f. 
eigentums ${ }^{866}$. Danach sollte ein „European Economic Board“ zunächst die „Europäisierung“ der Hermann-Göring-Werke, der Schwerindustrie und der Chemie als Basis für eine planwirtschaftliche Gestaltung Europas betreiben und in einem zweiten Schritt die Banken und Versicherungen, das Verkehrswesen und andere zentrale Bereiche in das Eigentum der Föderation übertragen ${ }^{867}$.

Für die supranationale Koordination schlug Kreyssig die Gründung spezifischer Europagemeinschaften vor, von denen der „Europa-Gemeinschaft Eisen und Stahl" und der separaten „Europa-Gemeinschaft Kohle“ eine zentrale Funktion zukam. Gegenüber dem außereuropäischen Markt würde die jeweilige supranationale Europagemeinschaft folgerichtig als alleiniger Handelspartner auftreten. Für die ausgleichende Versorgung mit Rohstoffen und anderen Waren sei eine - von Kreyssig in einem gesonderten Manuskript ${ }^{868}$ eingehend erläuterte - Europäische Handelskorporation einzurichten, die über ein zentrales innereuropäisches Warenclearing Angebot und Nachfrage in ein für die Gemeinschaft möglichst optimales Verhältnis setzen würde.

Am Beispiel der Eisen- und Stahlindustrie sei Kreyssigs Wirtschaftskonzept der europäisierten Monopolpositionen kurz erläutert ${ }^{869}$. Nach den Vorstellungen des IGB-Funktionärs müßten zunächst auf nationaler Ebene sämtliche Eisen- und Stahlwerke enteignet werden. Sodann sollte jeder Staat die enteignete Schwereisenindustrie der zu gründenden „Europagemeinschaft Eisen und Stahl" übertragen. Ein allein entscheidungsbefugter Europäischer Eisen- und Stahlrat würde als oberste europäische Planungsbehörde für die Schaffung, Erweiterung und Verteilung der europäischen Kapazitäten sorgen. Innerhalb des Europäischen Eisen- und Stahlrates hielt Kreyssig die Festlegung der Stimmrechtsverteilung aufgrund des nationalen Anteils an der Gesamtproduktion zuzüglich des Anteils an der Erzgewinnung für sinnvoll, da dadurch das ohnehin gegebene Übergewicht Deutschlands am wirkungsvollsten relativiert werden könne ${ }^{870}$. Die kapazitätskonforme Rohstoffversorgung würde der Rat in Zusammenarbeit mit der Europäischen Handelskorporation durchführen. Dabei würden durch ein innereuropäisches Clea-

866 Zuerst in: Towards European Unity 1943, S. 16, später konkretisiert in: Eichler, Zum Problem Europa, o. D. [1943], S. 3, AsD, Bestand IJB/ISK, Box 50.

${ }^{867}$ Eichler, Zum Problem Europa, o. D. [1943], S. 3, AsD, Bestand IJB/ISK, Box 50. 868 Kreyssig, Europaeisches Waren-Clearing, 10.11. 1942, AsD, NL Kreyssig, M. 20. 869 Ders., Memorandum, 15. 7. 1942, S. 39-48, AsD, NL Kreyssig, M. 20. Daraus die folgenden Zitate.

870 Dies ergab sich für Kreyssig aus einer Gegenüberstellung zweier Berechnungsmodelle: Eine Stimmrechts- und Mitentscheidungsquote, die sich unter Zugrundelegung nur der jeweils eingebrachten Produktionskraft errechne, ergäbe eine überproportional starke Stellung Deutschlands mit 38 Mio. Tonnen gegenüber 43 Mio. Tonnen aller anderen Länder (ohne Großbritannien). Unter zusätzlicher Berücksichtigung auch des nationalen Anteils an der Erzgewinnung, die insbesondere den Abstand zwischen der zweitplazierten französischen und der erstplazierten deutschen Position deutlich verringern würde, ergäbe sich ein relativiertes deutsches Gewicht von $38 \mathrm{Mio}$. Tonnen gegenüber 70 Mio. Tonnen aller anderen Länder (Memorandum, S. 40). 
ring von Angebot und Nachfrage die günstigsten Versorgungsmöglichkeiten festgesetzt sowie Gesamtimport und Gesamtexport einheitlich geregelt. $\mathrm{Zu}-$ gleich könnte das zentrale Clearingverfahren das wirtschaftliche Ungleichgewicht zwischen den beteiligten Staaten, das im Zuge der internationalen Arbeitsteilung und der unterschiedlichen Kapazitätenzuteilung notwendig entstünde, durch eine Gewinn- und Verlustpoolung ausgleichen ${ }^{871}$.

Kreyssigs Ansicht zufolge bot die Europäisierung der Monopolindustrien vor allem drei wichtige Vorteile: die Industrialisierung der rückständigen europäischen Länder, die Verhinderung künftiger Kriege durch eine vollumfängliche supranationale Rüstungskontrolle und die Gewährleistung wirtschaftlicher Gerechtigkeit, die möglicherweise durch das zusätzliche Instrument eines grenzüberschreitend ausgleichenden Lohnpools optimiert werden könnte ${ }^{872}$. Darüber hinaus böte sich die Chance, den Europäischen Eisen- und Stahlrat als Hebel einer sozialistischen Revolution zu nutzen, wenngleich Kreyssig diese Möglichkeit als unrealistisch einschätzte ${ }^{873}$. Jedenfalls aber wäre der Weg frei für eine europäische Sozialpolitik, die die „Überprofite“ dem Ausbau der europäischen Binnenstruktur und der Erfüllung dringender sozialer Aufgaben widmen würde ${ }^{874}$.

Neben den Europäischen Eisen- und Stahlrat sollte nach Kreyssigs Vorstellungen ein Europäischer Wirtschaftsrat als oberstes Organ der zentralen Clearingstelle, der Europäischen Handelskorporation treten. Dessen Aufgabe wäre der innereuropäische Ausgleich von Bedarf und Überschuß in allen anderen Handelsbereichen außerhalb der Schwerindustrie ${ }^{875}$. Dies beinhalte sowohl die Regulierung und damit Stabilisierung des Preisniveaus als auch eine am Gesamtwohl orientierte Vorratspolitik. Durch solche zentralen Maßnahmen wollte Kreyssig Spekulationen verhindern und die unterschiedlichen Industrialisierungsgrade in Ost- und Westeuropa nivellieren. Damit setzte sich der IGB-Funktionär bewußt in Gegensatz zu den in den 20er Jahren vielfachen Bestrebungen der deutschen Wirtschaft, die Überlegenheit der am weitesten fortgeschrittenen Länder zu stabilisieren ${ }^{876}$. Entsprechend der supranationalen Position des Europäischen Eisen- und Stahlrates sollte auch

${ }^{871}$ Kreyssig dachte dabei an die Errichtung einer „Rekonstruktions- und Ausbau-

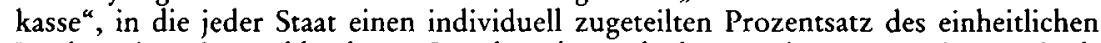
Marktpreises einzuzahlen hätte. Erst danach würde der gemeinsame Gewinn ermittelt und nach einem Erzeugungsschlüssel an die Werke verteilt. Die weitere Verwendung dieses werkspezifischen Reingewinns sollte den einzelnen Werken überlassen bleiben (Memorandum, S. 43).

${ }^{872}$ Kreyssig, Memorandum, 15. 7. 1942, S. 44f. sowie S. 47, AsD, NL Kreyssig, M. 20.

873 Ibid. S. 46.

874 Ibid. S. $48 \mathrm{f}$.

875 Kreyssig, Europäisches Waren-Clearing, 10. 11. 1942, S. 20, AsD, NL Kreyssig, M. 20.

876 Vgl. dazu KRUGGER, Ansätze zu einer europäischen Wirtschaftsgemeinschaft 1984, S. 153 . 
der Europäische Wirtschaftsrat auf den außereuropäischen Märkten als alleiniger Handelspartner auftreten ${ }^{877}$.

Obwohl der Sozialdemokrat und Gewerkschafter im Grundsatz von einer europäischen Planwirtschaft ausging, ist sein Konzept doch differenzierter als andere sozialistische Modelle, denn Kreyssig legte Wert darauf, in jeder Einzelfrage gesondert zu prüfen, „ob und inwieweit die Freizügigkeit einschränkende Kollektivmaßnahmen Platz greifen sollen "878. Hierin ähnelte sein Konzept dem Vorschlag des ISK-Mitglieds Walter Fliess, der der Öffentlichkeit im folgenden Jahr ein vergleichbar ausführliches Wirtschaftsmodell vorstellte.

Fliess, der im September 1943 die ISK-Broschüre „Die Wirtschaft im neuen Europa" fertigstellte, formulierte eine Zielverschmelzung von Frieden, wirtschaftlicher Gerechtigkeit und individueller Freiheit: „Es geht dahin, jedem die gleiche Möglichkeit zu geben, zu Wohlstand und Bildung zu gelangen - und ihm die Freiheit nur soweit zu beschränken, wie sich das dazu als nötig erweist. ${ }^{" 879}$ Wie Kreyssig empfahl auch Fliess die Übernahme der nationalsozialistischen Wirtschaftsstrukturen als "Aktivposten“ des neuen Europas. „Außerdem wäre es vielleicht töricht, alle von den Nazis beseitigten Zollschranken wieder auf den Stand von $1933 \mathrm{zu}$ bringen. Im übrigen aber verdient Hitlers ,Neue Ordnung' nur schnellste Beseitigung." 880 Dieser letzte Satz kann als politisches Lippenbekenntnis eingestuft werden, um sich nicht mit der Forderung einer ungeschminkten Übernahme des nationalsozialistischen Wirtschaftserbes selbst zu kompromittieren. Faktisch hielt Fliess eine weitgehende Anknüpfung für sinnvoll.

Doch bedürfe eine starke Föderation auch dauerhafter Institutionen ${ }^{881}$. Insoweit schlug der ISK-Vertreter im Hauptteil seines Werkes neun europäische Ämter und Körperschaften vor, die im Wege verwaltungstechnischer Arbeitsteilung die europäische Wirtschaftsplanung durchzuführen hätten. Die drei wichtigsten Institutionen waren die Europäische Wirtschaftskommission als europäisches "Wirtschaftsministerium" mit Beratendem Mitgliederausschuß ${ }^{882}$, das Europäische Monopolamt als Kartell- und Aufsichtsbehörde der europäischen Industrie- und Handelsunternehmen ${ }^{883}$ sowie das Europäische Montanamt als Eigentümer und Verwalter aller europäischen Kohlen- und Erzgruben sowie Eisen- und Stahlproduktion ${ }^{884}$. In seiner Konzeption des Europäischen Montanamtes übersah Fliess den juristisch

877 Kreyssig, Europäisches Waren-Clearing, S. 29.

878 Ibid. S. 15.

879 FLIESS, Wirtschaft im neuen Europa 1943, S. 73. Vgl. auch Bennemann, Fliess, Vorschlag für die Programmberatung über Wirtschaftsfragen, eingegangen am 11.6. 1943, abgedruckt in: EIBER (Hg.), Union 1998, Dok. Nr. 106, S. 241-244 (241).

880 Ibid. S. $21 \mathrm{f}$.

881 Ibid. S. 37-73.

882 Ibid. S. $36 \mathrm{f}$.

883 Ibid. S. $44 \mathrm{f}$.

884 Ibid. S. $39 \mathrm{ff}$. 
entscheidenden Aspekt der staats- und völkerrechtlichen Rechtsunfähigkeit eines einzelnen Amtes. Rechtsfähig im Sinne des Völkerrechts können neben Staaten nur Internationale Organisationen sein, nicht aber eo ipso deren Ämter.

Ergänzt wurden die drei führenden Ämter durch ein Aufsichtsamt für alle Körperschaften der Grundversorgung ${ }^{885}$ sowie eine öffentliche Körperschaft für die Rüstungskontrolle, also die zentrale Überwachung und das Management der zu entnationalisierenden europäischen Chemie-Industrie ${ }^{886}$, der Schwerindustrie und der Flugzeugbauindustrie ${ }^{887}$. Schließlich sollte das Europäische Patentamt ein einheitliches Patentrecht erarbeiten und durchsetzen $^{888}$.

Die zentrale Lenkung des internationalen Handels in Europa gedachte Fliess drei weiteren Institutionen zu übertragen. Zunächst würde eine Europäische Zentralbank die Wechselkurse fixieren, um zu einem späteren Zeitpunkt eine europäische Hilfswährung einzuführen ${ }^{889}$. In enger Kooperation mit der Zentralbank würde ein Europäisches Zentralkreditinstitut als Aufsichtsbehörde über das gesamte Kreditwesen fungieren und über eine eigene Kreditvergabekompetenz verfügen ${ }^{890}$. Den Verrechnungsverkehr des innereuropäischen Handels und die Koordination des außereuropäischen Handels schließlich sollte eine Warenclearing- und Außenhandelsstelle übernehmen, die in ihrer Konzeption der Kreyssigschen Europäischen Handelskorporation entsprach. Nach der Einführung der europäischen Hilfswährung wollte Fliess die Verrechnungsstelle für die zweckmäßige Ausnutzung der europäischen Produktionskräfte in Anspruch nehmen ${ }^{891}$.

Als dritter bedeutender Wirtschaftsentwurf ist Hilda Montes „The Unity of Europe" anzuführen, das im Herbst 1943 erschien. Monte hatte zwar ihre Mitgliedschaft im ISK aufgegeben, doch beweist die Nähe ihres Konzeptes zu demjenigen von Walter Fliess, daß sie gedanklich eng mit dem ISK verbunden blieb ${ }^{892}$. Im Alter von nur 28 Jahren präsentierte Monte einen stringenten Vorschlag für eine dezentralisierte Wirtschaftsplanung in Europa, wobei ihr Hauptaugenmerk der Überwindung der ökonomisch-sozialen Gegensätze zwischen den industrialisierten Staaten und den agrarischen Staaten Europas galt.

Auch für Monte sollte die Wirtschaftsföderation primär Frieden und Sicherheit dienen. Darüber hinaus aber nannte sie das bemerkenswerte Motiv der moralisch-historischen Verantwortung der Überlebenden: „And the mo-

885 Ibid. S. $41 \mathrm{f}$.

886 Ibid. S. 42 f. Gemeint waren die Betriebe der ehemaligen IG-Farben.

887 Ibid. S. $46 f$.

888 Ibid. S. $45 \mathrm{f}$.

889 Ibid. S. 54-58.

890 Ibid. S. 58.

891 Ibid. S. 63-66.

892 Vgl. dazu auch LINK, IJB/ISK 1964, S. 280, Anm. 36. 
ral reason is that the price paid by millions in two world wars imposes the obligation on those who survive, to insist on achieving a peace which is more than a temporary makeshift for the period between the end of this and the beginning of the next world war. "893 Wie Fliess und Kreyssig befürwortete Monte die Übernahme der nationalsozialistischen Wirtschaftsstrukturen, um das ehemalige NS-Europa in ein sozialistisches Europa zu verwandeln ${ }^{894}$. Charakteristisches Axiom ihres Entwurfes war ein dem Neu Beginnen-Ansatz ähnliches Europa der konzentrischen Kreise, das sie als Ausgangssituation definierte. Doch unterteilte sie Europa nicht in West und Ost, sondern in ein industrialisiertes, reiches „Inner Europe“ und ein agrarisch strukturiertes, unterentwickeltes „Outer Europe“. Auf Grund der ökonomischen Ungleichverteilung sei die Hauptaufgabe der Wirtschaftsföderation der wirtschaftliche Ausgleich zwischen diesen beiden Teilen Europas ${ }^{895}$. Montes Bezeichnungen der beiden Wirtschaftsgebiete rühren von ihrer - nach eigener Einschätzung schematischen und daher im einzelnen ungenauen - Vorstellung, daß der industrialisierte Part im wesentlichen von einem Ring agrarischer Länder umschlossen sei. Dabei ging die junge Sozialistin davon aus, $\mathrm{daß}$ sich die Armut in den industrialisierten Ländern durch eine gerechtere Verteilung des Einkommens bewältigen lasse. In den agrarischen Staaten dagegen sei mangels hinreichenden Industriepotentials allein eine Erhöhung des Pro-Kopf-Einkommens geeignet, die Armut zu überwinden. Diese wiederum könne nur durch eine gerechtere Verteilung des Vermögens zwischen dem inneren und dem äußeren Europa erreicht werden. Helfe die sozialistische Revolutionstheorie im Kern Europas entschieden weiter, gelte dies nicht für den agrarischen Staatenring, der selbst im Falle einer sozialistischen Revolution nicht über die notwendigen ökonomischen Mittel verfügen würde, den Lebensstandard seiner Bürger zu heben ${ }^{896}$. Sozialismus müsse also auf der gesamteuropäischen Ebene ansetzen, um die Klassendifferenzen zwischen "Inner Europe“ und „Outer Europe“ zu beseitigen. Das Ziel sei letztlich ein „socialist commonwealth of Europe“897, dessen Exekutive sich im wesentlichen auf eine „European Central Authority“ als übergeordneter Planungsbehörde mit weitreichenden Befugnissen insbesondere in der Finanzund Arbeitspolitik sowie ein „European Investment Board“ für die zentralisierte Investitionspolitik an außereuropäischen Börsen stützen würde ${ }^{898}$.

In einem separaten Kapitel setzte sich die junge Emigrantin mit möglichen Alternativen zu ihrer Konzeption eines von Beginn an gesamteuropäischen

893 MONTE, Unity of Europe 1943, S. 36.

894 Ibid. S. 130.

895 Ibid. S. 39 et passim. Zu den industrialisierten Ländern zählte Monte Großbritannien, Irland, Schweden, Norwegen, Dänemark, Niederlande, Belgien, Frankreich, Schweiz, Italien, Deutschland, Österreich und die Tschechoslowakei.

896 Ibid. S. 48 und $51 \mathrm{f}$.

897 Ibid. S. 128.

898 Ibid. S. $138 \mathrm{ff}$. 
Föderationsprojektes auseinander ${ }^{899}$. Dabei erteilte sie regionalen Teilföderationen in Europa wie der Balkanföderation eine klare Absage. Denn erstens würde eine südosteuropäische Regionalföderation in ökonomischer Hinsicht nicht den von Monte als zwingend angesehenen Ausgleich zwischen dem industrialisierten und dem agrarischen Teil Europas fördern, und zweitens würde eine solche Vorgehensweise kaum der Stabilisierung des europäischen Friedens dienen können ${ }^{900}$.

\section{5. „... und ganz Europa schwebt auf der Hängebrücke“ - Reaktionen auf Teberan (1944/45)}

Wenige Wochen nach dem Ende des Krieges in Europa resümierte Gerhard Kreyssig in einem Brief an einen Freund: „Vorläufig ist allenthalben wenig geschehen, um eine Gesamtlösung zu finden, ohne die sowieso nichts erreicht werden kann. Und das Golden Gate von San Francisco geht z. Zt. über den Abgrund San Fiasco, und ganz Europa schwebt auf der Hängebrücke. "901 Damit hatte der eigenwillige Sozialdemokrat und Gewerkschafter einige Eindrücke von der weltpolitischen Entwicklung vermittelt, wie sie sich unter dem Spannungsbogen der alliierten Konferenzen von Moskau, Teheran, Jalta und San Francisco für das deutsche politische Exil darstellte. Die Bemühungen um eine gesamteuropäische Lösung mußten als gescheitert betrachtet werden, die statt dessen von den Alliierten in San Francisco gegründete Weltorganisation entsprach in kaum einem Punkt den Vorstellungen des politischen Exils, und Europa drohte jeden Moment in den Abgrund nationalistischer Anachronismen und weltpolitischer Bedeutungslosigkeit gestürzt zu werden. Mochte sich dem düsteren Résumée Kreyssigs nicht jeder Emigrant ohne weiteres anschließen, so wurden seine Beobachtungen und Interpretationen des Weltgeschehens in den letzten anderthalb Kriegsjahren doch von vielen Schicksalsgenossen geteilt. Angesichts der seit den Konferenzen von Moskau und Teheran unübersehbaren Bestrebungen der Alliierten, auf den ausgetretenen Pfaden konventioneller Machtpolitik die Welt erneut in Interessensphären aufzuteilen, drängte sich den Exilierten die bittere Erkenntnis auf, daß ihre föderalen Europakonzepte der Politik der Entscheidungsträger diametral entgegenstanden. Selbst die zwischen 1941 und 1943 vermehrt aufgestellten Weltföderationspläne erwiesen sich schnell als unvereinbar mit den Interessen der „Großen Drei“. In der Folge ging das politische Exil in den Jahren 1944/45 dazu über, die inner- und außereuropäischen Widerstände gegen einen Zusammenschluß Europas zu benennen und zu analysieren - eine Aufgabe, die schon zu einem früheren Zeitpunkt hätte wahrgenommen werden können. Dabei wurde erwartungsgemäß der künftigen

899 Ibid. S. 173-190.

900 Ibid. S. $174 \mathrm{f}$.

901 Kreyssig an Rimsberger, 30. 5. 1945, AsD, NL Gerhard Kreyssig, Mappe 59. 
Rolle Deutschlands in Europa gesteigertes Interesse entgegengebracht und in diesem Zusammenhang nahezu einhellig eine Teilung Deutschlands im nationalen, europäischen und weltpolitischen Interesse abgelehnt. Zugleich konnte man sich einer Beurteilung der neuen Weltorganisation, wie sie die Alliierten nach Teheran auf den Konferenzen von Dumbarton Oaks und San Francisco entwickelt hatten, nicht entziehen, zumal sich diese Weltorganisation bereits in der Verhandlungsphase als kleinster gemeinsamer Nenner der widerstreitenden machtpolitischen Interessen in der Anti-Hitler-Koalition präsentierte.

In Teheran hatten sich Anfang Dezember 1943 die beiden kriegsentscheidenden Weltmächte, die USA und die UdSSR, geeinigt, daß Europa in den alliierten Neuordnungsplänen keine aktive Rolle mehr zugedacht werden sollte und folgerichtig die vielfach diskutierte Europaföderation schlicht abgelehnt. Statt dessen bewegte man sich gemäß dem Vorschlag Roosevelts auf eine umfassendere Weltorganisation auf der Grundlage einer mit individuellem Vetorecht bewehrten Kooperation der "Großen Drei“ und Chinas zu. Schockiert zeigte sich das deutsche Exil aber weniger über die Ablehnung der föderalen Idee als vielmehr über die in Teheran offenbar gewordene Teilung des europäischen Kontinents in einen Ost- und einen Westteil. Stalin, dessen Stimme in der Anti-Hitler-Koalition seit der Abwehrschlacht von Stalingrad an politischem Gewicht gewonnen hatte ${ }^{902}$, weigerte sich kategorisch, Churchills Pläne einer europäischen Föderation mitzutragen. Er beabsichtigte die Restauration der europäischen Nationalstaaten mit uneingeschränkter Souveränität, insbesondere in Ost- und Mitteleuropa. Diese Absicht hatte er zuvor in den "Kriegzielen der Sowjetunion“ vom 6. November 1943 bekanntgegeben ${ }^{903}$. Mit dem Zugeständnis der Verschiebung der polnischen Westgrenze an die Curzon-Linie hatte Stalin sich zudem die infolge des Hitler-Stalin-Paktes annektierten Gebiete gesichert und der militärischen Dominanz der Sowjetunion in Osteuropa den Weg geebnet. Damit war die von einigen Emigranten vorausgesagte Aufteilung Europas in eine östliche und eine westliche Einflußsphäre manifest geworden. Gefördert wurde diese bipolare Entwicklung durch die Aufteilung der Kriegsführung in Ost und West und den Verzicht auf eine Sicherung des zwischen Großbritannien und der Sowjetunion umstrittenen Balkan. Zwar war die Anerkennung der militärischen Zuständigkeit Stalins für Osteuropa keineswegs als Zugeständnis seiner politischen Hegemonie in Osteuropa intendiert gewesen, doch wirkte sich die Stärkung der russischen Position in Teheran faktisch so aus.

Damit war das tatsächliche Mächteverhältnis der "Großen Drei“ nun evident. Die britischen Alternativpläne einer gesamteuropäischen Föderation mit dem Ziel, den sowjetischen Einfluß in Europa zurückzudrängen, konn-

902 Vgl. DÜlFFER, Jalta 21999, S. 125.

903 Die Kriegsziele sind abgedruckt in: MisGeLD, Die „Internationale Gruppe demokratischer Sozialisten“ in Stockholm 1976, S. 34. 
ten auf Grund der geschwächten Position der faktisch entthronten Weltmacht Großbritannien nicht durchgesetzt werden. Hierzu wäre die Unterstützung des amerikanischen Präsidenten erforderlich gewesen. Roosevelt hatte noch bis zum Sommer 1943 gemeinsam mit Churchill einen intensiven Gedankenaustausch über kontinentale Regionalföderationen als Glieder einer Weltorganisation betrieben. Auch das zu dieser Frage eingerichtete amerikanische Advisory Committee hatte in zwei Stellungnahmen vom Mai 1940 und Frühjahr 1943 die Unterstützung einer europäischen Föderation befürwortet ${ }^{904}$. Im Sommer 1943 aber hatte Stalin alle Hebel der Diplomatie in Bewegung gesetzt, um vehement gegen den angloamerikanischen Gedanken einer europäischen Föderation zu protestieren, und war sogar so weit gegangen, die sowjetischen Botschafter in London und Washington abzuziehen. Seitdem war Roosevelt um eine Verständigung mit Stalin bemüht. Für Roosevelt war die Idee einer europäischen Föderation ohnehin keine Frage der inneren Überzeugung gewesen, sondern eine mögliche Antwort auf die Frage nach dem politisch Notwendigen und dem Vorteil Amerikas. Persönlich war Roosevelt ganz der konventionellen Machtpolitik verhaftet und hatte daher keinerlei Schwierigkeiten, sich nach der Abwendung vom föderativen Ansatz auf die Idee der vier "Weltpolizisten“ im Sinne klassischer Großmachtpolitik zu besinnen. Zudem hatte er in Außenminister Hull einen vehementen Gegner jeder angeblich hinderlichen Kontinentalföderation und einen ebenso engagierten Verfechter einer alleinigen Weltorganisation ${ }^{905}$. Doch bedarf auch das immer wieder bemühte Bild von Churchill als dem Protektor der Vereinigten Staaten von Europa einer Korrektur. Denn Churchill war nicht vorrangig Europaenthusiast, sondern ebenfalls ein taktierender Machtpolitiker. Seine Unterstützung einer europäischen Föderation galt in erster Linie der Abwehr des übermächtig werdenden Einflusses der Sowjetunion in Europa. Und hinsichtlich des umstrittenen Balkangebietes hatte Churchill keine Skrupel gehabt, sich mit Stalin in einem Geheimabkommen über die prozentuale Aufteilung des Balkans in Einflußsphären zu verständigen ${ }^{906}$.

In den der Teheraner Konferenz folgenden Stellungnahmen des politischen Exils fand zunächst die „tiefe Sorge über die jüngste Entwicklung der alliierten Politik“ 907 Ausdruck, und zwar sowohl mit Blick auf die dezimierten Chancen einer europäischen Föderation als auch hinsichtlich der vereinbarten Teilung Deutschlands. Udo Rukser faßte den „gewaltige[n] Szenenwechsel auf der Weltbühne“ in seiner europäischen Dimension treffend

904 Vgl. LIPGENS (Hg.), Föderationspläne 1968, S. $20 \mathrm{f}$.

905 Vgl. Ders. (Hg.), Europäische Verfassung 1986, S. 29 sowie DERs. (Hg.), Föderationspläne 1968, S. 22 f.; LOTH, Teilung der Welt ${ }^{7} 1989$, S. 85.

906 Vgl. ibid. S. 56 sowie die weiterführenden Verweise in Anm. 8.

907 Vogel, Brief an die Exekutive der Labour Party, 25. 4. 1944, unter dem Titel: Stellungnahme zur Nachkriegspolitik der Alliierten gegenüber Deutschland abgedruckt in: Zur Politik deutscher Sozialisten 1945, S. 31 f. (31). 
zusammen: Europa habe in rasantem Tempo seine weltpolitische Bedeutung nahezu völlig eingebüßt und sei nun eher ein Krankheitsherd als ein politischer Faktor 908 . In unwissentlicher Übereinstimmung mit dem Sozialdemokraten Kreyssig kritisierte Rukser die Passivität sowohl der Europäer selbst als auch der Alliierten bezüglich einer Lösung der europäischen Frage und konstatierte: „Alles arbeitet leidenschaftlich gegeneinander." 909

Diese Beobachtung veranlaßte viele Emigranten zu der naheliegenden Schlußfolgerung, daß die von den Alliierten angestrebte Konzeption der Nachkriegsordnung wohl eher eine rein machtpolitische Orientierung aufweisen werde 910 . Einzig die KPD und die ihr eng verbundenen Exilorganisationen wie die Freie Deutsche Bewegung in Großbritannien kamen zu einer positiven Beurteilung der alliierten Planungen. Man hob den kriegsverkürzenden Effekt der Konferenz von Teheran hervor ${ }^{911}$ und betonte erneut das Ziel der Freiheit und Unabhängigkeit der Nationen ${ }^{912}$. Zudem bot Teheran als das erste Treffen der „Großen Drei“ die willkommene Gelegenheit, die Wandlungen der sowjetischen Außenpolitik im Nachhinein zu exkulpieren, d.h. zu ideologisieren. So wurde der offensichtliche Widerspruch der früheren Moskauer Polemik gegen den imperialistischen Krieg einerseits und der aktiven Teilnahme an diesem imperialistischen Krieg andererseits damit erklärt, daß erst und allein durch Hitlers Überfall auf die Sowjetunion der Krieg seines imperialistischen Charakters enthoben und zu einem gerechten Krieg geworden sei. Somit lehre die Kriegsentwicklung erneut die Richtigkeit der Leninschen Differenzierung $z$ wischen ungerechten Eroberungskriegen und gerechten Befreiungskriegen ${ }^{913}$.

Nach den Dreier-Konferenzen von Moskau und Teheran stand jedenfalls fest, daß neben der UdSSR auch die USA europäische Föderationspläne nicht

908 RUKSER, Das neue Weltbild (Juni 1944), in: Deutsche Blätter, Reprint 1970, Bd. 2, S. $86-89(86)$.

909 Ibid. S. 87.

910 Vogel, Brief an die Exekutive der Labour Party, 25. 4. 1944, unter dem Titel: Stellungnahme zur Nachkriegspolitik der Alliierten gegenüber Deutschland abgedruckt in: Zur Politik deutscher Sozialisten 1945, S. 31.

911 [Georg], Kurze Disposition zum Referat über: Die Entwicklung des Krieges und die Rolle der Partei, gehalten auf der KPD-Parteikonferenz vom 26. 11. 1944, S. 4, HistArch KPD, BAB/SAPMO, RY 61/V232/1, M. I, Bl. 2-5 (5). Ebenso die Stellungnahme der Freien Deutschen Bewegung in Großbritannien zu den Ergebnissen von Teheran, 12. 12. 1943, BAB/SAPMO, SgY 13/V 239/9/46, M. III, Bl. 201.

912 [Georg], Kurze Disposition, 26. 11. 1944, S. 4, HistArch KPD, BAB/SAPMO, RY 61/V232/1, M. I, Bl. 2-5 (5).

913 Über den Charakter des Krieges, 19. 12. 1944, Bestand Emigration Frankreich 1939-1945, BAB/SAPMO, SgY 9/V 231/1/1, M. I, Bl. 41-50 (49f.). Vgl. auch den KPD-Schulungsvortrag auf dem Politischen Schulungstag der KPD: Der Sieg des Faschismus in Deutschland und seine Lehren für unseren Kampf, 11.6. 1945, BAB/ SAPMO, SgY 13/V 239/5/55, Bl. 9 sowie die Entschließung der Parteikonferenz der KPD in Frankreich (Paris, am 12. und 13. Mai 1945), S. 1, Bestand Emigration Frankreich 1939-1945, BAB/SAPMO, SgY 9/V 231/1/1, Bl. 1 f. (1). 
unterstützen wollten und Großbritannien, dessen Premierminister sich für die Vereinigten Staaten von Europa unter britischer Führung eingesetzt hatte, zu schwach war, um ein solches Vorhaben gegen den erklärten Widerstand der beiden Hauptverbündeten durchzusetzen. Gerade deshalb versuchten viele politische Flüchtlinge in den letzten anderthalb Kriegsjahren, die Alliierten in einer letzten verzweifelten Anstrengung an die Atlantikcharta zu erinnern, aus der sie den Anspruch auf eine europäische Föderation herauslesen zu können glaubten. Daß diese Föderation aber auf Initiative der Alliierten zumindest im Rahmen der geplanten Weltorganisation implementiert würde, mußte nach den Ergebnissen von Teheran als äußerst unwahrscheinlich erscheinen. Selbst das bisher als selbstverständlich angesehene Axiom, daß nur Gesamteuropa Gegenstand einer sinnvollen Nachkriegsordnung sein könne, wurde durch die faktische Teilung des Kontinents in Interessensphären in sein Gegenteil verkehrt. Zwar hatte man schon seit dem Kriegseintritt der Sowjetunion beobachten müssen, daß die befürchtete Spaltung Europas zwischen Ost und West zur Gewißheit wurde, doch gingen die Alliierten in Teheran nun noch einen Schritt weiter: Sie leiteten die institutionelle Zementierung der europäischen Ohnmacht ein, indem sie dem Kontinent eine eigene Friedensorganisation verwehrten und statt dessen eine ganz unter dem Einfluß der vier Weltmächte USA, Großbritannien, UdSSR und China stehende Weltorganisation zu errichten gedachten. Gebunden an eine völkerrechtlich verbindliche Satzung, die für europäische Stimmen kaum Raum bot, würde Europa auf lange Sicht keine Chance erhalten, sich mit der Idee einer eigenen Kontinentalföderation durchzusetzen.

Die in Teheran beschlossene institutionelle Zementierung der europäischen Ohnmacht war es, die dem Europadiskurs des politischen Exils einen letzten Wendepunkt verschaffte. Kennzeichnend für die letzte Diskursphase 1944/45 war ein analytischer Prozeß, im Zuge dessen die in den vergangenen Jahren gewonnenen Erkenntnisse über die Zukunft Europas zusammengefaßt, die Widerstände gegen den Föderationsgedanken benannt und die aus der Ost-West-Konfrontation resultierende Gefahr eines dritten Weltkrieges auf europäischem Boden analysiert wurden.

In aller Kürze und Prägnanz ließ Hans Jaeger einige zentrale Erkenntnisse des Europadiskurses im Exil Revue passieren. Jaeger erinnerte daran, daß die Idee des europäischen Zusammenschlusses in zweierlei Weise belastet sei: Zum einen mit der Diskreditierung durch Hitler und zum anderen mit dem durch die nationalsozialistische Tyrannei gestärkten Willen zur Erhaltung der nationalen Souveränität ${ }^{914}$. Dennoch sei man überzeugt, „daß die Schaf-

914 Jaeger, Was wollen die Deutschen Volkssozialisten? Konzeption und Programm einer neuen deutschen Bewegung, o. D. [März 1945], S. 20f., IfZ, NL Jaeger, ED 210/10a. Eine englische Version des Manuskriptes findet sich in der ebenfalls im IfZ archivierten Sammlung Röder, ED 200/1. Die Ansicht der Diskreditierung der Europaidee durch Hitler äußerte JAEGER erneut in seinem Beitrag: A New Form of Democracy, in: HILLER (Hg.), After Nazism - Democracy? 1945, S. 129-165 (155). 
fung übernationaler, transnationaler Einheit das Fernziel der Menschheit ist" 915 . Und Brehm ergänzte Jaegers Ausführungen um den Hinweis, daß der bloße Gebrauch von Schlagworten wie „Freiheit“, „Sozialismus“ oder „Demokratie" schon lange nicht mehr ausreiche, um dem politischen Willen Ausdruck zu verleihen. Durch demagogischen Mißbrauch seien diese Schlagworte ihrer präzisen Bedeutung enthoben worden, so daß jede politische Gruppe ihr individuelles Verständnis dieser Begrifflichkeiten vorab zu definieren habe, um eine Kommunikation zu ermöglichen ${ }^{916}$.

Als wesentliche Widerstände gegen eine europäische Föderation benannte das Exil neben den entgegenstehenden Interessen der Alliierten die historischen Gegensätze der europäischen Staaten den europäischen Nationalismus und die fehlende Bereitschaft der von Hitler unterdrückten Völker, gerade mit Deutschland einen engen Bund einzugehen. Ohne eine zumindest langfristige Beteiligung Deutschlands aber konnte nach der Überzeugung nahezu aller politischen Emigranten ein europäisches Friedenskonzept nicht erfolgreich sein. Nahezu einstimmig plädierte das deutsche Exil gegen eine konfliktträchtige Teilung Deutschlands und für seine Integration in einen europäischen Staatenverbund, wobei nun mehrheitlich mit einer notwendigen Übergangszeit gerechnet wurde, während der Deutschland aus Regenerationszwecken ausgeschlossen bleiben müsse. Ergänzt um die sozialistische Kritik an der kapitalistischen Grundausrichtung der europäischen Staaten fand die Auflistung der antiföderalen Tendenzen ihren Abschluß in dem Hinweis, daß „Hitlers Gangsterpolitik des ,neuen Europas' [...] den Gedanken einer gesamteuropäischen Lösung schwer kompromittiert" habe ${ }^{917}$. Damit schloß sich der Kreis zu Jaegers Ausführungen, die ebenfalls die Diskriminierung der europäischen Idee durch Hitlers Europapropaganda als schwere Hypothek nannten. Angesichts solch fundamentaler antiföderaler Widerstände rechneten viele exilierte Europaföderalisten vorerst nicht mit einer baldigen Verwirklichung, betrachteten aber gerade deshalb die Ausarbeitung eines „Föderationsprogramms“ für unerläßlich ${ }^{918}$, um das Ziel nicht aus den Augen zu verlieren. Dabei wurde in der Regel die parallele Einigung Europas in wirtschaftlicher und politischer Hinsicht für sinnvoll erachtet und nur bisweilen der kulturellen Einigung der Vorzug gegenüber der politischen Föderation gegeben ${ }^{919}$

Die mittlerweile offensichtlichen interalliierten Differenzen schürten die

915 Jaeger, Was wollen die Deutschen Volkssozialisten?, o. D. [März 1945], S. 21, IfZ, NL Jaeger, ED 210/10a.

916 E. B[REHM], Ideas of yesterday, in: Problems of Reconstruction, Rundschreiben der DVB (April 1945), S. 7-10 (8).

917 BEHM et al., Zur Nachkriegspolitik der deutschen Sozialisten 1944, S. 36. 918 Ibid.

919 Nur wenige Gruppierungen sprachen sich für eine ausschließlich wirtschaftliche Einigung aus, so etwa die Gruppe deutscher Sozialisten in Frankreich in ihrem Statut vom 18. 12. 1944: Groupe de Socialistes Allemands en France, Statuts, 18. 12. 1944, BAB/SAPMO, HistArch KPD, RY 61/V232/13, M. II, 87f. (87). 
Angst vor einem dritten Weltkrieg als Folge der Ost-West-Konfrontation auf europäischem Boden. Vor dem Hintergrund dieser neuartigen weltpolitischen Dimension der europäischen Frage zeichnete sich der Europadiskurs nach der Konferenz von Teheran durch drei Hauptanliegen aus:

Zunächst zeigte man sich mit Blick auf die europäische Zukunft einig in dem Aufruf zu einer kontinuierlichen Zusammenarbeit Großbritanniens, der USA und der UdSSR über das Kriegsende hinaus. Doch erfuhren die Verwirklichungschancen dieses Aufrufes eine recht unterschiedliche Bewertung: Während einige auf die interalliierte Kooperation der "Großen Drei“ als dem einzigen momentan realisierbaren Sicherheitskonzept vertrauten, zweifelten andere sehr an der Fähigkeit der Alliierten zur dauerhaften Zusammenarbeit und setzten ihre Hoffnungen in einen langfristigen Prozeß europäischer Selbstbefreiung. Für das letztere Konzept kann plakativ Stampfers oppositionelle Formel von den „Anderen Drei“ herangezogen werden, wenngleich die teilweise beträchtlichen Differenzen innerhalb dieser zweiten Gruppe nicht nivelliert werden dürfen. Stampfer und andere vertraten den elitären Ansatz eines europäischen Neuaufbaus unter der verantwortlichen Führung Frankreichs, Italiens und Deutschlands als den "Anderen Drei“. Eine Variante dieser Konzeption favorisierte die Alleinverantwortung Frankreichs als dem einzigen nichtfaschistischen der drei kontinentaleuropäischen Staaten. Dagegen lehnten Heinrich Ritzel und andere jede Übertragung einer europäischen Führungsrolle auf einen einzelnen Staat ab und befürworteten einen egalitären Ansatz unter strikter Beachtung des völkerrechtlichen Grundsatzes der Gleichheit aller Staaten.

Neben den Diskussionen um die „Großen Drei“ und die „Anderen Drei“ trat als drittes Hauptanliegen des späten Europadiskurses die Perzeption der alliierten Weltorganisationspläne, die nicht nur auf Roosevelts "Vier Freiheiten“, sondern ebenso auf dem Konzept der "Vier Weltpolizisten“ beruhten.

\subsubsection{Die "Großen Drei“}

Viele Emigranten hielten den weltpolitischen Bedeutungsverlust Europas 1944 für längst vollzogen und vorerst unumkehrbar. Europa sei nun einmal durch eigenes Verschulden zum bloßen Spielball im west-östlichen Konfliktfeld degradiert worden. Daher wählte man in diesem Umfeld die beständige Kooperation der "Großen Drei“ als Grundlage der europäischen Friedenskonzepte, ohne auf eine eigene Stimme Europas zu bauen. Im Vordergrund stand die Befriedung Europas um des Weltfriedens willen und damit die Verhinderung einer militärischen Ost-West-Konfrontation auf europäischem Boden. Udo Rukser meldete sich aus dem südamerikanischen Exil mit der bitteren Bemerkung, daß Europa nur noch „Objekt der Politik“ sei, während das Schicksal der Welt in amerikanischen und sowjetischen Händen liege ${ }^{920}$.

920 RUKSER, Das neue Weltbild, Juni 1944, in: Deutsche Blätter, Reprint 1970, Bd. 2, S. 86-89(88). 
Als Kampfplatz außerkontinentaler Interessen aber wollte sich Rukser das künftige Europa nicht vorstellen, zumal die meisten europäischen Staaten als bloße „Anhängsel westlicher oder östlicher Gebilde“ nicht überlebensfähig wären ${ }^{921}$. Da einer gesamteuropäischen Lösung momentan die "tiefe Verstörtheit der europäischen Bevölkerung“ entgegenstehe, sei ein organisiertes Europa nur mit der aktiven und konzeptionellen Unterstützung der Alliierten möglich ${ }^{922}$.

Die faktische Auslieferung der europäischen Idee an außereuropäische Mächte ließ einige Emigranten wie den Sozialdemokraten Siegfried Marck in der europäischen Frage ebenso wie in der deutschen Frage resignieren. Marck sah keinen Sinn mehr darin, für Auffassungen zu kämpfen, die der Politik des allmächtigen "Welt-Direktoriums" widersprachen und schlug dem politischen Exil vor, sich von nun an auf die Unterstützung der deutschen Bevölkerung in Fragen der Grundversorgung zu beschränken ${ }^{923}$. Marcks Plädoyer für ein Ende der politischen Aufgabe des Exils rief die sofortige Distanzierung der Genossen in der NVZ-Redaktion hervor, für die Gerhart Seger unmittelbar anschließend an Marcks Artikel eine kontradiktorische Replik verfaßte ${ }^{924}$. Widerspruch provozierte vor allem Marcks Schlußfolgerung, gegenüber der Sowjetunion sei - im Gegensatz zu dem bisherigen strikt antisowjetischen Kurs der NVZ - nunmehr eine vorsichtige und taktvolle Einstellung angebracht, da die Sowjetunion nun einmal zu den entscheidenden Weltmächten zähle, die das Schicksal der europäischen und deutschen Bevölkerung in Händen hielten ${ }^{925}$. Seger entgegnete empört, „ein Kampf um die Verwirklichung einer Anschauung [wird] doch nicht dadurch beendet, daß eine Konferenz von einem demokratischen, einem ultrakonservativen und einem diktatorialen Staatsoberhaupt ihre Politik festlegen"926.

Während Marck das Ende des politischen Exils einläutete, besann sich der Sopade-Vorsitzende Hans Vogel nach der Landung der Alliierten erstmals seit 1933 zu der „Pflicht [...], unseren Beitrag zu den internationalen Diskussionen über die Nachkriegsgestaltung Deutschlands und Europas zu leisten“927. Vogel glaubte 1944 noch an die Möglichkeit eines europäischen Mitspracherechts an den alliierten Nachkriegsdiskussionen ${ }^{928}$. Doch hielt er im Gegensatz zu Stampfer unverändert an der Selbstüberschätzung fest, die sich in der Sopade von Beginn des Exils an besonders ausgeprägt offenbart hatte:

921 Ibid. S. 89.

922 Ibid.

923 MARCK, Nach der Konferenz von Yalta, in: NVZ, 14. Jg., Nr. 8 (24. 2. 1945), S. 3.

924 SEGER, Müssen wir aufgeben?, in: NVZ, 14. Jg., Nr. 8 (24. 2. 1945), S. 3.

925 MARCK, Nach der Konferenz von Yalta, in: NVZ, 14. Jg., Nr. 8 (24. 2. 1945), S. 3.

926 SEGER, Müssen wir aufgeben?, in: NVZ, 14. Jg., Nr. 8 (24. 2. 1945), S. 3.

927 VoGEL, Deutschland und Europa in der Nachkriegswelt, in: SM, Nr. 63/64 (Juni/ Juli 1944), S. 1-9 (1). Eine Zusammenfassung der Rede, die Vogel am 16. 6. 1944 gehalten hatte, erschien auch in der NVZ, 13. Jg., Nr. 32 (5. 8. 1944), S. 1f.

928 Vogel, Deutschland und Europa in der Nachkriegswelt, in: SM, Nr. $63 / 64$ (Juni/Juli 1944), S. 1-9 (3). 
„Wir deutschen im Exil lebenden Sozialisten sind uns [...] der großen Verantwortung, die auf uns zukommt, durchaus bewußt. Wir können nur immer wieder unsere Entschlossenheit zum Ausdruck bringen, in einem vom Hitlerismus und Militarismus befreiten Nachkriegsdeutschland und im Rahmen einer europäischen und internationalen Friedenspolitik mit allen Kräften an

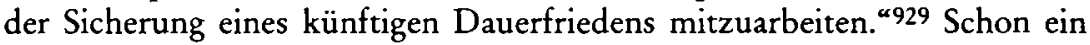
dreiviertel Jahr später mußte Ollenhauer in einer Rede vor den Mitgliedern der Londoner Union Vogels Einschätzung korrigieren und bezeichnete die deutschlandbezogenen Entscheidungen der Siegermächte als die bis auf weiteres bestimmenden Faktoren der Zukunft Deutschlands und Europas ${ }^{930}$. Bemerkenswerterweise äußerte Ollenhauer die Vermutung, daß anstelle der Europaföderation die sowjetische Hegemonie in Osteuropa das Erbe der nationalsozialistischen Neuordnung Europas antreten werde ${ }^{931}$. Auch aus diesem Grund war für Ollenhauer der Bestand der Anti-Hitler-Koalition von zentraler Bedeutung für den Erhalt des Friedens ${ }^{932}$, zumal die einzige Alternative einer sozialistisch-föderalistischen Neuordnung zur Zeit nicht durchzusetzen war und von der bevorstehenden Konferenz in San Francisco kaum wesentliche Veränderungen zu erwarten waren ${ }^{933}$.

Der sozialdemokratische Einzelgänger Arno Seidel glaubte zwar nicht an den dauerhaften Bestand der Anti-Hitler-Koalition, erwartete aber dennoch einen bestimmenden Einfluß der Ost-West-Konfrontation auf Europas Schicksal. In Übereinstimmung mit Rukser räumte Seidel der europäischen Selbstfindung keine Chancen ein, sondern prophezeite ebenfalls eine Degradierung Europas zum politischen Spielball der Weltmächte ${ }^{934}$. Seine Schlußfolgerung: „Internationale, völkerrechtliche Übereinkommen, Einrichtungen und Institutionen werden nur dann von realer Bedeutung sein, wenn hinter ihnen die gesamte militärische und wirtschaftliche Macht der drei siegrei-

929 Ibid. S. 9.

930 Ollenhauer, Zwischen Yalta und San Francisco, o. D. [17.3. 1945], S. 3, AsD, Bestand PV-Emigration Sopade, M. 156.

931 Ibid. S. 5. Ausweislich eines Veranstaltungshinweises in den Sozialistischen Mitteilungen, Nr. 72 (März 1945) hielt Ollenhauer diese Rede vor der Mitgliederversammlung der Union in London am 17. 3. 1945. Der möglicherweise erst im Archiv angebrachte handschriftliche Datierungsvermerk „Ollenhauer $1944^{“}$ ist offensichtlich unzutreffend, da der in Betracht kommende Datierungszeitraum durch Ollenhauers Titel vorgegeben ist: Die Konferenz von Jalta fand vom 4. bis zum 11. 2. 1945 statt, und die Konferenz von San Francisco dauerte von April bis Juni 1945.

932 Ibid. S. 11. Diesem im gesamten politischen Exil mehrheitsfähigen Urteil schloß sich auch die Auslandsvertretung der deutschen Gewerkschaften in: GOTTFURCHT, Welt-Gewerkschaftskonferenz in London, 6.-17. Februar 1945, S. 8.

933 Vogel an ISK/Eichler, 20. 3. 1945, S. 1, AsD, Bestand IJB/ISK, Box 55. Die in Teilen nahezu wortgetreue Anlehnung an die Rede, die Ollenhauer nur drei Tage zuvor gehalten hatte, legt den Schluß nahe, daß dieser Brief Vogels - wie ohnehin die gesamte offizielle Korrespondenz - von Ollenhauer verfaßt wurde.

934 A. S[eidel], Gedanken zur Neuordnung, 21. 7. 1944, S. 4, AsD, Bestand PV-Emigration Sopade, M. 166. 
chen Großmächte steht. “935 In diesem Rahmen werde sich das west-östliche Ringen um die politische und wirtschaftliche Vereinnahmung des „Zwischenraums" Europa entfalten und möglicherweise in einer erneuten militärischen Auseinandersetzung enden, die das bewegungsunfähige Europa endgültig zwischen Ost und West zerreißen und der einen oder der anderen Seite einverleiben würde ${ }^{936}$.

Seidels einseitig den Konflikt fokussierende Prognose wurde im Umfeld des 1944 von Paul Tillich gegründeten Council for a Democratic Germany $(\mathrm{CDG})^{937}$ nur ansatzweise geteilt. Tillich verschloß sich nicht der realen $\mathrm{Ge}$ fahr einer militärischen Auseinandersetzung zwischen der Sowjetunion und den Westmächten, der nach der Auffassung des gesamten Councils mit einer einseitigen Ausrichtung des neuen Europas nach Osten oder Westen unvermeidbar wäre ${ }^{938}$. Daran erinnerten im Frühsommer 1945 auch die verschiedenen Entwürfe für eine Erklärung des Councils zum Kriegsende939. Dennoch hielten die außenpolitischen Programmatiker des Councils den fortgesetzten Bestand der Anti-Hitler-Koalition nicht nur für möglich, sondern für dringend erforderlich ${ }^{940}$. Und Tillich selbst hoffte sogar auf eine den Siegermächten implementierte, ,von beiden Seiten unabhängige europäische Föderation mit einem ungeteilten Deutschland und einer ökonomischen, europäischen Einheit" "941. Nach dem Ende des Zweiten Weltkrieges aber mußte der Theologe eingestehen, daß Europa nun ein abhängiger Erdteil und ein unabhängiges vereinigtes Europa momentan „keine mögliche Lösung “ sei ${ }^{942}$.

935 Ibid.

936 Ibid.

937 Vgl. grundsätzlich zum Council for a Democratic Germany die ausführliche Dokumentation von LANGKAU-ALEX, RUPRECHT $(\mathrm{Hg}$.), Was soll aus Deutschland werden? 1995 sowie den instruktiven Aufsatz von BAHR, Paul Tillich und das Problem einer deutschen Exilregierung 1985.

938 Gründungserklärung des Council for a Democratic Germany, 3. 5. 1944, abgedruckt in: VOIGT (Hg.), Friedenssicherung 1988, S. 199-201 (199). Die englische Version datiert bereits von April 1944 und ist u. a. zu finden im IfZ, Slg. Glaser, ED 202/2. Veröffentlichungen der englischen Fassung enthalten MATTHIAS, Mit dem Gesicht nach Deutschland 1968, Dok. Nr. 163, S. 649-654 und LIPGENS (Hg.), Documents II 1986, Dok. Nr. 227, S. 610f. Die Gründungserklärung des CDG wurde von Exilpolitikern wie Aufhäuser, Baerwald, Budzislawski, Glaser, Grzesinski, Frank, Walcher und Hertz ebenso unterzeichnet wie von Repräsentanten des exilierten Geisteslebens wie Heinrich Mann, Bertholt Brecht, Ernst Bloch, Lion Feuchtwanger, Emil J. Gumbel, Veit Valentin und Alfred Kantorowicz; vgl. die Liste der Unterzeichner im Anhang des englischen Dokumentes, IfZ, Slg. Glaser, ED 202/2.

939 Aufhäuser, Budzislawski, Entwurf einer Erklärung, o. D. [Mai /Juni 1945], S. 1, IfZ, Slg. Glaser, ED 202/2; Tillich, Entwurf einer Erklärung des Councils, o. D. [Mai /Juni 1945], IfZ, Slg. Glaser, ED 202/2.

940 Aufhäuser, Budzislawski, Entwurf einer Erklärung, o. D. [Mai /Juni 1945], S. 3, IfZ, Slg. Glaser, ED 202/2.

941 Tillich an Löwenstein, 2. 3. 1944, BAK, NL Löwenstein, N 1222, Bd. 25a.

942 Tillich, Die christlichen Kirchen und die Aufkommende Gesellschaftsordnung in Europa. Vortrag vor der Divinity Church der Yale-University in New Haven im Sommer 1945, in: DERS., Impressionen und Reflexionen 1972, S. 291-295 (292f.). 


\subsubsection{Die "Anderen Drei“}

Ein Teil der Emigration hatte die Hoffnung auf ein selbständiges Europa, das sich aus eigener Kraft zwischen Ost und West werde behaupten können, noch nicht aufgegeben. So unterschiedliche Charaktere wie Stampfer, Siemsen, Eichler, Röpke und Weber weigerten sich, die Endgültigkeit des weltpolitischen Bedeutungsverlustes Europas hinzunehmen und engagierten sich unermüdlich für eine europäische Föderation als politisches Gegengewicht zum dominierenden Einfluß der „Großen Drei“. Neben den vier Säulen der Weltmacht dürfe Europa nicht als Trümmerhaufen liegenbleiben. „Eine demokratische Föderation europäischer Demokratien ist als fünfte Säule einer wirklichen Organisation des Weltfriedens unentbehrlich. ${ }^{\text {"943 }}$

Doch war man realistisch genug, um zu erkennen, daß ohne die Hilfestellung der Alliierten ein selbständig organisiertes Europa nicht mehr denkbar war. Deshalb wurde in der Regel der Wille zur Kooperation mit den Alliierten, zumeist den Westalliierten, betont, von denen man sich eine wohlwollend begleitende Unterstützung bei der selbstbewußten Neugestaltung Europas erhoffte. Innerhalb dieses Teils der politischen Emigration sind wiederum zwei verschiedene europäische Leitbilder zu unterscheiden: das elitäre Konzept der „Anderen Drei“, das heißt Frankreichs, Italiens und Deutschlands als europäische Führungsmächte, und das egalitäre Konzept einer von Beginn an gleichberechtigten Föderierung Europas ohne Führungsrolle eines einzelnen Staates.

Unter den europapolitischen Optimisten, die weiterhin an einen eigenständigen Kontinent Europa glaubten, war die namentlich von Friedrich Stampfer propagierte Konstruktion der "Anderen Drei“ recht populär. Entgegen den Friedenskonzepten, die eine dauerhafte Kooperation der „Großen Drei“ voraussetzten, sollte unter dem Schutz der westlichen Alliierten ein Triumvirat aus Frankreich, Italien und Deutschland mit der Umsetzung einer eigenen Nachkriegskonzeption der Europäer beauftragt werden. Dabei war in der Regel die aktive Einbindung der faschistischen Staaten Deutschland und Italien erst nach einer unterschiedlich bemessenen Übergangszeit vorgesehen, so daß die europäische Führungsrolle zunächst Frankreich allein zufiele. Eine Variante dieser elitären Konzeption übertrug die Führungsposition nur einem Staat, wobei hauptsächlich an Frankreich gedacht war.

Zentrale Figur der deutschen Sozialdemokraten im US-Exil war unverändert der mittlerweile 70jährige Friedrich Stampfer, der seit der Konferenz von Teheran in der NVZ eine „regelrechte europaföderalistische Kampagne " 944 inszeniert hatte. Hauptmotiv Stampfers war die Verhinderung des in Teheran beschlossenen Besatzungssystems für Deutschland, ohne daß er dies explizit erwähnte. Doch sollte Stampfers europapolitische Motivation nicht

943 STAMPFER, Für die Vereinigten Staaten von Europa: Der Stalin-Benesch-Pakt - und was weiter?, in: NVZ, 12. Jg., Nr. 52 (25. 12. 1943), S. 1.

944 VOIGT (Hg.), Friedenssicherung 1988, S. 37. 
unterschätzt werden. Der vormalige Chefredakteur des Vorwärts, der sich seit seinen Weimarer Tagen für die Idee einer europäischen Föderation eingesetzt hatte und frühzeitig der Paneuropa-Bewegung Coudenhove-Kalergis beigetreten war, nahm die aus seiner Sicht katastrophalen Konferenzergebnisse von Teheran zum Anlaß, der in der letzten Zeit häufig vorgeschlagenen Zusammenarbeit mit den „Großen Drei“ den Rücken zu kehren. Von nun an konzentrierte er sich auf die USA, die er sich als mehr oder weniger altruistischen Förderer einer europäischen Renaissance wünschte. Der trüben Aussicht auf eine von den „Großen Drei“" oktroyierten Nachkriegsordnung für Europa setzte er die "Anderen Drei“ entgegen: Frankreich, Deutschland und Italien als die drei führenden Repräsentanten europäischer Kultur sollten Stampfer zufolge den Wiederaufbau Europas in kooperativer Verantwortung in die Hand nehmen ${ }^{945}$. Da Deutschland und Italien auf Grund ihrer faschistischen jüngsten Vergangenheit momentan nur eingeschränkt zur Verfügung stehen könnten, käme vorerst allein Frankreich als primus inter partes in Betracht $^{946}$. Einen älteren Ansatz aus den Jahren 1938/39 wiederaufgreifend, unterstrich Stampfer die Kraft der revolutionären Tradition und der europäischen Idee in Frankreich.

Die Unabhängigkeit und Einheit Europas sah der altgediente Sozialdemokrat kaum durch den anglo-amerikanischen Westen, sondern vor allem durch den russischen Osten massiv bedroht. Dagegen gelte es ein Bündnis mit den Westmächten einzugehen, unter dessen Schutzschirm sich Europa eigenständig entfalten könne947. Folglich appellierte Stampfer an das "wohlwollende Verständnis der angelsächsischen Welt"948. Noch in Unkenntnis der Konferenzergebnisse von Teheran dachte er dabei an die USA, da er die Sowjetunion aus einem tief empfundenen Antibolschewismus und in Kenntnis der grundsätzlichen sowjetischen Vorbehalte gegenüber einer Europaorganisation ablehnte und Großbritannien der Vorherrschaft Amerikas zurechnete. Allein die USA seien in der Lage, „dem französischen Volk in seinem gegen-

945 STAMPFER, Die anderen Drei. Europas Rettung: Eine europäische Föderation. - Die Mission Frankreichs, in: NVZ, 12. Jg., Nr. 49 (4.12. 1943), S. 1. Die Fundstelle ist bei VoIGT (Hg.), Friedenssicherung 1988, S. 37, Anm. 21 irrtümlich mit Nr. 52 (25. 12. 1943) angegeben.

946 Einige Wochen später sah sich Stampfer durch einen Artikel Lord Vansittarts in der New York Times bestätigt, der gleichfalls Frankreich als Führungsmacht des europäischen Wiederaufbaus vorschlug; vgl. STAMPFER, Für die Vereinigten Staaten von Europa: Vive la France!, in: NVZ, 13. Jg., Nr. 2 (8.1. 1944), S. 1. Zustimmung erfuhr Stampfer auch seitens der Londoner Genossen, sowohl innerhalb des dortigen Rumpfvorstandes als auch von Einzelgängern wie Gerhard Kreyssig, vgl. Kreyssig an Rimsberger, 30. 5. 1945, AsD, NL Kreyssig, M. 59. Zum Londoner Sopade-Vorstand vgl. Ollenhauer, Zwischen Yalta und San Francisco, o. D. [17.3. 1945], S. 5, AsD, Bestand PV-Emigration Sopade, M. 156.

947 STAMPFER, Realistische Europa-Politik! Zerstörte Illusionen, in: NVZ, 13. Jg., Nr. 4 (22. 1. 1944), S. 1.

948 Ders., Die anderen Drei. Europas Rettung: Eine europäische Föderation. - Die Mission Frankreichs, in: NVZ, 12. Jg., Nr. 49 (4. 12. 1943), S. 1. 
wärtigen traurigen Zustand den Mut zu geben, an so große Aufgaben zu denken und sich auf sie vorzubereiten" 949 .

Im August 1944 ließ Stampfer erstmals seit langer Zeit erkennen, daß er trotz der betont prowestlichen Stellungnahmen für einen dritten Weg Europas zwischen den „russisch-bolschewistischen Methoden“ und dem „amerikanischen Evangelium der kapitalistischen Privatinitiative" kämpfte, also den europäischen Sozialismus als gelungene Synthese aus „wirtschaftlichem Kollektivismus und politischer Freiheit" favorisierte ${ }^{950}$. Darin sah er nicht nur die vorrangige Aufgabe Frankreichs, sondern vor allem der französischen Sozialisten. Der im Vergleich zu früheren Äußerungen deutlich sozialistischsolidarische Unterton ist möglicherweise darauf zurückzuführen, daß sich Stampfer angesichts der mittlerweile begonnenen Konferenz von Dumbarton Oaks an seine eigenen Worte vom Januar 1944 erinnerte: „Im Kanonendonner muß man laut reden." "951

Euphorisch begrüßte der Sozialdemokrat die Anerkennung der Regierung de Gaulle durch die Alliierten und deren Integration in die Nachkriegsverhandlungen der Anti-Hitler-Koalition. Seiner Ansicht nach legitimierte dies erst recht die herausgehobene Position, die er Frankreich beim Wiederaufbau Europas zuzubilligen gedachte. Damit war endlich die vermißte und ersehnte Stimme Europas in den Konferenzräumen der Alliierten vertreten ${ }^{952}$. In der politischen Aufwertung Frankreichs sah Friedrich Stampfer die letzte Chance, Europa vor einer Teilung in Einflußsphären zu retten und zugleich die deutsch-französische Verständigung als Nukleus einer neuen europäischen Sicherheitsarchitektur herbeizuführen ${ }^{953}$. Dabei dachte er insbesondere an eine intensive Kooperation der französischen Sozialisten als linkes Korrektiv zu General de Gaulle mit dem deutschen Volk. Unter dem Einfluß seiner regelmäßigen Korrespondenz mit Hubertus Prinz zu Löwenstein, den er als Mensch und Politiker achtete und mit dem ihn gewisse gemeinsame Grundanschauungen verbanden, bezeichnete der rechte Sozialdemokrat eine Koalition aus Sozialdemokratie und politischem Katholizismus als richtigen Ansprechpartner der Franzosen ${ }^{954}$. Sollte Frankreich jedoch seine europäische Mission verkennen, werde Europa unweigerlich zum „bloßen Objekt im Streit der Weltmächte“ herabsinken und tatsächlich in zwei Einflußsphären zerrissen. Auch Frankreich selbst wäre dann dem Untergang geweiht, denn es würde zum „Prellbock bei einem neuen, noch fürchterlicheren Zusammenstoß ${ }^{“}$ wer-

949 Ibid.

950 STAMPFER, Gruß nach Frankreich. Die europäische Mission der französischen Sozialisten, in: NVZ, 13. Jg., Nr. 34 (19. 8. 1944), S. 1.

951 DERS., Roosevelts Weihnachts-Ansprache: Keine Versklavung Deutschlands, in: NVZ, 13. Jg., Nr. 1 (1.1.1944), S. 1.

952 DERS., Gute Nachbar-Politik in Europa: De Gaulle am Kreuzweg, in: NVZ, 13. Jg., Nr. 44 (28. 10.1944), S. 1.

953 Ibid.

954 Ibid. 
den ${ }^{955}$. Stampfer wünschte sich daher dringend den „Tag der deutsch-französischen Völkerversöhnung im Lichte gemeinsamer Freiheit “956 herbei.

Die frankophile Färbung seiner zahlreichen Beiträge darf nicht darüber hinwegtäuschen, daß Stampfers außenpolitischer Blick stets von deutschen Interessen geleitet war. In der Betonung der französischen Führungsaufgabe sah er die einzige Möglichkeit, der Idee der Vereinigten Staaten von Europa in den USA Öffentlichkeit zu verschaffen. Dementsprechend versuchte er, mit einer hervorgehobenen Frankophilie die Befürchtungen um eine erneute deutsche Hegemonie auf dem europäischen Kontinent zu verdrängen und auf die antibolschewistische Zielrichtung seines Europakonzeptes zu lenken. Weniger aus Verbundenheit mit der Paneuropa-Bewegung als aus vergleichbar taktischen Erwägungen hatte Stampfer den Begriff der Vereinigten Staaten von Europa als Aufhänger seines Konzeptes der "Anderen Drei“" gewählt. Diese publizistische Strategie legte er in einem Brief an den SopadeVorsitzenden Vogel in London offen: „Wir haben dem russischen Herrschaftsanspruch die Parole der ,Vereinigten Staaten von Europa' entgegengestellt, die hier ungeheuer populär ist wegen ihres Gleichklangs mit dem Namen des eigenen Landes, und propagieren eine kontinentale Föderation unter Führung Frankreichs (um die hysterische Angst vor, verkapptem Pangermanismus' zu beruhigen). " 957

Wie eng sich der gelernte Journalist am Interesse der amerikanischen Öffentlichkeit orientierte, beweist auch der Versuch, ab Sommer 1944 die nunmehr unumstößlichen US-Pläne für eine neue Weltorganisation mit seinem Europakonzept zu verbinden. Stampfers anfänglich nur verhaltene Kritik an der antiföderalen Position der amerikanischen Europapolitik ${ }^{958}$ schlug angesichts der Polenkrise Ende des Jahres 1944 in offenen Widerspruch um. Es gebe eine im Niedergang befindliche nazistische Europapolitik in Berlin und eine im Aufstieg befindliche bolschewistische Europapolitik. „Aber von einer demokratischen Europapolitik, deren Sitz in Washington, London und Paris sein könnte, ist so gut wie nichts zu bemerken. "“959

Stampfers Konzept der "Anderen Drei“ fand bei dem Mitgliedern der schwedischen SAP-Gruppe um Brandt und Szende großen Anklang. Mit der

955 Ibid.

956 Vgl. etwa STAMPFER, „Keine Annexionen“: Neuer Geist in Frankreich, in: NVZ, 13. Jg., Nr. 47 (18. 11. 1944), S. 1: „Eine fruchtbare Völkerbundpolitik wird darauf ausgehen müssen, Zweckgemeinschaften jeder Art unter den Staaten Europas zu fördern. Die großen Ideale der Menschenliebe und Völkerverbrüderung hängen noch in den Wolken. Aber gegen Massenarbeitslosigkeit, Hungersnot und Epidemien werden die Regierungen Europas gemeinsame Maßnahmen treffen müssen - nicht aus Liebe zu den andern, sondern aus Liebe zu sich selbst."

957 Stampfer an Vogel, 12. 1. 1944, S. 2, AsD, Bestand PV-Emigration Sopade, M. 132. 958 STAMPFER, Für die Wiederauferstehung des Völkerbundes: Zurück zu Wilson!, in: NVZ, 13. Jg., Nr. 26 (24. 6. 1944), S. 1.

959 DeRS., Die Tragödie der europäischen Demokratie: Polenkrise - Europakrise!, in: NVZ, 13. Jg., Nr. 49 (2. 12. 1944), S. 1. 
Schrift „Zur Nachkriegspolitik der deutschen Sozialisten “960, deren außenpolitischen Teil Willy Brandt verfaßt hatte961, legte die Stockholmer Gruppe im Juli 1944 eine Zusammenfassung ihrer politischen Überzeugungen vor. Man teilte die Auffassung, daß für die innereuropäische Befriedung der deutsch-französische Ausgleich ausschlaggebend sein werde, und plädierte für eine zügige Erweiterung auf Italien als den dritten Staat im Bunde ${ }^{962}$. Im Unterschied zu Stampfers axiomatischem Antibolschewismus aber betonten die Stockholmer Emigranten, daß eine Europäische Föderation nicht in Frontstellung gegen die Sowjetunion geschaffen werden dürfe ${ }^{963}$, der man sich weiterhin in besonderer Weise verbunden fühlte ${ }^{964}$. Daher propagierte man die aktive Einbindung sowohl der Sowjetunion als auch Großbritanniens in das künftige Sicherheitssystem Europas. Auch mit der eigentlich naheliegenden Ablehnung einer Beteiligung der USA, die „aus geographischen Gründen gegenstandslos" sei ${ }^{965}$, trat der sozialistische Kreis den unveröffentlichten Überlegungen Stampfers aus dem Jahre 1943 entgegen $^{966}$.

Einig war man sich mit dem Sopade-Vorstandsmitglied ebenso wie mit dem ISK, daß eine europäische Föderation in einen neuen Völkerbund zu integrieren sei. Diesen neuen Völkerbund stellten sich die Sozialisten als eine Erweiterung des Kreises der Alliierten durch die Einbeziehung sowohl der Neutralen als auch der Besiegten vor ${ }^{967}$. Die in diesem Zusammenhang wiederholte Forderung nach einer "internationalen Rechtsorganisation“ und der Ausarbeitung eines „vollständigeren Völkerrechts“ verrät die Handschrift Willy Brandts 968 .

August Siemsen zeigte sich sehr kritisch gegenüber einer fortdauernden Einigung der "Großen Drei“ als Basis des europäischen Friedens ${ }^{969}$. Sarkastisch bemerkte er, daß er nicht zu denen zähle, „die von der Weisheit und Einigkeit der Sieger so tief überzeugt sind, daß sie glauben, das Schicksal Europas liege bei [den drei Großmächten] in den besten Händen"970. Eine Einigung der „Großen Drei“ konnte Siemsen nicht im Ansatz erkennen. Ohnehin würde es sich dabei notwendig um einen Kompromiß handeln müssen, bei dem Europa der Leidtragende wäre ${ }^{971}$. Denn von den Alliierten habe man

960 BEHM et al., Zur Nachkriegspolitik der deutschen Sozialisten 1944.

961 Vgl. BrandT, Links und frei 1982, S. 361.

962 BEHM et al., Zur Nachkriegspolitik der deutschen Sozialisten 1944, S. 37.

963 Ibid. S. 36f.

964 Ibid. S. 38.

965 Ibid.

966 Stampfer, Kampf um Deutschland, o. D. [1943], S. 204 f., AsD, NL Stampfer, Box 9, M. 44.

967 BEHM et al., Zur Nachkriegspolitik der deutschen Sozialisten 1944, S. 35.

968 Ibid.

969 SiEmsen, Kampf um Europa, in: La Otra Alemania. Das Andere Deutschland, März 1944, wieder abgedruckt in: Ders., Tragödie Deutschlands 1947, S. 112-117 (114).

970 Ibid.

971 Ibid. S. 115. 
keine konstruktiven Ideen für den europäischen Wiederaufbau gehört, zumal die Interessen unterschiedlich gelagert seien ${ }^{972}$.

Da eine erneute „Fehllösung des europäischen Problems ${ }^{\alpha 973}$ die Grundlage für einen dritten Weltkrieg schaffen würde, bezeichnete Siemsen die Errichtung einer eigenständigen Europaorganisation mehrfach als politische Hauptforderung und stimmte darin mit Stampfer und den SAPlern in Stockholm überein: „Es wäre verhängnisvoll, wollte das aus tausend Wunden blutende Europa darauf warten, daß die Sieger [...] neue Wege bei der Neuordnung Europas beschreiten würden. Die leidenden Massen Europas selbst müssen auf den Plan treten, um aus ihrem Glauben heraus zur Tat zu schreiten, um aus einem Objekt fremder Interessen endlich zum Subjekt bei der Gestaltung ihres eigenen Schicksals zu werden." ${ }^{\text {"974 }}$

Ungeachtet der äußeren Übereinstimmung in der Zielbeschreibung stand Siemsen ebenso wie die Stockholmer SAP-Gruppe einer dezidiert antibolschewistischen Europaföderation, wie sie Stampfer verfocht, ablehnend gegenüber. Anders als Stampfer, der wie Siemsen für sein Konzept das Schlagwort der Vereinigten Staaten von Europa in Anspruch nahm, beabsichtigte der später ausgetretene Mitgründer der SAP die aktive Beteiligung der UdSSR an der Restrukturierung Europas, da andernfalls dies die west-östlichen Spannungen noch erhöhen würde statt sie zu reduzieren ${ }^{975}$. Siemsens Kritik an einer überzogen antibolschewistischen Zieldefinition des neuen Europas richtete sich unmittelbar gegen Churchills Konzept der Vereinigten Staaten von Europa, obgleich der sozialistische Emigrant selbst in der europäischen Einheit eine Möglichkeit sah, das europäische Chaos der sowjetischen Dominanz zu entziehen ${ }^{976}$. Für Siemsen war Churchill ein Reaktionär, der „rettungslos dem überlebten Alten verhaftet“ sei, und dem „jegliches Verständnis für die Kräfte des Neuen, für den Willen der Massen und für die

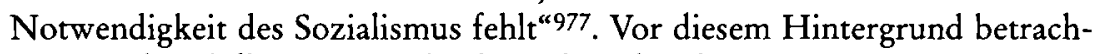
tete er Churchills Inanspruchnahme der Idee der Vereinigten Staaten von Europa als Diskreditierung des Europagedankens, da Churchill mit dieser Formel im Prinzip lediglich an das traditionelle britische Kalkül des europäischen Gleichgewichts zugunsten der englischen Machtpolitik anknüpfe ${ }^{978}$.

Auch Willi Eichler hatte sich durch die schwindenden Chancen einer von den Alliierten implementierten Europaföderation nicht entmutigen lassen und setzte sich nach Teheran erst recht für einen eigenen Nachkriegsplan der Europäer ein. Doch verfolgte er nicht das Ziel eines Europas der „Anderen

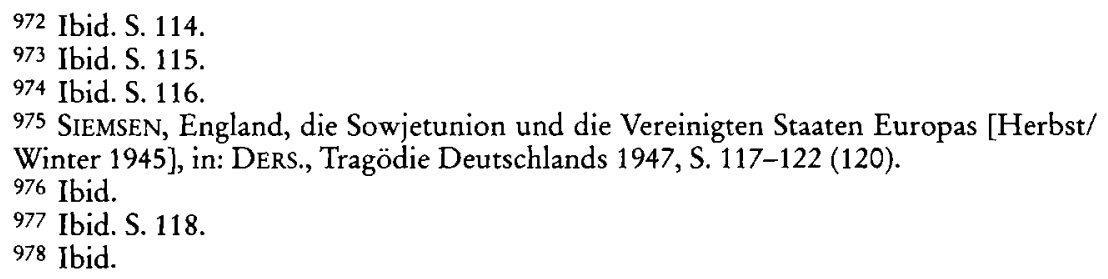


Drei“, sondern wollte die europäische Leitfunktion entsprechend der traditionellen Position des ISK allein Frankreich übertragen. Hinsichtlich der deutschen Beteiligung an der europäischen Neuordnung begnügte sich Eichler mit der Feststellung, daß die Idee der Föderation nicht als bloßes Mittel zum Schutz gegen einen deutschen Angriff betrachtet werden dürfe, sondern darüber hinaus die positive $Z$ weckbestimmung impliziere, die Früchte einer gelungenen Organisation von Frieden, Kultur und Wirtschaft möglichst allen zu Gute kommen zu lassen ${ }^{979}$.

Zugleich trat der ISK-Vorsitzende der Furcht vieler Europaföderalisten entgegen, „den herrschenden Mächten durch einen Plan mit eigener Konzeption zu nahe zu treten" $" 980$. Eichler dachte dabei insbesondere an die drohend ablehnende Haltung der Russen gegenüber einem "neuen europäischen Koloß"981. Diese Furcht der Föderalisten gelte es vor allen Dingen zu entkräften, um eine prinzipielle Rekonstruktion Europas zu ermöglichen, „statt hier und da etwas herumzuflicken"982.

Ähnlich dem ISK setzte sich der ehemalige Fraktionsvorsitzende der Deutschen Staatspartei, August Weber, für eine „League of European States“ unter französischer Führung ein ${ }^{983}$. Sein in institutioneller Hinsicht restriktives Konzept beschränkte sich auf ein Parlament der Nationen, dessen Abgeordnete von den Regierungen der Mitgliedstaaten ernannt werden sollten $^{984}$. Damit widersprach Weber seiner eigenen Forderung, eine Neuauflage des Völkerbundes unter allen Umständen zu verhindern ${ }^{985}$, denn gerade der Charakter der Völkerbundsversammlung als Forum von Regierungsvertretern hatte seit jeher im Zentrum der Völkerbundskritik gestanden. Andererseits entsprach der wenig progressive Entwurf der konservativen Einstellung Webers, der im Gegensatz zu Willy Brandt und anderen Emigranten auch auf die häufig geforderte Schaffung einer internationalen Rechtsorganisation verzichtete. Erst späteren Generationen wollte der ehemalige Reichstagsabgeordnete es überlassen, einen internationalen Rechtscode gegen Friedensbrecher, ein verständliches Strafrecht und den internationalen Schutz der Eigentumsrechte zu vereinbaren ${ }^{986}$. Dahinter stand die Überzeugung, daß die Diktatoren, namentlich Hitler und Mussolini, vom eigenen Volk zu richten $\operatorname{seien}^{987}$.

Als Weber im Oktober 1944 das Manuskript zu seinem Buch „A New Germany in a New Europe" abschloß, ging er noch von der aktiven Unter-

979 Eichler an Spinelli, 5. 4. 1945, S. 2, AsD, Bestand IJB/ISK, Box 56.

980 Eichler an Spinelli, 23. 3. 1945, S. 1, AsD, Bestand IJB/ISK, Box 56.

981 Ibid.

982 Ibid.

983 WEBER, A new Germany 1945, S. 170 f.; Auszüge sind abgedruckt in: LIPGENS (Hg.), Documents II 1986, Dok. Nr. 229, S. $614 \mathrm{ff}$.

984 Ibid. S. 192.

985 Ibid.

986 Ibid. S. $187 \mathrm{f}$.

987 Ibid. S. 187. 
stützung der drei Großmächte für einen europäischen Einigungsprozeß aus. Dies sei um so bedeutender, als sich nach seiner Einschätzung die Sowjetunion als die entscheidende Kraft auf dem europäischen Kontinent erweisen würde ${ }^{988}$. Inwiefern Weber die drei Großmächte in die europäische Sicherheitsarchitektur einzubinden gedachte, wird letztlich nicht deutlich. Einerseits betrachtete er sie als politisch außerhalb stehend ${ }^{989}$, andererseits jedoch sollten sie wirtschaftlich und währungstechnisch vollumfänglich integriert werden ${ }^{990}$. Dieses konzeptionelle Manko wirkt sich in Webers Europaentwurf um so gravierender aus, als der "Großmandarin der Staatspartei im britischen Exil“991 eine Einbindung der künftigen Europaorganisation in die Weltorganisation der Alliierten vorerst nicht für notwendig hielt ${ }^{992}$.

Ein weiterer Repräsentant des elitären Ansatzes war Hubertus Prinz zu Löwenstein, der letztlich allerdings an der deutschen Schlüsselfunktion für die Zukunft Europas nie ernsthaft gezweifelt hatte und insofern eine eigene Variante des elitären Ansatzes vertrat. Er bekannte sich zum europäischen Leitbild der abendländischen Föderation, die seines Erachtens „dem geschichtlichen, römisch-deutschen, übernationalen Erbe in moderner Form" entspreche ${ }^{993}$. Erwartungsgemäß wollte Löwenstein den Begriff der OstWest-Orientierung nicht als Auflösung der europäischen Eigenständigkeit verstanden wissen ${ }^{994}$, und warnte, wie viele Emigranten, vor einem allzu antisowjetischen Selbstverständnis Europas, wie es insbesondere von Stampfer, aber auch von Churchill verfochten wurde. Ungeachtet dieser Einsicht in die europäischen Machtverhältnisse zählte Löwenstein nach wie vor zu den erklärten Antikommunisten. Mit bemerkenswerter Präzision sah er die Entstehung eines kommunistischen ostdeutschen Staates unter sowjetischem Einfluß voraus, falls den Russen eine eigene Besatzungszone zugebilligt werden sollte: „Within a few months after the elimination of all opponents, just as it was done in Eastern Poland and the Baltic States, the provinces under Red Army rule would declare themselves, Soviet Germany'. "995 Eine solche Entwicklung würde die westlichen Gebiete Deutschlands unter erheblichen Druck setzen und sie vor die Wahl stellen, entweder Widerstand zu leisten und damit den dritten Weltkrieg zu provozieren oder sich zurückzuziehen und damit das gesamte Deutschland der unmittelbaren Sowjetisierung zu

988 Ibid. S. $170 f$.

989 Ibid. S. 185.

990 Ibid. S. 181.

991 So die sarkastische Beschreibung von HILLER, Zwischen TIMESdemokrat und Nietzschepapst (Antikritische Phantasie, London 1945), in: DeRS., Ratioaktiv 1966, S. 138-161 (160, Anm. 2).

992 WEBER, A new Germany 1945, S. 169.

993 Löwenstein an Tillich, 27. 4. 1944, BAK, NL Löwenstein, N 1222, Bd. 25a.

994 Ibid.

995 Löwenstein, As Germany goes, so goes Europe, Typoskript, 1944, S. 11, BAK, NL Löwenstein, N. 1222, Bd. 40 . 
öffnen ${ }^{996}$. Löwensteins Gegenkonzept beinhaltete die zügige Schaffung eines vereinigten Europas auf der Grundlage des päpstlichen Friedensplanes ${ }^{997}$, mit einem starken und ebenfalls ungeteilten Deutschland in seiner Mitte ${ }^{998}$. Unter solchen Umständen wäre Europa ebenso wie Deutschland in der Lage, sich vor einem Übergreifen des sowjetischen Einflusses zu bewahren und dennoch friedliche Beziehungen zu Rußland zu unterhalten.

Einer der bedeutendsten Repräsentanten des egalitären Ansatzes war Heinrich Ritzel. Ritzels Credo besagte, daß die Zukunft Europas nur europäisch im besten Sinne des Wortes sein könne - nämlich als Einheit in Freiheit ${ }^{999}$. Daraus folgerte der Generalsekretär der Europa-Union Schweiz zweierlei: Zum einen wandte er sich gegen alle Vorschläge, einem bestimmten Land eine europäische Leitfunktion zuzuerkennen, und zum anderen verweigerte er sich jedweder Anlehnung an eine der außereuropäischen Großmächte ${ }^{1000}$. Folgerichtig widersprach Ritzel Wehbergs Plädoyer für eine Weltorganisation anstelle einer Europaorganisation und nannte hierfür vier tragende Gründe: Der Entwicklungsstand der Welt sei zu verschieden, die kleinen europäischen Staaten würden in einer vielfach von außereuropäischen Interessen geleiteten Weltunion im Schatten der großen Wirtschaftsmächte untergehen ${ }^{1001}$, und im übrigen wäre Europa mit zusätzlichen außereuropäischen Angelegenheiten schlicht überfordert ${ }^{1002}$. Vor allem aber habe Europa "das Recht auf Selbstverwaltung, die für jede Gemeinde in der wahren Demokratie als selbstverständlich angesehen wird "1003. Angesichts der Tatsache, daß sich die Sowjetunion zu einem ernst zu nehmenden „osteuropäischen Faktor" 1004 entwickelt habe, formulierte Ritzel ein Konzept der distanzierten Nachbarschaft, die sich in erster Linie über die wirtschaftlichen Beziehungen zu definieren habe ${ }^{1005}$.

Ritzels eingängiges Credo von der europäischen Zukunft Europas fand bei dem ehemaligen Zentrumspolitiker Friedrich Baerwald großen An-

996 Ibid. S. 12.

997 Löwenstein bezog sich auf die Fünf-Punkte-Erklärung Papst Pius' XII. in der Weihnachtsansprache vom 24. 12. 1940, erneuert am 24. 12. 1941, in dem der Papst den fünffachen Sieg über den $\mathrm{Haß}$ und das Mißtrauen zwischen den Völkern, über den Vorrang der Macht vor dem Recht, über das Konfliktpotential des weltwirtschaftlichen Ungleichgewichts und über den nationalen Egoismus zu Lasten der Freiheit des einzelnen forderte. Die beiden Weihnachtsansprachen Papst Pius' XII. sind abgedruckt in: LIPGENS (Hg.), Documents II 1986, S. 710-713 und S. $716 \mathrm{ff}$.

998 Löwenstein, As Germany goes, so goes Europe, Typoskript, 1944, S. 13, BAK, NL Löwenstein, N. 1222, Bd. 40.

999 RITZEL, Kampf um Europa 1945, S. 63. Das Dokument ist auszugsweise abgedruckt in: LIPGENS, Documents II 1986, Dok. 230, S. 616-618.

1000 lbid.

1001 Ibid. S. $64 \mathrm{f}$.

1002 Ibid. S. 65.

1003 Ibid. S. 74.

1004 Ibid. S. 76.

1005 Ibid. S. 77. 
klang ${ }^{1006}$. Auch Baerwald war überzeugt, daß die „Vier Weltpolizisten“ allein nicht für die Sicherheit in Europa garantieren könnten. Deshalb müsse Europa innerhalb eines anglo-sowjetischen Rahmens eine neue "political solidarity" auf der Basis seiner historischen Einheit finden. Baerwald ging von einem langsamen Integrationsprozeß aus ${ }^{1007}$, der jedoch unvermeidlich sei, um Europa nicht gänzlich zum Spielball der Weltmächte verkommen zu lassen und die internationale Gefahr eines dritten Weltkrieges durch die Auflösung des politischen Vakuums in Europa zu minimieren ${ }^{1008}$.

Das Schreckensszenario eines dritten Weltkrieges stellte auch das bestimmende Thema in den letzten größeren Exilpublikationen des radikalpazifistischen Sozialisten Kurt Hiller dar, der in einer Teilung Europas den endgültigen Verlust der kontinentalen Selbstbestimmung in wirtschaftlicher, politischer und letztlich auch in kultureller Hinsicht prophezeite. Für Hiller nahm die Idee der europäischen Föderation daher die Funktion des ganz Europa einigenden Bandes wahr, auf das die Idealkonzeption eines Weltstaates nicht verzichten könne ${ }^{1009}$. Man dürfe sich also weder in eine „absurd-exklusivistische ,West-Orientierung “ " noch in eine Ostorientierung hineintreiben lassen, sondern müsse sich „eine west-östliche, eine internationalistische, eine europäische und planetarische Orientierung" geben ${ }^{1010}$. Dies setzte auch nach Hillers Einschätzung die Fortsetzung der Anti-Hitler-Koalition nach der Beendigung des Krieges voraus. Keinesfalls dürfe das vereinte Europa eine dezidiert antisowjetische Tendenz aufweisen ${ }^{1011}$. Hiller hatte sich entschlossen, statt eines realpolitischen Minimalprogramms weiterhin das Ideal einer umfassenden Integration zu propagieren. So forderte er noch im Mai 1945 in Kenntnis der entgegengesetzten alliierten Planungen unbeirrt den weitgehenden Souveränitätsverzicht der Nationalstaaten zugunsten einer europäischen Föderation als Zollunion, Währungsunion, Industrieunion, Militärunion und politischen Union ${ }^{1012}$ sowie das verbindliche Bekenntnis $\mathrm{zu}$ den gemeinsamen Menschenrechten ${ }^{1013}$.

1006 BAERWALD, The Future of Europe, in: Thought. Fordham University Quarterly, Bd. 19, Nr. 74 (September 1944), S. 407-420 (411) formulierte nahezu wortgleich:

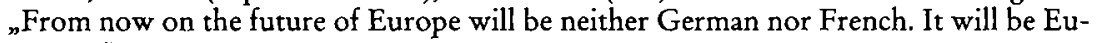
ropean."

1007 Ibid. S. 420.

1008 Ibid. S. 416.

1009 Hiller, The Problem of Constitution, in: DeRs. (Hg.), After Nazism - Democracy? 1945, S. 9-77 (29).

1010 Hiller an Englich, 30. 5. 1944, S. 2, AsD, Slg. Hiller/Englich, Box 1, M. 1944.

1011 In dem privaten Brief an Kurt Englich, ibid., zeigte Hiller die innenpolitische Konsequenz dieser Prämisse in drastischen Worten auf: „Daher müssen wir auch unser Nein zu dem Scheißhaufen, der sich im Exil KPD zu nennen wagt, säuberlich trennen von unsrer Stellungnahme zur SU als Staat."

1012 Hierin unterschied sich Hiller von seinem FDS-Partner Walter D. Schultz, der in derselben Publikation eine Beschränkung auf die Wirtschaftsföderation Europas favorisierte, weil er hoffte, daß sich die politische Einheit aus der Wirtschaftsintegration heraus entwickeln werde. Dem lag die sozialistische Überzeugung zugrunde, daß der 
Deutlicher als Ritzel und Baerwald hob Wilhelm Röpke die Notwendigkeit eines europäischen Bewußtseins hervor, das „eine gewisse Einzäunung gegenüber den ,anderen' “1014 bedinge. Diese Abgrenzungsfunktion des europäischen Wir-Gefühls bezog der Nationalökonom primär auf das Verhältnis zu den außereuropäischen Großmächten USA, UdSSR und Großbritannien: „Gerade in dem Maße, wie sich die außereuropäischen Großmächte - zu denen wir auch Sowjetrußland trotz aller Hochachtung vor der russischen Kultur rechnen müssen - erheben und die Zivilisationen anderer Kontinente uns mit herablassendem Selbstbewußtsein zu begegnen beginnen, wird es ebenso notwendig wie natürlich sein, daß das geistig-moralische $\mathrm{Zu}$ sammengehörigkeitsgefühl der Europäer mächtig anschwillt."1015 Durch das gestärkte Zusammengehörigkeitsgefühl glaubte Röpke zugleich der Gefahr des Totalitarismus wirksam begegnen zu können ${ }^{1016}$. Doch stellte sich ihm angesichts der Konstellation der Anti-Hitler-Koalition ein (ideo)logisches Problem. Denn im Gegensatz zu Löwenthals Formulierung der klaren Fronten aus dem Jahre 1941 hatte für Röpke der Ausbruch des deutsch-russischen Krieges das Ende der bis dahin klaren Front gegen die Totalitarismen des Hitler-Stalin-Paktes bedeutet. Mit Blick auf das seitdem bestehende Bündnis der Westalliierten mit dem stalinistischen Totalitarismus konstatierte der Hochschullehrer für Volkswirtschaft einen logischen Bruch in seiner eigenen Argumentation für einen antitotalitären Konsens der Europäer. Eine gewisse Verwirrung konnte er nicht verhehlen und befürchtete, daß diese Verwirrung der Fronten gegenüber dem Totalitarismus Europa schlimmer als je auseinander reißen werde ${ }^{1017}$. Denn eine europäische Einigung konnte sich der liberale Wirtschaftsexperte nur als einen Zusammenschluß liberaler Demokratien vorstellen, in deren Reihen sich ein totalitäres Rußland als Fremdkörper ausnehmen würde ${ }^{1018}$.

Röpke, der mit Blick auf die Verhandlungsergebnisse von San Francisco eine Weltföderation für unrealistisch hielt ${ }^{1019}$, zeigte sich bedingt zuversichtlich, daß eine europäische Einigung demnächst verwirklicht werden könnte ${ }^{1020}$. Um das Endziel, einem europäischen Kollektivbewußtsein Ent-

politische Konflikt unmittelbar aus sozialen Differenzen resultiere; SCHULTZ, Democracy, Freedom, Socialism, in: HILlER (Hg.), After Nazism - Democracy? 1945, S. 78$128(81)$.

1013 Hiller, The Problem of Constitution, in: Ders. (Hg.), After Nazism - Democracy? 1945 , S. 28.

1014 RÖPKE, Internationale Ordnung 1945, auszugsweise abgedruckt in: VOIGT ( $\mathrm{Hg}$.), Friedenssicherung 1988, S. 170-179 (Zitat auf S. 173) sowie bei LIPGENS, Documents II 1986, Dok. Nr. 232, S. $620 \mathrm{ff}$.

1015 RÖPKE, ibid. S. 174.

1016 Ibid. S. 176.

1017 Ibid.

1018 Ibid. S. 178. Dabei definierte Röpke den Begriff „liberal“ vorbehaltlich ausführlicherer Erörterungen zunächst einmal als nichtkollektivistisch (S. 179).

1019 Ibid. S. 172.

1020 Ibid. S. 173. 
faltungsraum zuzubilligen, nicht zu gefährden, müsse ein allmählicher Entwicklungsprozeß in Kauf genommen werden, der hauptsächlich zwei Gefahren ausgesetzt sein würde: Erstens berge der an sich sinnvolle und naheliegende Ansatz, den Integrationsprozeß mit kleineren Einheiten im Sinne von Regionalföderationen zu beginnen, die Gefahr einer weiteren Vertiefung der kontinentalen Zersplitterung. Hierfür bot sich nach Röpkes Überzeugung die Lösung einer von Anfang an zu errichtenden gesamteuropäischen Föderation als übergeordneter Kategorie an, innerhalb derer sich die einzelnen Regionalföderationen schrittweise annähern könnten ${ }^{1021}$. Zweitens sei ein Vorgehen in zeitlichen Etappen unumgänglich, auch wenn dies zu erheblichen Verzögerungen führen werde ${ }^{1022}$. Denn die Ablösung des Nationalismus durch einen „europäischen Patriotismus“ werde einen langen Zeitraum in Anspruch nehmen ${ }^{1023}$.

Gleich Röpke vertrat auch der christlich-konservative Rechtsgelehrte Friedrich Darmstaedter die Auffassung, daß das primäre Ziel jedes europäischen Einigungsprozesses die Schaffung eines identitätsstiftenden Europabewußtseins sein müsse, daß der Dozent der London School of Economics and Political Science an dem pädagogisch-gesellschaftlichen Leitbild des "guten Europäers" auszurichten gedachte ${ }^{1024}$. In seinen weiteren Ausführungen ließ sich Darmstaedter jedoch durch sein Interesse an einem strikt egalitären Europabund zu der abstrusen Zielvorstellung einer umfassenden Nivellierung der europäischen Staaten verleiten. Der optimale Europabund setzte sich ihm zufolge aus Mitgliedstaaten zusammen, die ausnahmslos auf eine vergleichbare Größe und Einwohnerzahl zugeschnitten seien und über vergleichbaren wirtschaftlichen Reichtum verfügten ${ }^{1025}$. Für den Fall, daß das politische Optimum einer völligen Nivellierung nicht durchzusetzen sei, hielt Darmstaedter eine weniger weitgehende Alternative bereit, die Ähnlichkeiten mit den Überlegungen Heinrich Ritzels in der Schweiz aufwies: Entweder solle jeder Staat mit einem identischen Stimmengewicht ausgestattet oder der Europabund aus gleich großen Regionalgruppen zusammengesetzt werden ${ }^{1026}$. Parallel zu der politischen Struktur empfahl Darmstaedter, der nach einem zweijährigen Exil in Rom 1939 nach London emigriert war, die Gründung einer alle christlichen Gruppierungen vereinigenden „all-European church"1027. Da eine solche Wiedervereinigung der christlichen Kirchen angesichts der geringen Erfolge der ökumenischen Bewegung aber kaum zu er-

1021 Ibid. S. 178.

1022 Ibid. S. 177.

1023 Ibid. S. 174. Ohne Röpkes Beitrag zum Europadiskurs der späten Kriegsjahre zu schmälern, bleibt doch fraglich, inwiefern der Nationalökonom tatsächlich Gedanken äußerte, die „dem deutschen Exil sonst im allgemeinen fern lagen“, wie VOIGT ( $\mathrm{Hg}$.), Friedenssicherung 1988, S. 132 behauptet.

1024 DARMSTAEDTER, Germany and Europe 1945, S. 207.

1025 Ibid. S. 209.

1026 Ibid. S. 208.

1027 Ibid. S. $211 \mathrm{f}$. 
warten sei, wollte der bekennende Christ zumindest eine gemeinsame europäische Kirchenorganisation zur gemeinsamen Wahrnehmung der sozialen Aufgaben ins Leben rufen und regte die Schaffung eines "Chamber of the Churches" als Europäischen Kirchenrat an ${ }^{1028}$. Darmstaedters Vision stand nicht nur hinsichtlich ihrer dezidiert christlichen Komponente der beispielsweise von Ritzel vertretenen Konzeption von der Einheit in Vielfalt also diametral entgegen, obschon beide in der gemeinsamen Zieldefinition eines antihegemonialen Europabundes übereinstimmten.

\subsection{3. „Vier Weltpolizisten"}

Nicht nur in der Hoffnung auf eine föderale Lösung der europäischen Krisensituation, sondern auch in der Erwartung eines neuen, starken Völkerbundes hatte Roosevelt viele deutsche Emigranten enttäuscht - um so mehr, als nicht wenige Emigranten gerade dem amerikanischen Präsidenten eine weitsichtige, über die unmittelbaren Interessen des eigenen Staates hinausreichende Politik zugetraut hatten. Statt dessen war es Roosevelt, der in Teheran das Gespräch mit Stalin suchte, um ihn für seine Idee einer Weltorganisation zu gewinnen und auf diese Weise Churchills Widerstand zu brechen. Zwar hatten sich Churchill und Roosevelt in Quebec im August 1943 über eine neue internationale Organisation, einen verbesserten Völkerbund verständigt und wollten diese Überlegungen Stalin in Teheran vorstellen. Jedoch hatte Roosevelt in Teheran einen eigenen Vorschlag im Gepäck, der sich von der Quebec-Skizze vor allem dadurch unterschied, daß er den neuen Völkerbund gerade nicht auf Kontinentalföderationen stützte. Diese regionale Untergliederung der neuen Weltorganisation in kontinentale Föderationen, insbesondere eine europäische Föderation war ein zentrales Anliegen des britischen Premiers. Roosevelt unterbreitete Stalin in einem Gespräch unter vier Augen den Vorschlag einer Weltorganisation ohne regionale Untergliederung, weil er zu Recht annahm, daß Stalin jedem versteckten Hinweis auf die Errichtung einer europäischen Föderation härtesten Widerstand entgegenbringen würde. Jedenfalls entsprach Roosevelts Entwurf in allen entscheidenden Punkten dem genauen Gegenteil dessen, was das politische Exil seit 1933 für einen modifizierten Völkerbund gefordert hatte ${ }^{1029}$. Nach den amerikanischen Vorstellungen, die sich letztlich auf den Konferenzen von Dumbarton Oaks und San Francisco durchsetzen sollten, würde es sich bei der neuen Weltorganisation gerade nicht um einen modifizierten Völkerbund, sondern um eine gänzlich neue Institution handeln. Statt einer starken Exekutive, die die Emigranten immer wieder als dringendsten Reformbedarf bezeichnet hatten, sollte der Exekutivrat lediglich Empfehlungen abgeben können. Auch sollte die Welt-

1028 Ibid.

1029 Vgl. die Aufzeichnung über die Unterredung Stalins mit Roosevelt im Rahmen der Konferenz von Teheran am 29.11. 1943, abgedruckt in: Ministerium für Auswärtige Angelegenheiten der UdSSR ( $\mathrm{Hg}$.), Die Sowjetunion auf internationalen Konferenzen 1986, Dok. Nr. 56, S. 94-98, insb. S. 95. 
organisation über keinerlei militärische Befugnisse verfügen, so daß weder die im deutschen Exil seit 1941 in den Vordergrund gestellte internationale Abrüstung noch die damit zusammenhängende Rüstungskontrolle hätten realisiert werden können. Und schließlich wurde als völkerrechtliche Grundlage zwar die Atlantikcharta benannt, doch sollte sie entgegen der hoffnungsfrohen Interpretation des deutschen Exils gerade nicht auf den Kriegsgegner Deutschland anwendbar sein, dessen Territorium nach der Teheraner Übereinkunft der "Großen Drei“ geteilt werden sollte. Auch die Gedanken der Demokratie und der Gleichberechtigung aller Staaten, die Vertreter des deutschen Exils als Grundsätze eines weiterentwickelten Völkerrechts verankert sehen wollten, fanden in Roosevelts Vorstellungen keinen Raum. Gedacht war vielmehr an ein Exekutivkomitee unter dem dominierenden Einfluß der USA, der Sowjetunion, Großbritanniens und Chinas. Diese vier Großmächte sollten darüber hinaus ein sogenanntes Polizeikomitee zur Vermeidung künftiger Aggressionen bilden. Als drittes Organ war eine Art Völkerparlament vorgesehen, in dem in Roosevelts Worten „jedes Land so viel, wie es will, sprechen kann und in dem kleine Länder ihre Meinung zum Ausdruck bringen können" 1030 - ohne wirklichen Einfluß auszuüben.

Als im Verlaufe des Jahres 1944 nähere Einzelheiten der alliierten Weltorganisationspläne ruchbar wurden, trafen sie auf die gruppenübergreifende Ablehnung der deutschen Exilgruppen. Überwiegend beurteilte man die Idee der „Vier Weltpolizisten“ als einen Rückschritt in der Entwicklung des modernen Völkerrechts. Sozialisten, Sozialdemokraten und Liberale stimmten darin überein, daß die Nachkriegskonzeption der Alliierten nicht nur den Fehler aufwies, die europäische Ebene völlig auszublenden, sondern ebenso wenig geeignet war, neue Maßstäbe der globalen Friedenssicherung zu setzen. Erich Koch-Weser brachte es gegenüber Arnold Brecht auf den Punkt, indem er bereits zu Beginn der Konferenz von Dumbarton Oaks feststellte: „Es ist betrüblich, daß der Europabund jetzt hinter den Plänen einer weltweiten Kooperation und - noch schlimmer - einer Welthegemonie der vier Mächte so in den Hintergrund tritt. ${ }^{1031}$ Er empfahl einen restriktiven Aufgabenkatalog der Weltorganisation, die entsprechend seines Satzungsentwurfs für einen Europabund die Hauptverantwortung in der internationalen Konfliktprävention auf der kontinentalen Ebene der ,fortgeschrittenen und schon jetzt ausgeglichenen Regionen wie Europa" belassen sollte ${ }^{1032}$.

Hatten viele Emigranten zwischen 1941 und 1943 die Errichtung einer Weltföderation oder gar einer "Weltregierung“ unter der Führung der USA und Großbritanniens, möglicherweise auch der Sowjetunion als Ersatz der von den Alliierten abgelehnten Europaföderation betrachtet, so wurden diese Hoffnungen durch die Konferenzergebnisse von Teheran, Dumbarton

1030 Ibid. S. 96.

1031 Koch-Weser an Brecht, 3. 8. 1944, S. 1, BAK, NL Brecht, N 1089, Bd. 11.

1032 Ibid. 
Oaks und San Francisco zerstört. Das alliierte Nachkriegskonzept der „Vier Weltpolizisten" bot keinerlei Raum für einen föderalen Zusammenschluß1033, erst recht nicht für einen starken Weltbund mit einer supranationalen Regierung, wie sie dem ehemaligen Fraktionsvorsitzenden der Deutschen Staatspartei, August Weber, vorschwebte ${ }^{1034}$. Weber nannte mehrere Gründe, warum eine anglo-amerikanische Weltregierung, die er sich als Fortentwicklung der von den Alliierten beabsichtigten Weltorganisation vorstellte, vorerst keine Verwirklichungschancen besaß: Zunächst stimmte er mit der Einschätzung überein, daß die Einheit der "Großen Drei“ nach Kriegsende nicht aufrechterhalten werden könne. Darüber hinaus argumentierte Weber, daß Asien und Afrika einer Weltföderation der Demokratien nicht angehören könnten, solange sie ihre undemokratischen Herrschaftsstrukturen nicht überwunden hätten. Schließlich vermutete er, daß Südamerika sich nicht ohne weiteres unter die Führung der USA begeben wollen würde ${ }^{1035}$. Dennoch weigerte sich Weber, die Hoffnung auf eine weltweite Einigung endgültig fahren lassen und plädierte für die Einberufung einer Weltkonferenz mit dem langfristigen Ziel einer Weltregierung.

Während Weber, Koch-Weser und die schwedische SAP-Gruppe frühzeitig erkannt hatten, daß von den Alliierten keine progressive Weltorganisation zu erwarten war, suchte Stampfer bis zur Konferenz von San Francisco vergeblich nach einem Hoffnungsschimmer. Getrieben von der drohenden Isolation Deutschlands auch im Rahmen der künftigen Weltorganisation, mahnte er die Wiederauferstehung des Völkerbundes an und appellierte an die amerikanische Politik, sich auf die völkerrechtlich progressive Linie Wilsons zu besinnen ${ }^{1036}$. Stampfers Appell an die politische Vernunft, die er kaum von Europa, aber um so eher von den Vereinigten Staaten erwartete, sollte nicht nur dem deutschen Exil mehr Beachtung verschaffen und die Seele seines Gastlandes streicheln, sondern entsprach seiner außenpolitischen Grundüberzeugung, daß allein die USA imstande seien, der Welt eine neue Ordnung zu geben und zugleich die Gefahr eines sowjetisch dominierten Europas abzuwenden.

Erst nach der Konferenz von San Francisco mußte der Föderalist Stampfer einsehen, daß die dort geschaffene Organisation der Vereinten Nationen in keiner Weise dem modifizierten Völkerbund à la Wilson entsprach, den Stampfer sich gewünscht hatte: Die Entscheidung zwischen dem Prinzip des Völkerbundes und dem der neuen Organisation ist mit der Entscheidung in der Vetofrage gefallen. "1037 Das neue System funktioniere nur, solange sich

1033 BeHM et al., Zur Nachkriegspolitik der deutschen Sozialisten 1944, S. 36.

1034 WeBER, A new Germany 1945, S. 167 f.

1035 Ibid.

1036 STAMPFER, Für die Wiederauferstehung des Völkerbundes: Zurück zu Wilson!, in: NVZ, 13. Jg., Nr. 26 (24. 6. 1944), S. 1.

1037 DERS., Vom Völkerbund zur Großen Allianz: Das neue Welt-Statut, in: NVZ, 14. Jg., Nr. 26 (30. 6. 1945), S. 1. 
die USA und die UdSSR einig seien. Fehle diese Übereinstimmung, bleibe es bei der altbekannten Alternative: diplomatischer Ausgleich oder Krieg. Unter Aufgabe der bisherigen Zurückhaltung geißelte der wortgewandte Journalist die neuen Vereinten Nationen als systematisierte Machtpolitik alten Stils, die die Großmächte auf Kosten der kleineren Staaten bevorzuge ${ }^{1038}$. Gerade die Konflikte zwischen den Großmächten aber seien für das internationale Unheil verantwortlich gewesen. Hierin stimmte ihm Oda Olberg zu, die ihrer Überzeugung Ausdruck verlieh, daß „der heute international anerkannte Grundsatz der Nicht-Intervention bisher weder einen kleinen Staat geschützt, noch einen Krieg verhindert hat" ${ }^{* 1039}$. Daher maß sie der Anerkennung eines Rechts internationaler Einmischung größte Bedeutung für die Verhütung weiterer Kriege $z^{1040}$. Trotz aller Enttäuschung hatte sich der Realpolitiker Stampfer schnell mit der Organisation von San Francisco als dem kleinsten gemeinsamen Nenner abgefunden: „Das Höchsterreichbare ist die Errichtung eines Notgerüstes, das durch eine solidere Konstruktion zu ersetzen künftiger Staatsmannskunst vorbehalten bleibt.“1041

Einer der wenigen Befürworter einer prioritären Weltorganisation war der in der Schweiz lehrende Völkerrechtsexperte Hans Wehberg. Hatte sich der Professor für Völkerrecht schon 1943 eine auf Europa beschränkte Staatenföderation mit dem Hinweis auf die Unteilbarkeit internationaler Sicherheit abgelehnt ${ }^{1042}$, so holte er nun die Begründung nach. Eine ausschließlich europäische Organisation sei aus drei Gründen zwecklos ${ }^{1043}$ : Erstens sei die Beteiligung der großen außereuropäischen Mächte unabdingbar, da das zerrissene Europa nicht in der Lage sei, sich selbst zu organisieren und zu befrieden. Zweitens werde nach Kriegsende ohnehin eine stärkere Zusammenarbeit mit der Sowjetunion notwendig sein. Die dadurch hervorgerufenen neuen Probleme könnten ebenfalls nur unter Mitwirkung der nichteuropäischen Staaten gelöst werden ${ }^{1044}$. Und drittens seien die wirtschaftlichen Beziehungen aller Völker so ineinander verflochten, „daß die Regelung der ent-

1038 So schon der Verdacht Vogels, Deutschland und Europa in der Nachkriegswelt, in: SM, Nr. 63/64 (Juni/Juli 1944), S. 1-9 (4).

1039 OlBERG, Intervention - Nichtintervention, in: NVZ, 13.Jg., Nr. 35 (26. 8. 1944), S. 1 f. (1).

1040 Ibid.

1041 STAMPFER, Vom Völkerbund zur Großen Allianz: Das neue Welt-Statut, in: NVZ, 14. Jg., Nr. 26 (30. 6. 1945), S. 1.

1042 WEHBERG, Zum gegenwärtigen Stande des Problems einer künftigen Weltorganisation, in: Die Friedens-Warte, 43. Jg., Nr. 5 ([September] 1943), S. 207.

1043 Ders., Die Organisation der Staatengemeinschaft nach dem Kriege. Das Problem einer wahren Repräsentation der Völker, in: Die Friedens-Warte, 44. Jg., Nr. 2/3 (1944), S. 49-74 (56f.).

1044 Klarsichtig bemerkte Wehberg, ibid. S. 57: „Oft tauchte im Laufe der Geschichte der Idee der ,Vereinigten Staaten von Europa' der Gedanke auf, Rußland auszuschließen. Heute liegt das Problem wesentlich anders, da es sich nur noch darum handeln kann, die künftige Zusammenarbeit mit Sowjetrußland zu erleichtern." 
scheidenden wirtschaftlichen Probleme ohne eine weltumspannende Organisation nicht gut möglich ist “ ${ }^{\text {}} 1045$.

In mehreren Vorlesungen und Vorträgen beschäftigte sich der Jurist mit den Stärken und Schwächen der alliierten Weltorganisation und verknüpfte seine Kritik mit der Darstellung seines Ideals eines Weltbundes mit einer starken Weltregierung und einem unmittelbar demokratisch legitimierten Weltparlament. Noch während der Konferenz von Teheran hielt Wehberg einen Vortrag vor Studenten, in dem er davor warnte, allzu hohe Erwartungen an die amerikanische Außenpolitik zu stellen. Dabei verwies er auf den bedeutsamen Umstand, daß Roosevelt „nicht etwa von den Grundlagen einer neu zu schaffenden internationalen Organisation gesprochen, sondern sich darauf beschränkt hat, die Durchsetzung von vier notwendigen menschlichen Freiheiten zu fordern"1046. In dieser Selbstbeschränkung des amerikanischen Präsidenten sah Wehberg eine verpaßte Chance, den von ihm favorisierten Weltbundesstaat zu errichten. Zwar bezeichnete er die in Dumbarton Oaks vereinbarte alleinige Zuständigkeit des künftigen Weltsicherheitsrates für alle Angelegenheiten des Friedens als „durchaus annehmbar"1047, doch kam er letztlich zu einer überwiegend negativen Bewertung an der alliierten Konzeption. Mit Friedrich Stampfer kritisierte er das Einstimmigkeitsprinzip im Sicherheitsrat, das die Weltorganisation ihrer Handlungsfähigkeit beraube, sobald sich die Mitglieder des Sicherheitsrates nicht einig seien. Zudem sah sich Wehberg nach der Konferenz von Dumbarton Oaks in seiner Befürchtung einer „Kollektivhegemonie“ der Siegermächte bestätigt, die „an sich stets das Zeichen der Schwäche in sich trägt"1048. Statt einer solchen kollektivhegemonial geprägten, notwendig brüchigeren Allianz solle ein wirklicher Völkerbund geschaffen werden ${ }^{1049}$. Um zumindest die seiner Ansicht nach größte Strukturschwäche der neuen Weltorganisation, die „Überspannung des Hegemonieprinzips“ zu verhindern, empfahl der Kommentator der Völkerbundsatzung vier konkrete Modifikationen des neuen Statuts ${ }^{1050}$. Zunächst sollte auf das Vetorecht im Sicherheitsrat ebenso verzichtet werden wie dies für die Generalversammlung vereinbart worden war. Darüber hinaus müsse dem IGH das Auslegungsmonopol für die juristische Interpreta-

1045 Ibid. S. 57.

1046 Ibid. S. 54. Der Aufsatz basiert auf einem Vortrag, den Wehberg am 1. 12. 1943 vor Studenten der rechts- und staatswissenschaftlichen Fakultät der Universität Zürich gehalten hatte.

${ }^{1047}$ DERS., Historische und grundsätzliche Betrachtungen zur Völkerbundfrage. Zugleich ein Beitrag zur Struktur und Fortbildung der Empfehlungen von Dumbarton Oaks, in: Die Friedens-Warte, 45. Jg., Nr. 1/2 (1945), S. 1-29 (20).

1048 Ibid. S. 25.

1049 Die terminologische Differenzierung zwischen einer „voraussichtlich kurzfristigen“ Allianz und einem wirklichen Völkerbund, der dem allgemeinen Interesse der Staatengemeinschaft in höherem Maße entspreche, ist eine Konstituante der Arbeiten Wehbergs; vgl. auch ibid. S. 24, Anm. 37.

1050 Ibid. S. 26. 
tion der UN-Satzung eingeräumt werden. Als Gegengewicht zur politischen Dominanz der Großmächte schlug Wehberg die Einrichtung unabhängiger Sachverständigenausschüsse vor, die dem Sicherheitsrat in allen entscheidenden Fragen zur Seite stehen sollten. Als letzten Punkt griff Wehberg eine Idee auf, die Erich Koch-Weser zu einem zentralen Element seiner Europabundsatzung erhoben hatte: die Stärkung der Stellung des Generalsekretärs, der die Interessen der gesamten Organisation gegenüber dem Einfluß der Großmächte wahrzunehmen habe. Auf diese Weise hoffte der Völkerrechtler, in die alliierte Konzeption zumindest einige karge Ansätze einer späteren Weltföderation zu implementieren, deren Verwirklichung er gleich Stampfer künftigen Generationen zu überlassen gedachte.

Wehbergs Ideal einer Weltorganisation war eine konzeptionelle Fortentwicklung des Völkerbundes mit einem starken, demokratisch legitimierten Weltparlament ${ }^{1051}$. Wichtig war ihm nach wie vor eine internationale Autorität mit Befehlsgewalt gegenüber den Mitgliedstaaten ${ }^{1052}$. Diese starke internationale Autorität dachte er sich in institutioneller Hinsicht als eine Kombination aus Weltregierung und Weltparlament. Für die demokratische Legitimation des Weltparlaments sei entscheidend, daß die Abgeordneten nicht von den Staaten ernannt, sondern von den Völkern gewählt würden, so daß das Parlament ein gleichberechtigtes Pendant des Staatenrates sei. Während dem Parlament zentrale Befugnisse wie das Bundeshaushaltsrecht, die völkerrechtliche Gesetzgebung und die Ernennung der Weltregierung übertragen werden sollten, kam dem Staatenrat in Wehbergs Entwurf die Funktion einer zweiten Kammer zu, in der jeder Staat nur eine einzige Stimme haben dürfe ${ }^{1053}$. Dies entsprach Wehbergs Anliegen, die hervorgehobene Stellung der Großmächte in beiden Kammern so weit wie möglich zu beschneiden ${ }^{1054}$. Zweifellos zählte Wehberg zu den profiliertesten Kritikern der alliierten Nachkriegskonzeption, der sich um konstruktive Mitarbeit bemühte. In diesem Sinne betonte er wiederholt, daß die Schaffung des von ihm und anderen geforderten Weltparlaments nicht notwendig die Konstituierung eines Weltbundesstaates bedeuten müsse, wenngleich dies sicherlich das politische Optimum gewesen wäre. Angesichts der eher antiföderalen Grundtendenz der alliierten Großmächte konnte sich der Völkerrechtler mit der Begründung eines universellen „Friedens-Zweckverbandes" 1055 zufriedengeben, wenn im Statut der neuen Weltorganisation jedenfalls die Option auf eine spätere Weiterentwicklung angelegt werde.

1051 Ibid. S. 57.

1052 Ders., Die Organisation der Staatengemeinschaft nach dem Kriege, in: Die Friedens-Warte, 44. Jg., Nr. 2/3 (1944), S. 57.

1053 Ibid. S. 72.

1054 Ibid. S. 72.

1055 Ibid. S. 70. 